\title{
WestVirginiaUniversity
}

THE RESEARCH REPOSITORY @ WVU

Graduate Theses, Dissertations, and Problem Reports

2009

\section{Kinetic analysis of coal and biomass co-gasification with carbon dioxide}

Jiachuan Bu

West Virginia University

Follow this and additional works at: https://researchrepository.wvu.edu/etd

\section{Recommended Citation}

$\mathrm{Bu}$, Jiachuan, "Kinetic analysis of coal and biomass co-gasification with carbon dioxide" (2009). Graduate Theses, Dissertations, and Problem Reports. 2036.

https://researchrepository.wvu.edu/etd/2036

This Thesis is protected by copyright and/or related rights. It has been brought to you by the The Research Repository @ WVU with permission from the rights-holder(s). You are free to use this Thesis in any way that is permitted by the copyright and related rights legislation that applies to your use. For other uses you must obtain permission from the rights-holder(s) directly, unless additional rights are indicated by a Creative Commons license in the record and/ or on the work itself. This Thesis has been accepted for inclusion in WVU Graduate Theses, Dissertations, and Problem Reports collection by an authorized administrator of The Research Repository @ WVU. For more information, please contact researchrepository@mail.wvu.edu. 


\title{
Kinetic Analysis of Coal and Biomass Co- gasification with Carbon Dioxide
}

\author{
Jiachuan Bu \\ Thesis submitted to the \\ College of Engineering and Mineral Resources at \\ West Virginia University \\ In partial fulfillment of the requirements for the degree of \\ MASTER OF SCIENCE IN CHEMICAL ENGINEERING
}

John W. Zondlo, Ph.D., Chair

Charter D. Stinespring, Ph.D.

Dady B. Dadyburjor, Ph.D.

Todd H. Gardner, Ph.D

Department of Chemical Engineering

Morgantown, West Virginia

2009

Keywords: Coal Char, Biomass Char, Gasification with Carbon Dioxide, TGA Experiment, Kinetic Modeling, Synergistic Effect. 


\begin{abstract}
Kinetic Analysis of Coal and Biomass Co-gasification with Carbon Dioxide
\end{abstract}

Jiachuan Bu

Based on Thermogravimetric Analysis (TGA) experimental data, a kinetic analysis of the Boudouard reaction was studied for three different coal chars, three different biomass chars, and their mixtures. The coal chars included: North Dakota Lignite, Illinois No.6, and Powder River Basin char; the biomass chars included: Hardwood, Switchgrass, and Corn Stove char. The reaction temperature ranged from $900^{\circ} \mathrm{C}$ to $1100^{\circ} \mathrm{C}$. Different kinetic models were used for modeling the reaction rate. For the simplified Dutta and Wen model, it was found that the reaction rate was first order with respect to both $\mathrm{CO}_{2}$ and carbon. For the modified shrinking sphere model, the reaction rate was first order with respect to $\mathrm{CO}_{2}$ but $2 / 3$ order with respect to carbon. For simplicity, none of the models incorporated physical characteristics such as porosity or surface area. Statistical analysis showed the shrinking sphere model provided the best fit for most of gasification rates. Kinetic parameters, such as the apparent rate constant $k_{a p p}$, and apparent activation energy $E_{a p p}$, were derived from the simplified model and shrinking sphere model. The values of the apparent activation energy were comparable for the two models and to those from earlier studies.

A positive synergistic effect on the gasification reaction rate was observed between some coal char and biomass char pairs. These char pairs included: Illinois No.6 mixed with Switchgrass, Illinois No.6 mixed with Hardwood, and Powder River Basin mixed with Corn Stover. Based on Inductively Coupled Plasma - Mass Spectrometry (ICPMS) analysis and predictive modeling of the apparent activation energy, the amount of Alkali and Alkaline Earth metals bound in the biomass chars was found to cause the positive synergistic effect and the enhanced gasification rate of the coal char. 


\section{ACKNOWLEDGEMENT}

First of all, I wish to thank Dr. John W. Zondlo, a righteous advisor with a considerate heart. His patient instructions always show me the direction and inspired me. Special thanks are given to Dr. Charter D. Stinespring and Dr. Dady B. Dadyburjor; their encouragements on the hard-time of my studying are unforgettable. I appreciate that Dr. Todd H. Gardner of the NETL/DOE gave me the opportunity to complete this work. Thanks to Mr. Joshua A. Parenti; his contributions on the TGA experiment were indispensable for this work. Also thanks a lot to Mr. Ken Stewart for his support on ICPMS analysis.

Last but not least, I would like thank my wife Dr. Juan Chen, for her always standing with me and giving me the spiritual support. I'd like present this work as a special gift to my new born daughter, Kathleen $\mathrm{Bu}$, thanks for her patience! 
TABLE OF CONTENTS

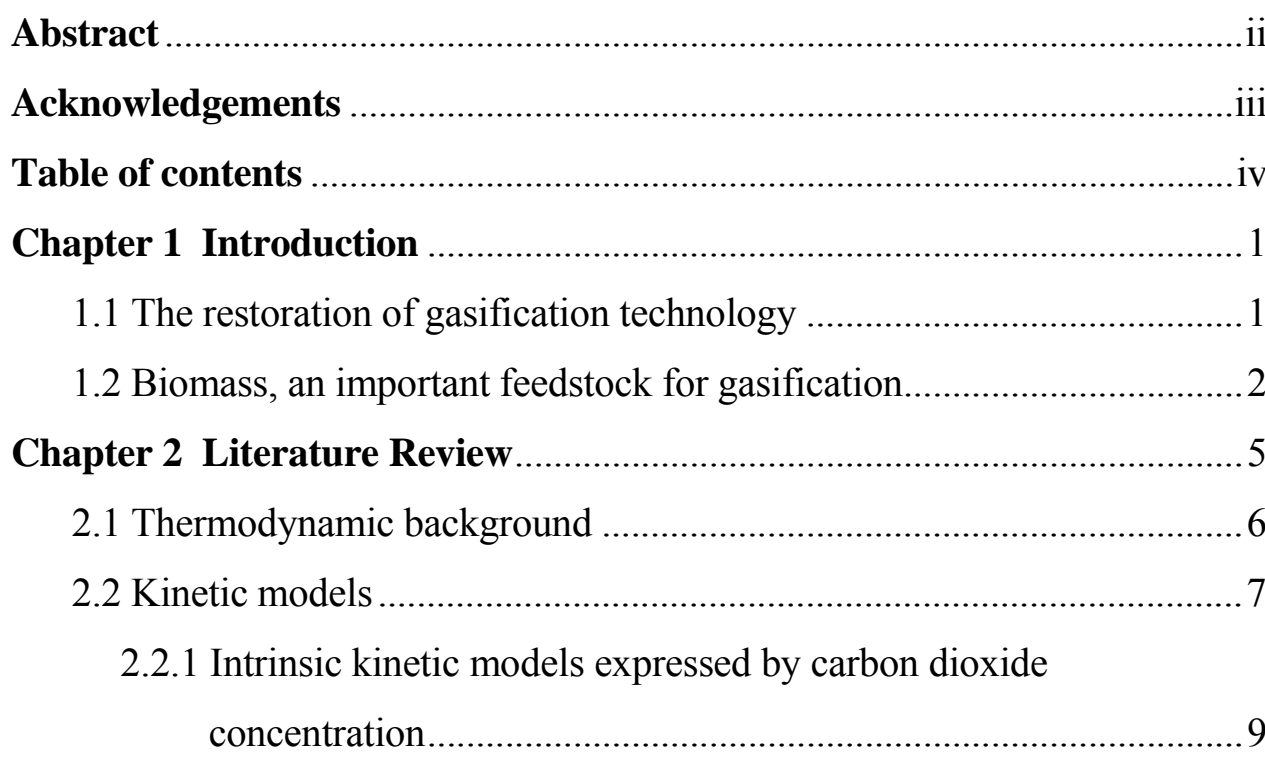

2.2.2 Kinetic models expressed as the reactivity of the carbon char ....11

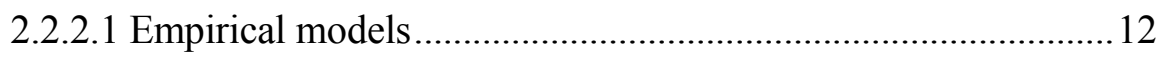

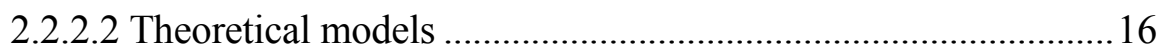

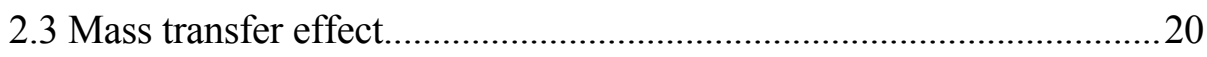

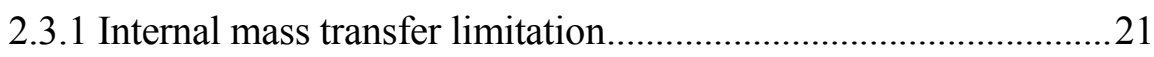

2.3.2 External mass transfer limitation ............................................... 22

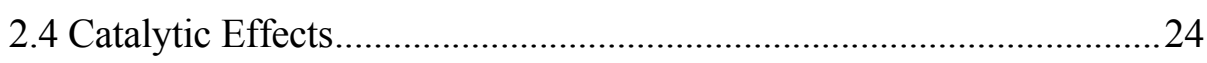

Chapter 3 Experimental Methods and Data Analysis................................26

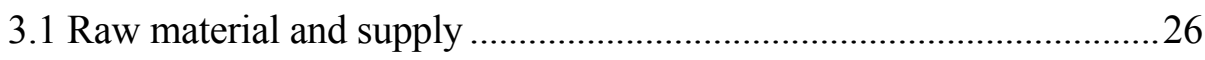

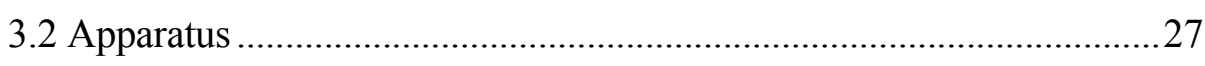

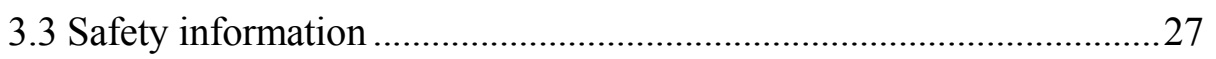

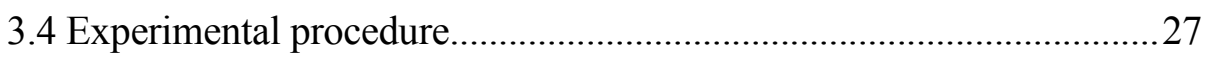

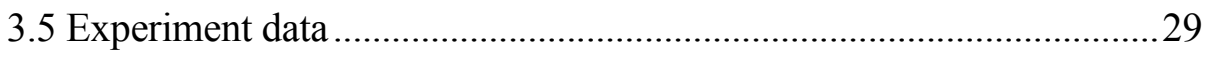

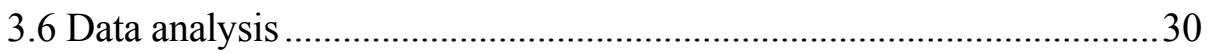

3.6.1 Definition of carbon conversion fraction $X$................................30

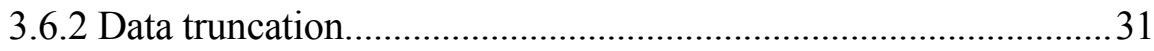

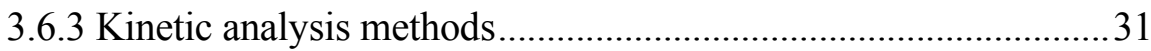




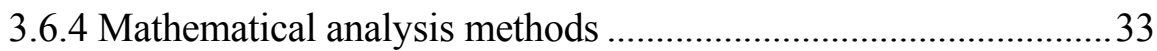

3.7 Evaluation of external mass transfer effects ...........................................34

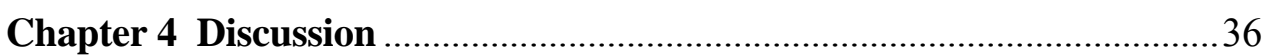

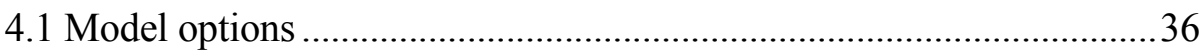

4.1.1 Selection of the representative reaction order for carbon dioxide

4.1.2 Selection of appropriate models for carbon reactivity...................37

4.1.3 Initial reaction rate constant as compensation .............................38

4.2 Kinetic parameters regression with different models .............................39

4.2.1 Fitting the data with Model 5

( A simplified Dutta and Wen's Model) ........................................39

4.2.2 Fitting the data with Model 10 (Shrinking sphere model) ........... 43

4.2.3 Fitting the data with Model 7 (Chornet's Model).........................47

4.2.4 Fitting the data with the Initial Rate Model ..................................50

4.3 Evaluation of Model 5 and Model 10 ...............................................52

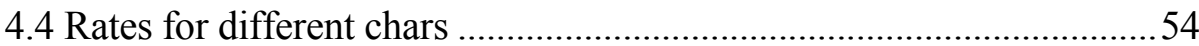

4.5 Synergistic effect between coal chars and biomass chars ....................58

4.5.1 Reaction rate for char mixtures .....................................................58

4.5.2 Prediction of synergistic effects (Prediction Model A) .................62

4.5.3 Synergistic effect inspection plots and discussion..........................63

4.5.4 The explanation of the synergistic effect between chars pair ...... 74

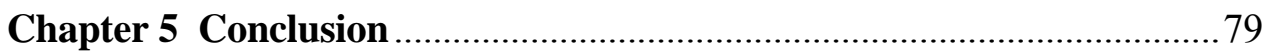

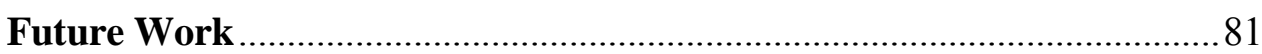

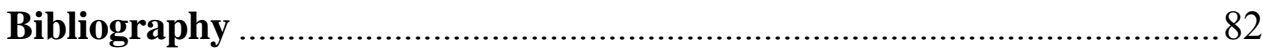

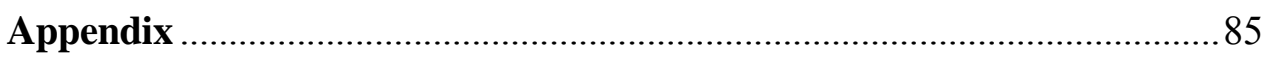

A Plots of apparent rate constant $k_{\text {app }}$ fitted with Model $5 \ldots \ldots \ldots \ldots \ldots \ldots \ldots \ldots . . . .85$

B Plots of $E_{a p p}$ regression based on Model 5 ............................................113

C Plots of apparent rate constant $k_{\text {app }}$ fitted with Model $10 \ldots \ldots \ldots \ldots \ldots \ldots \ldots . . . .119$

D Plots of $E_{a p p}$ regression based on Model 10 ........................................... 147

E Plots of $E_{a p p}$ regression based on Initial Rate Model .............................153 
F Experimental value of $(1-X)_{\text {average }}$ with different mixture ratio at $900^{\circ} \mathrm{C}, 1000^{\circ} \mathrm{C}$, and $1100^{\circ} \mathrm{C}$

G Synergistic effect inspection plots for

Group 1 ND lignite \& Hardwood chars

165

H Synergistic effect inspection plots for

Group 2 ILL No.6 \& Switchgrass chars

I Synergistic effect inspection plots for

Group 3 PRB \& Corn Stover chars 177

J Safety information 183 


\section{Chapter 1 Introduction}

Gasification is a process that converts low-value carbonaceous materials, such as coal, coke, biomass and other organic wastes into high-value synthesis gas composed mainly of carbon monoxide and hydrogen. The raw materials are heated at high temperatures with a controlled amount of oxygen and/or steam. The mixture of product gas, called synthesis gas or syngas, can be used as a fuel directly or as a raw chemical feedstock. Compared to other processes, gasification is a flexible, reliable, clean and effective technology, and more importantly, it provides an alternative energy source for natural gas and crude oil.

Gasification, especially coal gasification, has a long application history since being invented in the early $19^{\text {th }}$ century. In these early years, coal gasification processes were used to produce a fuel gas, called town gas. At that time, town gas was primarily used for lighting and heating. From the beginning of $20^{\text {th }}$ century, coal gasification technology experienced a rapid development to meet the demand for chemicals. During this time, syngas was the building block of so-called $\mathrm{C}_{1}$ chemistry products, such as ammonia and methanol. Developed in the 1920s in Germany, the Fischer-Tropsch process (or Fischer-Tropsch Synthesis) provided a way to produce a synthetic liquid fuel by the gasification route. Although coal gasification technology had a wide range of applications during World War II, petroleum and natural gas with their overwhelming advantages and plentiful quantities appeared on the stage of modern industry in the 1950s. The importance of gasification soon declined.

\subsection{The restoration of gasification technology}

Modern life depends on energy, and that energy mostly comes from the combustion of fossil fuel. The world has been consuming fossil fuels at an accelerating rate since the beginning of the industrial age. According to a report from U.S.DOE, world energy consumption is expected to expand by 50 percent from 2005 to 2030, and total world energy use will rise from 462 quadrillion British thermal units (Btu) in 2005 to 563 quadrillion Btu in 2015 and then to 695 quadrillion Btu in 2030 (USDOE, 2008). Moreover, it is reported that in the early 21 st century, more than 85 percent of world energy will come from fossil fuels. Currently the breakdown of the total energy 
consumption is: natural gas $24 \%$, oil $39 \%$, coal $24 \%$, nuclear $6 \%$, hydro $6 \%$, and other $1 \%$ (Wolfson, 2008). However, there is growing evidence that the use of natural gas and oil may peak within the 21-century and then their supply will be depleted soon after. Considering all of these conditions, it is not surprising that the price of crude oil and natural gas keeps rising in the long-term trends. For example, in Summer 2008 the price climbed to US\$147/bbl for oil and US\$13/MMBtu for natural gas. Consequently, it is this increased cost of energy that forced the world to look at coal as an alternative source of energy, since coal is abundant and is found widely around the world.

Integrated Gasification Combined Cycle (IGCC) technology was initiated during the 1970s and demonstrated in several commercial projects in the 1980s (Joshi and Lee, 1996). The IGCC technology not only enhances the environmental acceptability of coal, but also increases the overall efficiency of the conversion of the chemical energy in coal into electricity (because the syngas can be combusted at higher temperatures than direct combustion of the original fuel). Actually, electricity generation has emerged as the largest new field for the application of gasification processes. In addition, coal gasification derivative chemicals are another major focus for coal utilization. The products derived from gasification processes show an abundant diversity, from bulk chemicals like ammonia, methanol and Fisher-Tropsch hydrocarbon products, through industrial gases to utilities such as clean gaseous fuel.

Generally speaking, the cost of energy, the advantages of IGCC technology, and the requirement for diversity chemicals call for the development of coal gasification technology. This being the case, in the last 10-15 years, coal gasification technology experienced a rapid restoration (Higman and Burgt, 2008).

\subsection{Biomass, an important feedstock for gasification}

Contrary to fossil fuels (coal, natural gas, petroleum), biomass is a renewable resource. Due to environmental considerations and the increasing demands for energy, the application of biomass has received great attention. The main biomass resources include the following: forest and mill residues, agriculture crops and wastes, wood and wood wastes, animal wastes, livestock operation residues, aquatic plants, fast-growing trees and plants, and municipal and industrial wastes. Since biomass has negligible 
amounts of sulfur, nitrogen, and ash-forming constitutes, it gives lower emissions of sulfur dioxide, nitrogen oxides, and soot than other conventional fossil fuels. During World War II, primarily as a source of fuel gas, biomass gasification was widespread. After the war, however, biomass gasification was forgotten for many years, until the first oil crisis in the 1970's. Again, it was the pressure of energy costs that pushed people to expand the diversity of energy sources, of which biomass is one. Since that time, investigation and application of biomass gasification launched a new age for gasification technology. It is reported that in 2007 , biomass contributed $2 \%$ worldwide as a gasification feedstock (NETL, 2007).

Meanwhile, to answer the challenges of global climate change, greenhouse-gas (GHGs) emissions from fossil fuels must be reduced. It is reported that the atmospheric carbon dioxide concentration had increased by almost $100 \mathrm{ppm}$ in comparison to the preindustrial levels, reaching 379 ppm in 2005 (IPCC, 2007). Since GHGs are primarily caused by the combustion of fossil fuels, the top priority is to change or partly change the current energy sources so that they will not produce so much climate-changing emissions or pollution. Biomass gasification technology has this potential advantage and is one of the options to fulfill this transition. Biomass gasification can produce not only chemical feedstock but also fuels and electric power. More importantly, it is a carbon-neutral process, which will decrease the total GHG emissions. For example, based on a well-towheels analysis, $\mathrm{Wu}$ and co-workers estimated that using biomass as the raw material, the combination of biological (fermentation ethanol) and thermochemical (Fisher-Tropsch diesel) processes with power co-generation (IGCC) is very effective because it consumes the least fossil energy and achieves the greatest reductions in GHGs and pollutants when used with both conventional and HEV (hybrid electric vehicle) technologies compared with conventional gasoline and diesel (Wu et al. , 2006).

A large effort has been made into the development of advanced biomass gasification technologies since the 1970's. The current developments are essentially based on coal gasification processes. In contrast to coal gasification, which is currently used in several commercial processes, biomass is more reactive and can be effectively gasified at lower temperatures than coal. Coal and biomass co-gasification is another noteworthy field in the gasification process. On the one hand, co-gasification increases 
the variety of the available feedstock. On the other hand, by displacing part of the fossil fuel with biomass, GHGs emissions and pollution can be reduced.

For these gasification systems, as in all other chemical processes, fundamental knowledge of the reaction rate and mechanism is essential for the proper design and control of the process. Therefore, based on Thermogravimetric Analysis (TGA) experimental data, the present thesis work focuses on the chemical reaction kinetics for the gasification in carbon dioxide of coal char, biomass char, and the co-gasification of their mixtures. The detailed objectives of the work are as follows:

(1) Gasification data will be acquired for the reaction of carbon dioxide with three different coal and three different biomass chars, both alone and for selected mixtures;

(2) The $\mathrm{CO}_{2}$ gaseous flow rate through the reactor will be varied to investigate the external mass transport effects on the gasification reaction, further confirming the appropriate $\mathrm{CO}_{2}$ flow rate;

(3) Using different kinetic models, fits of the TGA data will be performed; a reasonable model will be determined to describe the gasification reaction rate with respect to fractional carbon conversion $v s$. time;

(4) By either the integral or differential approach, the TGA data will be regressed according to different kinetic models. Kinetic parameters will be obtained for each char, such as apparent rate constant $k_{a p p}$, and apparent activation energy $E_{a p p}$;

(5) From the experimental results, any potential synergism will be examined between pairs of coal char and biomass char that can increase the gasification reaction rate of the coal;

(6) An explanation of the synergistic phenomena of the biomass char will be presented. 


\section{Chapter 2 Literature Review}

Reacted with air, oxygen, steam, carbon dioxide or other reagent gases, a solid or liquid carbonaceous material is converted into gaseous products, and this series of reactions is known as gasification. The gaseous product primarily contains $\mathrm{CO}, \mathrm{H}_{2}, \mathrm{CO}_{2}$, $\mathrm{H}_{2} \mathrm{O}$, and light hydrocarbons mixed with volatile and condensable organic and inorganic compounds. A simplified reaction sequence for coal or biomass gasification can be described by the following two stages: raw material pyrolysis followed by char gasification.

Pyrolysis or devolatilization is the first stage of the gasification process. The chemical components in the raw coal decompose by heating to a relatively low temperature $\left(350-800^{\circ} \mathrm{C}\right)$ in the absence of oxygen. The products include: pyrolysis gases ( $\mathrm{CO}, \mathrm{H}_{2}, \mathrm{CH}_{4}$, and $\mathrm{H}_{2} \mathrm{O}$ ), tar, oil, naphtha, and residual solid char. A complete description of the characteristics of pyrolysis is complicated, but for a given sample, the pyrolysis behavior depends on: (1) heating rate, (2) final decomposition temperature, (3) vapor residence time, (4) the environment under which the pyrolysis takes place, (5) pressure, (6) coal particle size, and (7) coal rank (Dutta et al. , 1977).

In the second stage, the remaining carbonaceous solids from the pyrolytic reactions are further oxidized to syngas through heterogeneous reactions with carbon dioxide, carbon monoxide, steam, oxygen, and hydrogen. The reactivity of chars in gaseous atmospheres is a complicated function of temperature, particle structure, carbon source, and thermal history of the char. Additionally, the overall rate of char gasification may be affected not only by chemical kinetics but also by intraparticle and external mass transfer resistances (Kapteijn and Moulijn, 1986). Therefore, any description of the kinetics of the gasification reactions must include: (1) its intrinsic chemical rate and (2) the effects of mass transfer.

This thesis work will focus on the kinetic modeling of one of the char gasification reactions, the Boudouard reaction:

$$
\mathrm{CO}_{2}(\mathrm{~g})+\mathrm{C}(\mathrm{s}) \rightleftharpoons 2 \mathrm{CO}(\mathrm{g})-\mathrm{Q}
$$


Since the reaction starts with a solid and produces gaseous products, the reaction kinetics can easily be followed by measuring the change in weight via Thermogravimetric Analysis (TGA).

\subsection{Thermodynamic background}

Although the chars come from different sources, either from coal or biomass, the essential chemical reaction is the same: the redox reaction of a mixture of the $\mathrm{C}-\mathrm{CO}_{2}-\mathrm{CO}$ system at a given temperature. Understanding the thermodynamic characteristics of the gasification reaction [2.1] is important. For instance, the equilibrium constant and heat of reaction are very important parameters to evaluate the limiting performance of the reaction.

The equilibrium constant of the reaction [2.1] are expressed as (Kapteijn and Moulijn, 1986):

$$
K_{e q}=\frac{\left(\frac{P_{C O}}{P_{r e f}}\right)^{2}}{\left(\frac{P_{C O_{2}}}{P_{r e f}}\right) \cdot\left(\frac{a_{c}}{P_{r e f}}\right)}=\frac{P_{C O}^{2}}{P_{C O_{2}} \cdot a_{c}}=\frac{x_{C O}^{2}}{x_{C O_{2}}} \cdot\left(\frac{P}{a_{c}}\right)
$$

where $x_{\mathrm{i}}$ is the mole fraction of component $\mathrm{i} ; P$ is the total pressure of the reaction system (bar); $P_{\mathrm{i}}$ is the partial pressures of the ideal gases $\mathrm{i}$ (bar); $P_{\text {ref }}$ is the pressure of the thermodynamic standard reference state for gases (1.01bar); $a_{c}$ is the "activity" of a particular carbon, referenced to graphite (for graphite $a_{\mathrm{c}}=1$ ).

Since the carbon structure of the chars is highly disordered (amorphous), so-called "polycrystalline-graphite", it is analogous to the "glassy carbons" derived from poly furfuryl alcohol by pyrolysis. However, for convenience, one of the assumptions is that the carbon in the char for the gasification reaction has the same free energy of formation as the graphite (Kapteijn and Moulijn, 1986). That means, $\Delta \mathrm{G}_{\mathrm{f}}=0$, because graphite is the reference substance in thermodynamic calculations. Some researchers also assume that the carbon in the char may have a higher free energy of formation than graphite, and that causes the chars carbon to have a higher heat of formation (Johnson, 1979). Researchers also tried to establish values of $a_{\mathrm{c}}$ by measuring the thermodynamic equilibrium 
composition for a particular char and comparing it with the one calculated for graphite. Values of $a_{c}$ between 1 and 20 have been reported in the literature (Kapteijn and Moulijn, 1986).

The equilibrium constant, $K_{e q}$, is a function of temperature and reacting molecules. It can be easily calculated from tabulated thermochemical data, such as those listed in the JANAF tables, the expression shown as:

$$
\begin{aligned}
& R T \cdot \ln K_{e q}=-\Delta G^{o}(T) \\
& \Delta G^{o}(T)=\sum_{i} v_{i} \Delta G_{f_{i}}^{o}(T)
\end{aligned}
$$

where $\Delta G^{o}(T)$ is the free energy change of the reaction $(\mathrm{KJ} / \mathrm{mol})$ at temperature $T$; $\Delta G_{f_{i}}^{o}(T)$ is the free energy of formation of compound $i(\mathrm{KJ} / \mathrm{mol})$ at temperature $T ; v_{i}$ is the stoichiometric coefficient for each particular species in the reaction expression, $v_{\mathrm{CO}_{2}}=$ $-1, v_{C}=-1$, and $v_{C O}=2$ for reaction $[2.1]$.

The forward reaction of [2.1] is endothermic, and the number of vapor-phase moles is increased. Consequently, according to Le Chatelier's Principle, high temperature and lower total pressure is favorable for the forward reaction. Actually, for the $\mathrm{C}-\mathrm{CO}_{2}-$ $\mathrm{CO}$ system, equilibrium gas compositions are a function only of temperature and total pressure. Equilibrium carbon monoxide mole fractions for this system increase with increasing temperature and decreasing pressure (Johnson, 1979).

The enthalpy changes associated with the reaction [2.1] have different values at different temperatures. The heats of reaction for [2.1] using graphite as the carbonaceous material are listed as follows: $+172.5 \mathrm{~kJ} / \mathrm{mol}(800 \mathrm{~K}) ;+170.7 \mathrm{KJ} / \mathrm{mol}(1000 \mathrm{~K}) ;+168.7$ KJ/mol (1200K) (Kapteijn and Moulijn, 1986).

\subsection{Kinetic models}

Before discussing the kinetic models for reaction [2.1], it is necessary to define the reaction rate expressions with respect to different reaction reagents (solid carbon and gaseous carbon dioxide). For an arbitrary chemical reaction, $a A+b B \rightarrow c C+d D$, the rates of formation of each component per unit reactor volume, $r_{i}$, can be described 
respectively as: $-\frac{d C_{A}}{d t},-\frac{d C_{B}}{d t}, \frac{d C_{C}}{d t}$, and $\frac{d C_{D}}{d t}$, where $C_{i}$ is the molar concentration of the $\mathrm{i}^{\text {th }}$ species. This assumes a batch reactor at constant volume. The rates correlate as: $-\frac{1}{a} \frac{d C_{A}}{d t}=-\frac{1}{b} \frac{d C_{B}}{d t}=\frac{1}{c} \frac{d C_{C}}{d t}=\frac{1}{d} \frac{d C_{D}}{d t}$. Typically, the species whose concentration is easy to measure is used as the concentration for the rate expression. For the heterogeneous reaction [2.1], the rate expression of carbon is related to the rate of formation above but is based on a unit mole of solid initially in this gas-solid system instead of the reactor volume, and can be written as:

$$
r_{C}=-\frac{1}{w_{C o}} \frac{d w_{C}}{d t}=-\frac{1}{N_{C_{o}}} \frac{d N_{C}}{d t}=\frac{d X}{d t}
$$

where $w_{C}$ is the carbon weight at any time; $w_{\text {Co }}$ is the initial carbon weight; $N_{C}$ is the number of moles of carbon at any time; $N_{C o}$ is the initial moles of carbon; $X$ is the fractional conversion of carbon and defined as the fraction of carbon converted into product as follows:

$$
X=\frac{w_{C o}-w_{C}}{w_{C o}}=\frac{N_{C o}-N_{C}}{N_{C o}}
$$

$r_{\mathrm{C}}$ is the carbon reaction rate or reactivity, $\left(\operatorname{time}^{-1}\right)$.

The "specific carbon gasification rate", also given the symbol $R_{s p}$, is defined as:

$$
R_{s p}=\frac{r_{C}}{1-X}=\frac{1}{(1-X)} \frac{d X}{d t}
$$

The rate expression of $\mathrm{CO}_{2}$ as defined on per unit volume of the reactor and can be written:

$$
r_{\mathrm{CO}_{2}}=-\frac{d C_{\mathrm{CO}_{2}}}{d t}
$$

Although continuous monitoring of gas chromatographic data is possible, tracking the weight change of the carbon char in a TGA is more conveniently and directly measured. 
2.2.1 Intrinsic kinetic models expressed by carbon dioxide concentration

Generally, the intrinsic kinetic reaction rate expressions are derived from different proposed reaction mechanisms, each of them consisting of a series of elementary reaction steps, such as adsorption, surface reactions and desorption that are involved in the overall reaction. Sometimes, supported by more recent investigation, the reaction mechanisms may be changed, but the kinetic model remains essentially the same, and the rate expression is unaltered. For reaction [2.1], numerous intrinsic kinetic models expressed by carbon dioxide concentration are listed in reviews papers or books (Reif, 1952) (Ergun and Mentser, 1965) (Johnson, 1979), and (Kapteijn and Moulijn, 1986). Most of them are of the so-called Langmuir-Hinshelwood type. Some of the more widely-known models are described in detail below:

\section{Model 1}

This model was proposed by Reif (Reif, 1952) and Ergun (Ergun, 1956), and is based on a two-step oxygen exchange mechanism. The final rate expression with respect to $\mathrm{CO}_{2}$ can be written as:

$$
r_{\mathrm{CO}_{2}}=\frac{k_{1} p_{\mathrm{CO}_{2}}}{1+k_{2} p_{\mathrm{CO}}+k_{3} p_{\mathrm{CO}_{2}}}
$$

where $p_{\mathrm{CO}}, p_{\mathrm{CO}_{2}}$ are carbon monoxide and carbon dioxide partial pressures; $k_{1}, k_{2}, k_{3}$ are kinetic parameters that depend on temperature and the nature of the char carbon.

Equation [2.9] shows that gasification rate decreases with increasing carbon monoxide partial pressure because of an inhibiting effect that is not directly related to thermodynamic reversibility. The rate expression also implies that the reaction rate with respect to $\mathrm{CO}_{2}$ concentration is approximately a first or fractional order at low pressure, but approaches zero-th order at high pressure.

\section{Model 2}

Kapteijn and Moulijn came up with a mechanism different from Model 1 and gave the rate expression as [2.10] (Kapteijn and Moulijn, 1986): 


$$
r_{\mathrm{CO}_{2}}=\frac{k_{4} p_{\mathrm{CO}_{2}}-k_{5} p_{C O}^{2}}{1+k_{6} p_{C O}+k_{7} p_{\mathrm{CO}_{2}}}
$$

where $p_{C O}, p_{\mathrm{CO}_{2}}$ are carbon monoxide and carbon dioxide partial pressures; $k_{4}, k_{5}, k_{6}, k_{7}$ are kinetic parameters that depend on temperature and the nature of the char carbon.

With the exception of the term $p^{2}{ }_{C O}$ in the numerator of equation [2.10], the form of the expression is the same as that of equation [2.9], which is frequently used to describe results in studies at or near atmospheric pressure. If the partial pressure of carbon monoxide is negligible, such as in a pure $\mathrm{CO}_{2}$ reaction system, equations [2.9] and [2.10] have essentially the same form.

\section{Model 3}

Blackwood and Ingeme have proposed a mechanism different from Model 1 and Model 2 to interpret the reaction rate at pressure up to 40 atm (Blackwood and Ingeme, 1960). Based on a number of simplifying approximations, they reported the rate expressions as:

$$
r_{\mathrm{CO}_{2}}=\frac{k_{8} p_{\mathrm{CO}_{2}}+k_{9} p_{\mathrm{CO}_{2}}^{2}}{1+k_{10} p_{\mathrm{CO}}+k_{11} p_{\mathrm{CO}_{2}}}
$$

where $p_{\mathrm{CO}}, p_{\mathrm{CO}_{2}}$ are carbon monoxide and carbon dioxide partial pressures; $k_{8}, k_{9}, k_{10}, k_{11}$ are kinetic parameters that depend on temperature and the nature of the char carbon.

Except for the term $p_{\mathrm{CO}_{2}}^{2}$ in the numerator of equation [2.11], the form of the rate expression is the same as that of equation [2.9]. For the gasification of coconut charcoal at $790-870^{\circ} \mathrm{C}$ and a total pressure up to $40 \mathrm{~atm}$, the numerical evaluation results show that the term $k_{9} p_{\mathrm{CO}_{2}}^{2}$ can be neglected at carbon dioxide partial pressures less than $1 \mathrm{~atm}$. However, at sufficiently high pressures, equation [2.11] can be approximately rewritten as:

$$
r_{\mathrm{CO}_{2}} \cong \frac{k_{9} p_{\mathrm{CO}_{2}}^{2}}{k_{10} p_{C O}+k_{11} p_{\mathrm{CO}_{2}}}
$$


Therefore, the reaction rate with respect to $\mathrm{CO}_{2}$ partial pressure is approximately first order at high pressure of $\mathrm{CO}_{2}$ rather than zero-th order, which is predicated by Model 1 , equation [2.9].

\section{Model 4}

Gadsby suggested a mechanism based on experimental results (Gadsby et al., 1948), and reported the rate expressions as :

$$
r_{\mathrm{CO}_{2}}=\frac{k_{12} p_{\mathrm{CO}_{2}}}{1+k_{13} p_{\mathrm{CO}}+k_{14} p_{\mathrm{CO}_{2}}}
$$

where $p_{\mathrm{CO}}, p_{\mathrm{CO}_{2}}$ are carbon monoxide and carbon dioxide partial pressures; $k_{12}, k_{13}, k_{14}$ are kinetic parameters that depend on temperature and the nature of the char carbon.

Comparing the equations [2.9] and [2.13], Model 1 and Model 4 have the same rate expression with respect to the carbon dioxide concentration, but have different definitions and meanings for the kinetic parameters.

2.2.2 Kinetic models expressed as the reactivity of the carbon char

The reactivity of a coal char or carbon $\left(r_{C}\right.$, or $\left.R_{s p}\right)$ is a complicated function that includes the active site density at the carbon surface, the total specific surface area, gas phase conditions, temperature, etc. It is noted that some physical parameters, such as the active site density and surface area, may significantly change during the carbon gasification process. Generally, for an uncatalyzed gasification, the carbon rate expression can be written as equations [2.14] and [2.15](Kapteijn and Moulijn, 1986):

$$
\begin{aligned}
& r_{C} \propto N_{T} \cdot f\left(T, p_{i}, \cdots\right) \\
& N_{T}=S_{a} \cdot \lambda
\end{aligned}
$$

where $N_{T}$ is total number of active sites per amount of carbon present $(\mathrm{mol} / \mathrm{mol}) ; S_{a}$ is the specific surface area $\left(\mathrm{m}^{2} / \mathrm{mol} \mathrm{C}\right)$; and $\lambda$ is surface concentration of active sites $\left(\mathrm{mol} / \mathrm{m}^{2}\right)$.

Although numerous kinetic models for the carbon reactivity have been reported, they can be generally classified into two categories: (1) empirical models and (2) theoretical models. 


\subsubsection{Empirical models}

\section{Model 5}

Dutta and Wen proposed an empirical model in 1977 (Dutta et al., 1977; Sears and Wen, 1981). For chemical reaction control, the reactivity of the char carbon can be expressed as follows:

$$
\begin{aligned}
& \frac{d X}{d t}=\eta \cdot S \cdot k_{r} \cdot C_{\mathrm{CO}_{2}} \cdot(1-X) \\
& S=1 \pm X^{\nu \beta} e^{-\beta X},(0 \leq v \leq 1)
\end{aligned}
$$

where $k_{r}$ is the global rate constant; $X$ is the carbon conversion; $t$ is time; $\eta$ is an effectiveness factor (dimensionless); $S$ is relative surface area (dimensionless); $\mathrm{C}_{\mathrm{CO}_{2}}$ is the concentration of carbon dioxide; $v, \beta$ are physical parameters characteristic of a given coal char.

The basic assumptions of Model 5 are: (1) an isothermal reaction system; (2) the gas flow rate is high enough so that external mass transfer effects are negligible; (3) the term, $\eta$, the effectiveness factor, is introduced to deal with the internal mass transfer effects, and this will be discussed in a later section.

The " $S$ " term in Model 5 is defined as the ratio of the surface area at any time during the reaction to the surface area at the beginning of the reaction. Equation [2.17] is an empirical relationship with no theoretical basis. The parameter $\beta$ has no physical meaning. The parameter $v$ is defined as the fractional conversion of the char at which the surface area is a maximum. By introducing the term " $S$ ", Model 5 allows the model to relate the rate to the surface area that changes during the reaction.

In Model 5, the reaction order with respect to carbon is a pseudo first-order, and the intrinsic chemical reaction is occurring on the changing surface of the char particle. However, the global reaction kinetics order of the char gasification is the sum of the orders with respect to carbon and carbon dioxide; consequently, it is not a pseudo firstorder. 


\section{Model 6}

Based on a series of experimental results of coal char gasified in air $\left(405^{\circ} \mathrm{C}\right.$, $0.101 \mathrm{Mpa})$, carbon dioxide $\left(900^{\circ} \mathrm{C}, 0.101 \mathrm{Mpa}\right)$, steam $\left(910^{\circ} \mathrm{C}, 0.101 \mathrm{Mpa}\right)$, and hydrogen $\left(980^{\circ} \mathrm{C}, 2.76 \mathrm{Mpa}\right)$, Mahajan et al. proposed a three-parameter model (Mahajan et al. , 1978). The equation is shown in [2.38] and [2.39]:

$$
\begin{aligned}
& X=a_{0} \cdot \tau+a_{1} \cdot \tau^{2}+a_{2} \cdot \tau^{3}, \text { or } \frac{d X}{d \tau}=a_{3}+a_{4} \tau+a_{5} \tau^{2}, X=0 \sim 0.7 \\
& \tau=\frac{t}{t_{X=0.5}}
\end{aligned}
$$

where $X$ is the conversion; $a_{0} \sim a_{5}$ are parameters for different chars and are without physical meaning; $\tau$ is a dimensionless time scale such that $t / t_{0.5}$ equals one at a fractional conversion of 0.5 . Up to a conversion of 0.7 , it is reported that equation [2.18] fits reasonably well for different char gasification reactions.

By comparison of results, the authors reported that for most coal chars, from anthracite to lignite, the conversion-time profiles exhibit a similarity in shape. Moreover, if time is normalized by equation [2.19], then the curves of conversion versus dimensionless time are almost converged into one universal curve.

\section{Model 7}

Chornet (Chornet et al., 1979) proposed a more compact model with two variable parameters, shown in the following equations:

$$
\frac{d X}{d \tau}=k_{r} \cdot X^{b} \cdot(1-X)^{c}
$$

where $k_{r}$ is a global rate constant; $X$ is the conversion; $b, c$ are adjustable characteristic parameters without physical meaning; $\tau$ is a dimensionless time scale such that $t / t_{0.5}$ equals one at a fractional conversion of 0.5 , the same definition as in equation [2.19].

The theoretical assumptions for Model 7 are: (1) the active sites for the reaction are increasing during the first half of the reaction, so the reaction rate increases in the first half of the reaction; (2) with the char further decomposed, the active sites collapse and the rate of reaction decreases. Through those assumptions, Model 7 can explain the 
phenomena that for most chars, the reaction rate increases to a maximum and then decreases. After much numerical regression, the authors also gave the value of the three parameters: $k_{r}=1.763 ; b=0.5 ; c=1.0$ and equation $[2.20]$ is rewritten as:

$$
\frac{d X}{d \tau}=k_{r} \sqrt{X}(1-X)
$$

\section{Model 8}

Simons later adapted and modified the Chornet model (Simons, 1980). It is a semi-theoretical model, and the theoretical assumption is that the pore structure changes to account for the varying surface area during the reaction. During the reaction, the pores inside the char particles will develop, and as they grow, they combine with other nearby pores. Thus the internal surface area increases with pore growth and decreases with pore combination. For a chemical kinetic-controlled reaction, the pore internal surface area $\left(S_{p}\right)$ follows the relation as:

$$
S_{p} \propto \varepsilon^{1 / 2}(1-\varepsilon)
$$

where $\varepsilon$ is the porosity of the char particle. If the reaction rate is directly proportional to the pore internal surface area, the following relation arises:

$$
\frac{d X}{d \tau} \propto \varepsilon^{1 / 2}(1-\varepsilon)
$$

If the carbon conversion, $X$, is further defined as:

$$
X=\frac{\varepsilon-\varepsilon_{o}}{1-\varepsilon_{o}}
$$

where $\varepsilon_{o}$ is the initial porosity at $\tau=0(X=0)$, the rate expression can be rewritten as:

$$
\frac{d X}{d \tau}=k_{r}\left[X+\varepsilon_{o}(1-X)\right]^{1 / 2}(1-X)
$$

where $k_{r}$ is the global rate constant; $X$ and $\varepsilon_{o}$ are as defined earlier; $\tau$ is a dimensionless time scale such that $t / t_{0.5}$ equals one at a fractional conversion of 0.5 , the same definition 
as in equation [2.19]. When $\varepsilon_{o}$ approaches zero, equation [2.25] reduces to [2.21], and Model 8 and Model 7 have the same form.

\section{Model 9}

Liliedahl and coworkers presented another semi-empirical model (Liliedahl and Sjostrom, 1997). They adapted the Ergun mechanism (Model 1) and incorporated it in their model. In contrast to most other modeling approaches, a non-steady-state condition is assumed, and the mass balance equation is:

$$
\frac{d^{2} m}{d \tau^{2}}+c_{0} \frac{d m}{d \tau}+c_{1} m=0
$$

where $m$ is the carbon mass; $c_{0}$ and $c_{l}$ are constants; $\tau$ is a dimensionless time scale such that $t / t_{0.5}$ equals one at a fractional conversion of 0.5 , the same definition as in equation [2.19]. By normalizing $m$ as $M=m / m_{0}$ and applying the boundary condition: (1) $M=1$ at $\tau=0$; (2) $M=0.5$ at $\tau=1$, also provided that $c_{0}>2 \sqrt{c_{1}}$, the solution to equation [2.26] can be written as:

$$
M=B \exp \left(-x_{1} \tau\right)+(1-B) \exp \left(-x_{2} \tau\right)
$$

where $B=\frac{0.5-\exp \left(-x_{2}\right)}{\exp \left(-x_{1}\right)-\exp \left(-x_{2}\right)}$, and $x_{1}$ and $x_{2}$ are rate constants.

A further non-linear least-square regression found that equation [2.27] can be rewritten as:

$$
M=(1+1.18 \tau) \exp (-1.47 \tau)
$$

It should be noted that $M$ could be written as $(1-X)$, and the equation is consistent with the reactivity profiles that exhibit a maximum during the gasification reaction for most of chars.

In summary, most of the above empirical models mathematically describe the char gasification kinetics very well. However, neither these mathematical functions nor their adjustable parameters have any physical significance. The advantage of those empirical models is that they are simple for application. They also can be used to predict 
reaction rate increasing to a maximum, and after this maximum rate, the models further predict a decreasing rate.

\subsubsection{Theoretical models}

The theoretical models can be classified into two categories: (1) those that consider the reaction on the surfaces of nonporous grains; (2) those that attribute the reaction to the pore surfaces within the solid.

\section{Model 10 (Shrinking sphere model)}

When a solid char carbon consists of a cluster grains, and the reaction occurs on the surface area of the grain, the shrinking sphere model can be used to analyze the reaction kinetics. The model was first introduced by Yagi and Kunii, and was later studied by Szekely and Evans (Szekely and Evans, 1970) who introduced a moving boundary. Park and Levenspiel further developed the model, and presented the cracking core model (Park and Levenspiel, 1975). Levenspiel gives a very detailed analysis in his textbook (Levenspiel, 1972).

An analysis of the kinetics of reaction [2.1] with this model, assumes that there are three steps during the reaction: (1) carbon dioxide diffuses from the bulk of gas through the gas film to the surface of the solid char carbon (cluster grain); (2) gasification reaction occurs on the surface of the cluster grain; (3) the reaction gaseous product $(\mathrm{CO})$ diffuses from the surface of the cluster grain through the gas film back into the main body of gas. The rate-controlling step is either the reaction (step 2), or the diffusion (step 1, or 3). The additional assumptions are: (4) the surface chemical reaction is a first-order irreversible reaction with respect to $\mathrm{CO}_{2} ;(5)$ there is no mass transfer resistance in the ash layer; and (6) the particle is spherical.

According to above assumptions, the rate of formation or loss is proportional to the available surface area of unreacted sphere, and the kinetic equations are deduced based on the boundary surface area of a particle, $S_{b}$. The stoichiometry relation of reaction [2.1], $d N_{C}=d N_{C_{2}}$, yields the following expression:

$$
-\frac{1}{S_{b}} \frac{d N_{C}}{d t}=-\frac{1}{4 \pi r_{p}^{2}} \frac{d N_{C}}{d t}=-\frac{1}{4 \pi r_{p}^{2}} \frac{d N_{C O_{2}}}{d t}=k_{s} C_{C O_{2}}
$$


where $k_{s}$ is the rate constant for the surface reaction with respect to $\mathrm{CO}_{2}$, here assumed to be first-order; $r_{p}$ is the radius of the unreacted spherical particle at a given time; $N_{C}$ is the number of moles of carbon; $\mathrm{NCO}_{2}$ is the number of moles of the gas $\mathrm{CO}_{2}$; and $\mathrm{C}_{\mathrm{CO}_{2}}$ is the bulk concentration of carbon dioxide, and assumed to be equal to the surface concentration.

If $\rho_{\mathrm{C}}$ is the molar density of char carbon and $V_{C}$ is the volume of a particle, then:

$$
-d N_{C}=-d N_{C O_{2}}=-\rho_{C} d V_{C}=-\rho_{C} d\left(\frac{4}{3} \pi r_{p}^{3}\right)=-4 \pi \rho_{C} r_{p}^{2} d r_{p}
$$

Introducing equation [2.29] into [2.30], yields:

$$
-\frac{1}{4 \pi r_{p}^{2}} \rho_{C} 4 \pi r_{p}^{2} \frac{d r_{p}}{d t}=-\rho_{C} \frac{d r_{p}}{d t}=k_{s} C_{C O_{2}}
$$

Integrating the equation [2.31] and assuming $\mathrm{C}_{\mathrm{CO}_{2}}$ is constant, yields: $-\rho_{C} \int_{R_{o}}^{r_{p}} d r_{p}=k_{s} C_{C O_{2}} \int_{0}^{t} d t$, where $R_{o}$ is the initial radius of the spherical particle. The integrated form can be written as:

$$
t=\frac{\rho_{C}}{k_{s} C_{C O_{2}}}\left(R_{o}-r_{p}\right)
$$

Defining the time $t_{X=1}$ as the required time for complete reaction, or when $r_{p}=0$, yields:

$$
t_{X=1}=\frac{\rho_{C} R_{o}}{k_{S} C_{C O_{2}}}
$$

By normalizing the time $t$ as a dimensionless time, $\tau$, defined as:

$$
\tau=\frac{t}{t_{X=1}}=\frac{t k_{s} C_{C O_{2}}}{\rho_{C} R_{o}}
$$

Equation [2.32] reduces to: 


$$
\tau=1-\frac{r_{p}}{R_{o}}
$$

According to the definition of fractional conversion $X$, the following relationship can be written:

$$
1-X=\frac{\frac{4}{3} \pi r_{p}^{3} \rho_{C}}{\frac{4}{3} \pi R_{o}^{3} \rho_{C}}=\left(\frac{r_{p}}{R_{o}}\right)^{3}
$$

Substituting equation [2.36] into [2.35], finally yields equation [2.37] as:

$$
\tau=1-(1-X)^{1 / 3}
$$

Differentiating equation [2.37] with respect to $\tau$, produces an equation comparable with other models:

$$
\frac{d X}{d \tau}=3(1-X)^{2 / 3}, \text { or } \frac{d X}{d \tau} \propto(1-X)^{2 / 3}
$$

The general formulation of a rate expression analyzed by the shrinking sphere model was reviewed by Bhatia (Bhatia and Perlmutter, 1980). Assuming chemical reaction controlling, the reaction rate expression is shown as:

$$
\frac{d X}{d t}=\frac{k_{s} C_{C O_{2}}{ }^{n} S_{o}}{\left(1-\varepsilon_{o}\right)}(1-X)^{m}
$$

where $k_{s}$ is the rate constant for the surface reaction with respect to $\mathrm{CO}_{2}$, here it is $\mathrm{n}^{\text {th }}$ order; $m$ is identified as a shape factor that depends on the geometry of the particle: for spheres $m=2 / 3$, for cylinders $m=1 / 2$ and for flat plates $m=0 ; S_{o}$ is the initial reaction surface area per unit volume; $\varepsilon_{o}$ is the initial value of the porosity.

Equation [2.39] introduces into the model the structural parameters of the char carbon in terms of porosity and surface area. Since the reacting surface area of the sphere for each particle is decreasing, the model predicts a monotonic decrease of reaction rate. However, there is a discrepancy between the shrinking sphere model and the empirical models, which demonstrate the gasification reaction rate exhibits a maximum and then 
decreases. This is generally attributed to an increase in the reacting surface area during the early stages of the reaction. However, the shrinking sphere model does not account for such changes in the solid structure during the reaction.

\section{Model 11 (Random Pore model)}

The theoretical basis of the random pore model is that the reaction occurs on the pore surfaces within the solid particle. The basic assumptions about the pore structure are: (1) all pores are of the same size; and (2) during the whole reaction process, no new pore intersections occur so that the reaction surface area within the particles has no growth at all. Based on Petersen's structural characteristic parameters (Petersen, 1957), which included reaction surface area $S$ and porosity $\varepsilon$, Szekely et al. derived a complicated conversion-time relationship expression (Szekely et al., 1976).

Later, Bhatia and Perlmutter demonstrated a general model that considers the random overlap of reaction surface areas when the pores grow (Bhatia and Perlmutter, 1980). The key assumption of the model is that they propose a set of overlapping parallel cylinders within the particle, and the cylinders have a size distribution. After a series of mathematical deductions, the authors reported an expression of the conversion $X$ as [2.40] with three parameters defined as [2.41], [2.42], and [2.43]:

$$
\begin{aligned}
& X=1-\left(\frac{1-V}{1-V_{o}}\right)\left(1-\frac{k_{s} C_{\mathrm{CO}_{2}}{ }^{n} t}{R_{o}}\right)^{3} \\
& \sigma=R_{o} S_{o} /\left(1-\varepsilon_{o}\right) \text {, particle size parameter } \\
& \tau={ }{ }_{s} C_{C O_{2}}{ }^{n} S_{o} t /\left(1-\varepsilon_{o}\right), \text { dimensionless time } \\
& \psi=4 \pi L_{o}\left(1-\varepsilon_{o}\right) / S_{o}^{2}, \text { structural parameter }
\end{aligned}
$$

where $t$ is the time; $k_{s}$ is the rate constant for the surface reaction with respect to $\mathrm{CO}_{2}$, here it is $\mathrm{n}^{\text {th }}$ order; $V$ is the volume enclosed by the reaction surface at any time; $V_{o}$ is the initial volume enclosed by the reaction surface at $t=0 ; R_{o}$ is the initial radius of a carbon particle; $\mathrm{C}_{\mathrm{CO}_{2}}$ is the concentration of the gas $\mathrm{CO}_{2} ; S_{o}$ is the initial reaction surface area at 
$t=0 ; \varepsilon_{o}$ is the initial value of the porosity; $L_{o}$ is the initial length of the overlapped pore system at $t=0$.

Further derivation yields the following final expressions:

$$
\begin{aligned}
& \frac{S}{S_{o}}=\frac{1-X}{\left(1-\frac{\tau}{\sigma}\right)^{3}} \sqrt{1-\psi \ln \left[\frac{1-X}{\left(1-\frac{\tau}{\sigma}\right)^{3}}\right]} \\
& X=1-\left(1-\frac{\tau}{\sigma}\right)^{3} \exp \left[-\tau\left(1+\frac{\psi \tau}{4}\right)\right]
\end{aligned}
$$

where $\mathrm{S}$ is the reaction surface area at any time. When the particle size parameter, $\sigma$, is large as it is in many porous gas-solid reactions, or $\sigma \rightarrow \infty$, differentiating the equation [2.45], results in:

$$
\frac{d X}{d \tau}=(1-X) \sqrt{1-\psi \ln (1-X)}
$$

It is interesting to note that with different assumptions about the structure parameter $\psi$, equation [2.46] can be rewritten in the same form as that of Model 10 and Model 5. For example, if $\psi=0$, then expression [2.46] has the same form as Model 5, shown in [2.16].

To summarize the theoretical models, it is noted that the theoretical models give a clear physical meaning either in their mathematical formulation or parameters which include the structural characteristics of the char. However, more than two parameters make the application of these theoretical models difficult. Furthermore, theoretical models cannot explain some phenomena in the gasification reaction, such as the reactivity climbing up to a maximum and then decreasing.

2.3 Mass transfer effect

According to Sears (Sears and Wen, 1981) and Kapteijn (Kapteijn and Moulijn, 1986), typically, with the increase of temperature, the controlling steps for a gasification reaction are: (1) chemical reaction controlling, or Region I, at relative lower temperature; 
(2) internal diffusion controlling, or Region II, at medium temperature; and (3) external gas-film diffusion controlling, or Region III, at higher temperature. To conduct a chemical kinetic analysis, it is generally assumed that the gasification reaction is chemically controlled. However, before performing a kinetic analysis, it should be confirmed that the reaction conditions are valid for this assumption.

\subsubsection{Internal mass transfer limitation}

For a porous carbon particle, the gasification reaction occurs principally on the pore surface within the particle. Except at very high temperature, $\mathrm{CO}_{2}$ must diffuse into the pore and react on the pore surface. Therefore, in Region II, an effectiveness factor must be introduced. The effectiveness factor, $\eta$, is defined as follows (Graboski, 1979):

$$
\eta=\frac{r_{\text {average }}}{r_{\text {surface }}}
$$

where $r_{\text {average }}$ is the mean reaction rate within the particle; $r_{\text {surface }}$ is the assumed reaction rate that only occurs on the particle surface area without diffusion resistance.

The effectiveness factor is a function of a dimensionless group termed the Thiele modulus, which includes the diffusivity inside the pore, the rate constant for reaction, pore dimensions, and external surface concentration of $\mathrm{CO}_{2}, C_{S}$. For instance, for an isothermal particle, the $\mathrm{n}^{\text {th }}$ order reaction effectiveness factor, $\eta$, is given as follows:

$$
\eta=\frac{\tanh (\phi)}{\phi}
$$

where $\phi$ is the Thiele modulus and defined as:

$$
\phi=L_{P} \sqrt{\frac{k_{S} C_{S}^{n-1}}{V_{P} D}}
$$

where $L_{P}$ is effective pore length, for spheres $L_{P}=R / 3$ ( $R$ is particle radius); $k_{s}$ is the rate constant for the surface reaction with respect to $\mathrm{CO}_{2} ; C_{S}$ is external surface concentration for $\mathrm{CO}_{2} ; n$ is reaction order with respect to $\mathrm{CO}_{2} ; V_{P}$ is pore volume; $D$ is gas diffusivity.

From these definitions, it can be shown: 
Condition (1): when the mass diffusion is faster than the mass consumed by the surface reaction, $\phi \rightarrow 0, \eta \rightarrow 1$, then $r_{\text {average }}=r_{\text {surface }}$. Under this condition, all of the pore area inside the particles is accessible and effective for gaseous reactant, $\mathrm{CO}_{2}$, to react with solid carbon. Condition (2): contrary to the first condition, when mass diffusion is slower than the reaction rate or $\phi \rightarrow \infty, \eta \rightarrow 0$, then the reaction occurs exclusively at the particle external surface and the reactant gas does not penetrate into the pores. It should be noted that in Region I (chemical controlling), the effectiveness factor, $\eta$, almost equals 1. But for most of the cases, the value of $\eta$ is between 0 and 1 .

Based on this approach, Dutta and Wen considered the diffusion resistance within the solid particle in their model, Model 5 (Dutta et al., 1977), and gave the expression [2.16], shown as:

$$
\frac{d X}{d t}=\eta \cdot S \cdot k_{r} \cdot C_{\mathrm{CO}_{2}} \cdot(1-X)
$$

\subsubsection{External mass transfer limitation}

External mass transport generally becomes dominant at temperatures higher than that at which internal mass transfer limits the gasification rate. In Region III, the gaseous reactant $\mathrm{CO}_{2}$ must penetrate through a hydrodynamic boundary layer and a stationary gas film surrounding the particle, to arrive at the solid particle boundary surface or diffuse further into the pore surface inside the particle. External mass transfer resistance reduces the concentration of reactant gas close to the particle surface and thus reduces the overall process rate. Generally speaking, increasing the external gas velocity or mass flux and decreasing the particle size can minimize external mass transfer effects.

To analyze an external mass transfer problem, Fogler developed a model for a single particle (Fogler, 1999). Based on a hydrodynamic analysis on a single particle, and a steady-state static assumption, he gave a relationship as:

$$
W_{\mathrm{CO}_{2}}=-r_{\mathrm{CO}_{2}}=K_{g} \cdot\left(C_{\mathrm{CO}_{2}}-C_{S}\right)=k_{s} \cdot C_{S}
$$

where $W_{\mathrm{CO} 2}$ is the mass diffusion flux of $\mathrm{CO}_{2} ; r_{\mathrm{CO}_{2}}$ is the reaction rate with respect to $\mathrm{CO}_{2} ; K_{g}$ is the gas mass transfer coefficient; $\mathrm{C}_{\mathrm{CO}_{2}}$ is the bulk concentration of $\mathrm{CO}_{2} ; C_{S}$ is 
the surface concentration of $\mathrm{CO}_{2} ; k_{s}$ is the rate constant for the surface reaction with respect to $\mathrm{CO}_{2}$, here assumed to be first order.

Further mathematical manipulation yields:

$$
W_{\mathrm{CO}_{2}}=-r_{\mathrm{CO}_{2}}=k_{e f f} \cdot C_{\mathrm{CO}_{2}}, \text { and } k_{e f f}=\frac{K_{g} \cdot k_{s}}{K_{g}+k_{s}}
$$

Consequently, further analysis shows two extreme conditions:

Under condition (1), for a rapid chemical reaction, it is assumed that $k_{s}>K_{g}$, then:

$$
-r_{\mathrm{CO}_{2}}=\frac{K_{g} \cdot C_{\mathrm{CO}_{2}}}{1+K_{g} / k_{s}} \approx K_{g} \cdot C_{\mathrm{CO}_{2}}
$$

For this condition, the external mass transfer is the controlling step, and one can use a dimensionless number, such as the $S h$ (Sherwood number), to calculate the value of $K_{g}$.

Under condition (2), for a slow chemical reaction, it is noted that $k_{s}<<K_{g}$, then:

$$
-r_{\mathrm{CO}_{2}}=\frac{k_{s} \cdot C_{\mathrm{CO}_{2}}}{1+\frac{k_{s}}{K_{g}}} \approx k_{s} \cdot C_{\mathrm{CO}_{2}}
$$

For this condition, the chemical reaction is the controlling step, and mass transfer has no contribution on the reaction resistance. In other cases, if $k s$ and $K_{g}$ are of the same order of magnitude, one can first employ a $S h$ number-type correlation to obtain $K_{g}$ and then use equation [2.51] to extract the value of $k_{s}$ from experimental data of $k_{\text {eff. }}$.

Doraiswamy presented an experimental method to evaluate the external mass transfer effect (Doraiswamy and Sharma, 1984). The theoretical principle for this method is that if there exists no external mass transfer limitation during a reaction, then at a fixed residence time, the measured conversion $X$ at a given time should be independent of either the mechanical agitation or the hydrodynamic agitation caused by a fluid flow. Consequently, the first step for an experimental procedure should be the investigation of the conversion $X$ as a function of the agitation characteristic, but the experiment should 
be conducted under a fixed value of $W / F$, where, $W$ is the sample weight, and $F$ is the gas flow rate. Actually, $W / F$ is a measurement for the fluid residence time in a reactor. Afterward, a plot of the conversion vs. the flow velocity is constructed. If the conversion $X v s$. different flow velocities levels off beyond a certain flow velocity, then it can be concluded that external mass transfer has no effect at these relatively high velocities. For example, Sofekun successfully used this approach in the kinetic modeling of the oxidation of zinc sulfide with a set of TGA data (Sofekun and Doraiswamy, 1996).

\subsection{Catalytic Effects}

It is reported that most metals, their oxides, and their salts are more or less catalytic. For instance, Huggins and coworkers using an in situ XAFS approach revealed that alkali and alkaline-earth cations were initially bound in lignite by carboxyl groups, and later transformed in their states during the gasification and showed a catalytic effect (Huggins et al., 1989).

Mims and Pabst also reported a kinetic model for alkali-catalyzed carbon gasification (Mims and Pabst, 1987). They employed a surface alkylation technique to measure the relative reaction rate, and quantitatively unified the relative reaction rates for alkali ( $\mathrm{Li}$ through $\mathrm{Cs}$ ) salt-catalyzed carbon gasification with reactants such as $\mathrm{H}_{2} \mathrm{O}, \mathrm{D}_{2} \mathrm{O}$, and $\mathrm{CO}_{2}$. Their results indicated that the rates are governed by a surface oxidation step in equilibrium with the gas phase, which is general to all three gaseous reactants.

Based on a molecular orbital calculation, Chen and Yang proposed a mechanism for the gasification reaction of graphite with $\mathrm{CO}_{2}$ catalyzed by alkali and alkaline earths (Chen and Yang, 1997). Their mechanism explained all major experimental features. For instance, the experiment results showed that alkali and alkaline earth catalysts only increase the gasification rate but keep the activation energy unchanged. Based on their reaction mechanism, Chen and Yang further gave a rate equation for a catalyzed gasification reaction.

Adjorlolo and Rao gave a so-called "vapor cycle" mechanism (Adjorlolo and Rao, 1984). The two-reaction sequence is shown as: 


$$
\begin{aligned}
& \mathrm{M}_{2} \mathrm{CO}_{3}(\mathrm{~s})+2 \mathrm{C}(\mathrm{s}) \longrightarrow 2 \mathrm{M}(\mathrm{g})+3 \mathrm{CO}(\mathrm{g}) \\
& 2 \mathrm{M}(\mathrm{g})+2 \mathrm{CO}_{2}(\mathrm{~g}) \longrightarrow \mathrm{M}_{2} \mathrm{CO}_{3}(\mathrm{~s})+\mathrm{CO}(\mathrm{g})
\end{aligned}
$$

The first step [2.54] is a metal reduction step, and the second step [2.55] is an oxidation step. Based on experimental results, they pointed out that potassium and sodium carbonate proved to be effective catalysts for the coke- $\mathrm{CO}_{2}$ gasification reaction, and the former was slightly more effective. The key issue in this mechanism is the metal vapor cycle. Later, by an approach of molecular beam/mass spectrometry, Dayton directly observed the alkali vapor release during biomass combustion and gasification (Dayton et al., 1995). This observation provides some objective support to the "vapor cycle" mechanism.

It is noteworthy that Brown et al. reported a series of $\mathrm{CO}_{2}$-char gasification experiments performed in a TGA to evaluate the catalytic activity of an alkali-rich biomass, switchgrass (Brown et al., 2000). Their results demonstrated that switchgrass char and switchgrass ash displayed significant catalytic activity when mixed with Illinois No.6 coal char. It was reported that, when a mixture of $10 \%$ (weight) coal char and $90 \%$ switchgrass ash was reacted with $\mathrm{CO}_{2}$ at $895^{\circ} \mathrm{C}$, the gasification rate impressively increased by almost eight-fold. Encouraged by this work, it can be expected that biomass, char or its ash could be a source of coal gasification catalysts, which are both cheap and abundant. 


\section{Chapter 3 Experimental Methods and Data Analysis}

3.1 Raw material and supply

\section{Chars:}

Considering the geographical location of coal and biomass for economical reasons, three groups of coal char and biomass char are paired as gasification feedstock for reaction with carbon dioxide. Group 1 includes North Dakota lignite coal (Lignite) char and Hardwood char; Group 2 includes Illinois No.6 coal (Bituminous) char and Switchgrass char; and Group 3 includes Powder River Basin (Sub-bituminous) coal char and Corn Stover char.

The raw coal and biomass were obtained from the Pennsylvania State University Coal Bank. Coworkers in the NETL/DOE laboratory of Morgantown prepared the chars by flowing nitrogen past a hot plate containing the raw sample at $900^{\circ} \mathrm{C}$. Afterward, the chars were ground and homogenized at WVU for the gasification experiments. No attempt was made to control the particle size of the char.

The proximate analysis data of raw coal and biomass are collected in Table 3.1. The analysis data of raw coal were obtained from the Pennsylvania State University Coal Bank Database and the raw biomass data were determined at WVU.

Table 3.1 Proximate analysis of raw coal and biomass

\begin{tabular}{|c|l|c|c|c|c|}
\hline Type & \multicolumn{1}{|c|}{ Sample Name } & Moisture (\%) & Volatile (\%) & Ash (\%) & Fixed Carbon (\%) \\
\hline \multirow{3}{*}{ Coal } & Illinois No.6 & 13.20 & 35.44 & 11.62 & 39.74 \\
\cline { 2 - 6 } & North Dakota lignite & 33.38 & 37.36 & 6.37 & 22.89 \\
\cline { 2 - 6 } & Powder River Basin & 26.30 & 33.06 & 5.58 & 35.06 \\
\hline \multirow{3}{*}{ Biomass } & Switchgrass & 8.58 & 68.75 & 6.27 & 16.41 \\
\cline { 2 - 6 } & Hardwood & 5.21 & 67.17 & 10.54 & 17.08 \\
\cline { 2 - 6 } & Corn Stover & 4.61 & 77.62 & 0.30 & 17.47 \\
\hline
\end{tabular}

Note: * Raw biomass data are the average value of three duplicate analyses.

\section{Gases:}

The following gases were used in the study;

- Carbon dioxide: Airgas Inc., ultra high purity grade, 99.999\% purity;

- Nitrogen: Airgas Inc., ultra high purity grade, $99.999 \%$ purity; 
- Helium: Airgas Inc., ultra high purity grade, $99.999 \%$ purity.

\subsection{Apparatus}

For all three groups of chars, a TherMax 500 TGA instrument was employed to obtain gasification data for the pure coal chars, the pure biomass chars, and the above three char blends. The TGA unit consisted of a stainless steel furnace vessel with a quartz reactor tube inserted in the center of the vessel. The top part of the vessel houses the micro-balance assembly which is protected by a helium gas purge during the reaction. The specifications of TherMax 500 are as follows:

- Temperature range: ambient to $1100^{\circ} \mathrm{C}$;

- Sensitivity: $1 \mu \mathrm{g}\left(1 * 10^{-6} \mathrm{~g}\right)$;

- Pressure: up to $100 \mathrm{~atm}$;

- Quartz reactor tube dimensions: Diameter, 31.75mm; Height, 428.625mm.

\subsection{Safety information}

Details of the safe operation of the gas cylinders and the TGA experiment are given in the Appendix J. Parenti included more safety information in his master thesis (Parenti, 2009).

\subsection{Experimental procedure}

The TherMax 500 TGA system was used to measure the gasification kinetics of the coal and biomass chars. The arrangement of the instrument is shown in the Figure 3.1. After the regulators on the cylinders, the gases $\mathrm{CO}_{2}$ and $\mathrm{N}_{2}$, go through a common flow meter (gas flow rate controller) that is calibrated at room temperature for different gases. The gas flow rate controller also acts as a gas switch between $\mathrm{CO}_{2}$ and $\mathrm{N}_{2}$. The gases then go into the bottom of the reactor tube and the product gases after exiting the top of the reactor zone, pass through a valve (installed in TGA analyzer) and are exhausted into the atmosphere. Data acquired by the TGA analyzer in the form of sample mass $v s$. time are transferred to a computer for further analysis. 


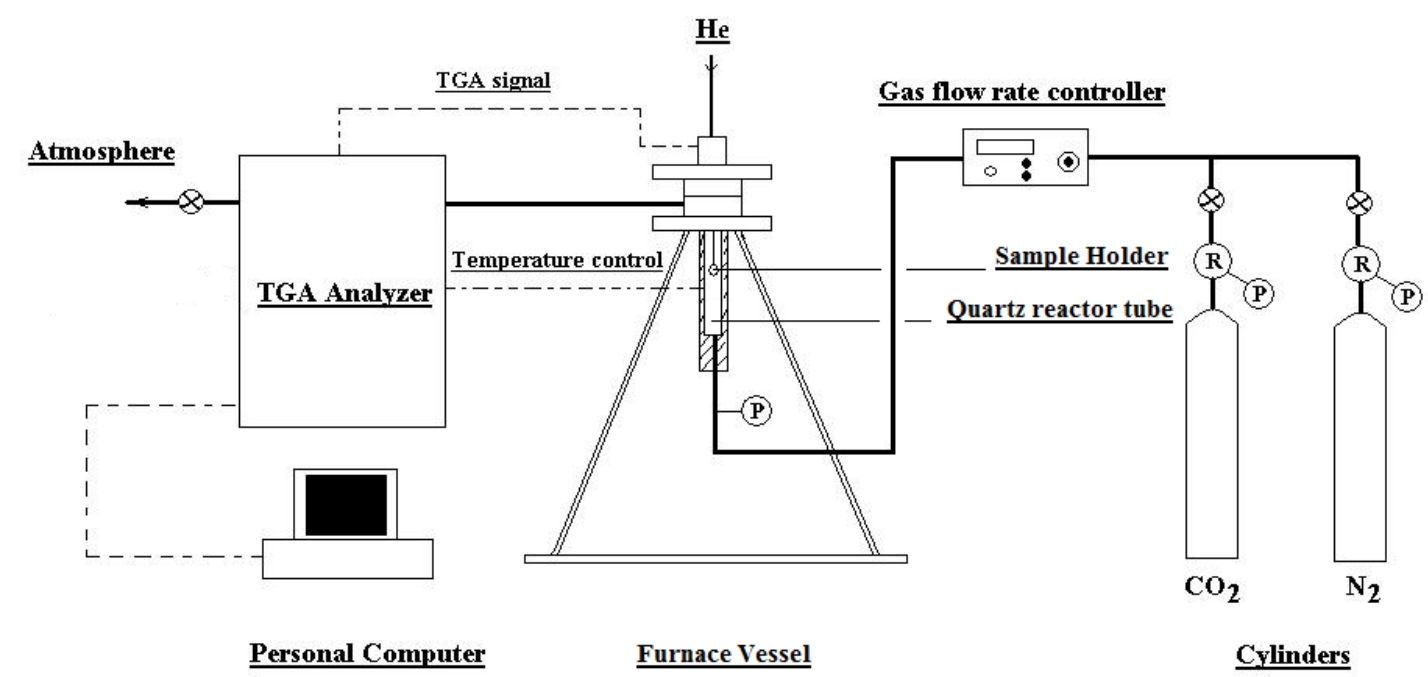

Figure 3.1 Schematic of the experimental TGA apparatus

For a standard TGA run, about 50mg of char sample is put into the specially designed sample holder and the furnace vessel is assembled according to the manual. The sample holder appears like a basket with a Platinum mesh shelf inserted in the middle. The sides are also made of Platinum mesh and there is a Platinum foil in the bottom to catch any particles which may pass through the basket.

There are three steps to carry out the carbon dioxide gasification reaction:

- Step 1: Isothermal preparation stage

Switching the gas to pure nitrogen, and setting the $\mathrm{N}_{2}$ flow rate at $187 \mathrm{ml} / \mathrm{min}$, the temperature is held at $20^{\circ} \mathrm{C}$ for 15 minutes to equilibrate the instrument. The TGA sample time interval is set at 10 seconds.

- Step 2: Temperature increasing stage

Keeping the nitrogen gas flowing through the reactor and the $\mathrm{N}_{2}$ flow rate at $187 \mathrm{ml} / \mathrm{min}$, the reactor temperature is increased at a rate of $20^{\circ} \mathrm{C} / \mathrm{min}$ to the set point $\left(900^{\circ} \mathrm{C}, 1000^{\circ} \mathrm{C}\right.$, or $\left.1100^{\circ} \mathrm{C}\right)$. After reaching the set point, the reactor is held at that temperature for a time such that the entire time from the beginning of step 1 to the end of step 2 is 200 minutes. This time was arbitrarily decided upon after many runs. This step is to drive off the remaining volatile material in the chars as much as possible. 
- Step 3: Isothermal gasification stage

Once the time at the end of step 2 is 200 minutes, the gas is switched from nitrogen to carbon dioxide to start the gasification reaction. The $\mathrm{CO}_{2}$ flow rate is set at $118 \mathrm{ml} / \mathrm{min}$ for most runs. TGA sample time interval is set at 0.5 seconds. Since the whole system is connected to the atmosphere, it is assumed that the reaction pressure is $1 \mathrm{~atm}$. This is confirmed by a pressure gauge on the reactor. The reaction completion time is quite different with respect to different chars. Once the sample weight drops to a constant value, the experiment was terminated by switching to $\mathrm{N}_{2}$ and cooling the system to room temperature.

\subsection{Experiment data}

All $\mathrm{CO}_{2}$ gasification experiments were carried out by Mr. Joshua A. Parenti, and the experimental matrix is shown in the Table 3.2. Full details on the experiment can be found in his thesis (Parenti, 2009). 
Table 3.2 Gasification experimental matrix

\begin{tabular}{|c|c|c|c|c|}
\hline Groups & Chars & \multicolumn{3}{|c|}{ Temperature $\left(\mathrm{C}^{\mathrm{o}}\right)$ and replication ${ }^{(\mathrm{f})}$} \\
\hline \multirow{4}{*}{1} & ND lignite ${ }^{(a)}$ & $900(\mathrm{~A}, \mathrm{~B})$ & $1000(\mathrm{~A}, \mathrm{~B})$ & $1100(\mathrm{~A}, \mathrm{~B})$ \\
\hline & Hardwood & $900(\mathrm{~A}, \mathrm{~B})$ & $1000(\mathrm{~A}, \mathrm{~B})$ & $1100(\mathrm{~A}, \mathrm{~B})$ \\
\hline & Mixed 10\% ${ }^{(b)}$ & $900(\mathrm{~A}, \mathrm{~B})$ & $1000(\mathrm{~A}, \mathrm{~B})$ & $1100(\mathrm{~A}, \mathrm{~B})$ \\
\hline & Mixed 30\% ${ }^{(\mathrm{c})}$ & $900(\mathrm{~A}, \mathrm{~B})$ & $1000(\mathrm{~A}, \mathrm{~B})$ & $1100(\mathrm{~A}, \mathrm{~B})$ \\
\hline \multirow{4}{*}{2} & ILL No.6 ${ }^{(\mathrm{d}),(\mathrm{g})}$ & $900(\mathrm{~A}, \mathrm{~B})$ & $1000(\mathrm{~A}, \mathrm{~B})$ & $1100(\mathrm{~A}, \mathrm{~B})$ \\
\hline & Switchgrass & $900(\mathrm{~A}, \mathrm{~B})$ & $1000(\mathrm{~A}, \mathrm{~B})$ & $1100(\mathrm{~A}, \mathrm{~B})$ \\
\hline & Mixed 10\% ${ }^{(\mathrm{b})}$ & $900(\mathrm{~A}, \mathrm{~B})$ & $1000(\mathrm{~A}, \mathrm{~B})$ & $1100(\mathrm{~A}, \mathrm{~B})$ \\
\hline & Mixed 30\% ${ }^{(\mathrm{c})}$ & $900(\mathrm{~A}, \mathrm{~B})$ & $1000(\mathrm{~A}, \mathrm{~B})$ & $1100(\mathrm{~A}, \mathrm{~B})$ \\
\hline \multirow{4}{*}{3} & $\mathrm{PRB}^{(\mathrm{e})}$ & $900(\mathrm{~A}, \mathrm{~B})$ & $1000(\mathrm{~A}, \mathrm{~B})$ & $1100(\mathrm{~A}, \mathrm{~B})$ \\
\hline & Corn Stover & $900(\mathrm{~A}, \mathrm{~B})$ & $1000(\mathrm{~A}, \mathrm{~B})$ & $1100(\mathrm{~A}, \mathrm{~B})$ \\
\hline & Mixed 10\% ${ }^{(b)}$ & $900(\mathrm{~A}, \mathrm{~B})$ & $1000(\mathrm{~A}, \mathrm{~B})$ & $1100(\mathrm{~A}, \mathrm{~B})$ \\
\hline & Mixed 30\% ${ }^{\text {(c) }}$ & $900(\mathrm{~A}, \mathrm{~B})$ & $1000(\mathrm{~A}, \mathrm{~B})$ & $1100(\mathrm{~A}, \mathrm{~B})$ \\
\hline 4 & \multicolumn{2}{|c|}{ ILL No.6 Mixed 30\% Hardwood $^{(\mathrm{c})}$} & \multicolumn{2}{|c|}{$900(\mathrm{~A}, \mathrm{~B})$} \\
\hline 5 & \multicolumn{2}{|c|}{ ND lignite Mixed 30\% Switchgrass ${ }^{(\mathrm{c})}$} & \multicolumn{2}{|c|}{$900(\mathrm{~A}, \mathrm{~B})$} \\
\hline
\end{tabular}

Note:

(a) ND lignite presents the North Dakota lignite char;

(b) $10 \%$ is based on weight, or as 10:90 (weight) of biomass char to coal char;

(c) $30 \%$ is based on weight, or as 30:70 (weight) of biomass char to coal char;

(d) Ill No.6 presents the Illinois No.6 coal char;

(e) PRB presents the Powder River Basin coal char;

(f) The (A, B) symbols means that each of the experiments was done in duplicate;

(g) For Ill No.6 only, the matrix also includes single runs at $950^{\circ} \mathrm{C}$ and $1050^{\circ} \mathrm{C}$;

\subsection{Data analysis}

\subsubsection{Definition of carbon conversion fraction $X$}

The original TGA data are presented in the form of sample weight $v s$. time ( $w_{C} v s$. $t$, where $t$ is time and $w_{C}$ is the sample weight at a given time). Dutta's definition of the carbon conversion $X$ (Dutta et al., 1977) includes ash weight in equation [2. 6]. For the work herein, the weight of the sample residue is used instead of the ash weight since the proximate analysis for all the chars could not be performed due to sample availability. Consequently, the initial sample weight is defined as $w_{C o}$ at $t=0$, and the finial sample weight as $w_{\text {residue }}$ when the reaction is terminated. As a consequence, the carbon conversion fraction $X$ is taken as follows;

$$
X=1-\frac{w_{C}-w_{\text {residue }}}{w_{C o}-w_{\text {residue }}}
$$


Equation [3.1] can be rearranged to give the relationship of $(1-X)$ as:

$$
1-X=\frac{w_{C}-w_{\text {residue }}}{w_{\text {Co }}-w_{\text {residue }}}
$$

\subsubsection{Data truncation}

During the data analysis process, it was found that more or less unstable data appear at the initial stage and the final stage of the reaction. In the initial stage, the phenomenon may be caused by the gas buoyancy impact on the microbalance during the gas switching. For the final stage, the small sample weight causes unstable readings. Considering all of situations, the conversion data are truncated from $X=0.1$ to 0.9 for the modeling fitting.

\subsubsection{Kinetic analysis methods}

\section{Differentiation of a polynomial fit data (Differential method):}

If the carbon reaction rate has the following relationship:

$$
r_{C}=\frac{d X}{d t} \propto k_{r} C_{C O_{2}}^{m}(1-X)^{n}
$$

(where $k_{r}$ is the global rate constant; $C_{\mathrm{CO}_{2}}$ is the concentration of carbon dioxide; $m$ is the reaction order for $\mathrm{CO}_{2} ; n$ is the reaction order for carbon), then directly determining the value of the derivative $\frac{d X}{d t}$ is one method of analysis for the reaction kinetics. This method is called the differential method (Fogler, 1999). Generally speaking, there are three methods to obtain the derivative, $\frac{d X}{d t}$ : (1) graphical differentiation; (2) numerical differentiation formulas; (3) differentiation of a polynomial fit of the data.

Here, the polynomial fit method is selected by first fitting all the conversion-time data to an $n$ th-order polynomial and the conversion $X$ is used from 0 to 1 :

$$
X=a_{0}+a_{1} t+a_{2} t^{2}+\ldots+a_{n} t^{n}
$$

Since $X=0$ at $t=0, a_{0}$ is set to 0 . After determining all the constants, $a_{i}$, the polynomial is directly differentiated with respect to $t$ to obtain the following expression: 


$$
\frac{d X}{d t}=a_{1}+2 a_{2} t+3 a_{3} t^{2}+\ldots+n a_{n} t^{n-1}
$$

By this approach, the $\frac{d X}{d t}$ value is obtained at any given time. By setting $t=0$, the initial reaction rate, $\left(\frac{d X}{d t}\right)_{t=0}$, is obtained. The polynomial order was used as $4^{\text {th }}$ order.

\section{Integral Method:}

If the carbon reaction rate has the same differential equation as [3.3], then the integral method can be used to obtain a function directly relating $X v s$. $t$ and the associated kinetic parameters. Upon separating variables and letting time go from 0 to $t$ and conversion from 0 to $X$, the resulting equation relates $X$ to $t$ with some constant terms. Finally a Least-Squares Regression method is employed to fit the experimental data and obtain kinetic parameters.

The integral method is generally used when the reaction model has been postulated and it is desired to evaluate the order of reaction and the rate constant at different temperatures to determine the activation energy. Since the relationship of $X v s . t$ depends on the kinetic model, more detailed information will be given in later section. It should note that for the integral method, here, the experimental data were truncated from $X=0.1$ to 0.9 .

\section{Arrhenius Activation Energy:}

The Swedish chemist Arrhenius suggested that the temperature dependence of the reaction rate constant, $k$, could be correlated by an equation as (Fogler, 1999):

$$
k(T)=A \exp \left(-\frac{E}{R T}\right)
$$

where $A$ is the pre-exponential or frequency factor, $E$ is the activation energy $(\mathrm{J} / \mathrm{mol}), R$ is the universal gas constant $\left(8.314 \mathrm{~J} \mathrm{~mol}^{-1} \mathrm{~K}^{-1}\right)$, and $T$ is the absolute temperature, $\mathrm{K}$.

The activation energy is determined experimentally by carrying out the reaction at several different temperatures and evaluating $k$ at each temperature. Taking logarithms of the above equation yields: 


$$
\ln k=\ln A-\frac{E}{R T}
$$

Hence a plot of lnk vs. $1 / T$ should give a straight line, and the slope is $-E / R$. From this, the activation energy is found.

\subsubsection{Mathematical analysis methods}

\section{Least-Squares Regression:}

The most common method of fitting a line to a scatter plot is the method of Least Squares. It describes how a response variable $y$ changes with an independent variable $x$ (Moore and McCabe, 2002). The least-squares regression to a straight line, $\hat{y}=a+b x$, minimizes the sum of the squares of the vertical distances of the observed-y value from the line. Here, $b$, is the slope of the line, and $b=R \frac{S_{y}}{S_{x}}$, where $R$ is the correlation between $x$ and $y ; S_{y}$ is standard deviation (STDEV) in $y$; $S_{x}$ is STDEV in $x$. The term " $a$ " is the intercept of the regression line, $a=\bar{y}-b \bar{x}$, where $\bar{y}$ is the mean value of $y$ (observed value), $\bar{x}$ is the mean value of $x$. The squared value of $R, R^{2}$, is the fraction of the variation in the $y$ (observed) variable that is explained by the least-squares regression. A perfect correlation means the points lie exactly on a line. In this case, $R^{2}=1$ and all of the variation in one variable is accounted for by the linear relationship with the other variable. In another words, an $R$-squared value close to 1 implies a relatively good linear relationship.

\section{Standard deviation (STDEV):}

According to Moore and McCabe (Moore and McCabe, 2002), STDEV is defined as following:

$$
S T D E V=\sqrt{\frac{1}{n-1} \sum\left(x_{i}-\bar{x}\right)^{2}}
$$

where $n$ is the number of samples of $x ; x_{i}$ is the value of $\mathrm{i}^{\text {th }}$ sample of $x$; and $\bar{x}$ is the mean value of $x$. 
STDEV (or variance) has the following rules:

- If $x$ is a random variable and $c$ and $\mathrm{d}$ are fixed numbers, then:

$$
\operatorname{STDEV} V_{c+d x}=d \cdot S T D E V_{x}
$$

- If $x_{1}$ and $x_{2}$ are two independent random variables, then:

$$
S T D E V_{x_{1}+x_{2}}=S T D E V_{x_{1}}+S T D E V_{x_{2}}
$$

\subsection{Evaluation of external mass transfer effects}

Based on the theoretical principle of Doraiswamy (Doraiswamy and Sharma, 1984), the Switchgrass char was selected as a candidate (since it exhibited a relatively fast reaction rate), and a series of experiments was designed to investigate external mass transfer effects at the highest temperature, $1100^{\circ} \mathrm{C}$. The combination of high temperature and fast reaction rate accentuates the presence of external mass transfer effects should they be present. The experiments were conducted under a fixed value of $W / F, 0.43$ $(\mathrm{mg} . \mathrm{min} / \mathrm{ml})$, where $W$ is the sample weight $(\mathrm{mg})$, and $F$ is the $\mathrm{CO}_{2}$ gas flow rate $(\mathrm{ml} / \mathrm{min})$. At three different reaction times, 60 seconds, 120 seconds, and 195 seconds, the values of conversion $X$ corresponding to the different $\mathrm{CO}_{2}$ gas flow rates are inspected. The corresponding experimental conditions are listed in the Table 3.3, while Figure 3.2 is a plot of the changes in $X$ at three different reaction times with the same value of $W / F$.

Table 3.3 Experimental conditions for external mass transfer effect evaluation

\begin{tabular}{|l|c|c|c|c|}
\hline Temperature $\left({ }^{\circ} \mathrm{C}\right)^{*}$ & 1100 & 1100 & 1100 & 1100 \\
\hline$W / F(\mathrm{mg} \cdot \mathrm{min} / \mathrm{ml})$ & \multicolumn{4}{|c|}{0.43} \\
\hline Sample weight $(W, \mathrm{mg})$ & 33.5 & 42 & 50 & 66.9 \\
\hline$F_{\mathrm{CO} 2}(\mathrm{ml} / \mathrm{min})$ & 79 & 99 & $118^{* *}$ & 158 \\
\hline$X$ at $60 \mathrm{~s}$ & 0.04 & 0.06 & 0.16 & 0.16 \\
\hline$X$ at $120 \mathrm{~s}$ & 0.21 & 0.25 & 0.42 & 0.38 \\
\hline$X$ at $195 \mathrm{~s}$ & 0.43 & 0.49 & 0.70 & 0.63 \\
\hline
\end{tabular}

Note:

* Switchgrass char is chosen as the gasification sample;

** All other kinetic analysis experiments are carried out at $118 \mathrm{ml} / \mathrm{min}$ of $\mathrm{CO}_{2}$ flow rate. 


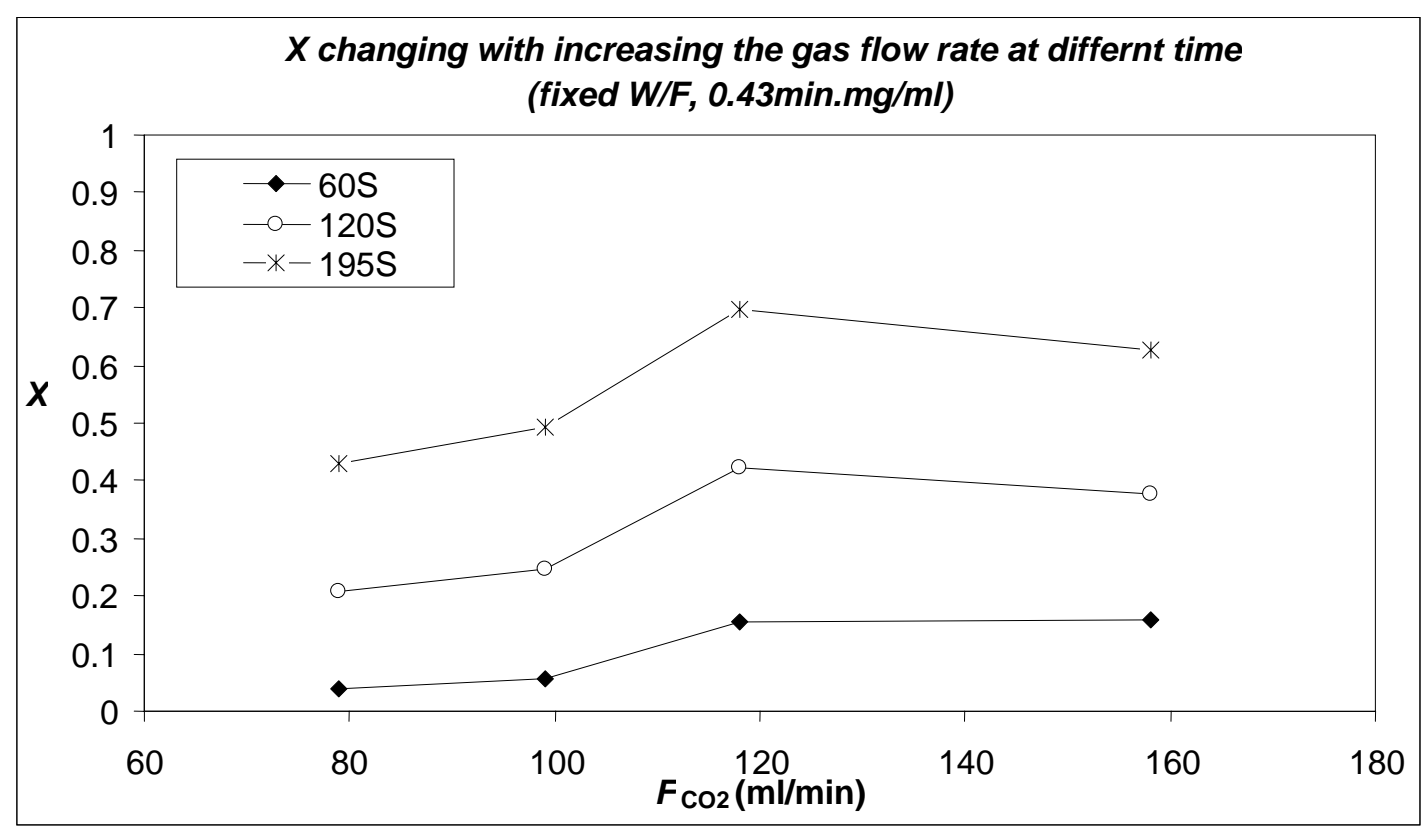

Figure 3.2 Changes in $\mathrm{X}$ at different reaction time with the same $W / F$ value

Figure 3.2 shows a nearly flat curve after the critical point $118 \mathrm{ml} / \mathrm{min}$ for three different residence times: 60s, 120s, and 195s. According to the principle of Doraiswamy, these preliminary results lead to the conclusion that for Switchgrass char, maintaining the $W / F$ value at $0.43(\mathrm{mg} . \mathrm{min} / \mathrm{ml})$ and $\mathrm{CO}_{2}$ flow rates greater than $118 \mathrm{ml} / \mathrm{min}$, the reaction rate is not impacted by external mass transfer for the gasification reaction at $1100^{\circ} \mathrm{C}$.

It should be noted that the above evaluation result is just a preliminary finding. To make a definitive conclusion, the study should include all the sample chars at all the temperature levels. However, since these mass transfer evaluation experiments were designed at the highest temperature, and the Switchgrass char is of a relative fast reaction rate, it is suggested that the kinetic experiments (described in Table 3.1 with a $\mathrm{CO}_{2}$ flow rate at $118 \mathrm{ml} / \mathrm{min}$ ) do not include significant external mass transfer effects. 


\section{Chapter 4 Discussion}

The following analysis and discussion section will include: (1) Selection of the appropriate models; (2) Calculation of kinetic parameters through the data regression; (3) Comparison of the regression quality for different models; (4) Discussion of the reaction rate for different chars at different temperatures; (5) Investigation and discussion of the synergistic effect between the different char pairs.

\subsection{Model options}

From the literature review, it is seen that the carbon reactivity for reaction [2.1] is dependent on the concentration of carbon and the concentration of carbon dioxide, and can be described as follows:

$$
r_{C} \propto C^{m} \mathrm{CO}_{2} ; \quad r_{C} \propto(1-X)^{n}
$$

Consequently, a rate expression is postulated that includes these terms:

$$
r_{c}=k_{a p p} C^{m} C O_{2}(1-X)^{n}
$$

where $k_{a p p}$ is the apparent global rate constant; $m$ is the kinetic reaction order with respect to carbon dioxide; $n$ is the kinetic reaction order for carbon.

In equation [4.2], the carbon dioxide concentration can also be written in terms of temperature and pressure with the ideal gas law. The carbon concentration, depending on the specific model, can be written as $(1-X)^{n}$, or $X^{n}$, or their combination.

4.1.1 Selection of the representative reaction order for carbon dioxide

Looking over all the intrinsic kinetic models (Model 1 to Model 4) expressed by carbon dioxide concentration, it is found that they all follow Langmuir-Hinshelwood kinetics. Providing the concentration of carbon monoxide is negligible, and then except for Model 3, they all have the same rate expression with respect to $\mathrm{CO}_{2}$ shown in Model 1 [2.9]:

$$
r_{\mathrm{CO}_{2}}=\frac{k_{1} p_{\mathrm{CO}_{2}}}{1+k_{2} p_{C O}+k_{3} p_{\mathrm{CO}_{2}}}
$$


The general rate expression [2.9] indicates that the reaction rate with respect to $\mathrm{CO}_{2}$ concentration is approximately a first order at low $\mathrm{CO}_{2}$ pressure, but approaches zero-th order at high $\mathrm{CO}_{2}$ pressure. In the present research, high purity carbon dioxide gas is used for the gasification reaction, and the system pressure is kept at one atmosphere (1atm). Consequently, the reaction is assumed to be first order with respect to carbon dioxide. Thus, in all the following modeling work, $m=1$ for equation [4.2].

\subsubsection{Selection of appropriate models for carbon reactivity}

A total of 7 different models were considered for carbon reactivity, from Model 5 to Model 11; five were empirical models (Model 5 to Model 9) and two were solely theoretical models (Model 10 and Model 11). The principles for the model chosen are: (1) the model should not include any particle structural parameter that can not be easily determined. Without the need for structural parameters, the model will be easier to apply. It should also be noted that structural parameters were not assessed in this study; (2) the model should allow easy deduction of an apparent rate constant. Some models can precisely describe the conversion-time relation. However, the main goal for a modeling study is to obtain kinetic parameters, such as an apparent rate constant $\left(k_{\text {app }}\right)$ and apparent activation energy $\left(E_{\text {app }}\right)$. The summary information about these seven different models is collected in the Table 4.1. 
Table 4.1 Carbon Reactivity Models Summary Information

\begin{tabular}{|l|c|c|c|c|}
\hline Model & Type & Model expressions & $\begin{array}{c}\text { Structural } \\
\text { parameter } \\
\text { numbers }\end{array}$ & $\begin{array}{c}\text { Can directly } \\
\text { deduce an } \\
\text { apparent rate } \\
\text { constant or not? }\end{array}$ \\
\hline$\underline{\text { Model 5 }}$ & Empirical & $\frac{d X}{d t}=\eta \cdot S \cdot k_{r} \cdot C_{C O_{2}} \cdot(1-X)$ & 2 & Yes \\
\hline Model 6 & Empirical & $\frac{d X}{d \tau}=a_{3}+a_{4} \tau+a_{5} \tau^{2}$ & 0 & No \\
\hline$\underline{\text { Model 7 }}$ & Empirical & $\frac{d X}{d \tau}=k_{r} \cdot X^{b} \cdot(1-X)^{c}$ & 0 & Yes \\
\hline Model 8 & Empirical & $\frac{d X}{d \tau}=k_{r}\left[X+\varepsilon_{o}(1-X)\right]^{1 / 2}(1-X)$ & 1 & Yes \\
\hline Model 9 & Empirical & $X=1-(1+1.18 \tau) \exp (-1.47 \tau)$ & 0 & No \\
\hline$\underline{\text { Model 10 }}$ & Theoretical & $\frac{d X}{d t}=\frac{k_{s} C_{C O_{2}}{ }^{n} S_{o}}{\left(1-\varepsilon_{o}\right)}(1-X)^{m}$ & 2 & Yes \\
\hline Model 11 & Theoretical & $X=1-\left(1-\frac{\tau}{\sigma}\right)^{3} \exp \left[-\tau\left(1+\frac{\psi \tau}{4}\right)\right]$ & 2 & No \\
\hline
\end{tabular}

Based on the above principles, Model 5, Model 7 and Model 10 are selected as the template for further modeling the gasification data. All of the three models can directly deduce an apparent rate constant. Model 7 does not include any particle structural parameter. Providing some reasonable assumptions (discussed in a later section), the structural parameters of Model 5 and Model 10 can be reduced from 2 to zero.

\subsubsection{Initial reaction rate constant as compensation}

As described in section 3.6.2, the experimental data have been truncated from $X=0.1$ to 0.9 for the fitting work for stability reasons. Obviously, some part of the reaction kinetics in the beginning stage of the reaction will be lost. To compensate for this, the differential method will be employed to obtain an initial reaction rate constant, and this is termed as the "Initial Rate Model". 
4.2 Kinetic parameters regression with different models

4.2.1 Fitting the data with Model 5 (A simplified Dutta and Wen Model)

The model expression referred to as Model 5 is:

$$
\begin{aligned}
& \frac{d X}{d t}=\eta S k_{r} C_{C_{2}}(1-X)^{n} \\
& S=1 \pm X^{\nu \beta} e^{-\beta X},(0 \leq v \leq 1)
\end{aligned}
$$

where $k_{r}$ is the global rate constant, $(\mathrm{L} / \mathrm{mol} \cdot \mathrm{s}) ; X$ is the carbon conversion, (dimensionless); $t$ is time, (s); $\eta$ is an effectiveness factor, (dimensionless); $S$ is relative surface area, (dimensionless); $\mathrm{C}_{\mathrm{CO}_{2}}$ is the concentration of carbon dioxide, (mol/L); $v, \beta$ are the physical parameters characteristic of a given coal or char, (dimensionless).

The following assumptions are made, and the resulting model is called as a "simplified" Dutta and Wen Model:

- Reaction order $n=1$ for carbon ;

- Chemical reaction controls: $\eta=1$;

- $S$ value stays constant during the reaction;

- Treat the $\mathrm{CO}_{2}$ gas as an ideal gas, thus for pure carbon dioxide, $C_{\mathrm{CO}_{2}}=\frac{P_{\mathrm{CO}_{2}}}{R T}$, where $\mathrm{C}_{\mathrm{CO}_{2}}$ is the concentration of carbon dioxide, (mol/L); $P_{\mathrm{CO}_{2}}$ is the pressure of carbon dioxide, (atm); $T$ is the temperature of reaction, $(\mathrm{K}) ; R$ is the universal gas constant, $\left(0.082 \mathrm{~L} \mathrm{~atm} \mathrm{~K}^{-1} \mathrm{~mol}^{-1}\right)$.

Then the global rate constant, $k_{r}$, and the relative surface area, $S$, are lumped into an apparent rate constant, $k_{a p p},(\mathrm{~L} / \mathrm{mol} \cdot \mathrm{s})$. Thus the rate expression of [4.3] is rewritten as a pseudo first-order reaction with respect to carbon as:

$$
\frac{d X}{d t}=k_{a p p} \frac{P_{C O_{2}}}{R T}(1-X)
$$


Assuming $P_{\mathrm{CO}_{2}}$ being constant, integration of the differential equation [4.5] with respect to $t$, yields the following expression:

$$
-\operatorname{Ln}(1-X)=k_{a p p} \frac{P_{\mathrm{CO}_{2}}}{R T} t
$$

Using the integral method of kinetic analysis (section 3.6.3), a plot of this linear relation, $-L n(1-X) v s . t$, is employed with the least-squares regression approach to fit the data. From the slope $\left(k_{a p p} \frac{P_{\mathrm{CO}_{2}}}{R T}\right)$ of the linear relationship, the apparent rate constant, $k_{a p p}$, can be obtained.

The temperature dependence of apparent rate constant, $k_{a p p}$, is described with the Arrhenius type equation as follows:

$$
k_{a p p}=A \exp \left(-\frac{E_{a p p}}{R T}\right)
$$

A plot of $\ln k_{\text {app }} v s .1 / T$ as described in the section 3.6.3, is prepared and from the slope $\left(-E_{a p p} / R\right)$, the apparent activation energy, $E_{a p p}$, is found.

Figures 4.1 and 4.2 are examples of the kinetic parameters fitted with the simplified Model 5. Figure 4.1 is equation [4.6] plotted for ILL No.6 char fitted at $900^{\circ} \mathrm{C}$, and Figure 4.2 is the $E_{a p p}$ regression of ILL No.6 char (Arrhenius plot) for five different temperatures. A total of 74 figures showing $k_{a p p}$ fitted with Model 5 are attached in Appendix A, and the $E_{\text {app }}$ regression figures (12 figures) based on Model 5 are attached in Appendix B. The $k_{a p p}$ derived from Model 5 are listed in Table 4. 2, and the R-squared values are listed in Table 4.3. The $E_{a p p}$ and frequency factor, $A$, are listed in Table 4.4. 


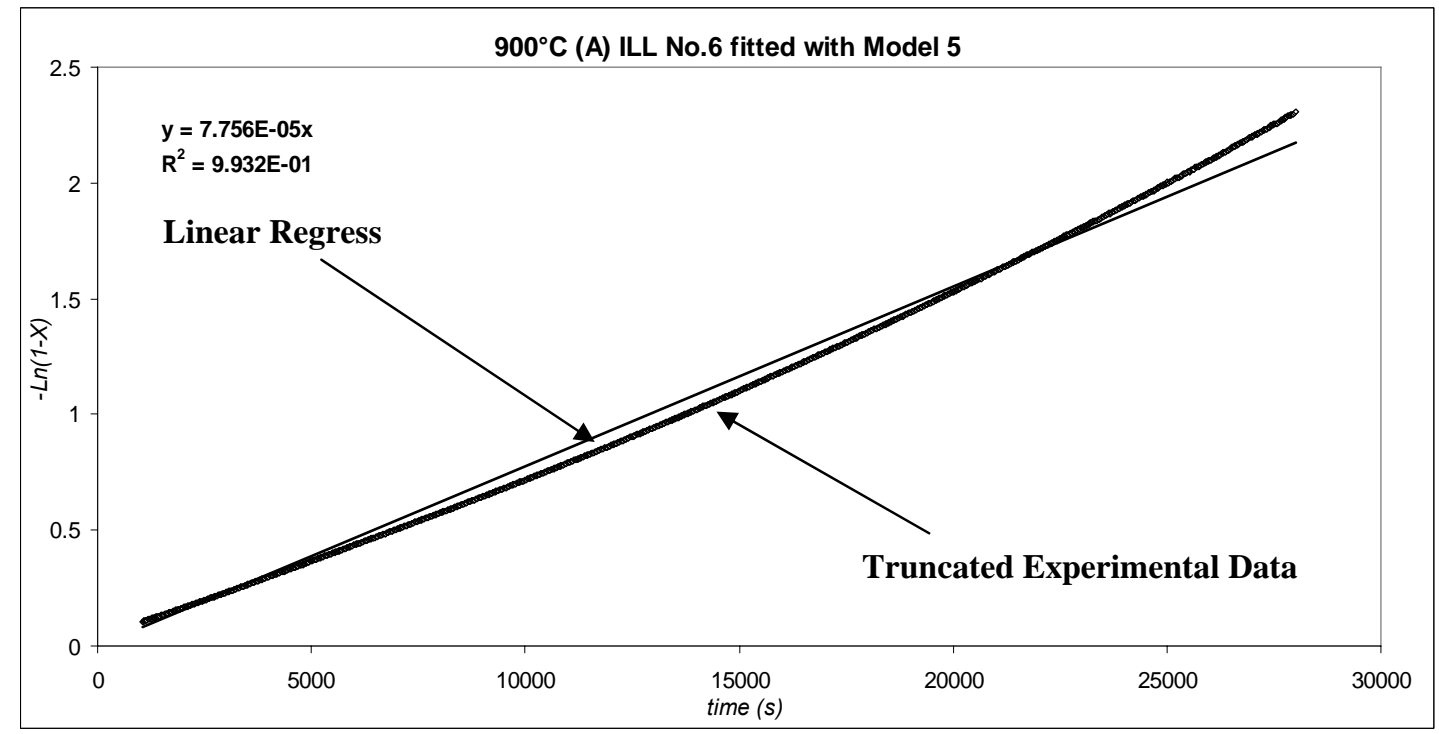

Figure 4.1 Gasification data for ILL No.6 char fitted with Model 5 at $900^{\circ} \mathrm{C}$

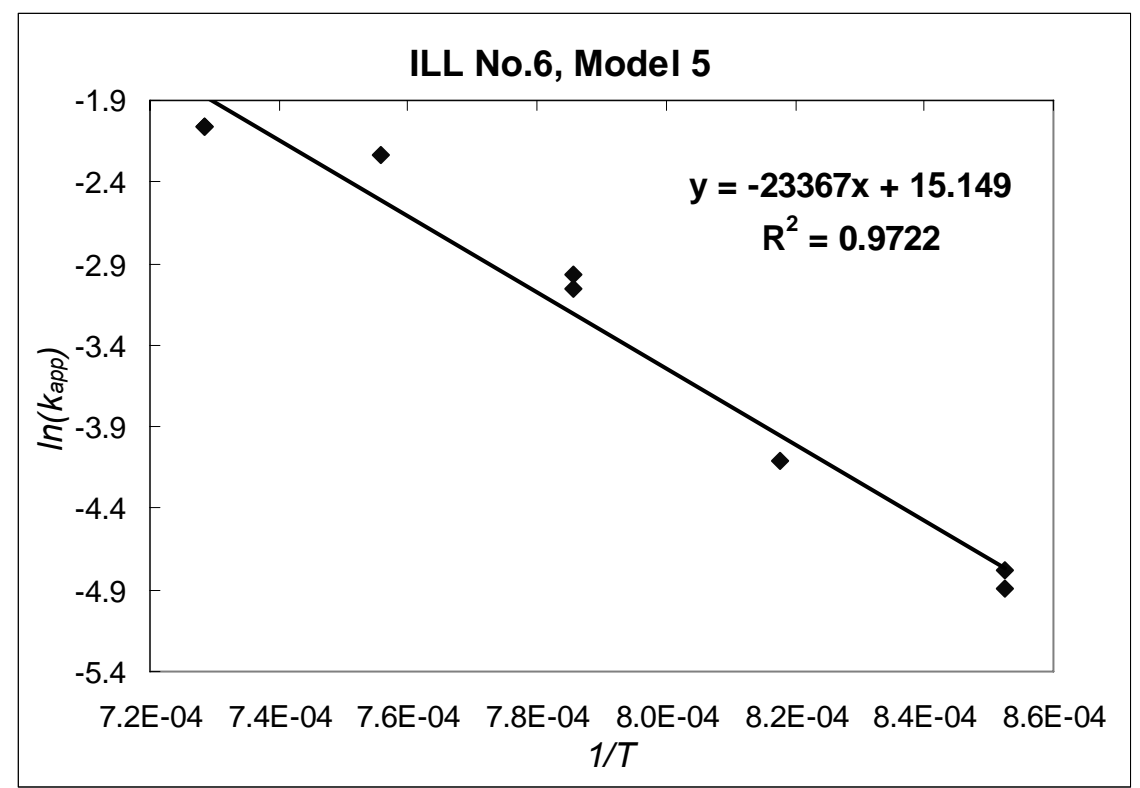

Figure 4.2 Arrhenius plot of ILL No.6 rate data based on Model 5 
Table $4.2 k_{\text {app }}$ obtained from on Model 5

\begin{tabular}{|c|c|c|c|c|c|c|c|}
\hline \multirow{3}{*}{ Group } & \multirow{2}{*}{ Chars } & \multicolumn{6}{|c|}{$k_{\text {app }}$ at different temperature (L/mol.s), Model 5 } \\
\cline { 3 - 8 } & & $900^{\circ} \mathrm{C}(\mathrm{A})$ & $900^{\circ} \mathrm{C}(\mathrm{B})$ & $1000^{\circ} \mathrm{C}(\mathrm{A})$ & $1000^{\circ} \mathrm{C}(\mathrm{B})$ & $1100^{\circ} \mathrm{C}(\mathrm{A})$ & $1100^{\circ} \mathrm{C}(\mathrm{B})$ \\
\hline \multirow{4}{*}{1} & ND lignite & 0.171752 & 0.171923 & 0.533742 & 0.43579 & 1.105913 & 0.9628376 \\
\cline { 2 - 8 } & Hardwood & 0.070924 & 0.069496 & 0.257195 & 0.256227 & 0.691021 & 0.6789016 \\
\cline { 2 - 8 } & Mixed 10\% & 0.137803 & 0.12968 & 0.391839 & 0.38369 & 0.860504 & 0.8569513 \\
\cline { 2 - 8 } & Mixed 30\% & 0.116714 & 0.121477 & 0.387826 & 0.396292 & 0.788712 & 0.7798934 \\
\hline \multirow{4}{*}{2} & ILL No.6 & 0.007467 & 0.008425 & 0.051509 & 0.047394 & 0.126883 & 0.127737 \\
\cline { 2 - 8 } & Switchgrass & 0.063828 & 0.063589 & 0.316203 & 0.293603 & 0.764191 & 0.8659263 \\
\cline { 2 - 8 } & Mixed 10\% & 0.012101 & 0.010818 & 0.076362 & 0.070245 & 0.20368 & 0.1835826 \\
\cline { 2 - 8 } & Mixed 30\% & 0.01748 & 0.016046 & 0.109603 & 0.097648 & 0.263488 & 0.2245671 \\
\hline \multirow{3}{*}{3} & PRB & 0.078208 & 0.079735 & 0.263127 & 0.269302 & 0.563648 & 0.5724371 \\
\cline { 2 - 8 } & Corn Stover & 0.178276 & 0.187475 & 0.547349 & 0.566229 & 1.054448 & 1.0489386 \\
\cline { 2 - 8 } & Mixed 10\% & 0.089112 & 0.08829 & 0.304069 & 0.308622 & 0.642649 & 0.5962948 \\
\cline { 2 - 8 } & Mixed 30\% & 0.111092 & 0.114936 & 0.381221 & 0.363069 & 0.727576 & 0.6771736 \\
\hline
\end{tabular}

Table 4.3 R-squared value of the $k_{a p p}$ regression based on Model 5

\begin{tabular}{|c|c|c|c|c|c|c|c|}
\hline \multirow{3}{*}{ Group } & \multirow{2}{*}{ Chars } & \multicolumn{7}{|c|}{$R$-squared value of $k_{\text {app }}$ (Model 5) } \\
\cline { 3 - 8 } & & $900^{\circ} \mathrm{C}(\mathrm{A})$ & $900^{\circ} \mathrm{C}(\mathrm{B})$ & $1000^{\circ} \mathrm{C}(\mathrm{A})$ & $1000^{\circ} \mathrm{C}(\mathrm{B})$ & $1100^{\circ} \mathrm{C}(\mathrm{A})$ & $1100^{\circ} \mathrm{C}(\mathrm{B})$ \\
\hline \multirow{3}{*}{1} & ND lignite & 0.9426 & 0.9292 & 0.9237 & 0.9216 & 0.8976 & 0.8985 \\
\cline { 2 - 8 } & Hardwood & 0.9159 & 0.8933 & 0.8334 & 0.8202 & 0.8139 & 0.8056 \\
\cline { 2 - 8 } & Mixed 10\% & 0.9269 & 0.9208 & 0.9128 & 0.9107 & 0.8947 & 0.8915 \\
\cline { 2 - 8 } & Mixed 30\% & 0.9341 & 0.9169 & 0.9044 & 0.9047 & 0.8922 & 0.8998 \\
\hline \multirow{4}{*}{2} & ILL No.6 & 0.9932 & 0.9834 & 0.9884 & 0.9930 & 0.9780 & 0.9852 \\
\cline { 2 - 8 } & Switchgrass & 0.9761 & 0.9706 & 0.8989 & 0.8870 & 0.8752 & 0.9180 \\
\cline { 2 - 8 } & Mixed 10\% & 0.9784 & 0.9694 & 0.9932 & 0.9884 & 0.9992 & 0.9976 \\
\cline { 2 - 8 } & Mixed 30\% & 0.9750 & 0.9627 & 0.9861 & 0.9842 & 0.9959 & 0.9971 \\
\hline \multirow{3}{*}{3} & PRB & 0.8590 & 0.8763 & 0.8770 & 0.8718 & 0.8928 & 0.8978 \\
\cline { 2 - 8 } & Corn Stover & 0.9349 & 0.9274 & 0.9019 & 0.9101 & 0.9199 & 0.9180 \\
\cline { 2 - 8 } & Mixed 10\% & 0.8688 & 0.8651 & 0.8774 & 0.8745 & 0.8917 & 0.9010 \\
\cline { 2 - 8 } & Mixed 30\% & 0.8649 & 0.8777 & 0.8801 & 0.8883 & 0.8887 & 0.8920 \\
\hline
\end{tabular}


Table 4.4 Parameters regressed from the Arrhenius plot using Model 5

\begin{tabular}{|c|c|c|c|c|}
\hline \multirow{2}{*}{ Group } & Chars & \multicolumn{3}{|c|}{ Model 5 } \\
\cline { 3 - 5 } & & $E_{\text {app }}(\mathrm{KJ} / \mathrm{mol})$ & $A\left(\mathrm{~L} . \mathrm{mol}^{-1} . \mathrm{s}^{-1}\right)$ & $R$-squared value \\
\hline \multirow{4}{*}{1} & ND lignite & 120.25 & $3.97 \times 10^{4}$ & 0.9890 \\
\cline { 2 - 5 } & Hardwood & 152.75 & $4.55 \times 10^{5}$ & 0.9987 \\
\cline { 2 - 5 } & Mixed 10\% & 124.75 & $4.89 \times 10^{4}$ & 0.9979 \\
\cline { 2 - 5 } & Mixed 30\% & 126.82 & $5.58 \times 10^{4}$ & 0.9885 \\
\hline \multirow{4}{*}{2} & ILL No.6 & 194.28 & $3.79 \times 10^{6}$ & 0.9722 \\
\cline { 2 - 5 } & Switchgrass & 171.2 & $2.84 \times 10^{6}$ & 0.9910 \\
\cline { 2 - 5 } & Mixed 10\% & 190.46 & $3.84 \times 10^{6}$ & 0.9805 \\
\cline { 2 - 5 } & Mixed 30\% & 180.48 & $2.05 \times 10^{6}$ & 0.9716 \\
\hline \multirow{3}{*}{3} & PRB & 132.63 & $6.66 \times 10^{4}$ & 0.9922 \\
\cline { 2 - 5 } & Corn Stover & 117.74 & $3.37 \times 10^{4}$ & 0.9872 \\
\cline { 2 - 5 } & Mixed 10\% & 130.75 & $6.25 \times 10^{4}$ & 0.9866 \\
\cline { 2 - 5 } & Mixed 30\% & 123.01 & $3.62 \times 10^{4}$ & 0.9822 \\
\hline
\end{tabular}

\subsubsection{Fitting the data with Model 10 (Shrinking sphere model)}

In the regime of chemical reaction control, the general form of a rate expression for the shrinking sphere model expresses the reaction rate as:

$$
\frac{d X}{d t}=\frac{k_{s} C_{\mathrm{CO}_{2}} S_{o}}{\left(1-\varepsilon_{o}\right)}(1-X)^{n}
$$

where $k_{s}$ is the rate constant for the surface reaction with respect to $\mathrm{CO}_{2},(\mathrm{~m} \cdot \mathrm{L} / \mathrm{mol} \cdot \mathrm{s})$. The parameter, $n$, is the reaction rate order with respect to carbon, and it is identified with a shape factor that depends on the geometry of the grains: for spheres $n=2 / 3$, for cylinders $n=1 / 2$ and for flat plate $n=0 . S_{o}$ is the initial reaction surface area per unit volume, $\left(\mathrm{m}^{2} / \mathrm{m}^{3}\right)$; and $\varepsilon_{o}$ is the initial value of the porosity, (dimensionless).

Assuming the following and the resulting model is actually a "modified" shrinking sphere model:

- The shape of the particle is spherical, and hence, $n=2 / 3$.

- Chemical reaction controls; 
- $\mathrm{CO}_{2}$ gas is an ideal gas, thus for pure carbon dioxide, $\mathrm{C}_{\mathrm{CO}_{2}}=\frac{P_{\mathrm{CO}_{2}}}{R T}$, where $\mathrm{C}_{\mathrm{CO}_{2}}$ is the concentration of carbon dioxide, $(\mathrm{mol} / \mathrm{L}) ; P_{\mathrm{CO}_{2}}$ is the pressure of carbon dioxide, (atm); $T$ is the temperature of reaction, $(\mathrm{K}) ; R$ is the universal gas constant, $\left(0.082 \mathrm{~L} \mathrm{~atm} \mathrm{~K}^{-1} \mathrm{~mol}^{-1}\right)$.

The intrinsic rate constant $k_{s}$, along with $\left(1-\varepsilon_{o}\right)$, and $S_{o}$ are lumped into an apparent rate constant, $k_{\text {app }},(\mathrm{L} / \mathrm{mol} \cdot \mathrm{s})$. Afterward, the rate expression of equation [4.8] is rewritten as $2 / 3$ order reaction with respect to carbon:

$$
\frac{d X}{d t}=k_{\text {app }} \frac{P_{C O_{2}}}{R T}(1-X)^{\frac{2}{3}}
$$

Integration of the differential equation [4.9] with respect to $t$, yields the following expression:

$$
1-(1-X)^{1 / 3}=\frac{1}{3} k_{a p p} \frac{P_{C O_{2}}}{R T} t
$$

Using the integral method of kinetic analysis described in section 3.6.3, a plot of the linear relation, $1-(1-X)^{1 / 3}$ vs. $t$, is made and the data are regressed with the leastsquares regression method. From the linear slope $\left(k_{\text {app }} \cdot \frac{P_{C O_{2}}}{R T}\right)$, the apparent rate constant, $k_{a p p}$, is found. A plot of $l n k_{a p p} v$ s. $1 / T$ as described in the section 3.6.3 is prepared. From this, the apparent activation energy, $E_{a p p}$, is calculated.

Figures 4.3 and 4.4 are examples of the kinetic parameters fitted with the "modified" Model 10. Figure 4.3 is equation [4.10] plotted for ILL No.6 char at $900^{\circ} \mathrm{C}$, and Figure 4.4 is the $E_{a p p}$ regression of ILL No.6 based on Model 10 (Arrhenius plot) for five different temperatures. A total of 74 figures from which $k_{a p p}$ is fitted with Model 10 are attached in Appendix C; $12 E_{a p p}$ regression figures based on the Model 10 are attached in Appendix D. The $k_{\text {app }}$ derived from Model 10 are listed in Table 4. 5, and the R-squared values are listed in Table 4.6. The $E_{a p p}$ and frequency factor, $A$, are listed in Table 4.7. 


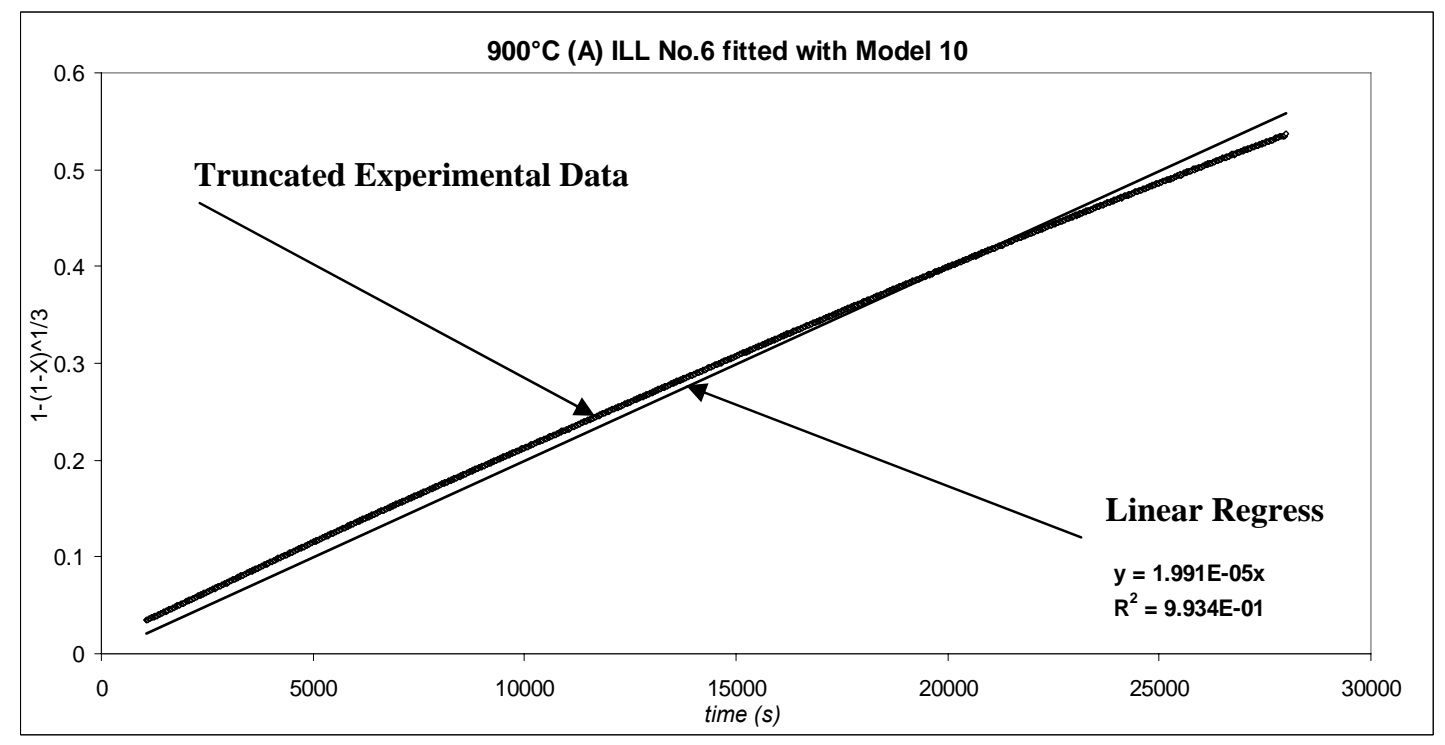

Figure 4.3 Gasification data for ILL No.6 char fitted with Model 10 at $900^{\circ} \mathrm{C}$

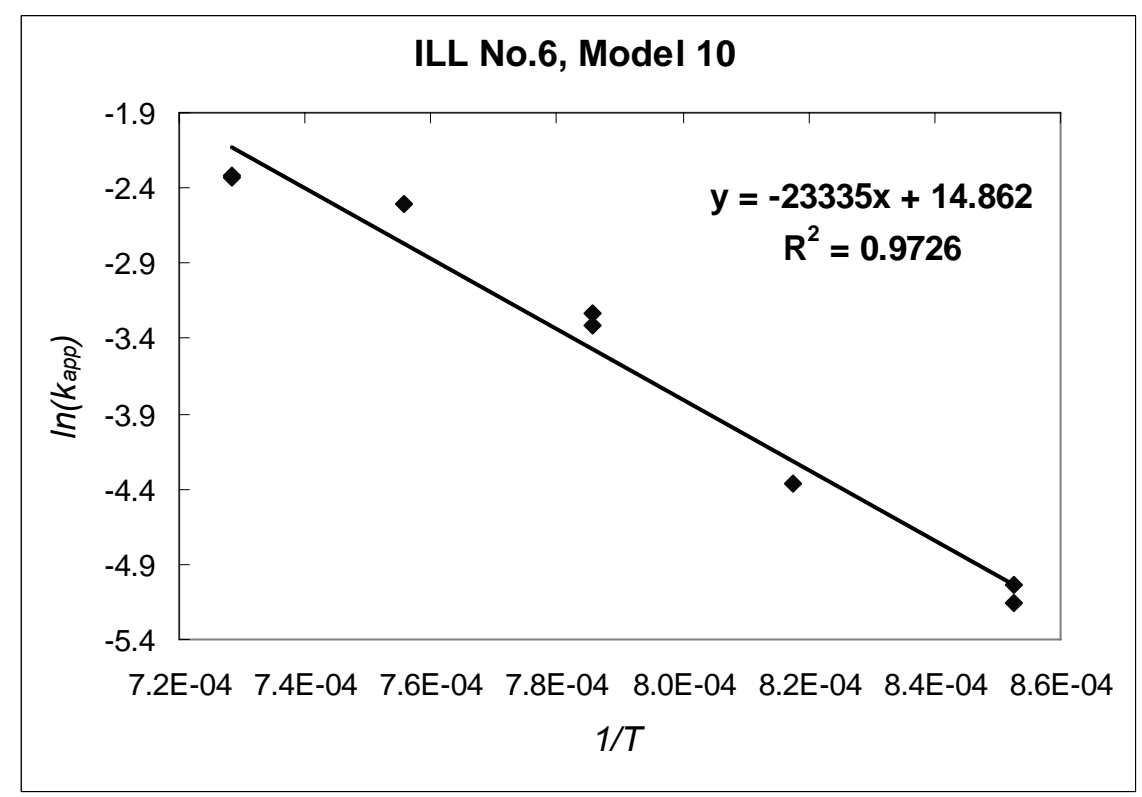

Figure 4.4 Arrhenius plot of ILL No.6 based on Model 10 
Table $4.5 k_{\text {app }}$ obtained from Model 10

\begin{tabular}{|c|c|c|c|c|c|c|c|}
\hline \multirow{3}{*}{ Group } & \multirow{2}{*}{ Chars } & \multicolumn{7}{|c|}{$k_{\text {app }}$ at different temperature (L/mol.s), Model 10} \\
\cline { 3 - 8 } & & $900^{\circ} \mathrm{C}(\mathrm{A})$ & $900^{\circ} \mathrm{C}(\mathrm{B})$ & $1000^{\circ} \mathrm{C}(\mathrm{A})$ & $1000^{\circ} \mathrm{C}(\mathrm{B})$ & $1100^{\circ} \mathrm{C}(\mathrm{A})$ & $1100^{\circ} \mathrm{C}(\mathrm{B})$ \\
\hline \multirow{4}{*}{1} & ND lignite & 0.134369 & 0.135257 & 0.417885 & 0.341652 & 0.863251 & 0.7508289 \\
\cline { 2 - 8 } & Hardwood & 0.056317 & 0.055225 & 0.204558 & 0.204268 & 0.552763 & 0.5444137 \\
\cline { 2 - 8 } & Mixed 10\% & 0.108609 & 0.102091 & 0.309418 & 0.302771 & 0.677172 & 0.6751961 \\
\cline { 2 - 8 } & Mixed 30\% & 0.092045 & 0.096537 & 0.307129 & 0.314122 & 0.620805 & 0.6151431 \\
\hline \multirow{4}{*}{2} & ILL No.6 & 0.005751 & 0.006497 & 0.039647 & 0.036407 & 0.097702 & 0.0981716 \\
\cline { 2 - 8 } & Switchgrass & 0.049303 & 0.049176 & 0.246378 & 0.229074 & 0.588339 & 0.6708649 \\
\cline { 2 - 8 } & Mixed 10\% & 0.00937 & 0.008403 & 0.058648 & 0.053989 & 0.155866 & 0.140694 \\
\cline { 2 - 8 } & Mixed 30\% & 0.013586 & 0.01252 & 0.083881 & 0.074748 & 0.199345 & 0.1708929 \\
\hline \multirow{3}{*}{3} & PRB & 0.062255 & 0.063318 & 0.20846 & 0.213835 & 0.444363 & 0.4500899 \\
\cline { 2 - 8 } & Corn Stover & 0.138854 & 0.146232 & 0.431114 & 0.44519 & 0.824471 & 0.8204961 \\
\cline { 2 - 8 } & Mixed 10\% & 0.070577 & 0.069908 & 0.241286 & 0.244579 & 0.506762 & 0.4703041 \\
\cline { 2 - 8 } & Mixed 30\% & 0.087895 & 0.090813 & 0.301367 & 0.287222 & 0.573937 & 0.5347549 \\
\hline
\end{tabular}

Table 4.6 R-squared value of the $k_{\text {app }}$ regression based on Model 10

\begin{tabular}{|c|c|c|c|c|c|c|c|}
\hline \multirow{3}{*}{ Group } & \multirow{2}{*}{ Chars } & \multicolumn{7}{|c|}{$R$-squared value of $k_{\text {app }}$ (Model 10) } \\
\cline { 3 - 8 } & & $900^{\circ} \mathrm{C}(\mathrm{A})$ & $900^{\circ} \mathrm{C}(\mathrm{B})$ & $1000^{\circ} \mathrm{C}(\mathrm{A})$ & $1000^{\circ} \mathrm{C}(\mathrm{B})$ & $1100^{\circ} \mathrm{C}(\mathrm{A})$ & $1100^{\circ} \mathrm{C}(\mathrm{B})$ \\
\hline \multirow{3}{*}{1} & ND lignite & 0.9891 & 0.9819 & 0.9795 & 0.9779 & 0.9607 & 0.9628 \\
\cline { 2 - 8 } & Hardwood & 0.9743 & 0.9595 & 0.9139 & 0.9022 & 0.8923 & 0.8844 \\
\cline { 2 - 8 } & Mixed 10\% & 0.9802 & 0.9762 & 0.9713 & 0.9700 & 0.9573 & 0.9584 \\
\cline { 2 - 8 } & Mixed 30\% & 0.9845 & 0.9746 & 0.9661 & 0.9665 & 0.9563 & 0.9619 \\
\hline \multirow{3}{*}{2} & ILL No.6 & 0.9934 & 0.9994 & 0.9972 & 0.9943 & 0.9973 & 0.9980 \\
\cline { 2 - 8 } & Switchgrass & 0.9996 & 0.9987 & 0.9636 & 0.9544 & 0.9448 & 0.9744 \\
\cline { 2 - 8 } & Mixed 10\% & 0.9999 & 0.9989 & 0.9945 & 0.9975 & 0.9773 & 0.9857 \\
\cline { 2 - 8 } & Mixed 30\% & 0.9997 & 0.9973 & 0.9963 & 0.9969 & 0.9445 & 0.9487 \\
\hline \multirow{3}{*}{3} & PRB & 0.9300 & 0.9430 & 0.9441 & 0.9399 & 0.9550 & 0.9592 \\
\cline { 2 - 8 } & Corn Stover & 0.9821 & 0.9778 & 0.9621 & 0.9678 & 0.9730 & 0.9718 \\
\cline { 2 - 8 } & Mixed 10\% & 0.9361 & 0.9334 & 0.9438 & 0.9415 & 0.9545 & 0.9616 \\
\cline { 2 - 8 } & Mixed 30\% & 0.9323 & 0.9433 & 0.9467 & 0.9524 & 0.9523 & 0.9551 \\
\hline
\end{tabular}


Table 4.7 Parameters regressed from the Arrhenius plot using Model 10

\begin{tabular}{|c|c|c|c|c|}
\hline \multirow{3}{*}{ Group } & Chars & \multicolumn{3}{|c|}{ Model 10 } \\
\cline { 3 - 5 } & & $E_{\text {app }}(\mathrm{KJ} / \mathrm{mol})$ & $A\left(\mathrm{~L} . \mathrm{mol}^{-1} . \mathrm{s}^{-1}\right)$ & $R$-squared value \\
\hline \multirow{4}{*}{1} & ND lignite & 119.89 & $3.00 \times 10^{4}$ & 0.9889 \\
\cline { 2 - 5 } & Hardwood & 153.29 & $3.82 \times 10^{5}$ & 0.9988 \\
\cline { 2 - 5 } & Mixed 10\% & 124.73 & $3.85 \times 10^{4}$ & 0.9978 \\
\cline { 2 - 5 } & Mixed 30\% & 126.52 & $4.29 \times 10^{4}$ & 0.9879 \\
\hline \multirow{4}{*}{2} & ILL No.6 & 194.02 & $2.85 \times 10^{6}$ & 0.9726 \\
\cline { 2 - 5 } & Switchgrass & 171.18 & $2.20 \times 10^{6}$ & 0.9902 \\
\cline { 2 - 5 } & Mixed 10\% & 189.61 & $2.73 \times 10^{6}$ & 0.9806 \\
\cline { 2 - 5 } & Mixed 30\% & 178.73 & $1.33 \times 10^{6}$ & 0.9716 \\
\hline \multirow{3}{*}{3} & PRB & 131.99 & $4.97 \times 10^{4}$ & 0.9918 \\
\cline { 2 - 5 } & Corn Stover & 117.99 & $2.70 \times 10^{4}$ & 0.9861 \\
\cline { 2 - 5 } & Mixed 10\% & 130.49 & $4.82 \times 10^{4}$ & 0.9861 \\
\cline { 2 - 5 } & Mixed 30\% & 122.9 & $2.83 \times 10^{4}$ & 0.9821 \\
\hline
\end{tabular}

\subsubsection{Fitting the data with Model 7 (Chornet's Model)}

If the real time, $t$, is employed in equation [2.20], after some mathematical rearranging, one form of Model 7 is found to be:

$$
\frac{d X}{d t}=k_{a p p} C_{C O_{2}} X^{b}(1-X)^{c}
$$

where $k_{\text {app }}$ is the apparent rate constant, $(\mathrm{L} / \mathrm{mol} \cdot \mathrm{s}) ; X$ is the conversion, (dimensionless); $t$ is time, $(\mathrm{s}) ; \mathrm{C}_{\mathrm{CO}_{2}}$ is the concentration of carbon dioxide, $(\mathrm{mol} / \mathrm{L}) ; b, c$ are adjustable characteristic parameters without physical meaning, (dimensionless).

Assuming the following and the resulting model is actually a "modified" Chornet Model:

- Chemical reaction controls;

- Adjustable characteristic parameters according to equation [2.21]: $b=0.5, c=1$;

- $\mathrm{CO}_{2}$ gas is an ideal gas, thus for pure carbon dioxide, $\mathrm{C}_{\mathrm{CO}_{2}}=\frac{P_{\mathrm{CO}_{2}}}{R T}$, where $\mathrm{C}_{\mathrm{CO}_{2}}$ is the concentration of carbon dioxide, $(\mathrm{mol} / \mathrm{L}) ; P_{\mathrm{CO}_{2}}$ is the pressure of carbon 
dioxide, (atm); $T$ is the temperature of reaction, $(\mathrm{K}) ; R$ is the universal gas constant, $\left(0.082 \mathrm{~L}\right.$ atm K $\left.\mathrm{K}^{-1} \mathrm{~mol}^{-1}\right)$.

Based on these assumptions, the rate expression of [4.11] is rewritten as follows:

$$
\frac{d X}{d t}=k_{\text {app }} \frac{P_{\mathrm{CO}_{2}}}{R T} \sqrt{X}(1-X)
$$

Integration of the differential equation [4.12] with respect to $t$, yields the following expression:

$$
\operatorname{Ln}\left(\frac{1+\sqrt{X}}{1-\sqrt{X}}\right)=k_{a p p} \frac{P_{\mathrm{CO}_{2}}}{R T} t
$$

Employing the integral method of kinetic analysis described in section 3.6.3, a linear plot of $\operatorname{Ln}\left(\frac{1+\sqrt{X}}{1-\sqrt{X}}\right) v s . t$, is fitted with the least-squares regression method. From the linear slope $\left(k_{a p p} \cdot \frac{P_{\mathrm{CO}_{2}}}{R T}\right)$, the apparent rate constant, $k_{a p p}$, is found.

However, as shown in the following example plots, it is seen that for the Ill No.6 and Switchgrass char, the linear correlation of the "modified" Model 7 shows a poor quality fit when compared with simplified Models 5 and 10. The details of the comparison are shown in the Figures 4.5 and 4.6. As a result, the model selection procedure is narrowed down to Model 5 and Model 10, and henceforth no kinetic parameters are obtained from Model 7. 


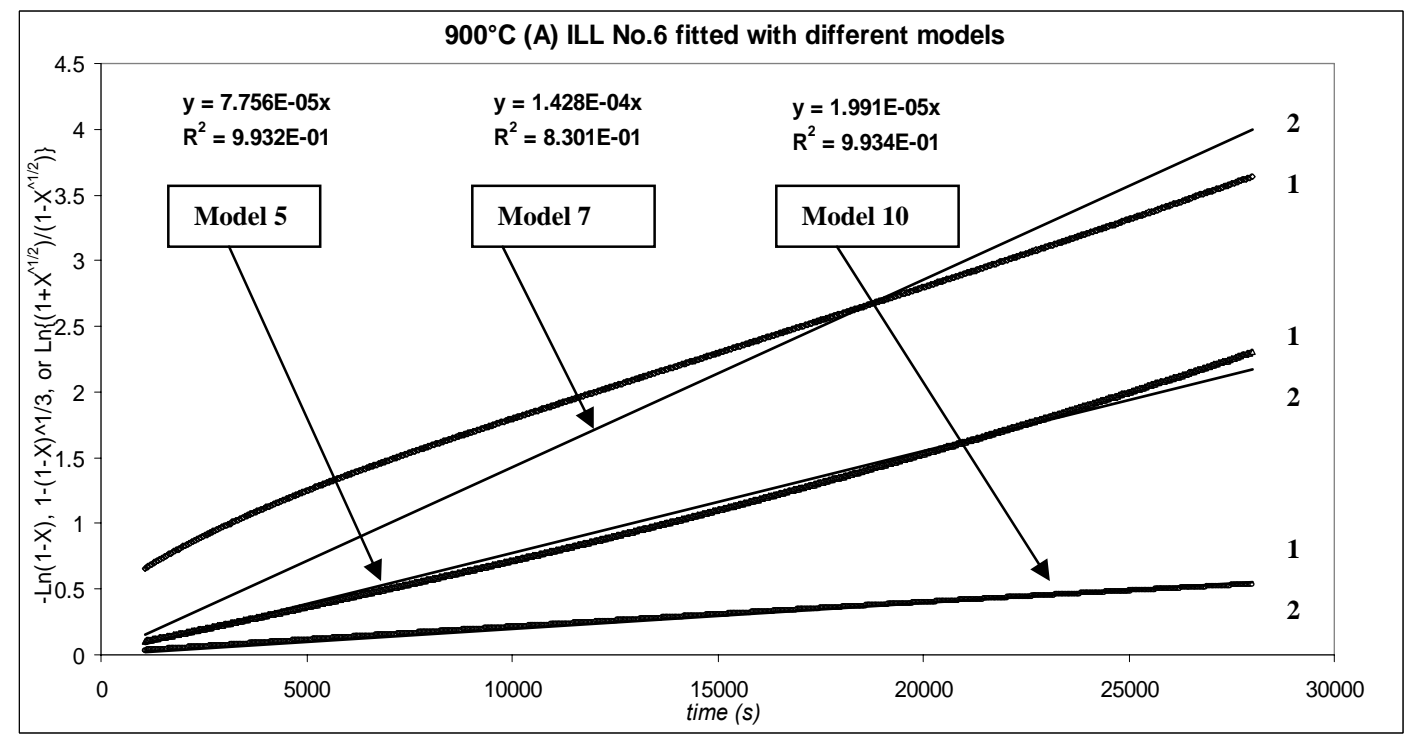

Figure 4.5 ILL No.6 char fitted with different models at $900^{\circ} \mathrm{C}$. Note: line 1 represents the truncated experimental data; line 2 represents the linear regression.

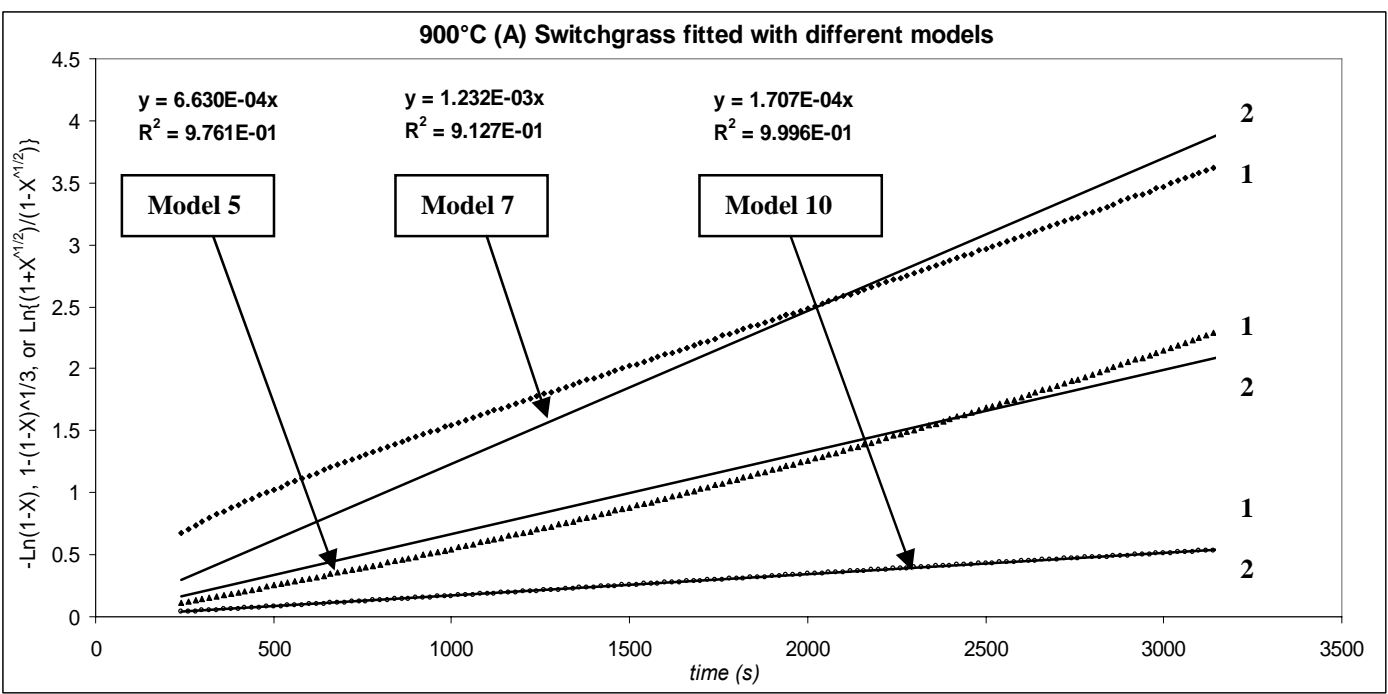

Figure 4.6 Switchgrass char fitted with different models at $900^{\circ} \mathrm{C}$. Note: line 1 represents the truncated experimental data; line 2 represents the linear regression. 


\subsubsection{Fitting the data with the Initial Rate Model}

As mentioned in an early section 3.6.2, to avoid the unstable data in the beginning and final stages of the reaction, the conversion data are truncated and only the region from $X=0.1$ to 0.9 is considered for the regression fitting. Consequently, obtaining the initial rate constant will compensate somewhat for the data truncation.

If $\mathrm{CO}_{2}$ gas is treated as an ideal gas, then $C_{\mathrm{CO}_{2}}=\frac{P_{\mathrm{CO}_{2}}}{R T}$, and a rate expression is postulated as the following:

$$
r_{c}=\frac{d X}{d t}=k_{a p p} \frac{P_{C_{2}}}{R T}(1-X)^{n}
$$

Then, if $n=1$, the expression follows the simplified Model 5; and if $n=2 / 3$, the expression [4.14] will obey the modified Model 10. But, at the initial condition: $t=0$, and $X=0$, equation [4.14] can be rewritten as:

$$
\left(\frac{d X}{d t}\right)_{t=0}=k_{a p p} \frac{P_{C O_{2}}}{R T}
$$

No matter which model is being used, from equation [4.15], an apparent rate constant $k_{\text {app }}$ can be found from the initial reaction rate $\left(\frac{d X}{d t}\right)_{t=0}$. From this point view, the initial rate constant can also supply additional information on any discrepancies between Model 5 and Model 10.

For the fitting of the initial rate data, the method of "differentiation of a polynomial" was employed as described in section 3.6.3. If the conversion-time data (from $X=0$ to 1 ) are expressed as a higher order polynomial, such as $4^{\text {th }}$-order:

$$
X=a_{1} t+a_{2} t^{2}+a_{3} t^{3}+a_{4} t^{4}
$$

Then direct differentiation of equation [4.16] with respect to $t$ yields the following:

$$
\frac{d X}{d t}=a_{1}+2 a_{2} t+3 a_{3} t^{2}+4 a_{4} t^{3}
$$

And at $t=0$, 


$$
\left(\frac{d X}{d t}\right)_{t=0}=k_{a p p} \frac{P_{\mathrm{CO}_{2}}}{R T}=a_{1}
$$

From the equation [4.18], one can directly extract the value of the initial apparent rate constant, $k_{a p p},(\mathrm{~L} / \mathrm{mol} \cdot \mathrm{s})$. Further, a plot of $\ln k_{a p p} v s$. $1 / T$ as described in section 3.6.3, allows the apparent activation energy, $E_{a p p}$, to be found from the slope.

The $k_{\text {app }}$ derived from the Initial Rate Model are listed in the Table 4.8. R-squared values are not available for the Differential method. The $E_{a p p}$ and frequency factor, $A$, are listed in Table 4.9. The Arrhenius plots for all the chars are listed in Appendix E.

Table 4.8 Apparent rate constants based on the Initial Rate Model

\begin{tabular}{|c|c|c|c|c|c|c|c|}
\hline \multirow{2}{*}{ Group } & \multirow{2}{*}{ Chars } & \multicolumn{5}{|c|}{$k_{\text {app }}$ at different temperature (L/mol.s), Initial Rate Model } \\
\cline { 3 - 8 } & & $900^{\circ} \mathrm{C}(\mathrm{A})$ & $900^{\circ} \mathrm{C}(\mathrm{B})$ & $1000^{\circ} \mathrm{C}(\mathrm{A})$ & $1000^{\circ} \mathrm{C}(\mathrm{B})$ & $1100^{\circ} \mathrm{C}(\mathrm{A})$ & $1100^{\circ} \mathrm{C}(\mathrm{B})$ \\
\hline \multirow{4}{*}{1} & ND lignite & 0.107577 & 0.103128 & 0.298645 & 0.249367 & 0.534476 & 0.4135675 \\
\cline { 2 - 8 } & Hardwood & 0.044959 & 0.040407 & 0.127364 & 0.115948 & 0.218143 & 0.1376477 \\
\cline { 2 - 8 } & Mixed 10\% & 0.082921 & 0.071822 & 0.199656 & 0.196774 & 0.504125 & 0.4771172 \\
\cline { 2 - 8 } & Mixed 30\% & 0.076277 & 0.080427 & 0.203449 & 0.197294 & 0.320759 & 0.3514781 \\
\hline \multirow{4}{*}{2} & ILL No.6 & 0.006994 & 0.006361 & 0.038666 & 0.039047 & 0.089109 & 0.090738 \\
\cline { 2 - 8 } & Switchgrass & 0.047791 & 0.0463 & 0.153112 & 0.174944 & 0.288961 & 0.4532513 \\
\cline { 2 - 8 } & Mixed 10\% & 0.00935 & 0.00788 & 0.064797 & 0.057006 & 0.189024 & 0.1659896 \\
\cline { 2 - 8 } & Mixed 30\% & 0.013493 & 0.013006 & 0.071008 & 0.077341 & 0.262946 & 0.239917 \\
\hline \multirow{4}{*}{3} & PRB & 0.031473 & 0.033794 & 0.103452 & 0.094598 & 0.224605 & 0.2433627 \\
\cline { 2 - 8 } & Corn Stover & 0.080158 & 0.078107 & 0.250553 & 0.270361 & 0.379336 & 0.3860734 \\
\cline { 2 - 8 } & Mixed 10\% & 0.028157 & 0.028339 & 0.108951 & 0.110232 & 0.126102 & 0.1152749 \\
\cline { 2 - 8 } & Mixed 30\% & 0.041835 & 0.047321 & 0.138295 & 0.131541 & 0.259519 & 0.252937 \\
\hline
\end{tabular}


Table 4.9 Parameters regressed from the Arrhenius plot using the Initial Rate Model

\begin{tabular}{|c|c|c|c|c|}
\hline \multirow{2}{*}{ Group } & \multirow{3}{*}{ Chars } & \multicolumn{3}{|c|}{ Initial Rate Model } \\
\cline { 3 - 5 } & & $E_{\text {app }}(\mathrm{KJ} / \mathrm{mol})$ & $A\left({\left.\mathrm{~L} . \mathrm{mol}^{-1} . \mathrm{s}^{-1}\right)}^{*}\right.$ & $R$-squared value \\
\hline \multirow{4}{*}{1} & ND lignite & 100.67 & $3.35 \times 10^{3}$ & 0.9967 \\
\cline { 2 - 5 } & Hardwood & 94.93 & $7.86 \times 10^{2}$ & 0.8979 \\
\cline { 2 - 5 } & Mixed 10\% & 123.63 & $2.43 \times 10^{4}$ & 0.9954 \\
\cline { 2 - 5 } & Mixed 30\% & 97.99 & $1.90 \times 10^{3}$ & 0.9827 \\
\hline \multirow{4}{*}{2} & ILL No.6 & 187.43 & $1.55 \times 10^{6}$ & 0.9485 \\
\cline { 2 - 5 } & Switchgrass & 137.12 & $6.28 \times 10^{4}$ & 0.9679 \\
\cline { 2 - 5 } & Mixed 10\% & 203.80 & $1.13 \times 10^{7}$ & 0.9818 \\
\cline { 2 - 5 } & Mixed 30\% & 197.47 & $8.58 \times 10^{6}$ & 0.9963 \\
\hline \multirow{3}{*}{3} & PRB & 132.05 & $2.51 \times 10^{4}$ & 0.9967 \\
\cline { 2 - 5 } & Corn Stover & 106.72 & $4.97 \times 10^{3}$ & 0.9416 \\
\cline { 2 - 5 } & Mixed 10\% & 99.17 & $8.77 \times 10^{2}$ & 0.8328 \\
\cline { 2 - 5 } & Mixed 30\% & 117.79 & $8.23 \times 10^{3}$ & 0.9856 \\
\hline
\end{tabular}

\subsection{Evaluation of Model 5 and Model 10}

Since the integral and least-squares regression method is employed in the modeling process, the R-squared values can be used to evaluate the quality of the data regression. As mentioned in section 3.6.4, an R-squared value close to 1 implies a better linear relationship. A better linear relationship in the $k_{\text {app }}$ fitting process implies that the postulated model is a good kinetic representation of the reaction. For an Arrhenius plot, a better linear relationship can be used as a positive support for the exclusion of external mass transfer effect; however this is just a necessary but not a sufficient condition.

A total of 36 pairs of R-squared data for the $k_{\text {app }}$ fitted with the simplified Model 5 and the modified Model 10 are listed in the Table 4.10. Since at each temperature level there were two repeat experiments, the two models are compared by the average Rsquared value \pm standard deviation (STDEV). Meanwhile, a similar comparison of the results from the Arrhenius regressions is listed in Table 4.11. 
Table 4.10 Comparison of $k_{a p p}$ fitted with different models

\begin{tabular}{|c|c|c|c|c|c|c|}
\hline \multirow{2}{*}{ Chars } & \multicolumn{6}{|c|}{$R$-squared value Comparison (Average value $\pm S T D E V$ ) } \\
\cline { 2 - 7 } & \multicolumn{2}{|c}{$900^{\circ} \mathrm{C}$} & \multicolumn{2}{c|}{$1000^{\circ} \mathrm{C}$} & \multicolumn{2}{c|}{$1100^{\circ} \mathrm{C}$} \\
\cline { 2 - 7 } & Model 5 & Model 10 & Model 5 & Model 10 & Model 5 & Model 10 \\
\hline ND lignite & $0.9359 \pm 0.010$ & $0.9855 \pm 0.005$ & $0.9227 \pm 0.001$ & $0.9787 \pm 0.001$ & $0.8980 \pm 0.001$ & $0.9617 \pm 0.001$ \\
\hline Hardwood & $0.9046 \pm 0.016$ & $0.9669 \pm 0.011$ & $0.8268 \pm 0.009$ & $0.9081 \pm 0.008$ & $0.8097 \pm 0.006$ & $0.8884 \pm 0.006$ \\
\hline Mixed 10\% & $0.9239 \pm 0.004$ & $0.9782 \pm 0.003$ & $0.9117 \pm 0.001$ & $0.9707 \pm 0.001$ & $0.8931 \pm 0.002$ & $0.9578 \pm 0.001$ \\
\hline Mixed 30\% & $0.9255 \pm 0.012$ & $0.9796 \pm 0.007$ & $0.9046 \pm 0.000$ & $0.9663 \pm 0.000$ & $0.8960 \pm 0.005$ & $0.9591 \pm 0.004$ \\
\hline ILL No.6 & $0.9883 \pm 0.007$ & $0.9964 \pm 0.004$ & $0.9907 \pm 0.003$ & $0.9958 \pm 0.002$ & $0.9816 \pm 0.005$ & $0.9977 \pm 0.000$ \\
\hline Switchgrass & $0.9733 \pm 0.004$ & $0.9991 \pm 0.001$ & $0.8930 \pm 0.008$ & $0.9590 \pm 0.006$ & $0.8966 \pm 0.030$ & $0.9596 \pm 0.021$ \\
\hline Mixed 10\% & $0.9739 \pm 0.006$ & $0.9994 \pm 0.002$ & $0.9908 \pm 0.003$ & $0.9960 \pm 0.002$ & $\mathbf{0 . 9 9 8 4} \pm 0.001$ & $\mathbf{0 . 9 8 1 5} \pm 0.006$ \\
\hline Mixed 30\% & $0.9689 \pm 0.009$ & $0.9985 \pm 0.002$ & $0.9851 \pm 0.001$ & $0.9966 \pm 0.000$ & $\mathbf{0 . 9 9 6 5 \pm 0 . 0 0 1}$ & $\mathbf{0 . 9 4 6 6} \pm 0.003$ \\
\hline PRB & $0.8676 \pm 0.012$ & $0.9365 \pm 0.009$ & $0.8744 \pm 0.004$ & $0.9420 \pm 0.003$ & $0.8953 \pm 0.004$ & $0.9571 \pm 0.003$ \\
\hline Corn Stover & $0.9312 \pm 0.005$ & $0.9799 \pm 0.003$ & $0.9060 \pm 0.006$ & $0.9649 \pm 0.004$ & $0.9189 \pm 0.001$ & $0.9724 \pm 0.001$ \\
\hline Mixed 10\% & $0.8669 \pm 0.003$ & $0.9348 \pm 0.002$ & $0.8760 \pm 0.002$ & $0.9426 \pm 0.002$ & $0.8963 \pm 0.007$ & $0.9581 \pm 0.005$ \\
\hline Mixed 30\% & $0.8713 \pm 0.009$ & $0.9378 \pm 0.008$ & $0.8842 \pm 0.006$ & $0.9496 \pm 0.004$ & $0.8904 \pm 0.002$ & $0.9537 \pm 0.002$ \\
\hline
\end{tabular}

Note:

1. Almost all the data show that Model 10 has a better fit quality than Model 5;

2. The data typed in Bold show the fit quality of Model 5 is better than Model 10 for only two experiments.

Table 4.11 Comparison of $E_{a p p}$ from Arrhenius plot regressions based on different models

\begin{tabular}{|c|c|c|c|c|c|c|}
\hline \multirow[b]{2}{*}{ Group } & \multirow[b]{2}{*}{ Chars } & \multicolumn{2}{|c|}{ Model 5} & \multicolumn{3}{|c|}{ Model 10} \\
\hline & & $\begin{array}{c}E_{a p p} \\
(\mathrm{KJ} / \mathrm{mol})\end{array}$ & $R$-squared & $\begin{array}{c}E_{a p p} \\
(\mathrm{KJ} / \mathrm{mol})\end{array}$ & $R$-squared & $\begin{array}{c}\text { Error based on } \\
\text { Model } 5(\%)\end{array}$ \\
\hline \multirow{4}{*}{1} & ND lignite & 120.25 & 0.9890 & 119.89 & 0.9889 & -0.30 \\
\hline & Hardwood & 152.75 & 0.9987 & 153.29 & 0.9988 & 0.35 \\
\hline & Mixed 10\% & 124.75 & 0.9979 & 124.73 & 0.9978 & -0.02 \\
\hline & Mixed 30\% & 126.82 & 0.9885 & 126.52 & 0.9879 & -0.24 \\
\hline \multirow{4}{*}{2} & ILL No.6 & 194.28 & 0.9722 & 194.02 & 0.9726 & -0.13 \\
\hline & Switchgrass & 171.2 & 0.9910 & 171.18 & 0.9902 & -0.01 \\
\hline & Mixed 10\% & 190.46 & 0.9805 & 189.61 & 0.9806 & -0.45 \\
\hline & Mixed 30\% & 180.48 & 0.9716 & 178.73 & 0.9716 & -0.97 \\
\hline \multirow{4}{*}{3} & PRB & 132.63 & 0.9922 & 131.99 & 0.9918 & -0.48 \\
\hline & Corn Stover & 117.74 & 0.9872 & 117.99 & 0.9861 & 0.21 \\
\hline & Mixed 10\% & 130.75 & 0.9866 & 130.49 & 0.9861 & -0.20 \\
\hline & Mixed 30\% & 123.01 & 0.9822 & 122.9 & 0.9821 & -0.09 \\
\hline
\end{tabular}


For the total 36 data pairs shown in Table 4.10, all but two pairs indicate that Model 10 is better than Model 5 for the fitting of the apparent rate constant. Only one of the average R-squared values for Model 10 is below 0.9, but for Model 5, 16 values are below 0.9. The data in Table 4.11 show that: (1) for both Model 5 and Model 10, the Rsquared value for the $E_{a p p}$ regression are above 0.97, implying Arrhenius regressions are good; (2) $E_{a p p}$ data regressed from different models are almost identical, the difference between Model 5 and Model 10 is no more than 1\%.

The above comparisons lead to the conclusion that, for the chars studied here, Model 10 is better than Model 5 in the kinetic analysis for gasification of most of the chars with $\mathrm{CO}_{2}$, but for Group 2 chars there are some exceptions. For the ILL No.6 char, $k_{\text {app }}$ fitting quality of Model 5 and Model 10 is almost the same and the average values of R-squared are near 0.99 for both models. However, when the ILL No.6 is mixed with Switchgrass, especially at higher temperature $\left(1100^{\circ} \mathrm{C}\right)$, the fitting quality of Model 5 is better than Model 10.

It is noted that the results of apparent activation energy in this study are in good agreement with the previous researchers' results. For example, Brown et al. reported (Brown et al. , 2000) for a char gasification with $\mathrm{CO}_{2}$, in the temperature range of 760 to $980^{\circ} \mathrm{C}$, the $E_{a p p}$ was about $176(\mathrm{KJ} / \mathrm{mol})$ for ILL No.6 char, and $174(\mathrm{KJ} / \mathrm{mol})$ for Switchgrass char. The results of $E_{a p p}$ in this study are $194(\mathrm{KJ} / \mathrm{mol})$ for ILL No.6 char, and $171(\mathrm{KJ} / \mathrm{mol})$ for Switchgrass char.

\subsection{Rates for different chars}

Before further discussion of the synergism between different coal and biomass char pairs, it is necessary to compare their individual gasification rates since the average reaction rate of the mixture will depend on each of the individual rates. For the coal char gasification with carbon dioxide, it has been reported that the reactivity of Lignite char is higher than Bituminous char (Scott, 1983). In other words, the lower rank coal char's reaction rate is higher than for the higher rank coal. Low-rank coals, including lignite and sub-bituminous coals, have lower energy content because they have lower carbon content. They generally have higher volatile matter and moisture levels. High-rank coals, including bituminous and anthracite coals, contain more carbon than lower-rank coals 
which results in a much higher energy content. They also have lower moisture content than lower-rank coals.

From a geological point of view, coals can be classified in an increasing order of rank as: Lignite (immature), Sub-bituminous, Bituminous, and Anthracite (mature) (Given, 1984). Coal starts off as peat. After a considerable amount of time, heat, and burial pressure, it is metamorphosed from peat to lignite. Lignite is considered to be "immature" coal at this stage of development because it is still somewhat light in color and remains soft. As time passes, lignite increases in maturity by becoming darker, harder and higher in carbon. It is then classified as sub-bituminous coal. As this process of burial and alteration continues, more chemical and physical changes occur and the coal is classified as bituminous. At this point the coal is dark and hard. Anthracite is the last of the classifications, and this terminology is used when the coal has reached ultimate maturation. Anthracite coal is very hard, shiny and high in carbon.

There is lack of the information about biomass char gasification reaction rates. However, it can be postulated that biomass chars are somewhat like the "immature" Lignite coal chars. The following figures (Figures 4.7, 4.8 and 4.9) compare the gasification reaction rate constant (obtained through different models) for a total of the six different chars used in this study. It should be mentioned that the average value of $k_{a p p}$ is reported along with the standard deviation $(S T D E V)$ of the two repeat runs for each temperature level shown as the error bar in the figures. 


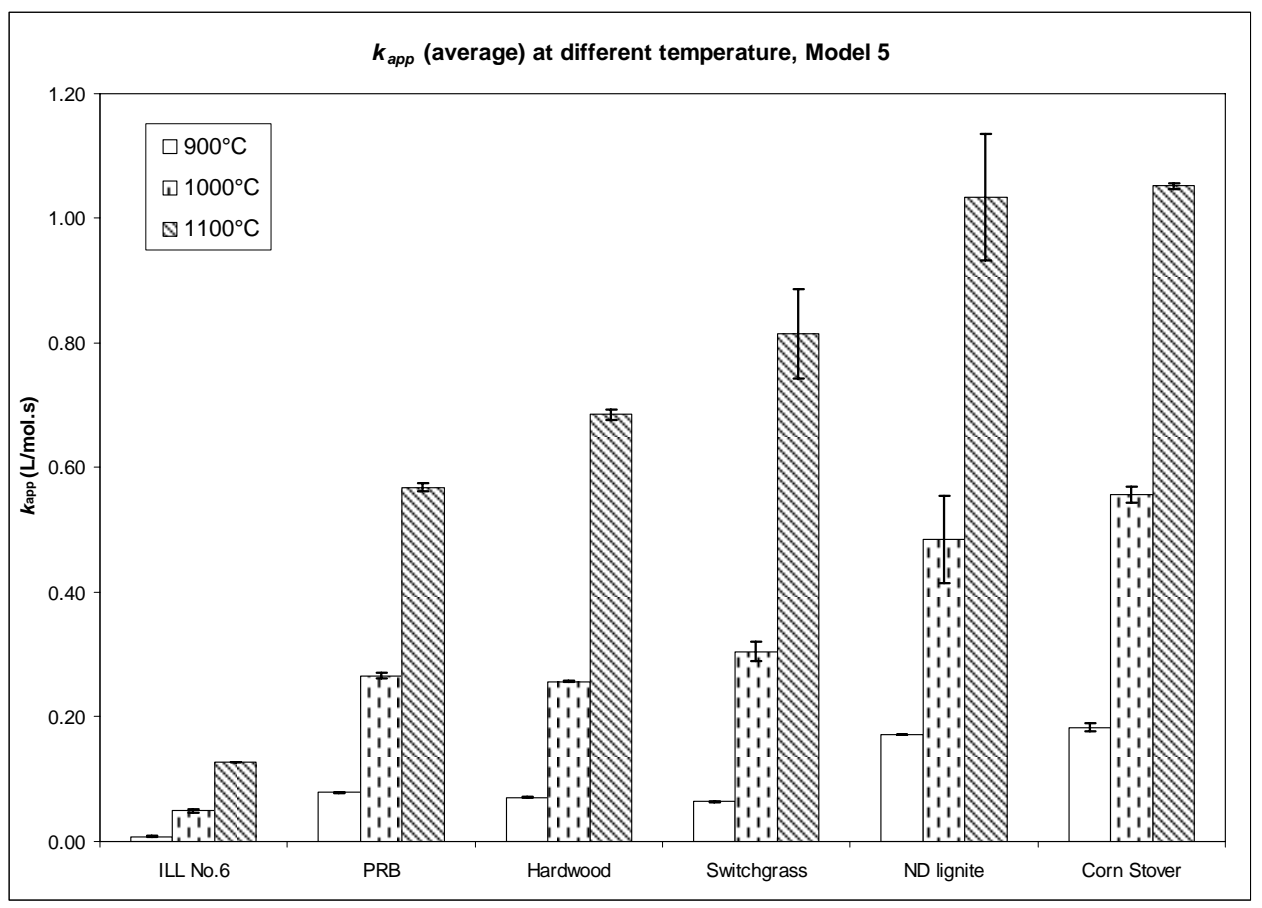

Figure 4.7 Comparison of $k_{a p p}$ for pure coal or biomass fitted with Model 5 at three different temperatures

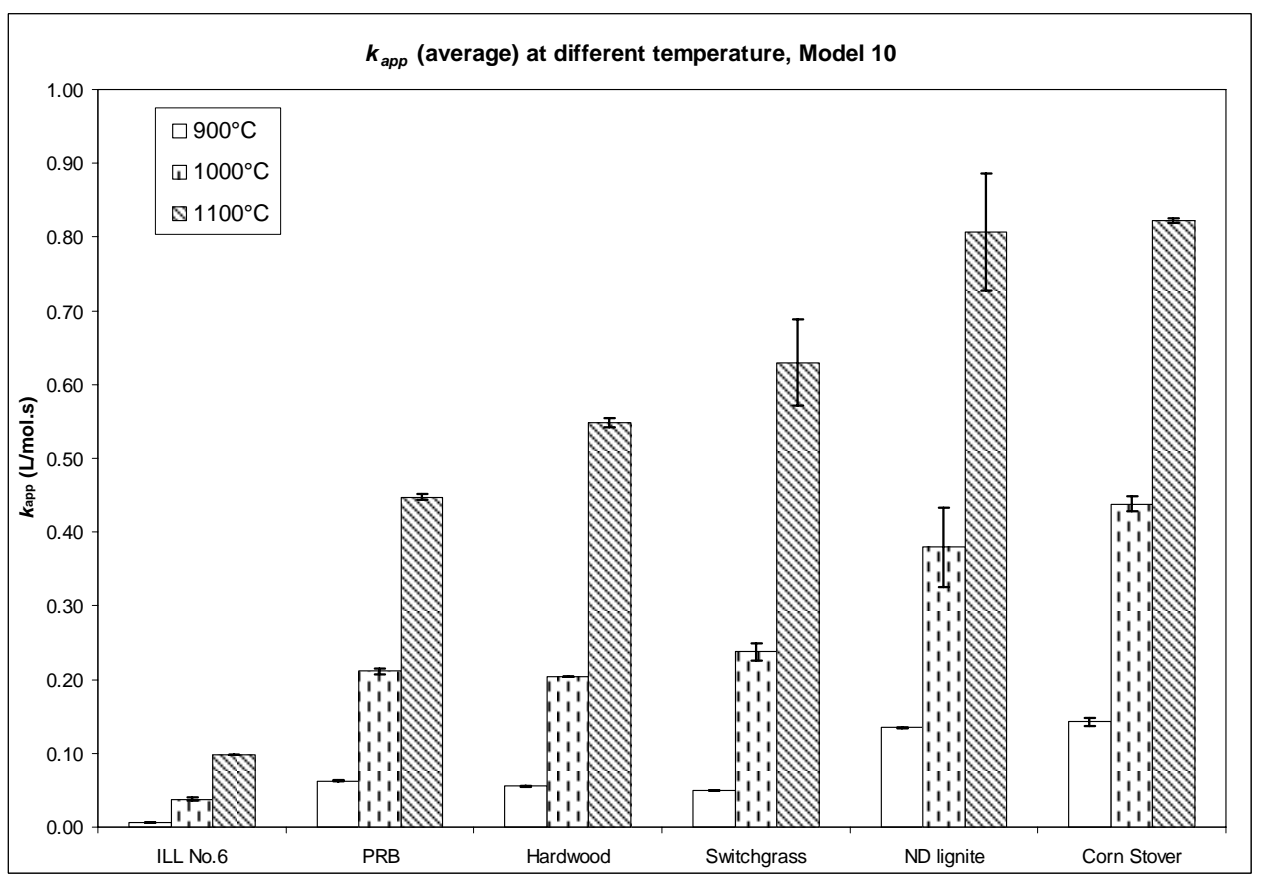

Figure 4.8 Comparison of $k_{a p p}$ for pure coal or biomass fitted with Model 10 at three different temperatures 


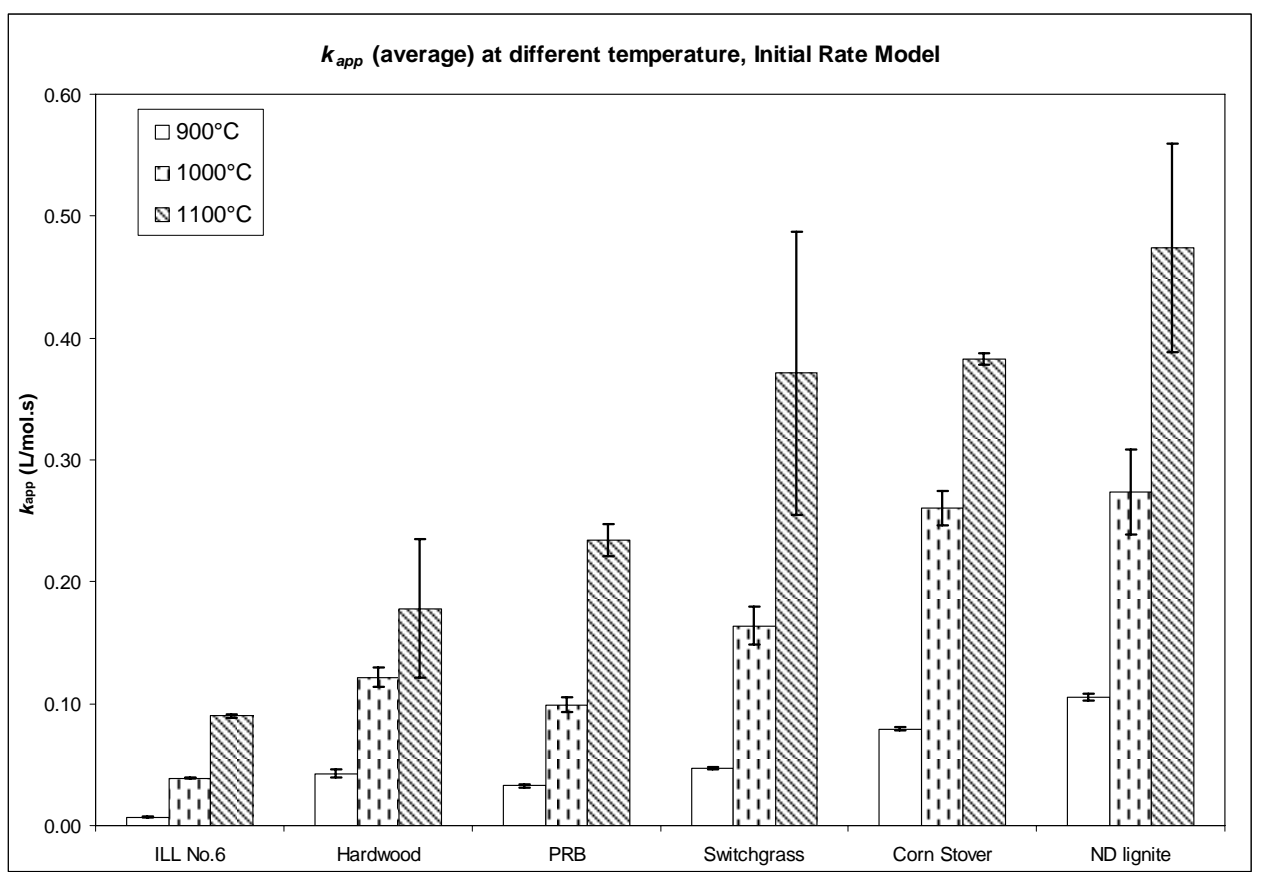

Figure 4.9 Comparison of $k_{a p p}$ for pure coal or biomass fitted with Initial Rate Model at three different temperatures

From the above figures, it can be observed that, although the rate comparison results have some small discrepancies in different temperature levels and also have some data scatter, the general reaction rate sequence for six chars at the three different temperatures is:

$($ Corn Stover $\approx N D$ lignite $) \geq$ Switchgrass $>($ Hardwood $\approx P R B)>$ Ill No.6

The rate sequence for the three coal chars is:

ND lignite $>P R B>$ Ill No.6

It can be seen that the gasification reactivity increases from the higher rank to lower rank coal chars as expected.

For the three biomass chars, the rate sequence is:

Corn Stover $\geq$ Switchgrass $>$ Hardwood

It should also be noted that at higher temperature $\left(1100^{\circ} \mathrm{C}\right)$, the top three chars of the rate sequence, Corn Stover, ND lignite, and Switchgrass have almost the same 
reaction rate. This similarity on the reaction rate supports the assumption that biomass chars (Corn Stover and Switchgrass) can be treated as "immature" Lignite coal chars.

\subsection{Synergistic effect between coal chars and biomass chars}

Here, for the gasification of char mixtures, if the interaction of two chars shows a faster reaction rate than the sum of the rate of each pure char individually (weighted according to their mixture mass ratio) accounting for experimental uncertainty, then a positive synergistic effect or synergy is noted between the char pair. On the contrary, if the interaction of two chars shows a slower reaction rate than the sum of the weighted rates based on the individual chars, a negative synergistic effect is demonstrated.

\subsubsection{Reaction rate for char mixtures}

Based on the above observation of the relative char gasification reaction rates, if a fast-reacting char and a relatively slow one are mixed, it will be expected that the rate for the mixture should be between the rates of the individual chars. Moreover, the rate for the mixture will be in proportion to the mixture ratio.

In the following figures, the experimental value of $(1-X)_{\text {average }}$ (mean value of two repeat experiments for a char blend) is evaluated for char mixture with different mixture ratios reacting at $900^{\circ} \mathrm{C}$. They include the mixture chars of Group 1, 2, and 3 as described earlier. For data at other reaction temperature, please see Appendix F. In all of these figures $(4.10,4.11$ and 4.12$)$, the $(1-X)_{\text {average }}$ data come from the average of two repeat experiments at each temperature level, the error bars (gray bands) are presented as \pm STDEV, and a lower curve indicates a faster reaction rate. 


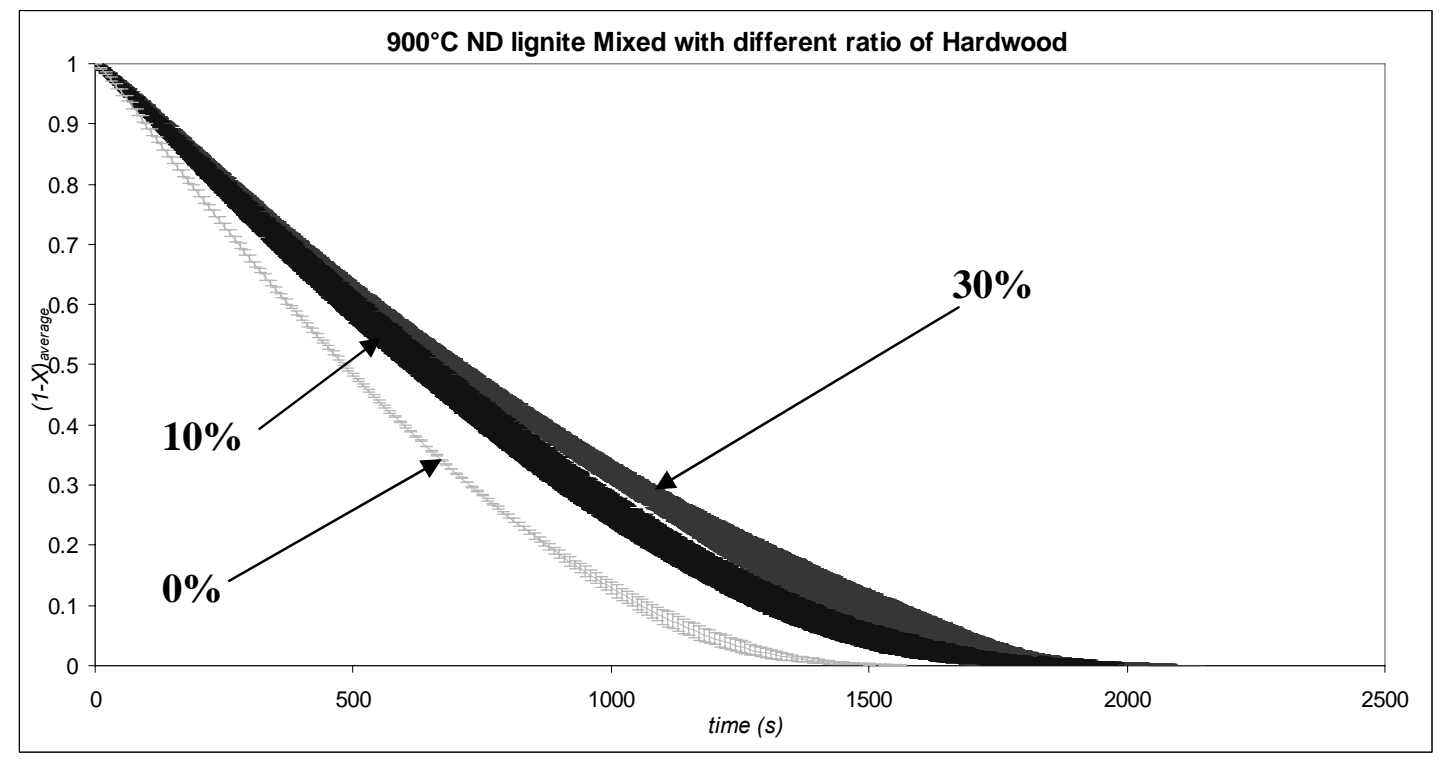

Figure 4.10 Reaction rate data for various Group 1 char mixtures of $900^{\circ} \mathrm{C}$

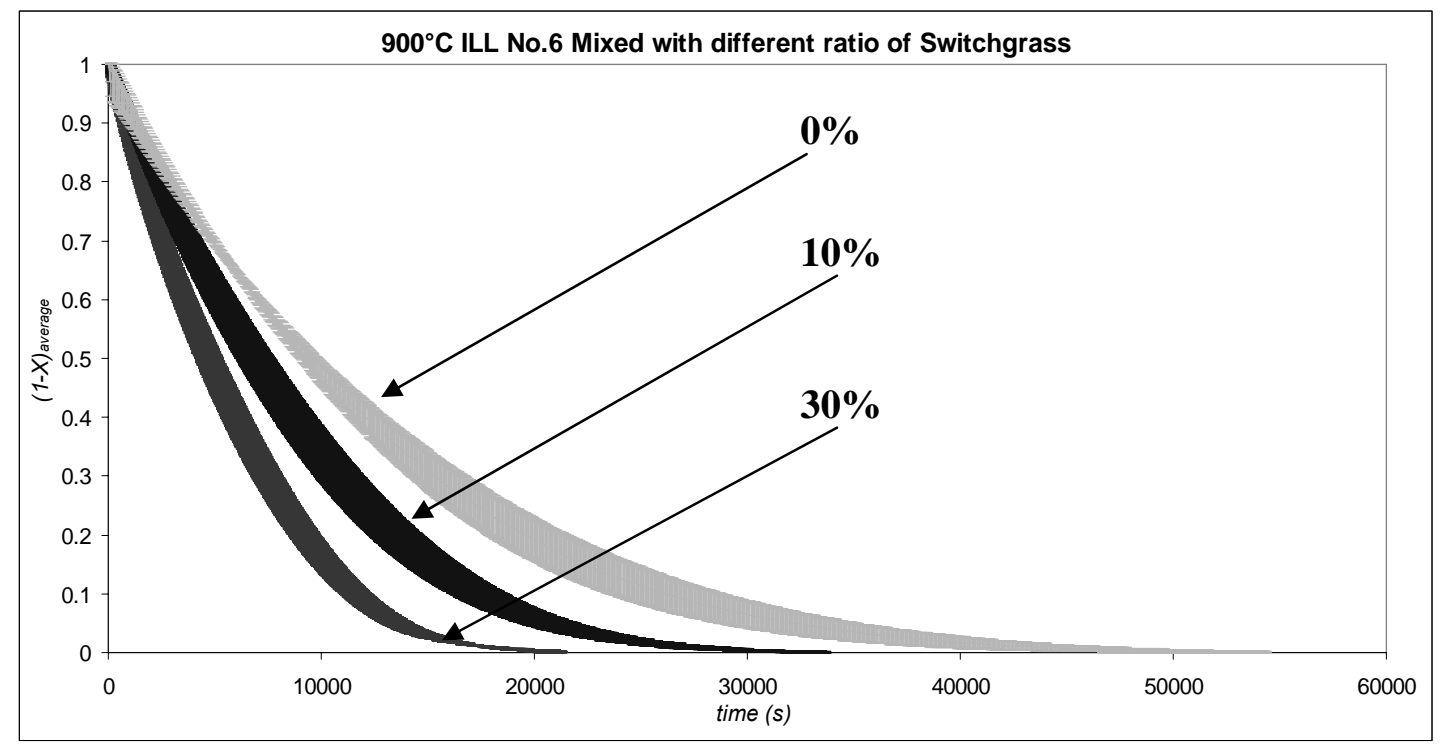

Figure 4.11 Reaction rate data for various Group 2 char mixtures of $900^{\circ} \mathrm{C}$ 


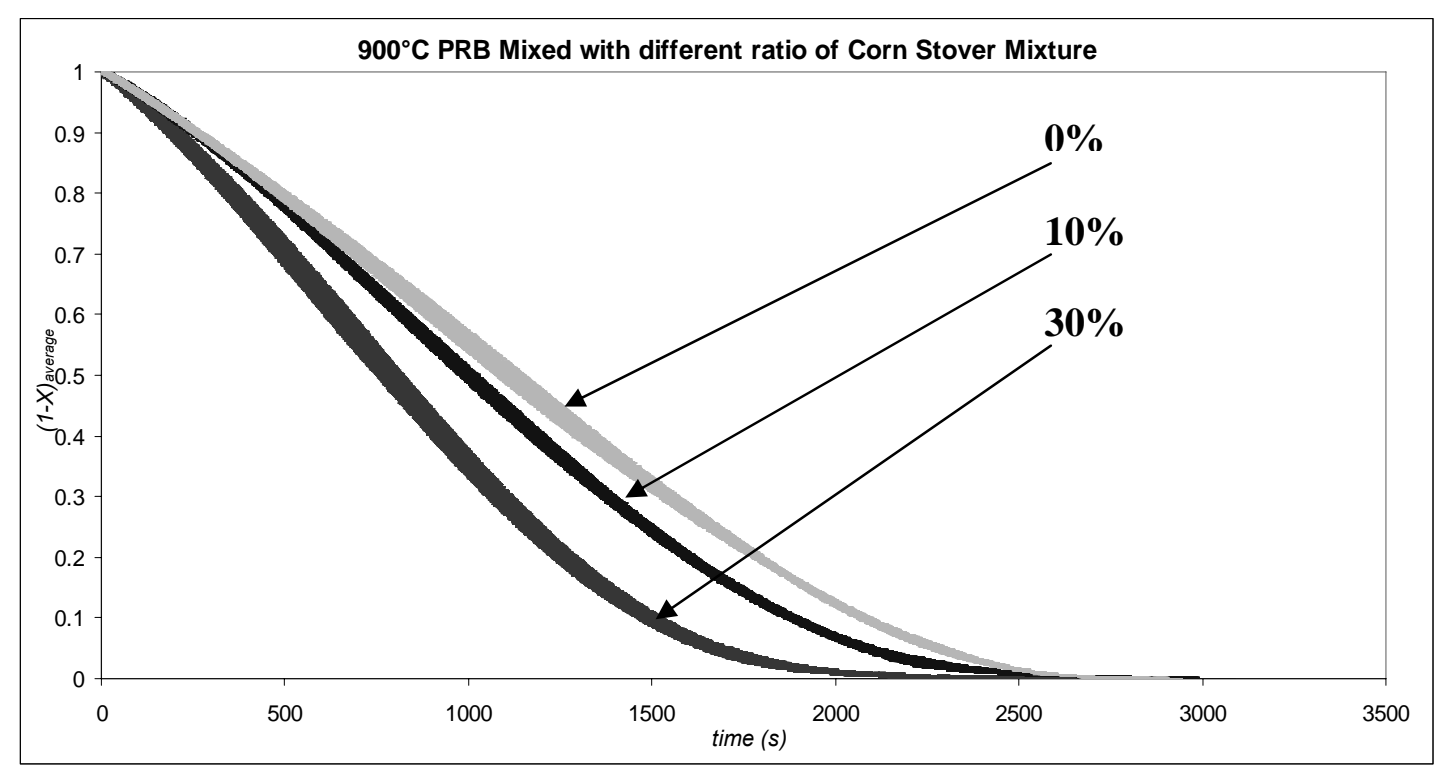

Figure 4.12 Reaction rate data for various Group 3 char mixtures of $900^{\circ} \mathrm{C}$

For the mixtures of Group 1 chars shown in Figure 4.10, since the reaction rate of ND Lignite char is much faster than that for the Hardwood char, the reaction rate of the mixture is slower than the pure ND Lignite. With an increasing weight ratio of Hardwood char, from $0 \%$ to $30 \%$, the mixture's rate is decreased. The same result appears in the reaction at 1000 and $1100^{\circ} \mathrm{C}$, as seen in the detailed figures in Appendix F.

For the mixtures of Group 2 and 3, gasification reaction rates of the pure coal chars (ILL No.6 and PRB) are correspondingly slower than those of the pure biomass chars (Switchgrass, Corn Stover). Consequently, as demonstrated in Figure 4.11 and 4.12 for reactions at $900^{\circ} \mathrm{C}$, the reaction rate for the mixture is faster than the pure coal char, and the higher mixture ratio of biomass char results in a higher reaction rate. This phenomenon appears not only at $900^{\circ} \mathrm{C}$, but also is observed at 1000 and $1100^{\circ} \mathrm{C}$. Detailed figures for Groups 2 and 3 are collected in Appendix F for 1000 and $1100^{\circ} \mathrm{C}$.

Since the mixtures of Group 2 and 3 show an increasing tendency on their reaction rate with increasing the mixture ratio of biomass, the $k_{a p p}$ data derived from Model 10 at different temperature were employed to investigate the correlation of the rate constant with respect to the biomass mixture ratio. Figures 4.13 and 4.14 illustrate this correlation for the Group 2 and Group 3 mixtures respectively. 


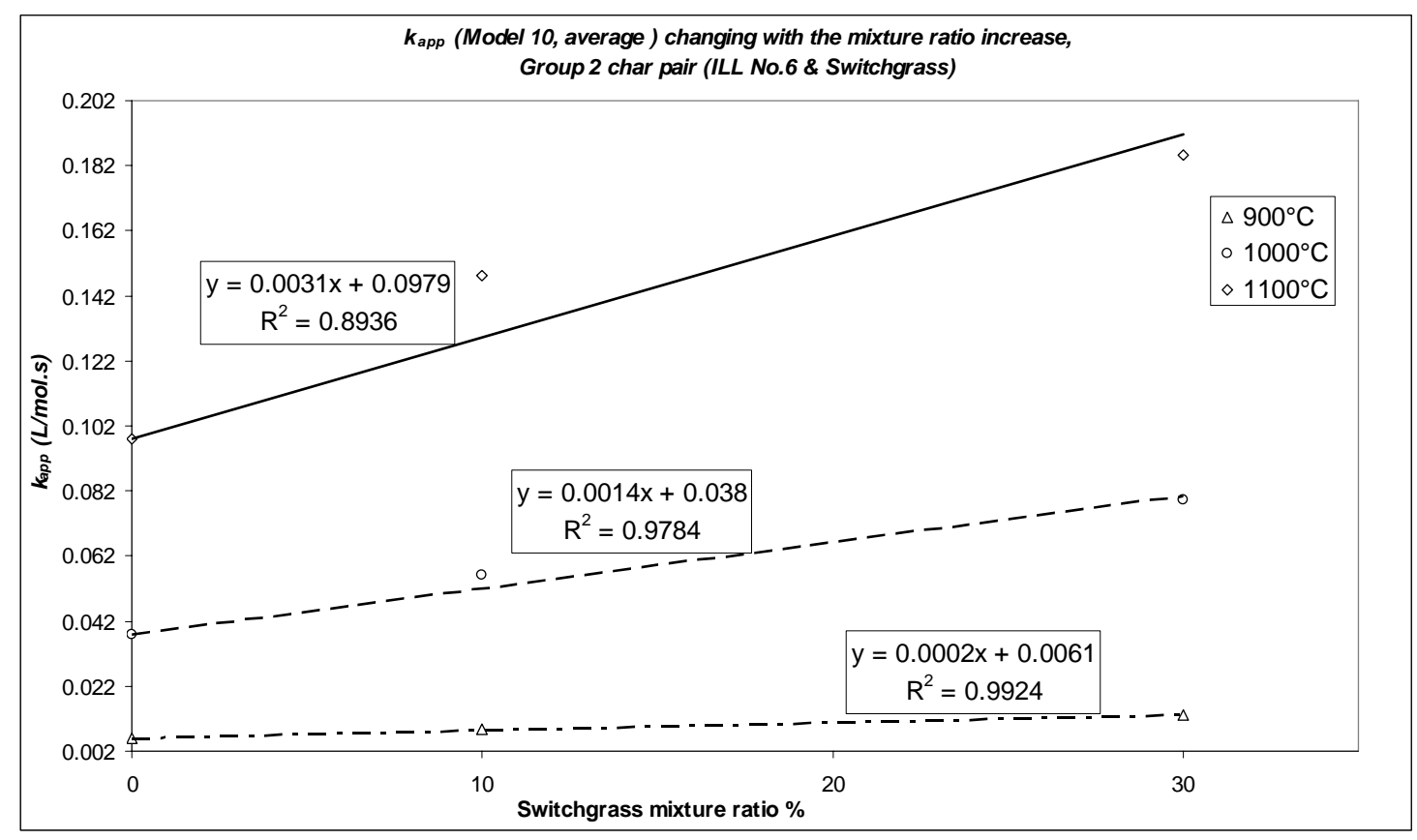

Figure 4.13 Changes in the apparent rate constant, $k_{a p p}$, (Model 10) with biomass weight ratio for the Group 2 char pair

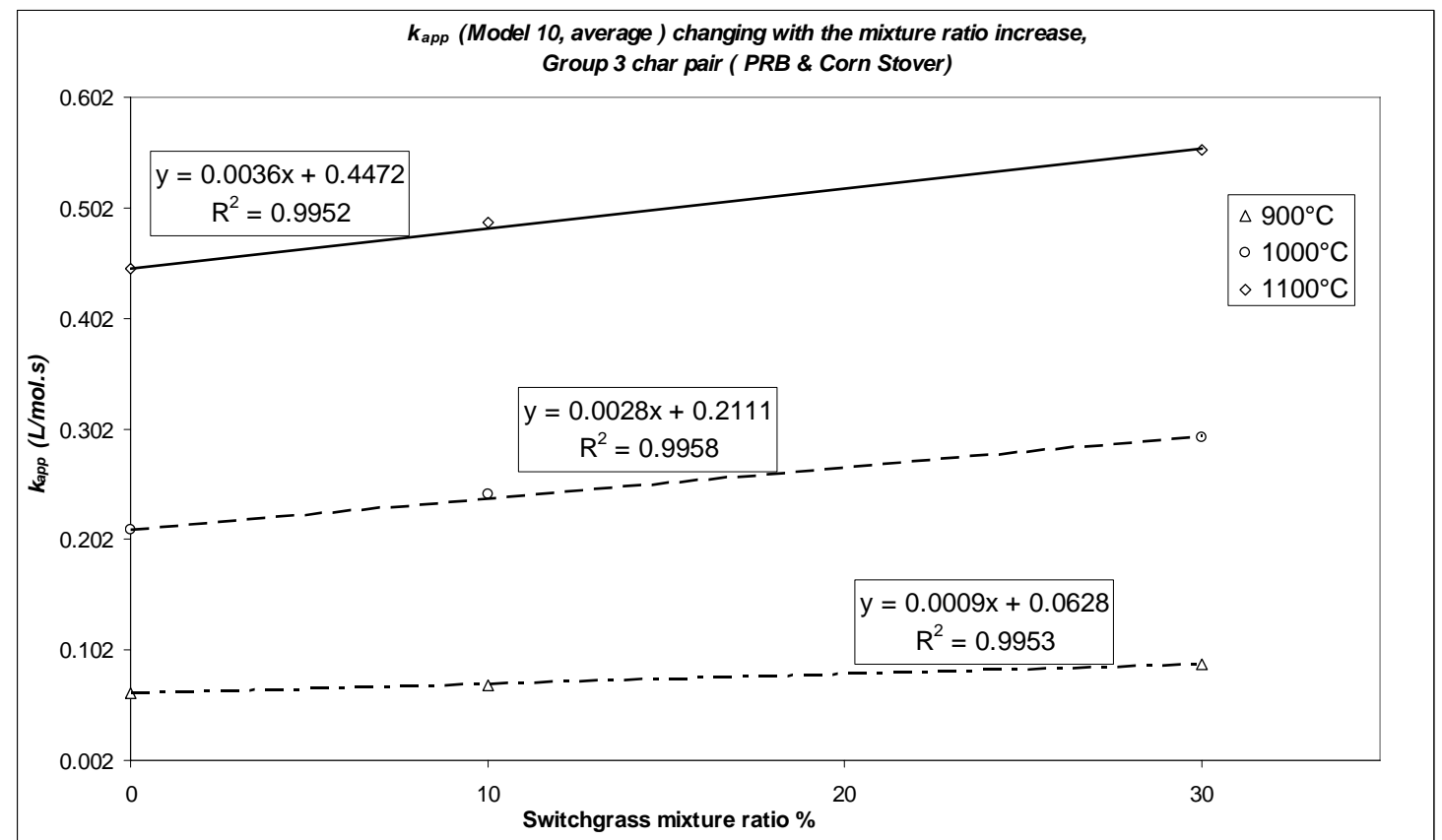

Figure 4.14 Changes in the apparent rate constant, $k_{a p p}$, (Model 10) with biomass weight ratio for the Group 3 char pair 
In both Figure 4.13 and 4.14 , the relationship between the rate constant and the biomass mixture ratio is the same: the $k_{a p p}$ increases linearly with the increasing biomass mixture ratio. Therefore, for these char mixtures, the reaction rate expression can be described as: $r_{C} \propto R_{\text {Biomass }}$, where $R_{\text {Biomass }}$ is the weight ratio of the biomass char in the mixture. From the linear regression result shown in Figure 4.13 and 4.14, the apparent rate constant (derived from Model 10) for mixture chars at each of the three temperatures can be written as:

$$
k_{\text {app }}(\text { mixture char })=\text { Slope } * R_{\text {Biomass }}+\text { Intercept }
$$

where $k_{\text {app }}$ is the rate constant, (L/mol.s); $R_{\text {Biomass }}$ is the weight ratio of the biomass char in the mixture, \%; the slope is the value from the regression linear line, dimensionless; the intercept is the rate constant for pure coal char, $(\mathrm{L} / \mathrm{mol} . \mathrm{s})$. The linear regression parameters for Group 2 and Group3 char pairs are listed in Table 4.12.

Table 4.12 The linear regression parameters of $k_{a p p}$ (Model 10) with biomass mixture ratio for Group 2 and Group 3 char pairs

\begin{tabular}{|c|c|c|c|c|}
\hline Group & Temperature $\left({ }^{\circ} \mathrm{C}\right)$ & Slope & Intercept(L/mol.s) & R-squared Value \\
\hline \multirow{3}{*}{2} & 900 & 0.0002 & 0.0061 & 0.9924 \\
\cline { 2 - 5 } & 1000 & 0.0014 & 0.038 & 0.9784 \\
\cline { 2 - 5 } & 1100 & 0.0031 & 0.0979 & 0.8936 \\
\hline \multirow{3}{*}{3} & 900 & 0.0009 & 0.0628 & 0.9953 \\
\cline { 2 - 5 } & 1000 & 0.0028 & 0.2111 & 0.9958 \\
\cline { 2 - 5 } & 1100 & 0.0036 & 0.4472 & 0.9952 \\
\hline
\end{tabular}

Generally, based on the gasification kinetic analysis of pure coal and pure biomass chars, trends for the reaction rate of the mixture can be roughly predicted. A biomass char with a faster reaction rate than its coal char partner, will increase the reaction rate of the mixture, and vice versa.

\subsubsection{Prediction of synergistic effects (Prediction Model A)}

To inspect the synergistic effect, the conversion-time correlation for the mixture char is employed with the assumption that there is no interaction between the two chars. Referred to as Prediction Model A, it can be described by a purely additive model as follows: 
$(1-X)_{\text {predicted }}=\left(1-R_{\text {Biomass }}\right) \cdot(1-X)_{\text {coal_experimental }}+R_{\text {Biomass }} \cdot(1-X)_{\text {biomass_experimental }}$

where $(1-X)_{\text {predicted }}$ is the predicted value of conversion for the mixture with no interaction; the $(1-X)_{\text {coal_experimental }}$ and $(1-X)_{\text {biomas_experimental }}$ values come from the real experimental data of pure coal and biomass char; $R_{\text {Biomass }}$ is the weight ratio of the biomass char in the mixture. The predicted value is a weighted average of individual $(1-X)$ data for the two chars, the pure coal char and pure biomass char. For example, for a weight mixture ratio of 90:10 (coal char to biomass char):

$$
(1-X)_{\text {predicted }}=0.9 \cdot(1-X)_{\text {coal_experimental }}+0.1 \cdot(1-X)_{\text {biomass_experimental }}
$$

A plot of the actual experimental data for the gasification of the char mixture, $(1-X)_{\text {experimental }}$ vs. $t$, is superposed on the plot of the data calculated from Prediction Model A $\left((1-X)_{\text {predicted }} v s . t\right)$ so that a direct comparison can be made. The approach here is to compare the value of $(1-X)_{\text {predicted }}$ with the real experiment data $(1-X)_{\text {experimental }}$ at a given time and examine them for any difference in the reaction rate.

In other words, for Prediction Model A, it is assumed that there is no synergistic effect at all. If the real experimental conversion kinetics $(1-X)_{\text {experimental }}$ are faster than the value of $(1-X)_{\text {predicted }}$ after accounting for experimental error, then a positive synergy is identified between the char pairs. On the contrary, if the kinetics of $(1-X)_{\text {experimental }}$ are slower than the value $(1-X)_{\text {predicted }}$, then there is a negative synergistic effect between the char pairs.

\subsubsection{Synergistic effect inspection plots and discussion}

Since for each pure coal or pure biomass char there are two repeat runs at each temperature level, the data of $(1-X)_{\text {coal_experimental }}$ and $(1-X)$ biomass_experimental in equation [4.23] are presented as the average, and data scatter presented as $\pm(\mathrm{STDEV})_{\text {coal_experimental }}$ and $\pm(\mathrm{STDEV})_{\text {biomass_experimental. }}$. Here, the conversion $X$ is used from 0 to 1 . Consequently, the $(1-X)_{\text {predicted }}$ value in Prediction Model $\mathrm{A}$ is also an average value. Assuming that there is no interaction between two pure chars, then based on the STDEV rules described in section 3.6.4 ([3.9] , [3.10]), the data scatter of $(1-X)_{\text {predicted }}$ can be presented by a \pm (STDEV) $)_{\text {mixture predicted, }}$ which is a sum of (STDEV) coal_experimental and

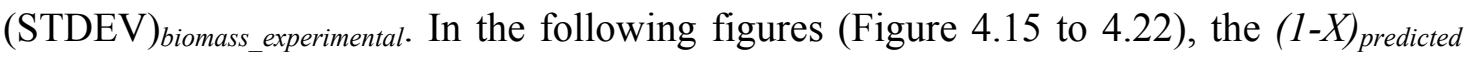


data of Prediction Model A are presented by an average with error bars, but the mixture experimental data of $(1-X)_{\text {experimental }}$ are presented without error bars. To emphasize of the synergistic effect, two separate plots were made at each mixture ratio, $10 \%$ and $30 \%$. The repeat runs are identified as A and B in the figures.

Figures 4.15 through 4.16 are used to determine any synergistic effect for the Group 1 char mixtures (ND Lignite \& Hardwood) at $900^{\circ} \mathrm{C}$. The profile curves for mixture ratios of $10 \%$ and $30 \%$ show the same tendency: the kinetics of $(1-X)_{\text {experimental }}$ are slower than $(1-X)_{\text {predicted }}$ during most of the reaction. Only in the final stage of the reaction $(X>0.8)$, the prediction profiles become faster than the experimental one. The higher temperature cases show the same tendency at 1000 and $1100^{\circ} \mathrm{C}$. Please see Appendix $\mathrm{G}$ for these detailed plots. At higher temperature, the only difference is that the experimental curves are slower than the predicted one during the whole reaction. It can be concluded that there is a negative synergistic effect of the Hardwood char in the gasification kinetics of the ND Lignite char.

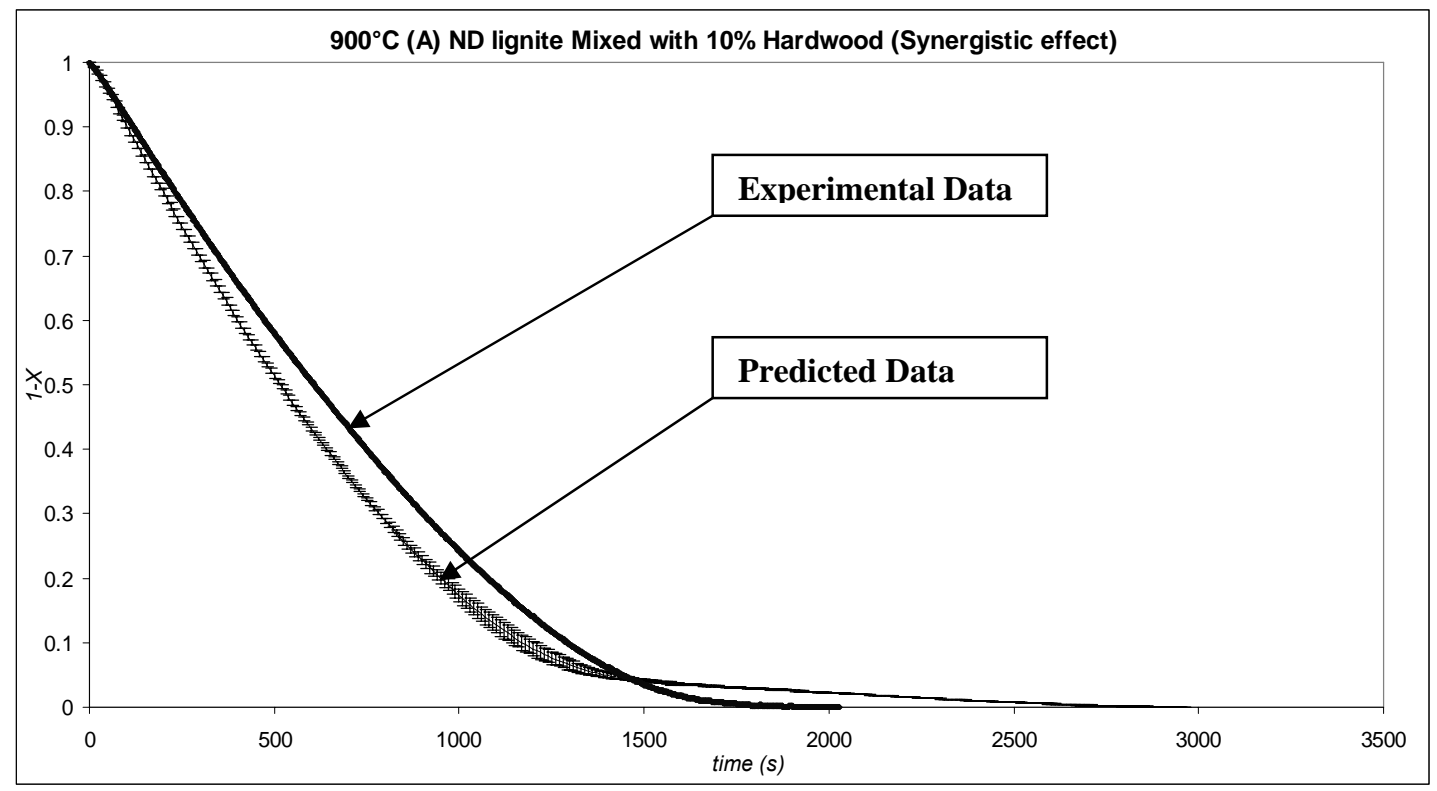

Figure 4.15A Synergistic effect inspection for Group 1 chars $10 \%$ mixture at $900^{\circ} \mathrm{C}$, A 


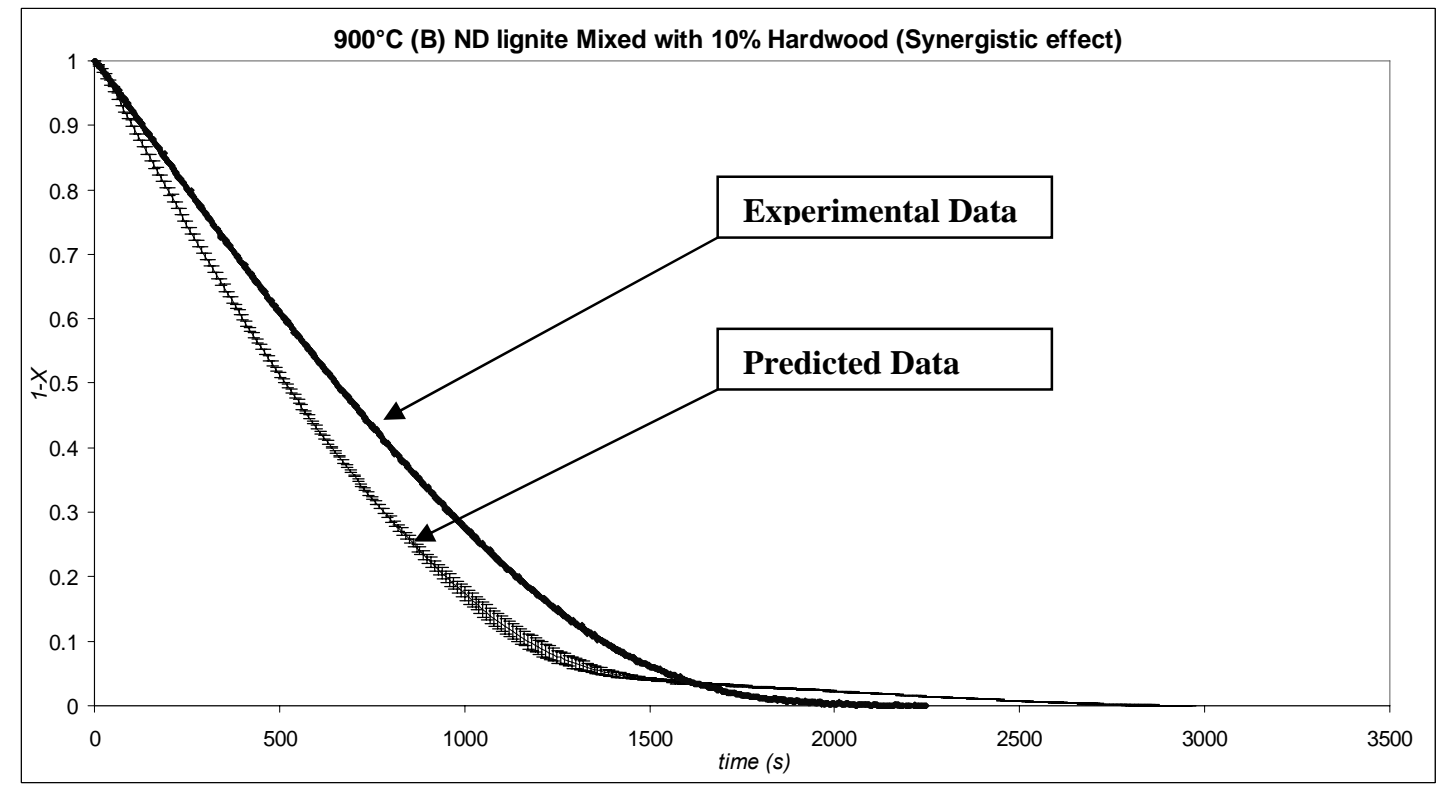

Figure 4.15B Synergistic effect inspection for Group 1 chars $10 \%$ mixture at $900^{\circ} \mathrm{C}, \mathrm{B}$

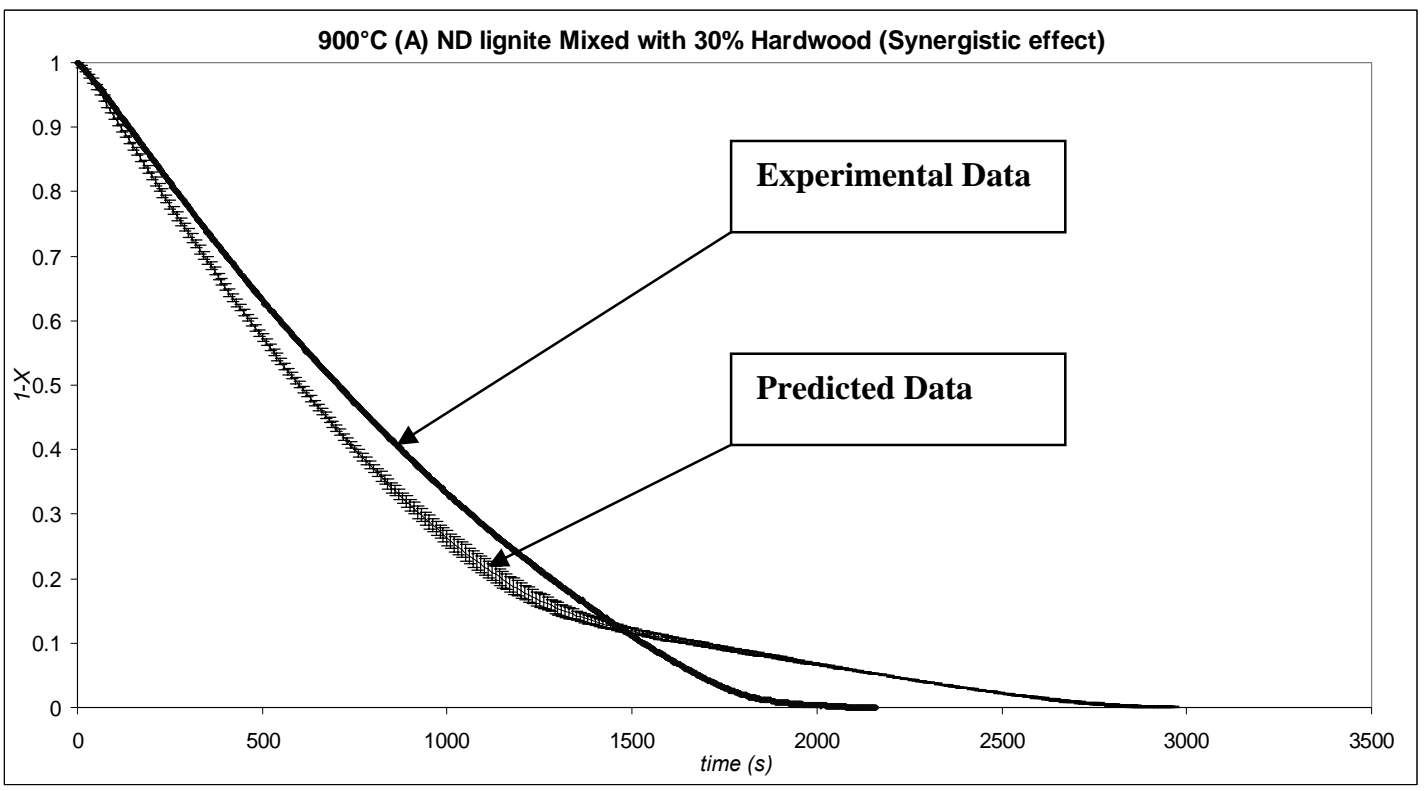

Figure 4.16A Synergistic effect inspection for Group 1 chars $30 \%$ mixture at $900^{\circ} \mathrm{C}, \mathrm{A}$ 


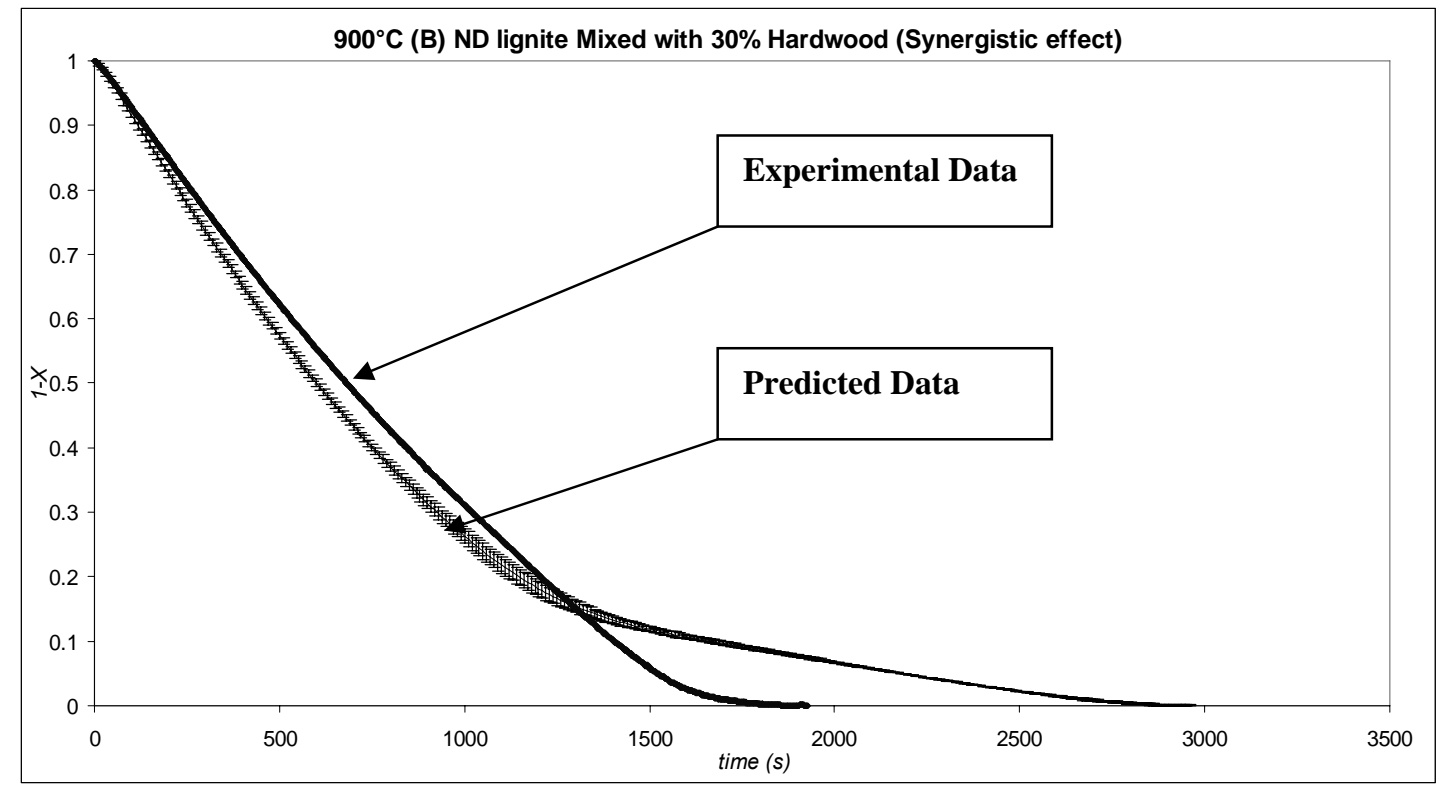

Figure 4.16B Synergistic effect inspection for Group 1 chars $30 \%$ mixture at $900^{\circ} \mathrm{C}, \mathrm{B}$

Figures 4.17 through 4.18 demonstrate the synergistic effect for the Group 2 char mixtures (ILL No.6 \& Switchgrass) at $900^{\circ} \mathrm{C}$. For both the cases of the mixture ratios of $10 \%$ and $30 \%$, the profile curves indicate the same result: after some time delay $(X>0.3)$, the actual kinetics of $(1-X)_{\text {experimental }}$ become faster than the value of $(1-X)_{\text {predicted }}$ for the remaining time of the reaction. Plots are listed in Appendix $\mathrm{H}$ for the higher temperature cases, 1000 and $1100^{\circ} \mathrm{C}$, and there are no exceptions. Thus there is a significant positive synergistic effect between the mixture char pair of ILL No.6 and Switchgrass, and it appears the higher the mixture ratio of Switchgrass char, the greater the synergistic effect. 


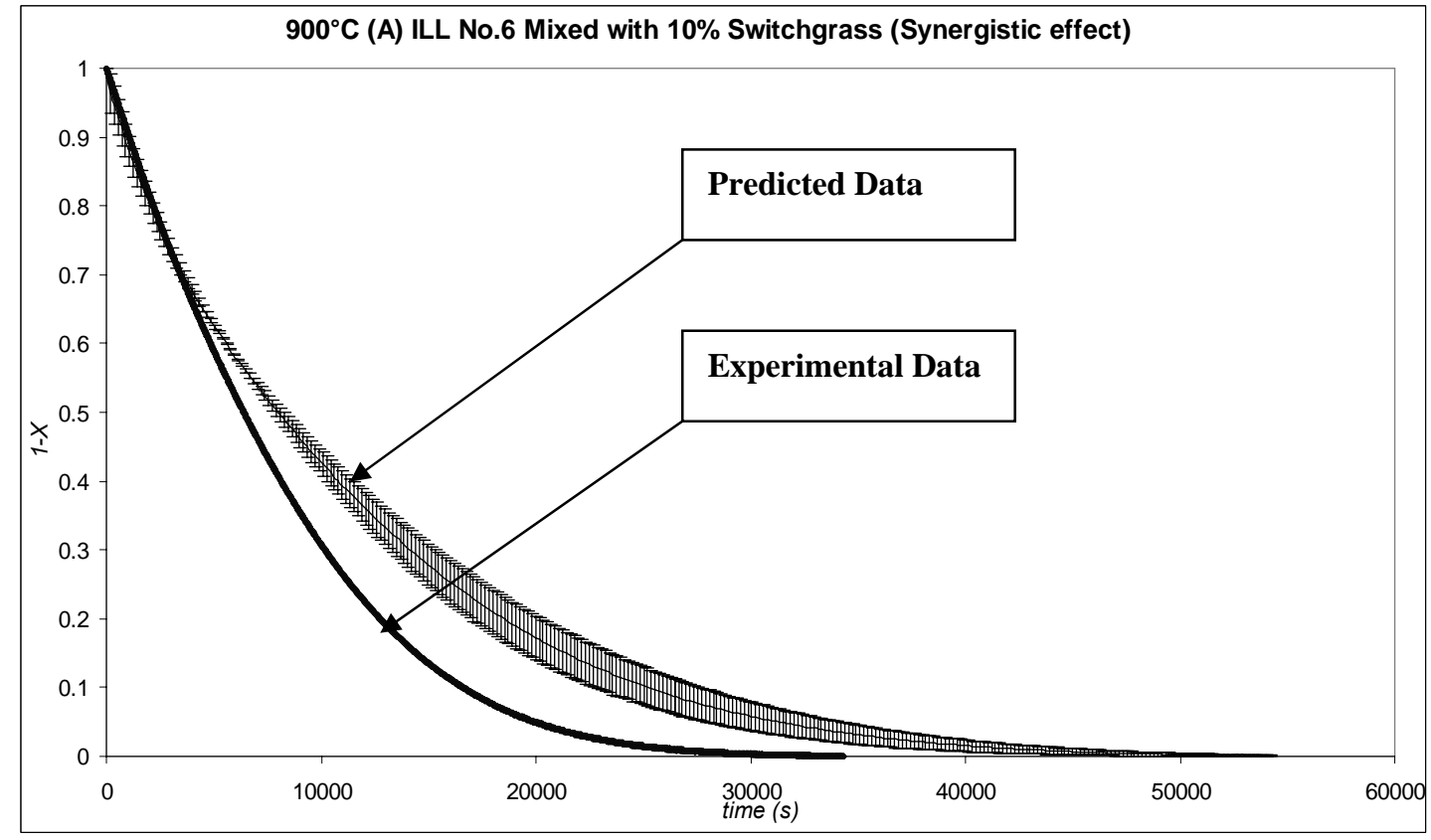

Figure 4.17A Synergistic effect inspection for Group 2 chars $10 \%$ mixture at $900^{\circ} \mathrm{C}, \mathrm{A}$

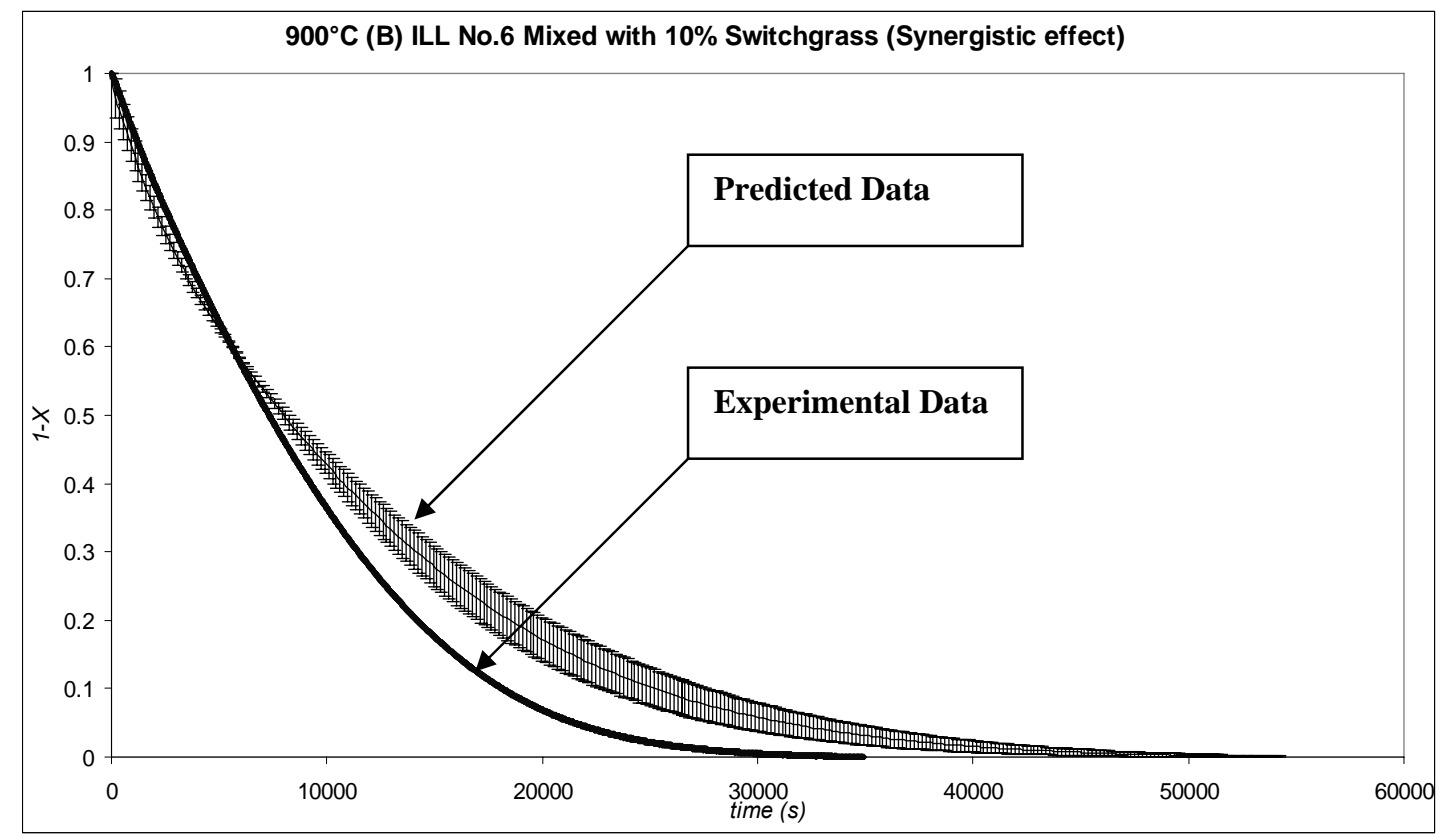

Figure 4.17B Synergistic effect inspection for Group 2 chars $10 \%$ mixture at $900^{\circ} \mathrm{C}, \mathrm{B}$ 


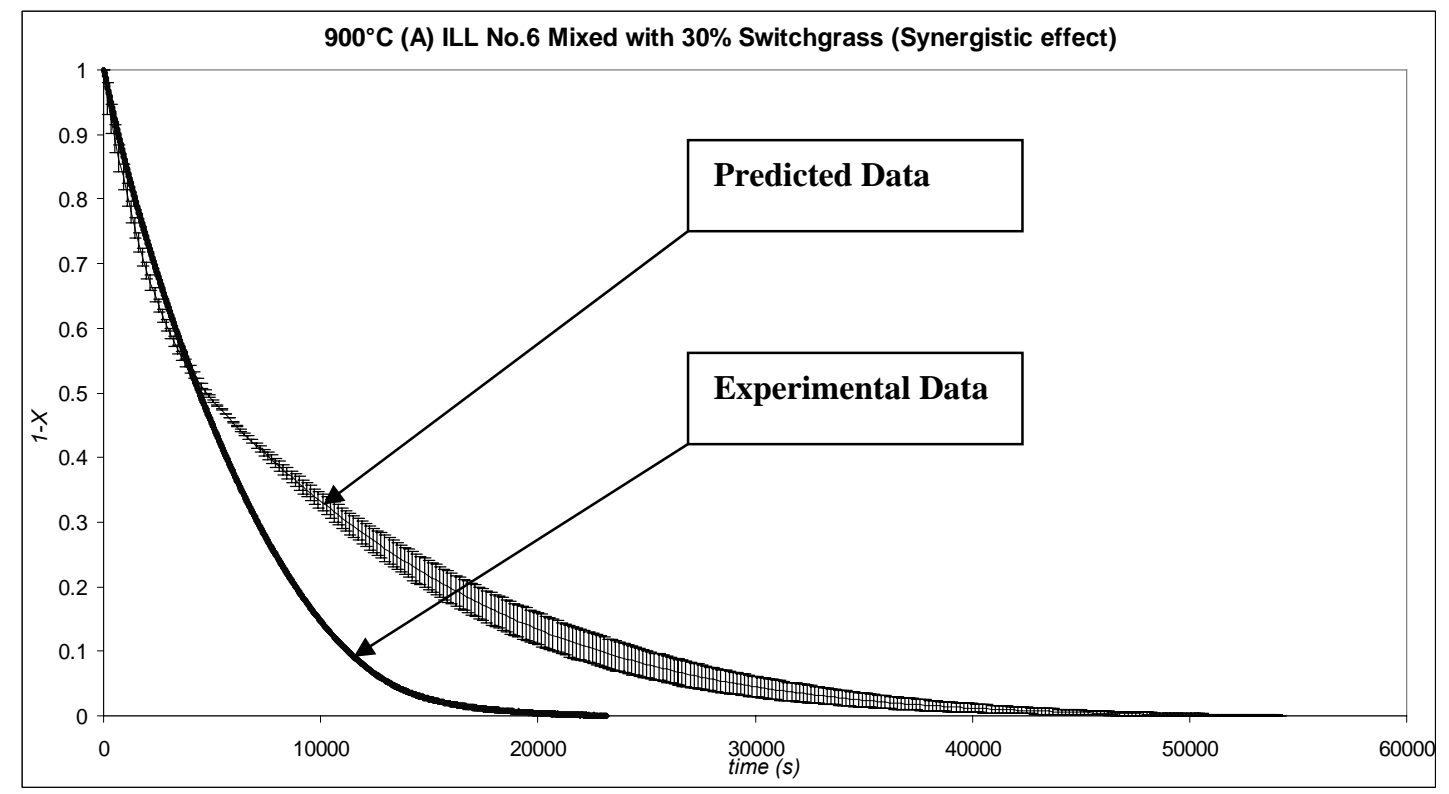

Figure 4.18A Synergistic effect inspection for Group 2 chars $30 \%$ mixture at $900^{\circ} \mathrm{C}, \mathrm{A}$

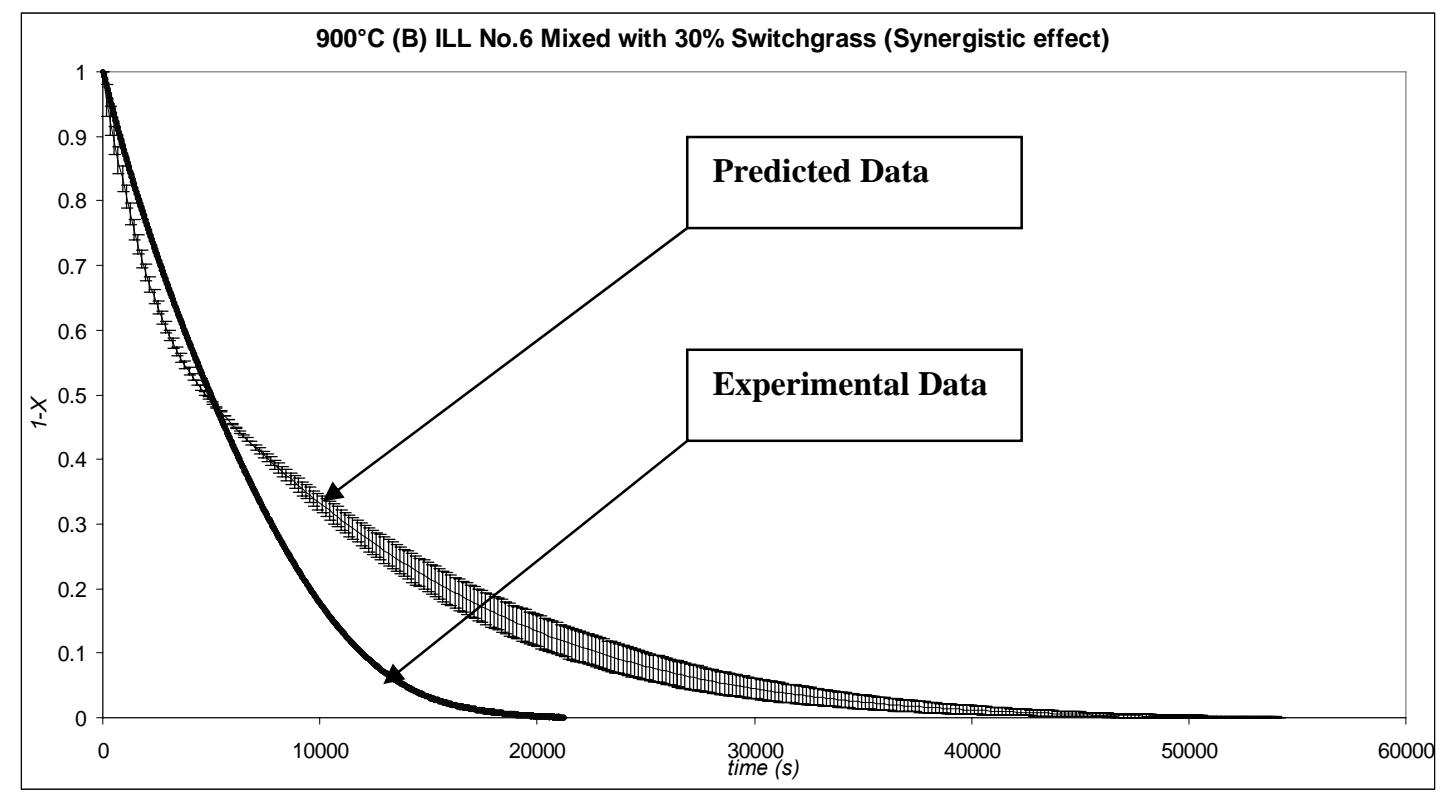

Figure 4.18B Synergistic effect inspection for Group 2 chars $30 \%$ mixture at $900^{\circ} \mathrm{C}, \mathrm{B}$

Figures 4.19 through 4.20 illustrate the synergistic effect for the Group 3 char mixtures (PRB \& Corn Stover) at $900^{\circ} \mathrm{C}$. At the lower mixture ratio of $10 \%$, after $X>0.6$, the experimental curves become slightly lower (i.e. faster kinetics) than the predicted one. For the mixture ratio of $30 \%$, once the $X$ reaches about 0.5 , the predicted kinetics are 
slower than the experimental ones. Detailed plots are displayed in Appendix I for the higher temperature cases, 1000 and $1100^{\circ} \mathrm{C}$, but the values of $X$ where the two curves diverge are different. There is some positive synergistic effect between the mixture char pair of PRB and Corn Stover, and it appears that the higher the mixture ratio of Corn Stover char, the greater the synergistic effect.

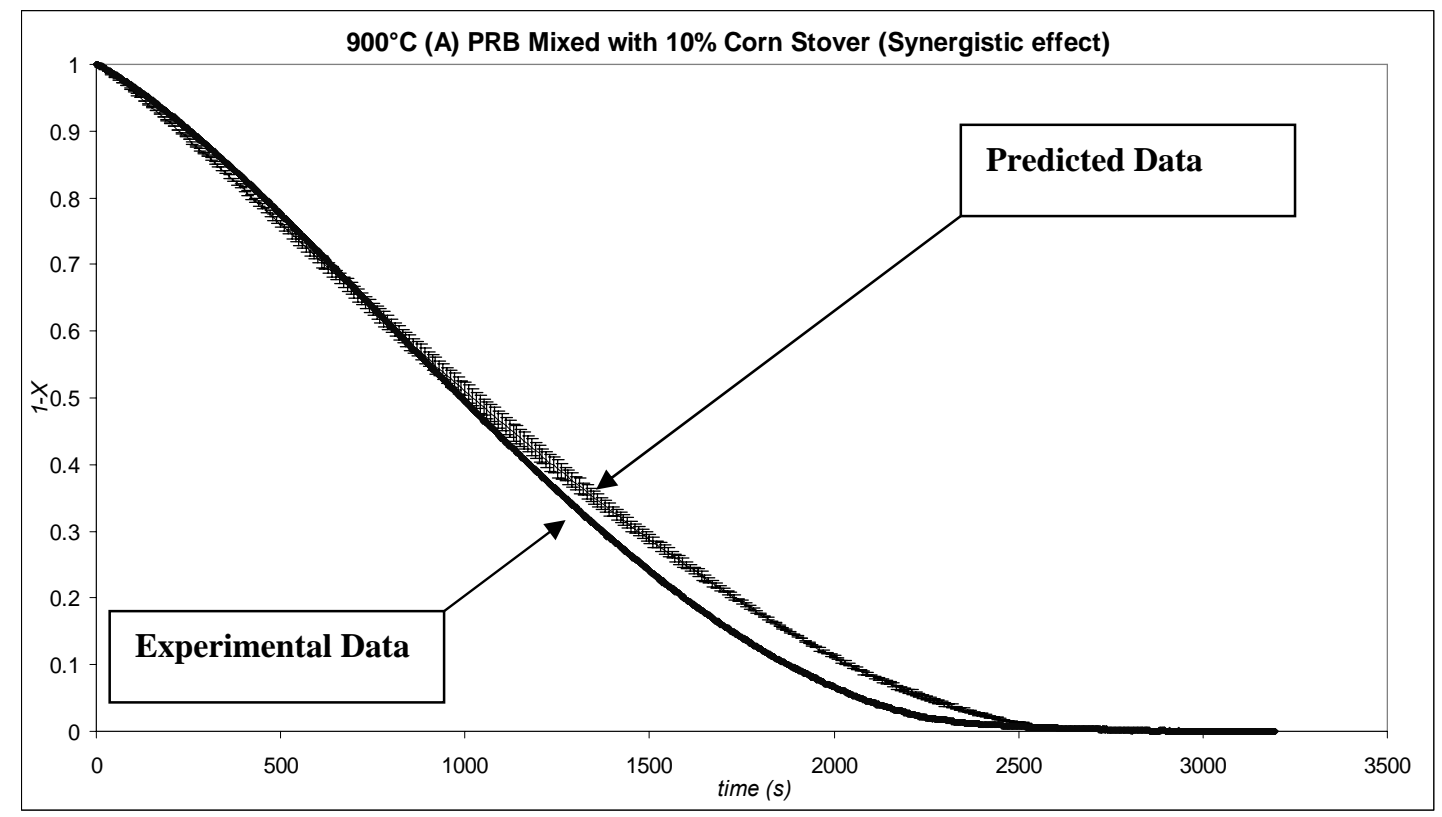

Figure 4.19A Synergistic effect inspection for Group 3 chars $10 \%$ mixture at $900^{\circ} \mathrm{C}, \mathrm{A}$ 


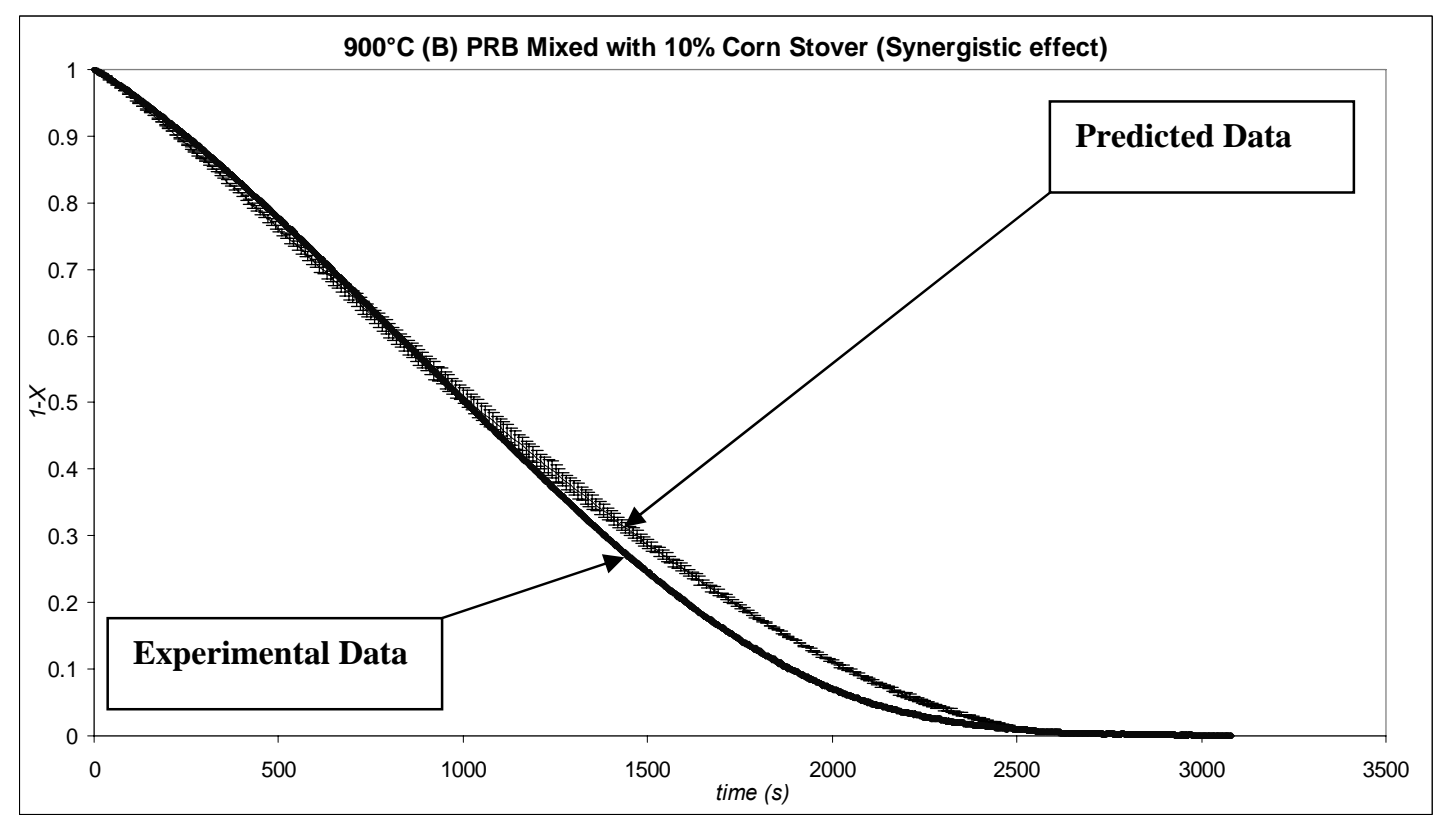

Figure 4.19B Synergistic effect inspection for Group 3 chars $10 \%$ mixture at $900^{\circ} \mathrm{C}$, B

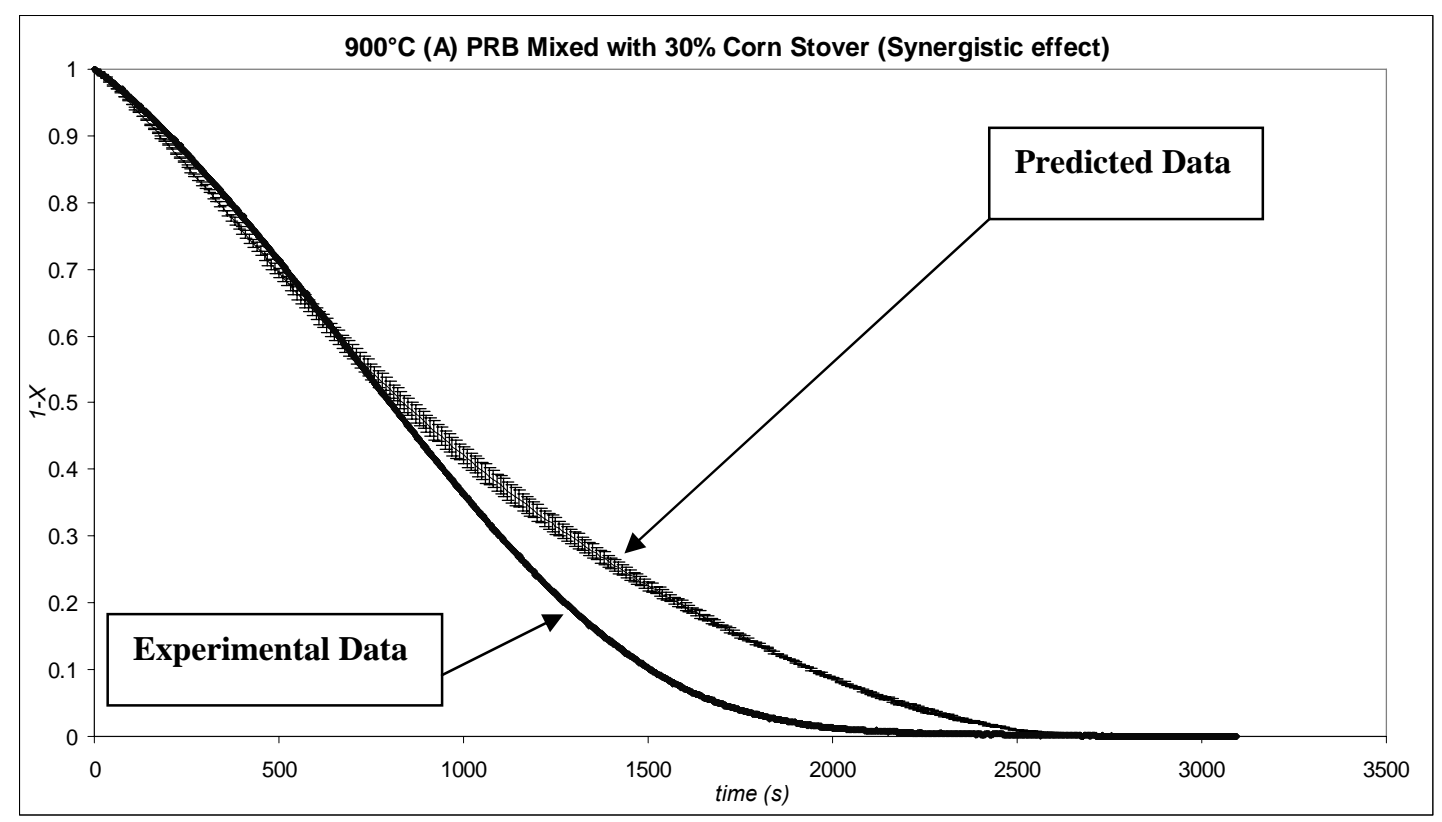

Figure 4.20A Synergistic effect inspection for Group 3 chars $30 \%$ mixture at $900^{\circ} \mathrm{C}$, A 


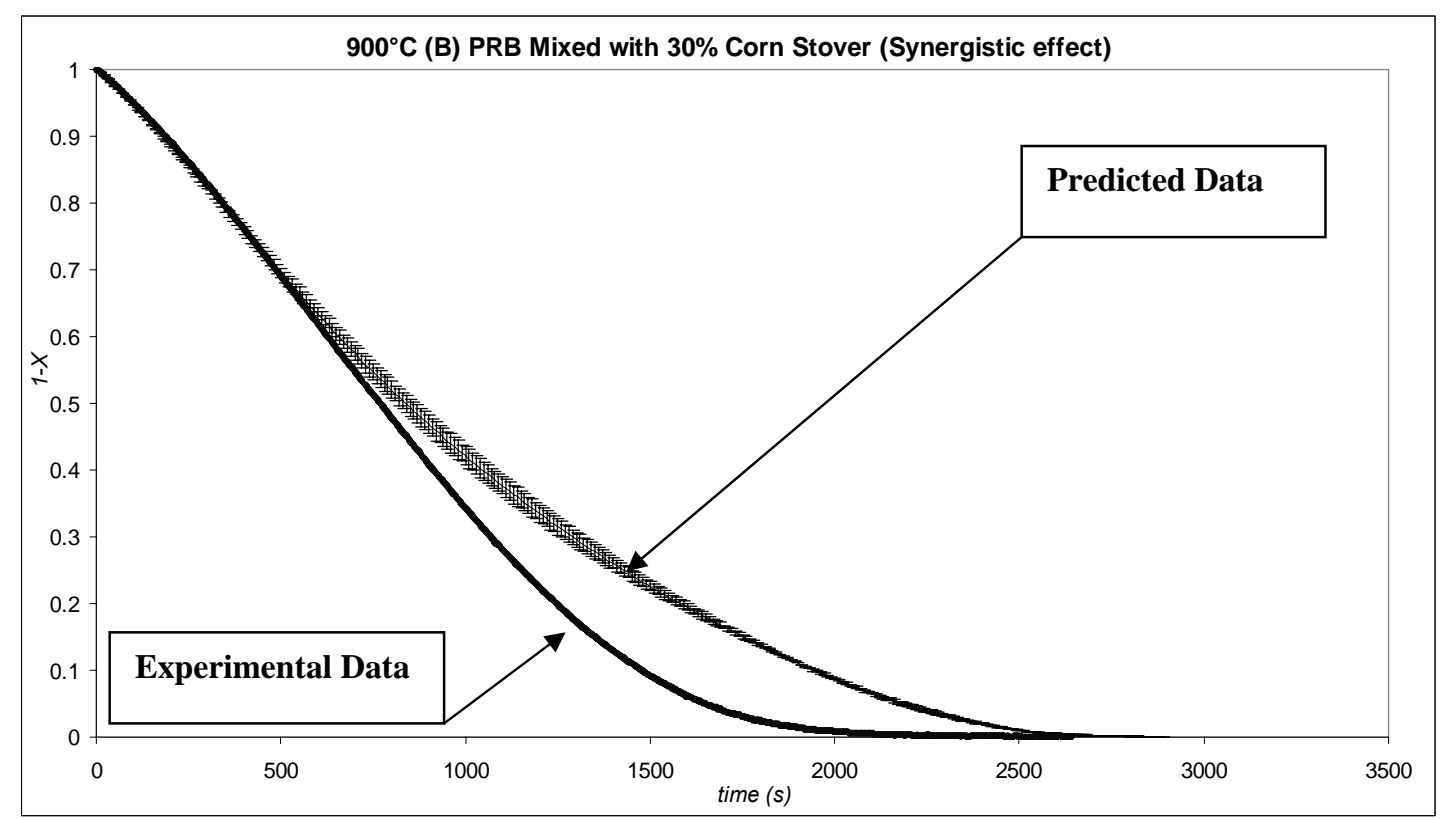

Figure 4.20B Synergistic effect inspection for Group 3 chars $30 \%$ mixture at $900^{\circ} \mathrm{C}, \mathrm{B}$

Figures 4.21 shows the synergistic effect of the Group 4 char mixtures (ILL No.6 \& Hardwood) at $900^{\circ} \mathrm{C}$. Both figures show, for a $30 \%$ mixture ratio case, after $X>0.4$, the experimental kinetics are significantly faster than the predicted one. Thus it is concluded that there is a significant positive synergistic effect between the mixture char pair of ILL No.6 and Hardwood. 


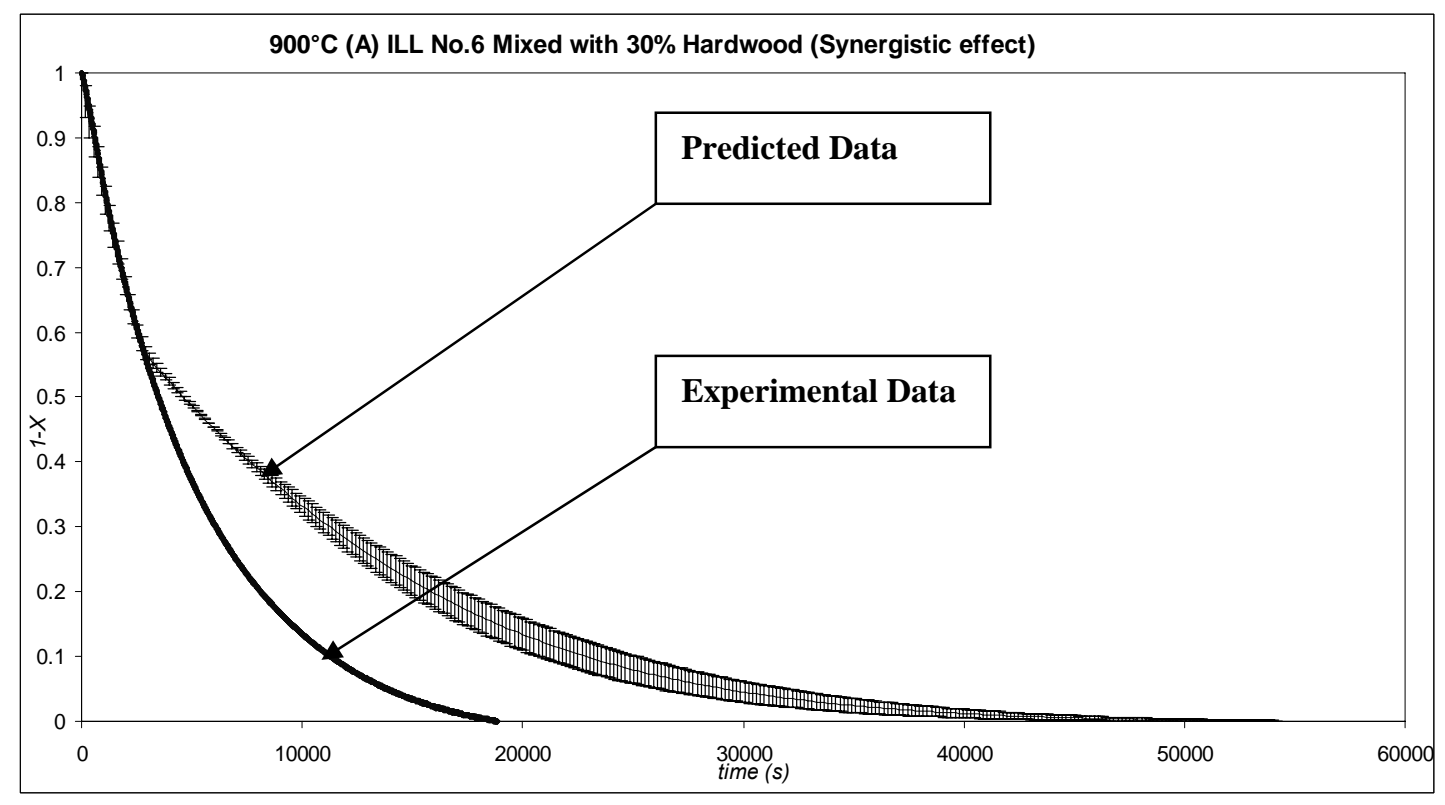

Figure 4.21A Synergistic effect inspection for Group 4 chars $30 \%$ mixture at $900^{\circ} \mathrm{C}, \mathrm{A}$

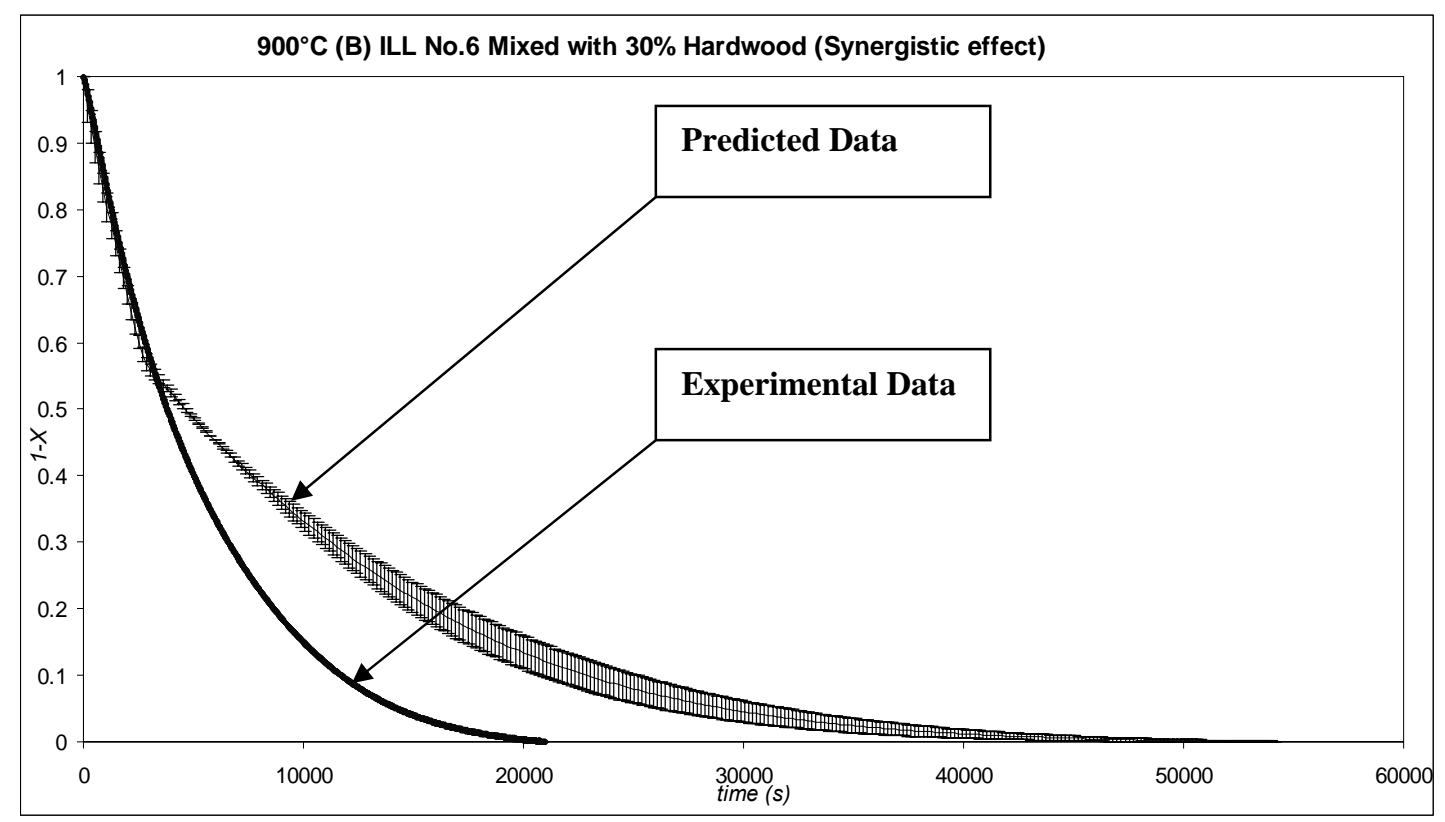

Figure 4.21B Synergistic effect inspection for Group 4 chars $30 \%$ mixture at $900^{\circ} \mathrm{C}, \mathrm{B}$

Figures 4.22 shows the synergistic effect of the Group 5 char mixtures (ND Lignite \& Switchgrass) at $900^{\circ} \mathrm{C}$. The figures show, at the mixture ratio of $30 \%$, before an $X$ value of 0.8 , the experimental and predicted kinetics are almost identical. Only in the final stage of the reaction $(X>0.8)$, the experimental kinetics become faster than the 
predicted one. Thus it is concluded that there is no significant synergistic effect between the char pair of ND Lignite and Switchgrass, neither positive nor negative.

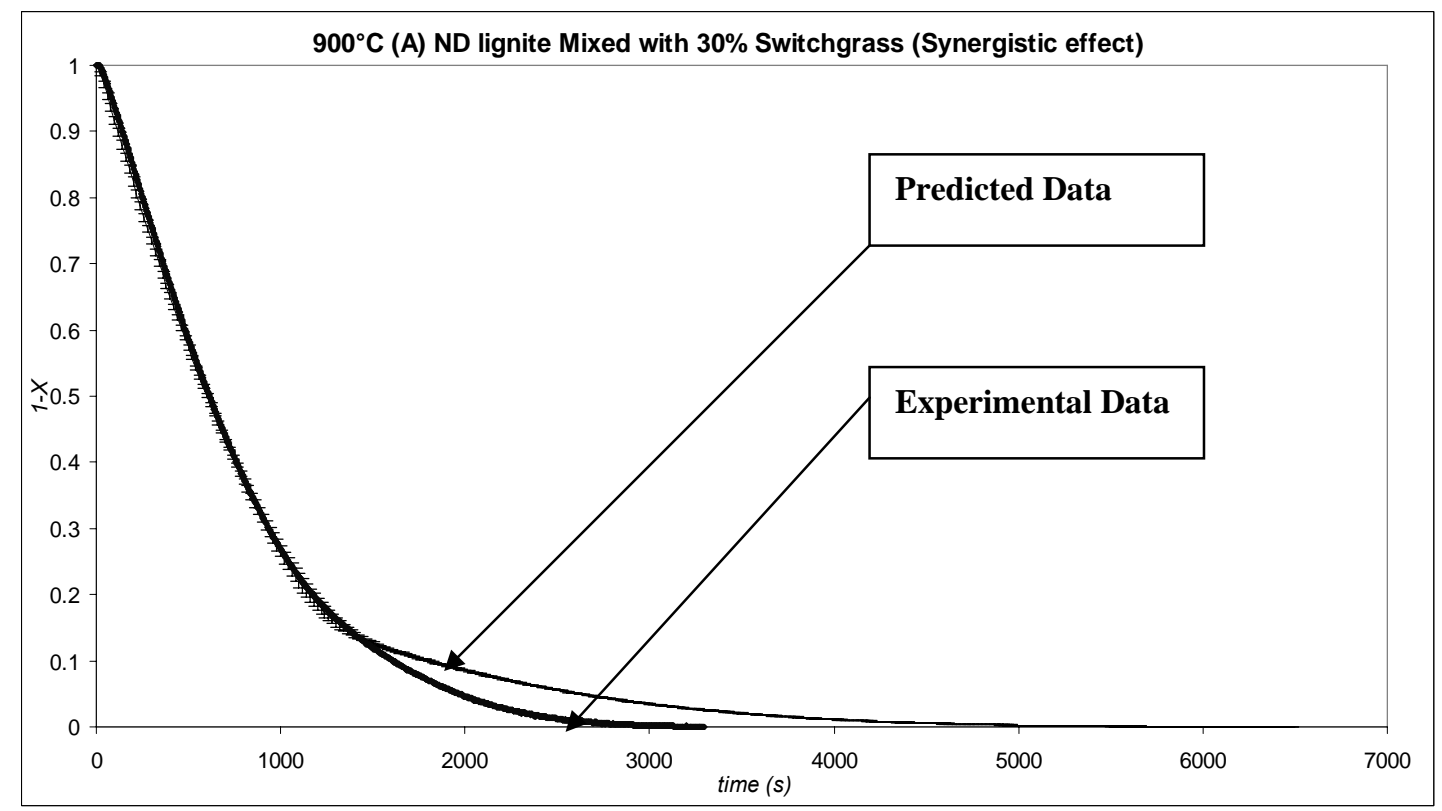

Figure 4.22A Synergistic effect inspection for Group 5 chars $30 \%$ mixture at $900^{\circ} \mathrm{C}, \mathrm{A}$

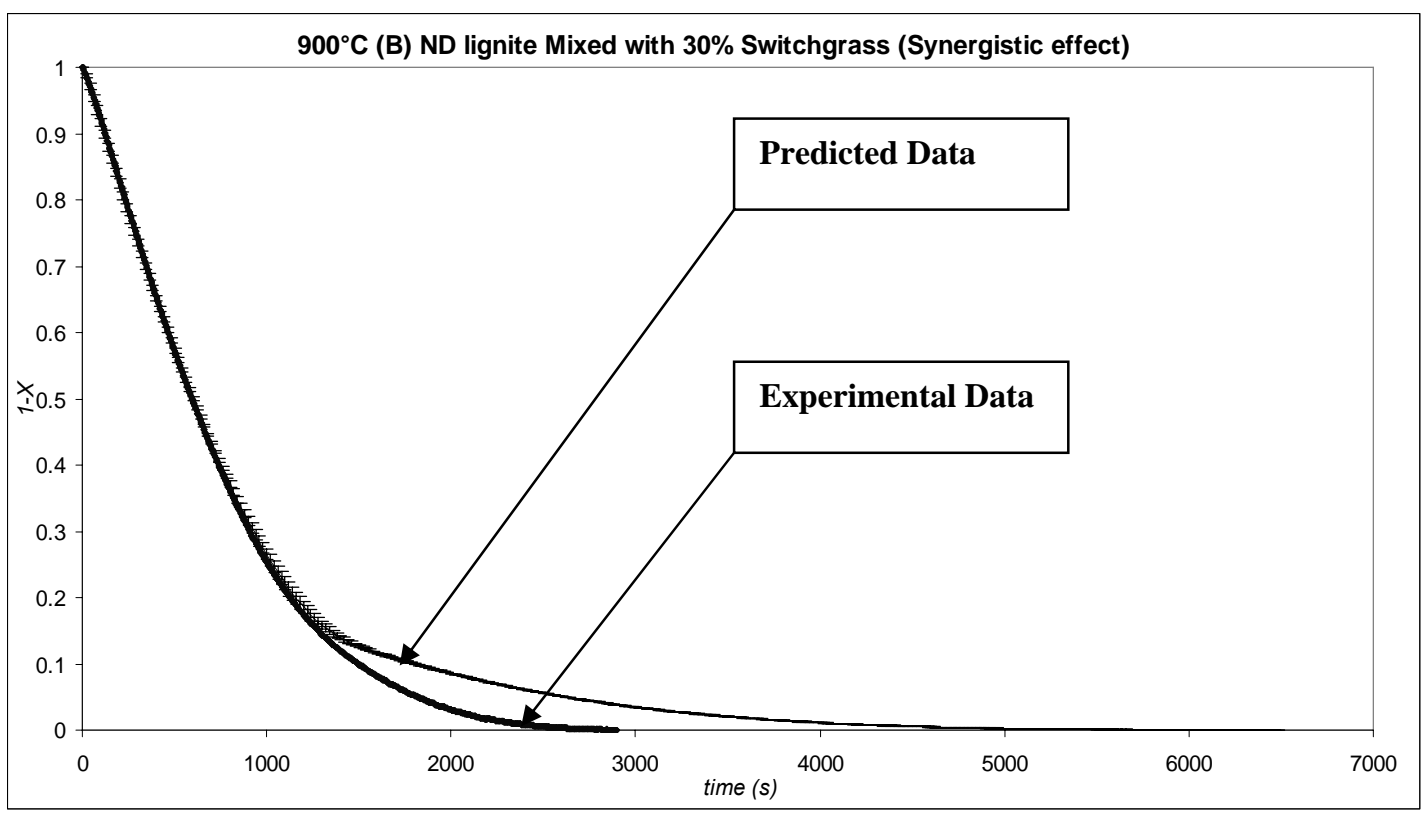

Figure 4.22B Synergistic effect inspection for Group 5 chars $30 \%$ mixture at $900^{\circ} \mathrm{C}$, B 
In summary, the Group 2 char pair (ILL No.6 \& Switchgrass), Group 3 char pair (PRB \& Corn Stover), and Group 4 char pair (ILL No.6 \& Hardwood) show a positive synergistic effect. For the Group 1 char pair (ND Lignite \& Hardwood), a negative synergistic effect is demonstrated. The Group 5 char pair (ND Lignite \& Switchgrass) does not show the synergistic effect at all, neither positive nor positive. It is interesting that all the positive synergistic effects appear only after some "critical" $X$ value, which is different for different char pairs and different temperatures. This may imply that the positive synergistic effect comes out only after the biomass char is close to being totally reacted away.

\subsubsection{The explanation of the synergistic effect between chars pair}

It is well known that plants uptake different minerals from the soil as they grow. For example, it is reported that Switchgrass takes up alkali metals from the soil (Brown et al., 2000). When considering the catalytic effect of these metal species on the gasification reaction, it is postulated that: (1) the char gasification is a catalytic reaction: (2) the positive synergistic effect between char pairs is caused by the additional metals contained in the biomass char.

To support the assumption, the metal content in each of the chars was analyzed by means of Inductively Coupled Plasma - Mass Spectrometry (ICPMS). The measured trace elements include Alkali metals (Group I: Li, Na, K, Rb, Cs) and Alkaline Earth metals (Group II: $\mathrm{Mg}, \mathrm{Ca}, \mathrm{Sr}, \mathrm{Ba}$ ). Previous researchers have reported that these elements show a significant catalytic effect in gasification (Kapteijn and Moulijn, 1986), (Sutton et al., 2001). Kapteijn and Moulijn also reported that the Alkali metal catalysts can lower the apparent activation energy for char gasification with $\mathrm{CO}_{2}$, but the Alkaline Earth catalysts will not affect the apparent activation energy. Although the catalytic activity of each metal should not be equal, here for purpose of argument, it is assumed that the effect is the same for each of the metal elements. The analytical results from the ICPMS are listed in the Table 4.13. Also a comparison of the total amount of Alkali and Alkaline Earth elements for each char is made in Figure 4.23. 
Table 4.13 ICPMS Spectrometry analysis results ${ }^{*}$

\begin{tabular}{|c|c|c|c|c|c|c|c|}
\hline \multirow{2}{*}{ Char Type } & \multicolumn{6}{|c|}{$\begin{array}{c}\text { Group I (Alkali Metal) } \\
\text { Amount (ppm) }\end{array}$} & \multicolumn{4}{|c|}{ Group II (Alkaline Earth Metal) } & \multirow{2}{*}{$\begin{array}{c}\text { Sum } \\
\text { (ppm) }\end{array}$} \\
\cline { 2 - 7 } & $\mathrm{Na}$ & $\mathrm{K}$ & $\mathrm{Mg}$ & $\mathrm{Ca}$ & $\mathrm{Sr}$ & $\mathrm{Ba}$ & \\
\hline ILL No.6 & 129 & 112 & 58 & 5127 & 184 & 618 & 6228 \\
\hline Switchgrass & 401 & 8107 & 1641 & 9245 & 137 & 1015 & 20546 \\
\hline ND Lignite & 7300 & 326 & 3832 & 16617 & 116 & 545 & 28736 \\
\hline Hardwood & 580 & 7849 & 1526 & 8737 & 213 & 674 & 19579 \\
\hline PRB & 1571 & 165 & 256 & 1415 & 148 & 322 & 3877 \\
\hline Corn Stover & 1574 & 12764 & 3733 & 11408 & 69 & 82 & 29630 \\
\hline
\end{tabular}

Note:

* The analysis was done in National Research Center for Coal and Energy (NRCCE) at WVU..

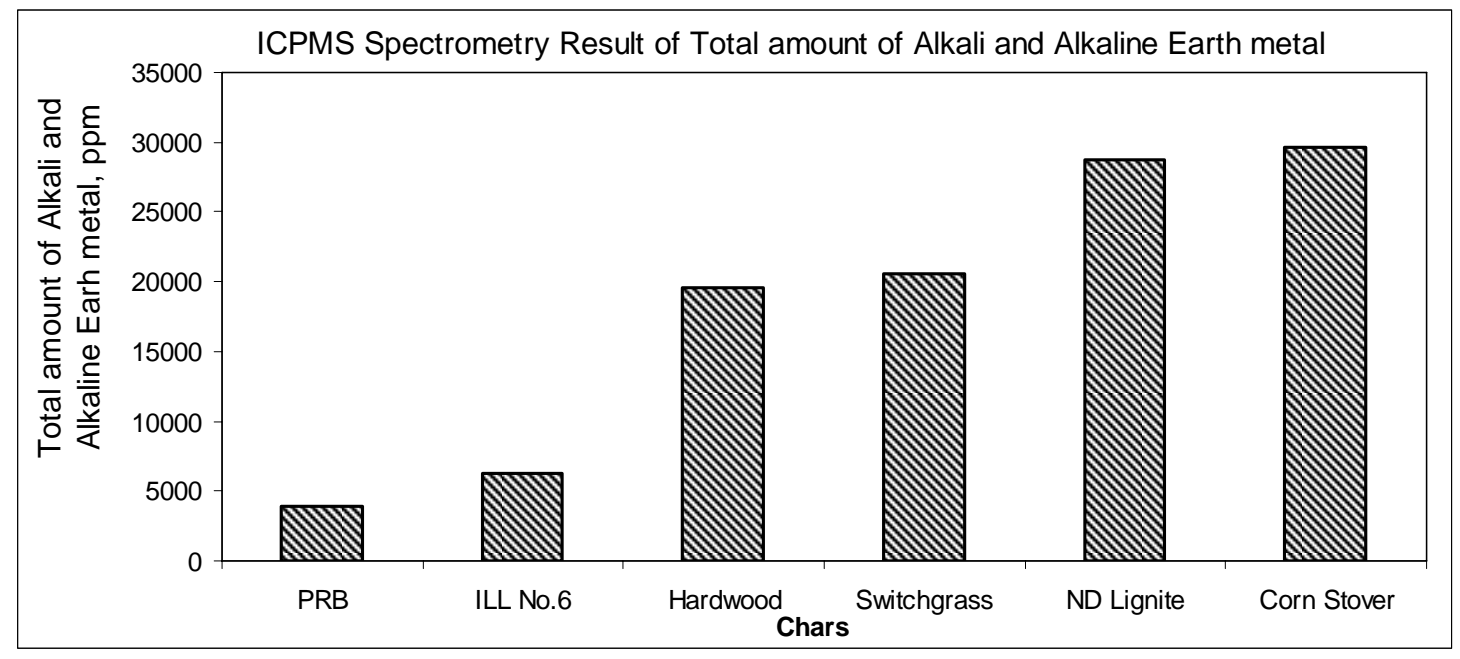

Figure 4.23 Comparison the total amount of Alkali and Alkaline Earth metal

As shown in the Figure 4.23, the decrease of the total amount of catalytic metal for these 6 chars follows the sequence:

$$
(\text { ND lignite } \approx \text { Corn Stover })>(\text { Switchgrass } \approx \text { Hardwood })>\text { Ill No. } 6>P R B
$$

It is noticeable that this sequence of the total metal amount is nearly identical to the decreasing reaction rate sequence for the six chars as described in equation [4.19], except that the reaction rate of PRB is larger than ILL No.6. Further, if the amount of Magnesium is compared separately with respect to the different pure chars, then as shown in the Figure 4.24, the $\mathrm{Mg}$ content decline sequence is exactly the same as the reaction rate decline sequence: 
$($ Corn Stover $\approx$ ND lignite $) \geq$ Switchgrass $>($ Hardwood $\approx P R B)>$ Ill No.6

This "coincidence" implies that it may be the amount of catalytic metals of the char, and especially the amount of Magnesium, that influences the reaction rate most significantly.

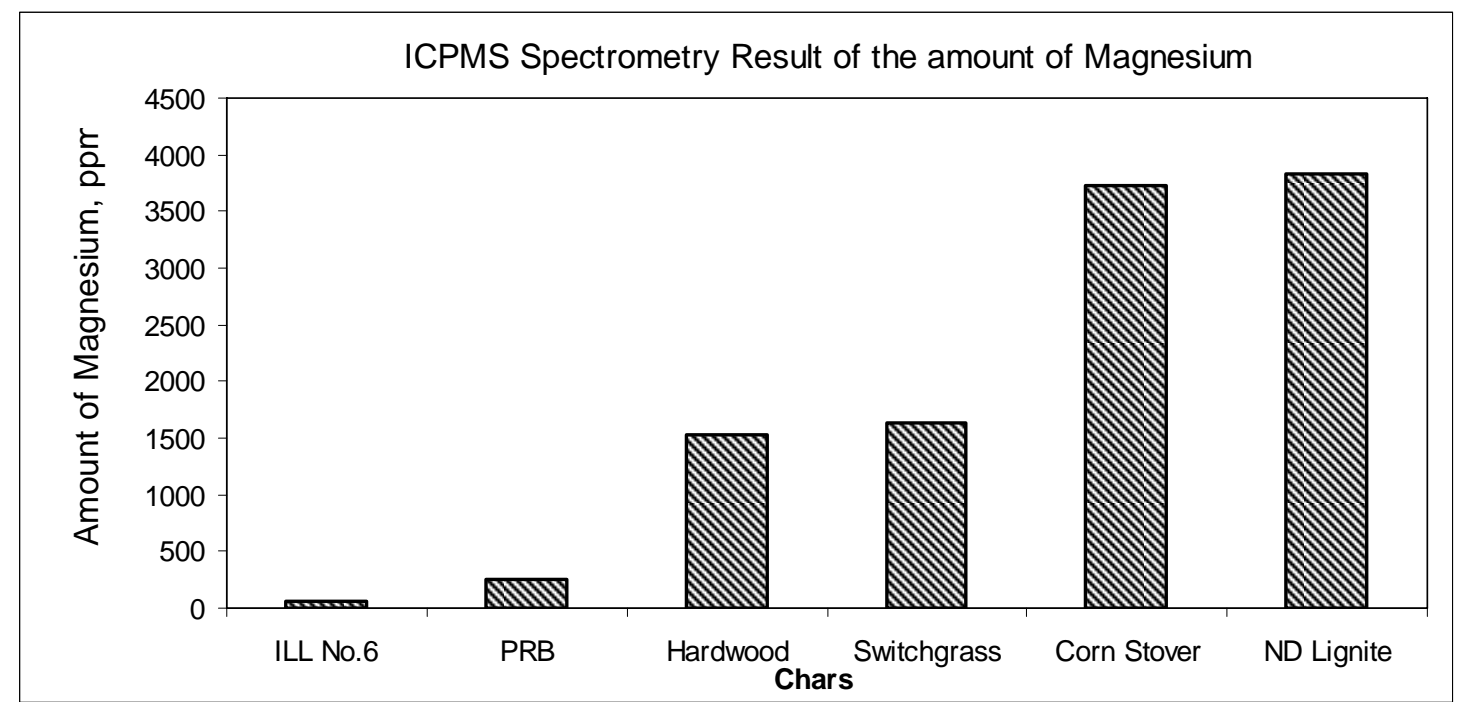

Figure 4.24 Comparison the Magnesium amount in six pure char

At a given reaction temperature, one of the general observations for a catalytic reaction is that the activity of a catalyst increases with the concentration of the catalyst to an optimum maximum, and beyond that maximum no further gain is made in the reaction rate (Berkowitz, 1985). From this point view, the similarity of the two reaction sequences ([4.19] and [4.25]) and the correlation shown in Figure 4.13, 4.14 supports the first postulate above that the char gasification is a catalytic reaction; and one of the determining factors for the reaction rate is the amount of the catalytic material present in the reacting char mixture.

As mentioned in the reference by Huggins (Huggins et al. , 1989), the initial state of the catalytic metal in the lignite char is as an organic complex. In this stage for example, some of the metal cations are bound in lignite by carboxyl groups so that they do not demonstrate initial catalytic activity. With the progress of the reaction, the complexes are decomposed and the minerals are transformed into the metal state, which does show some catalytic effect according to the "vapor cycle" mechanism (described in section Chapter 2.4). 
It is noted that for those pairs exhibiting a positive synergistic effect, Groups 2, 3, and 4, the coal chars ILL No.6 and PRB have a slower reaction rate. But for Groups 1, 5, since the ND lignite coal char has a faster rate, there is no positive synergistic effect demonstrated at all. It seems that the slower the reaction rate of coal char, the greater is the positive synergistic effect. The explanation for this phenomenon is that the catalytic metal (special for $\mathrm{Mg}$ ) contents in ILL No.6 or PRB coal char are far lower than the amount in ND lignite coal char or in three biomass chars. When ILL No.6 or PRB coal chars are mixed with biomass chars, the biomass char shows a faster reaction rate than the coal char. Once the faster char finishes the reaction, its catalytic metals still have a catalytic impact on the slower and currently reacting coal char. For the slower char, this increase of the catalytic metals causes an extra increase of the reaction rate, thus the "positive synergistic effect". On the other hand, since the ND lignite char contained a higher amount of catalytic metal than Switchgrass or Hardwood char, it shows a faster reaction rate than the biomass char. When ND lignite char is mixed with biomass char, there is no additional catalytic metal contributed by the biomass char and hence no positive synergistic effect is demonstrated. This explanation can also account for the phenomenon that the positive synergy is manifested only after the biomass char totally burns out. This observation supports the second postulate above: the positive synergistic effect between char pairs is caused by the additional metals contained in the biomass char.

The apparent activation energy, $E_{a p p}$, for the mixed char pair of Group 2 (ILL No. 6 \& Switchgrass) and Group 3 (PRB \& Corn Stover) also show a positive synergistic effect. Here, Prediction Model B is employed to predict the $E_{a p p}$ for the char reaction of the mixture, which is described as follows:

$$
E_{\text {app_predicted }}=\left(1-R_{\text {Biomass }}\right) \cdot E_{\text {app_coal }}+R_{\text {Biomass }} \cdot E_{\text {app_biomass }}
$$

where $E_{\text {app_predicted }}$ is the predicted value; $E_{\text {app_coal }}$ and $E_{\text {app_biomass }}$ values come from the regression analysis of data for the pure coal and biomass char; $R_{\text {Biomass }}$ is the weight mixture of the biomass char. A list and comparison of the $E_{\text {app_experimental }}$ and $E_{\text {app_predicted }}$ is shown in Table 4.14. 
Table 4.14 Apparent activation energy comparison for Group 2 and 3 char mixtures

\begin{tabular}{|c|c|c|c|c|c|}
\hline \multirow{3}{*}{ Group } & \multirow{2}{*}{ Chars } & \multicolumn{2}{|c|}{ Model 5 } & \multicolumn{2}{c|}{ Model 10 } \\
\cline { 3 - 6 } & ${ }^{*} E_{\text {app }}$ & $\begin{array}{c}{ }^{*} \text { PJedication } \\
\text { Model B(KJ/mol })\end{array}$ & $\begin{array}{c}{ }^{*} E_{a p p} \\
(\mathrm{KJ} / \mathrm{mol})\end{array}$ & $\begin{array}{c}{ }^{*} \text { Predication } \\
\text { Model B (KJ/mol) }\end{array}$ \\
\hline \multirow{3}{*}{2} & ILL No.6 & 194.28 & 194.28 & 194.02 & 194.02 \\
\cline { 2 - 6 } & Switchgrass & 171.2 & 171.2 & 171.18 & 171.18 \\
\cline { 2 - 6 } & Mixed 10\% & $\mathbf{1 9 0 . 4 6}$ & 191.97 & $\mathbf{1 8 9 . 6 1}$ & 191.74 \\
\cline { 2 - 6 } & Mixed 30\% & $\mathbf{1 8 0 . 4 8}$ & 187.36 & $\mathbf{1 7 8 . 7 3}$ & 187.17 \\
\hline \multirow{3}{*}{3} & PRB & 132.63 & 132.63 & 131.99 & 131.99 \\
\cline { 2 - 6 } & Corn Stover & 117.74 & 117.74 & 117.99 & 117.99 \\
\cline { 2 - 6 } & Mixed 10\% & $\mathbf{1 3 0 . 7 5}$ & 131.14 & $\mathbf{1 3 0 . 4 9}$ & 130.59 \\
\cline { 2 - 6 } & Mixed 30\% & $\mathbf{1 2 3 . 0 1}$ & 128.16 & $\mathbf{1 2 2 . 9}$ & 127.79 \\
\hline
\end{tabular}

Note:

* Here, the $E_{a p p}$ values are regressed from experiments, termed as $E_{\text {app_experimental }}$;

** The $E_{a p p}$ values are predicted by Predication Model B, termed as $E_{\text {app predicted }}$.

The results in Table 4.14 for either Model 5 or Model 10, show that for the Group 2 and Group 3 char mixtures, the experimental values ( $\left.E_{\text {app_experimental }}\right)$ are either equal to or less than the predicted values ( $\left.E_{\text {app_predicted_ }}\right)$. With the increasing amount of biomass, the apparent activation energies decrease further than the predication. According to the transition-state theory, a catalyst reduces the potential energy barrier, which is related to $E_{a p p}$. The decrease of the apparent activation energy promotes the enhanced catalytic activity, which is caused by the extra catalytic effects of the metal. The investigation of the $E_{a p p}$ gives additional support to the second postulate that the positive synergistic effect between char pairs is caused by the additional metal contained in the biomass char.

While the above explanation of the catalytic effects of the metal on the gasification rate of the char mixture does seem to elucidate the synergistic effect, it is far from definitive. Other physical properties (which were ignored here) such as particle size, porosity, surface area, etc, no doubt contribute to the observed gasification rate. A detailed study of these effects is left for future work. 


\section{Chapter 5 Conclusion}

Based on experimental data from Thermogravimetric Analysis (TGA) experiments, a kinetic analysis of the Boudouard reaction is studied for three different coal chars, three different biomass chars, and their selected mixtures. The coal chars include: North Dakota Lignite char (ND Lignite), Illinois No.6 char (ILL No.6), and Powder River Basin char (PRB). The biomass chars include: Hardwood char (Hardwood), Switchgrass char (Switchgrass), and Corn Stove char (Corn Stove). The char mixtures include: Group 1 (ND Lignite \& Hardwood), Group 2 (ILL No.6 \& Switchgrass), Group 3 (PRB \& Corn Stover), Group 4 (ILL No.6 \& Hardwood), and Group 5 (ND Lignite \& Switchgrass). The main conclusions drawn from this work are listed below:

1) After a series of experiment evaluations, it was determined the experimental conditions which exclude the external mass transfer effects were: sample weight of $50 \mathrm{mg}$ and $\mathrm{CO}_{2}$ flow rate of $118 \mathrm{ml} / \mathrm{min}$ for a $W / F=0.43$;

2) A total of four kinetic models were selected to fit the reaction data, $X v s$. $t$; the models included: Model 5 (Simplified Dutta and Wen model), Model 7 (Chornet model), Model 10 (modified shrinking sphere model), and the Initial Rate Model. The simplified formulation of the char gasification rate expression can be described as: $\frac{d X}{d t}=k_{a p p} \frac{P_{\mathrm{CO}_{2}}}{R T}(1-X)^{n}$. For the Model 5, $n$ equals one; and for Model $10 n$ equals 2/3;

3) Using the integral, differential, and least squares regression methods, kinetic parameters were obtained based on the three different models (Model 5, Model 10, and the Initial Rate Model) for each char. The kinetic parameters included: the apparent rate constant $k_{a p p}$, and the apparent activation energy $E_{a p p}$;

4) A comparison of the fitting quality for the three different models (Model 5, 7, 10), found that Model 10 was the best one for most of chars, while Model 7 was the worst one. Meanwhile, the use of an Initial Rate Model provided additional information for the initial stage of the reaction; 
5) A comparison of the reaction rates for the pure chars revealed the following reaction rate sequence:

$($ Corn Stover $\approx$ ND lignite $) \geq$ Switchgrass $>($ Hardwood $\approx$ PRB $)>$ Ill No.6.

6) It is found that the apparent rate constant varies linearly with the mixture weight ratio of the biomass in the coal/biomass mixture. This is true for Group 2 and 3 mixtures where a positive synergistic effect was observed;

7) Using Prediction Model A, the synergistic effect between coal char and biomass char pairs was examined. The results show that the Group 2 char pair (ILL No.6 \& Switchgrass), Group 3 char pair (PRB \& Corn Stover), and Group 4 char pair (ILL No.6 \& Hardwood) all exhibit a positive synergistic effect. Meanwhile, the Group 1 char pair (ND Lignite \& Hardwood) shows a negative synergistic effect;

8) Based on ICPMS data, plots of Prediction Model A, and the apparent activation energy data of Prediction Model B give a reasonable explanation for the positive synergistic effect. It was found that the positive synergistic effect of the reaction rate for the char mixtures correlated well with the amount of Alkali and Alkaline Earth metals bound in the biomass chars, and Magnesium appeared to be especially significant. 


\section{Future Work}

1. As mentioned above, the synergistic effects are correlated with the amount of catalytic metal contained in the char and the positive synergistic effect between char pairs is caused by the additional metal contained in the biomass char. However, for Group 1 char pair (ND Lignite \& Hardwood), a negative synergistic effect is noted. The metal amount difference in chars can not account for the negative synergistic effect. A further investigation should be done into this problem.

2. To explain the catalytic activity of Alkali and Alkaline earth metal, it was mentioned in Chapter 4.5.4 that the metal status in the char may be as an organic complex. This explanation is not always true for most of mineral matter in the coal. For example, Parenti reported in his thesis that there are four major mineral types in the coal: aluminosilicates, oxides, carbonates, and sulfides or sulfate, all of which are inorganic (Parenti, 2009). For those inorganic Alkali and Alkaline earth metals, during gasification, they first have to lose their interaction with lattice oxygen species and then migrate into the carbon matrix. Consequently, the catalytic effect is delayed and only part of the catalyst metal is active for reaction in the initial stage (Meijer et al., 1991). However, there is no information about the detailed status of those catalytic metals in chars, neither the coal chars nor the biomass chars. To understand fully the catalytic effect or synergistic effect, it is necessary to investigate the metal status and their surroundings in the molecules as a char.

3. The presence of external mass transfer needs to be investigated further along with the effects of the structural parameters of the char. The relationship between these and the reaction rate can then be determined. 


\section{Bibliography}

1. Adjorlolo, A. A., and Rao, Y. K. (1984). "Effect of Potassium and Sodium Carbonate Catalysts on the Rate of Gasification of Metallurgical Coke", Carbon, 22(2), 173176.

2. Berkowitz, N. (1985). "The Chemistry of Coal", Elsevier Science Publishers, Amsterdam, Oxford, New York, Tokyo, 367-369.

3. Bhatia, S. K., and Perlmutter, D. D. (1980). "A Random Pore Model for Fluid-Solid Reactions: 1. Isothermal, Kinetic Control", A. I. Ch. E. Journal, 26(3), 379-386.

4. Blackwood, J. D., and Ingeme, A. J. (1960). "The Reaction of Carbon with Carbon Dioxide at High Pressure", Australian Journal of Chemistry, 13(2), 194-209.

5. Brown, R. C., Liu, Q., and Norton, G. (2000). "Catalytic Effect Observed During the Co-gasification of Coal and Switchgrass", Biomass and Bioenergy, 18, 499-506.

6. Chen, S. G., and Yang, R. T. (1997). "Unified Mechanism of Alkali and Alkaline Earth Catalyzed Gasification Reactions of Carbon by $\mathrm{CO}_{2}$ and $\mathrm{H}_{2} \mathrm{O}$ ", Energy \& Fuels, $\underline{11}, 421-427$.

7. Chornet, E., Baldasano, J. M., and Tarki, H. T. (1979). "Kinetic Expressions for Coal Char-gas Reaction", Fuel, 58(5), 395-396.

8. Dayton, D. C., French, R. J., and Milne, T. A. (1995). "Direct Observation of Alkali Vapor Release During Biomass Combustion and Gasification: 1. Application of Molecular Beam/Mass Spectrometry to Switchgrass Combustion", Energy \& Fuels, $\underline{9}, 855-865$.

9. Doraiswamy, L. K., and Sharma, M. M. (1984). "Heterogeneous Reactions: Analysis, Examples, and Reactor Design Volume 1: Gas-Solid and Solid-Solid Reactions", John Willey \& Sons, New York Chichester Brisbane Toronto Singapore, 1- 298.

10. Dutta, S., Wen, C. Y., and Belt, R. J. (1977). "Reactivity of Coal and Char: 1. In Carbon Dioxide Atmosphere", Industrial and Engineering Chemistry Process Design and Development, 16(1), 20-30.

11. Ergun, S. (1956). "Kinetics of the Reaction of Carbon with Carbon Dioxide", The Journal of Physical Chemistry, 60(4), 480-485.

12. Ergun, S., and Mentser, M. (1965). "Reactions of Carbon with Carbon Dioxide and Steam", Chemistry and physics of carbon, 1, 203-263.

13. Fogler, H. S. (1999). "Elements of Chemical Reaction Engineering", Third Edition, Prentice Hall PTR.

14. Gadsby, J., Long, F. J., Sleightholm, P., and Sykes, K. W. (1948). "The Mechanism of the Carbon Dioxide-Carbon Reaction", Proceedings of the Royal Society (London), A193, 357.

15. Given, P. H. (1984). "An Essay on the Organic Geochemistry of Coal", Coal Science, Gorbaty, M. L., Larsen, J. W., and Wender, I., Academic Press, Inc., 67.

16. Graboski, M. (1979). "Kinetics of Char Gasification Reactions", Solar Energy Research Institute / DOE, Golden, Colorado 
17. Higman, C., and Burgt, M. v. d. (2008). "Gasification", Second Edition, Gulf Professional Publishing, 1-9.

18. Huggins, F. E., Huffman, G. P., and Jenkins, R. G. (1989). "In Situ XAFS Studies of Catalyzed Pyrolysis and Gasification Reaction of Lignite," Physica B, 158, 178179.

19. IPCC. (2007). "Climate Change 2007: Mitigation of Climate change, Chapter 1: Introduction", IPCC Working Group III, http://www.ipcc.ch.

20. Johnson, J. L. (1979). "Kinetics of Coal Gasification", John Wiley \& Sons, Inc., New York.

21. Joshi, M. M., and Lee, S. (1996). "Integrated Gasification Combined Cycle: A Review of IGCC Technology," Energy Sources, Part A, 18(5), 537-568.

22. Kapteijn, F., and Moulijn, J. A. (1986). "Kinetics of Catalysed and Uncatalysed Coal Gasification", Carbon and Coal Gasification: Science and Technology, Figueiredo, J. L. and Moulijn, J. A., Martinus Mijhoff Publishers, Dordrecht, 291354.

23. Levenspiel, O. (1972). "Chemical Reaction Engineering", Second, John Wiley \& Sons, Inc., New York, 357-377.

24. Liliedahl, T., and Sjostrom, K. (1997). "Modeling of Char-gas Reaction Kinetics," Fuel, 76(1), 29-37.

25. Mahajan, O. P., Yarzab, R., and Walker, P. L. (1978). "Unification of Coal-char Gasification Reaction Mechanisms", Fuel, 57(10), 643-646.

26. Meijer, R., Weeda, M., Kapteijn, F., and Moulijn, A. (1991). "Catalyst Loss and Retention During Alkali-Catalysed Carbon Gasification in $\mathrm{CO}_{2}$ ", Carbon, 29, 929-941.

27. Mims, C. A., and Pabst, J. K. (1987). "Alkali-Catalyzed Carbon Gasification Kinetics: Unification of $\mathrm{H}_{2} \mathrm{O}, \mathrm{D}_{2} \mathrm{O}$, and $\mathrm{CO}_{2}$ Reactivities", Journal of Catalysis, $\underline{107}, 209-220$.

28. Moore, D. S., and McCabe, G. P. (2002). "Introduction to The Practice of Statistics" Fourth, W. H. Freeman and Company, New York.

29. NETL. (2007). "Gasification World Database 2007", NETL USDOE

30. Parenti, J. A. (2009). "Thermo-gravimetric analysis of $\mathrm{CO}_{2}$ induced gasification upon selected coal/biomass chars and blends", Master of Science, West Virginia University, Morgantown.

31. Park, J. Y., and Levenspiel, O. (1975). "The Crackling Core Model for the Reaction of Solid Particles", Chemical Engineering Science, 30, 1207-1214.

32. Petersen, E. E. (1957). "Reaction of Porous Solids", A. I. Ch. E. Journal, 3(4), 443448.

33. Reif, A. E. (1952). "The Mechanism of the Carbon Dioxide-Carbon Reaction", The Journal of Physical Chemistry, 56(6), 785-788. 
34. Scott, P. E. (1983). "Evaluation of Several Kinetic Models For Coal Char Gasification with $\mathrm{CO}_{2}$ ", Master of Science, Vanderbilt University, Nashville, Tennessee.

35. Sears, J. T., and Wen, C. Y. (1981). "The Role of C-CO $\mathrm{CO}_{2}$ in Gasification of Coal and Char", United States Department of Energy, Morgantown, West Virginia

36. Simons, G. A. (1980). "The Unified Coal-char Reaction", Fuel, $\underline{59}$ (2), 143-144.

37. Sofekun, O. A., and Doraiswamy, L. K. (1996). "High-Temperature Oxidation of Zinc Sulfide: Kinetic Modeling under Conditions of Strict Kinetic Control", Industrial \&Engineering Chemistry Research, 35, 3163-3170.

38. Sutton, D., Kelleher, B., and Ross, J. R. H. (2001). "Review of literature on catalysts for biomass gasification", Fuel Processing Technology, 73, 155-173.

39. Szekely, J., and Evans, J. W. (1970). "A Structural Model for Gas-solid Reactions with a Moving Boundary", Chemical Engineering Science, 25(6), 1091-1107.

40. Szekely, J., Evans, J. W., and Sohn, H. Y. (1976). "Gas-Solid Reactions", Academic Press, London, England.

41. USDOE. (2008). "International Energy Outlook 2008", Energy Information Administration USDOE, www.eia.doe.gov/oiaf/ieo/index.htm/.

42. Wolfson, R. (2008). "Energy, Environment, and Climate", First Edition, W. W. Norton \& Company, New York, London, 29.

43. Wu, M., Wu, Y., and Wang, M. (2006). "Energy and Emission Benefits of Alternative Transportation Liquid Fuels Derived from Switchgrass: A Fuel Life Cycle Assessment", Biotechnology Progress, 22, 1012-1024. 


\section{Appendix}

Appendix A. Plots of apparent rate constant $\boldsymbol{k}_{\text {app }}$ fitted with Model 5

Group 1. ND lignite \& Hardwood chars (24 plots)
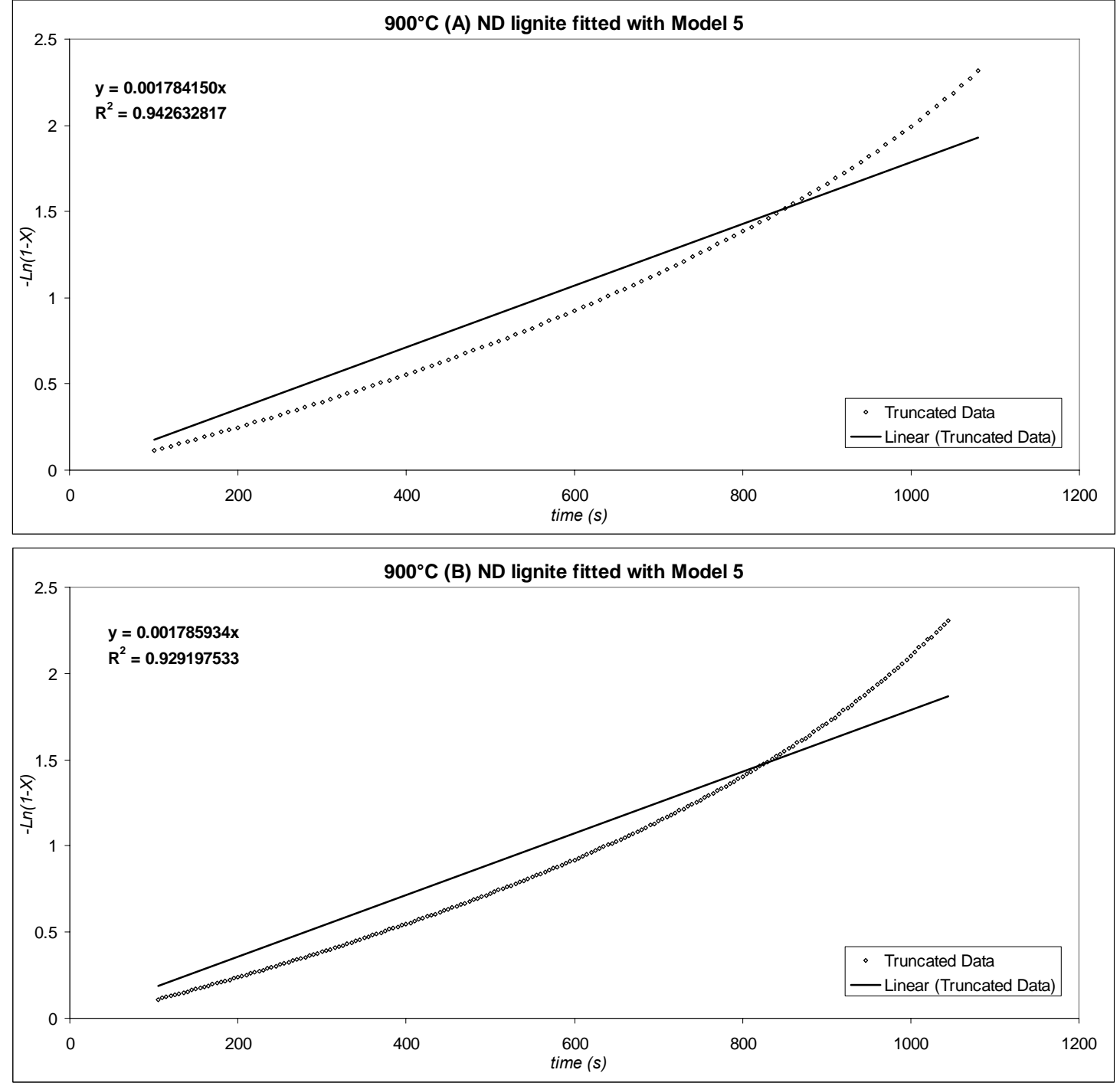

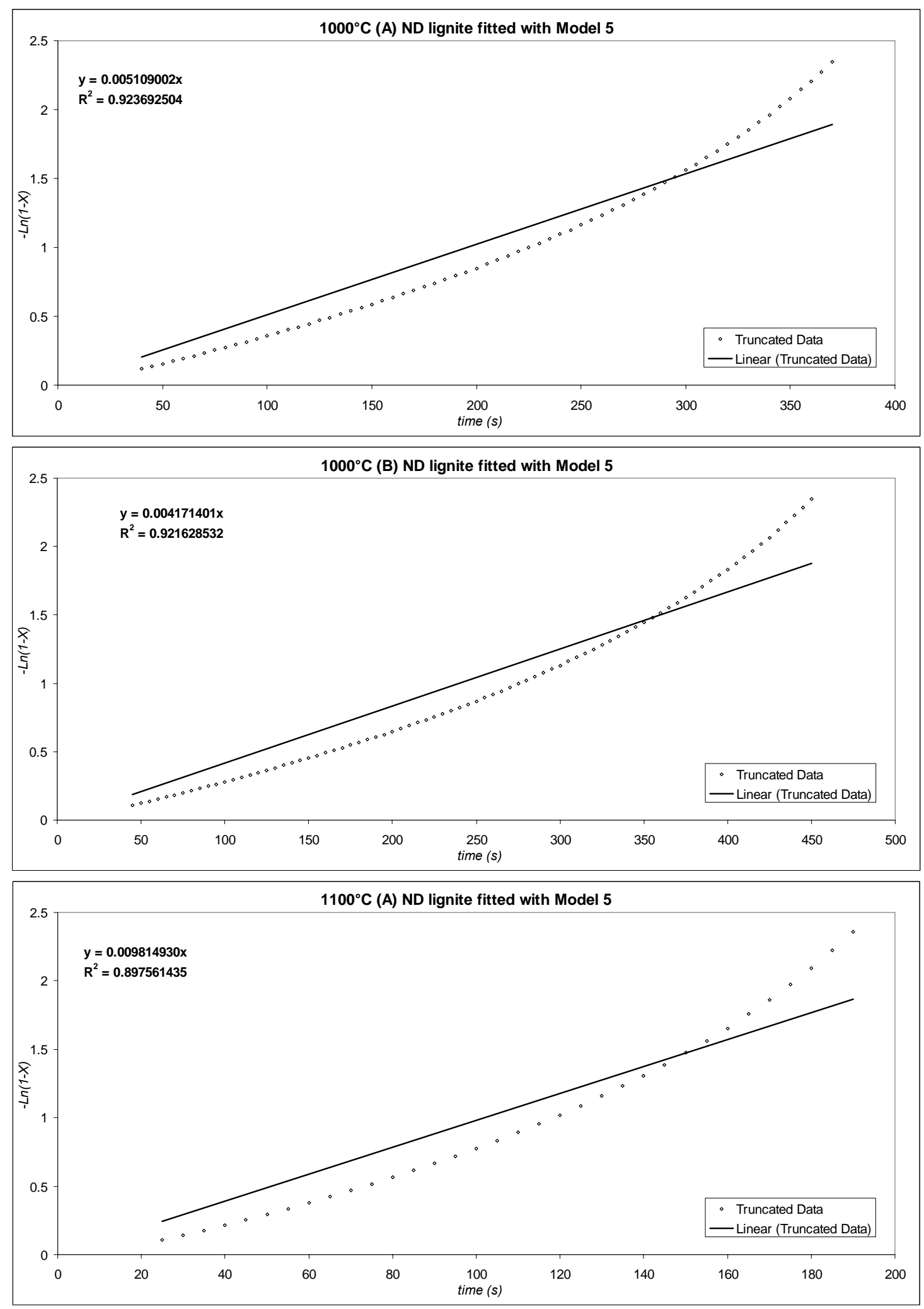

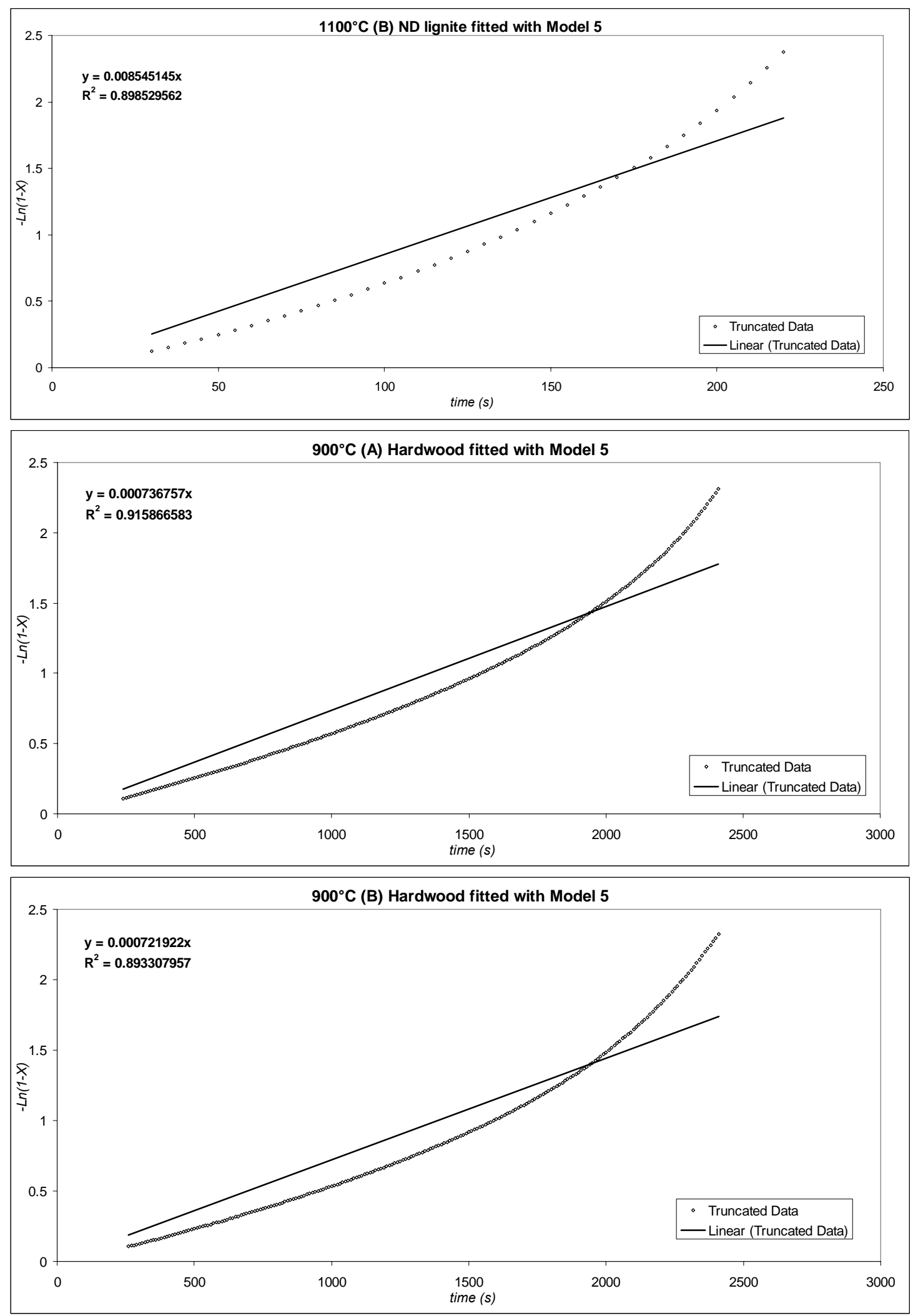

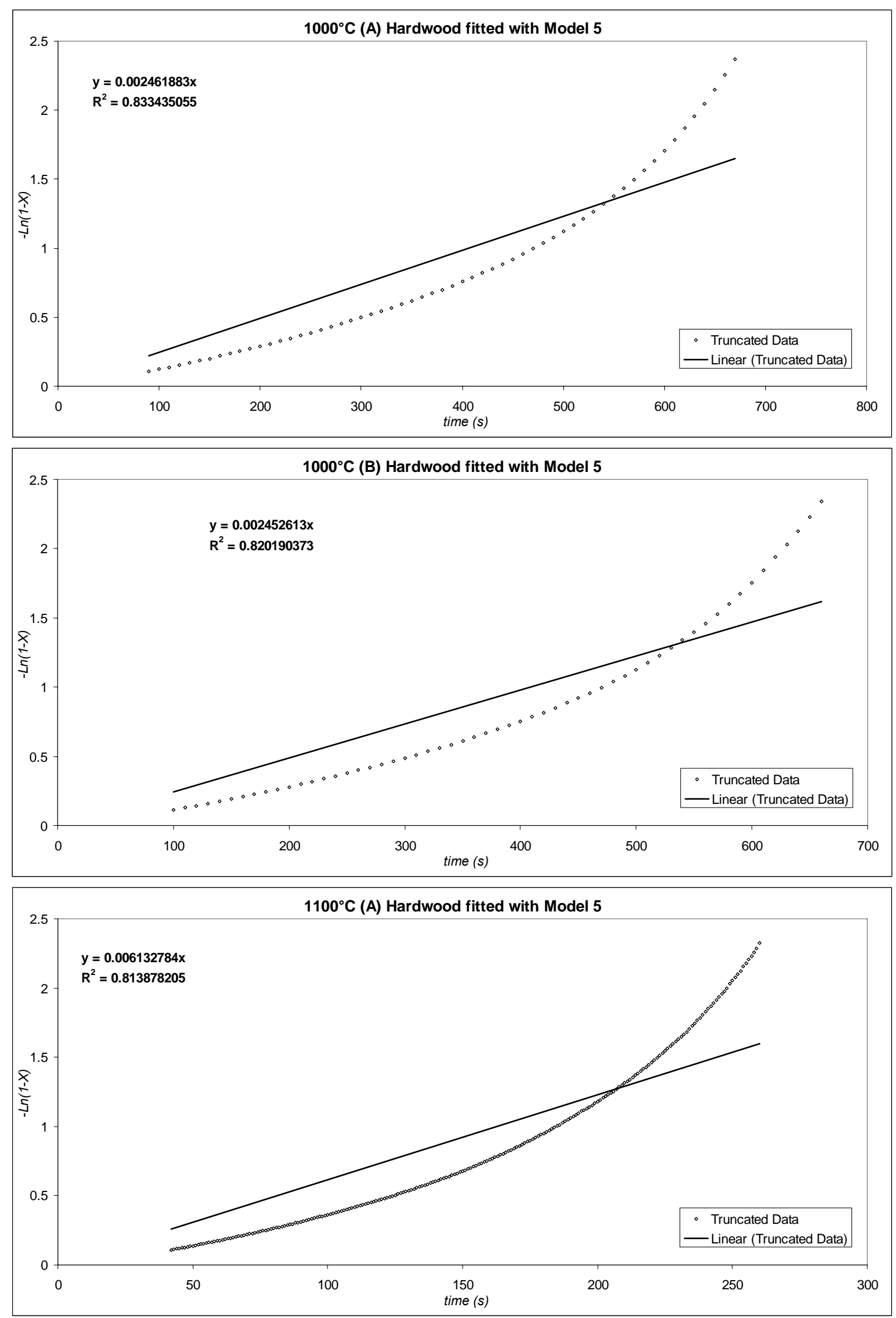

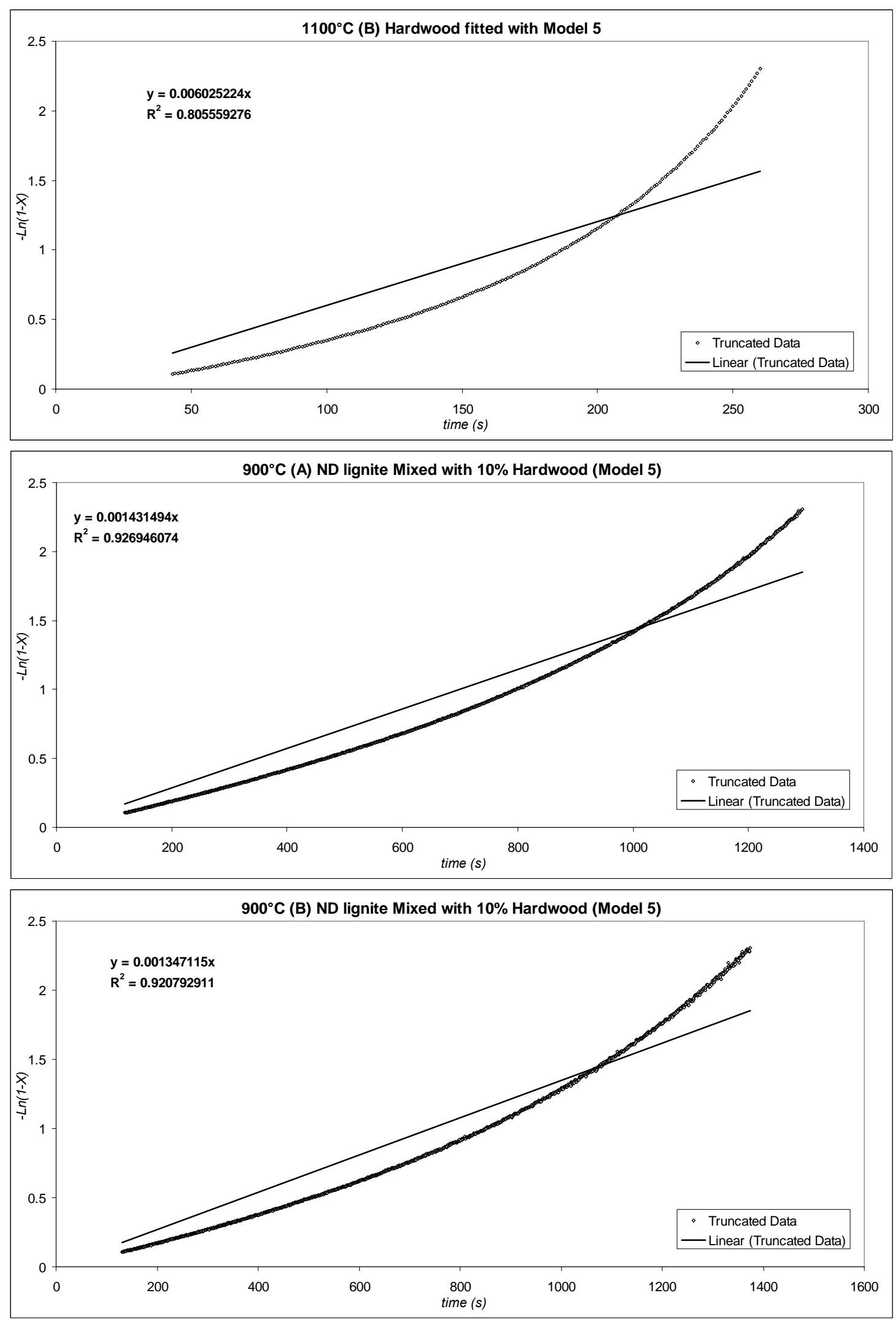

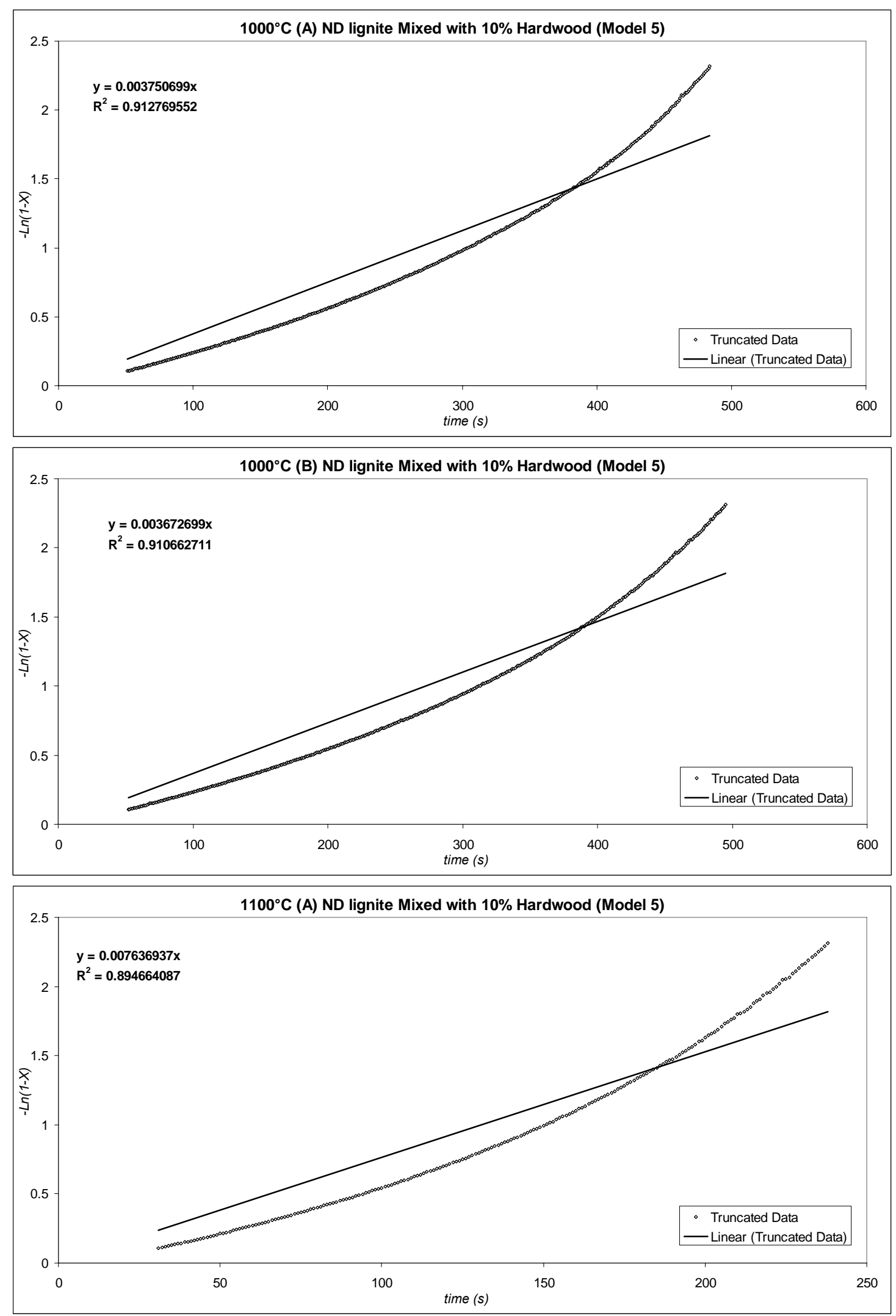

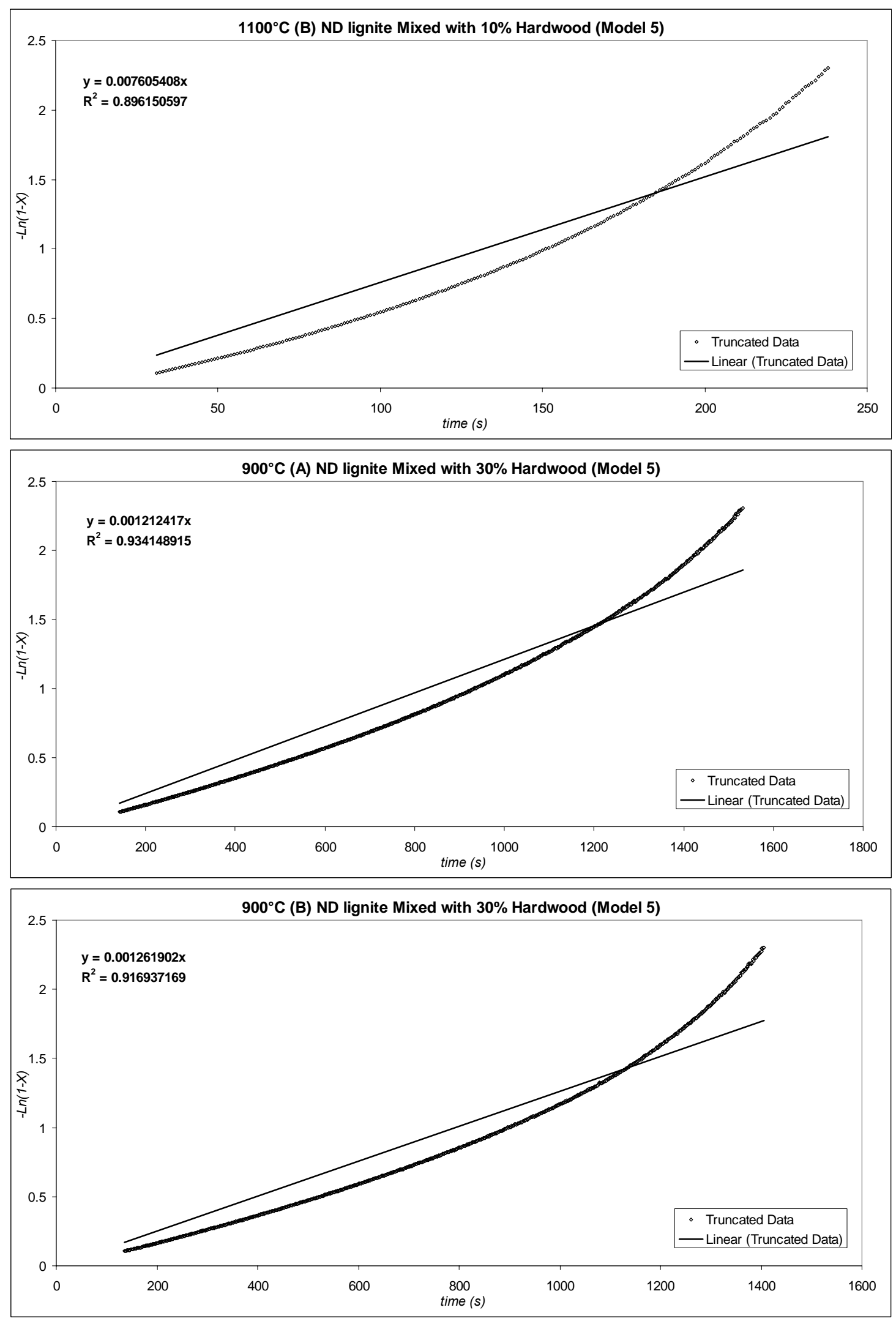

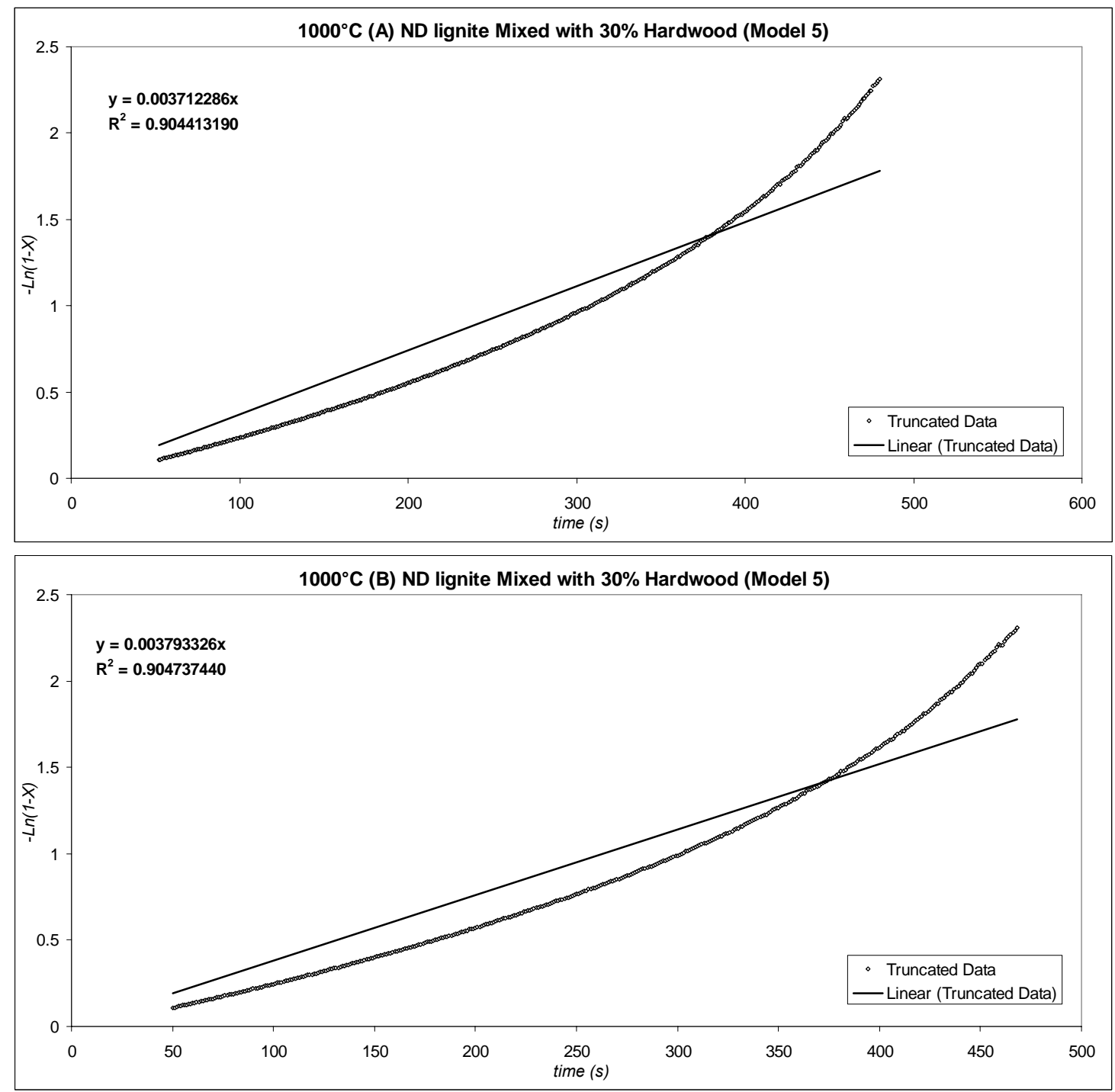

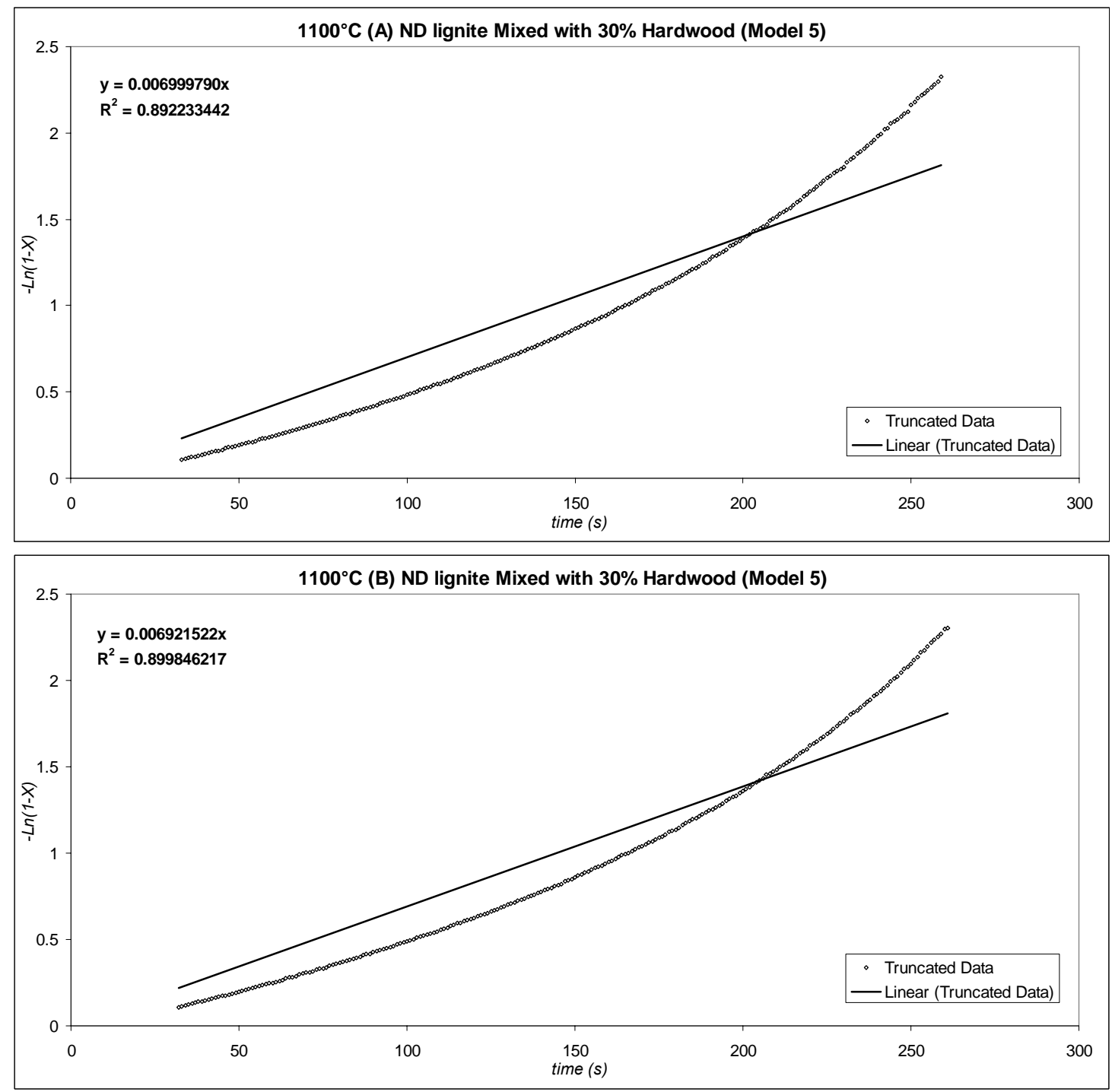
Group 2. ILL No.6 \& Switchgrass chars (26 plots)
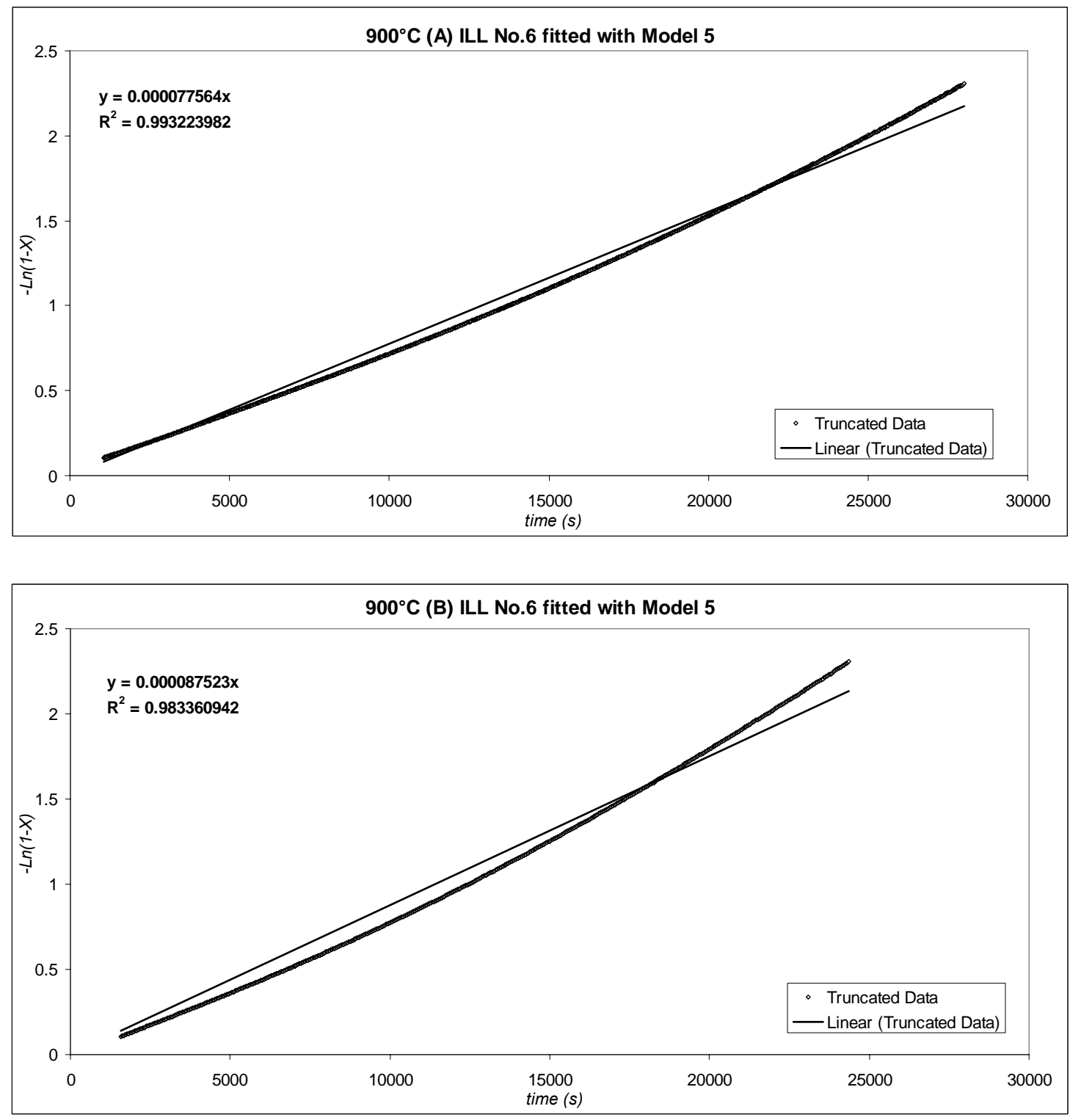

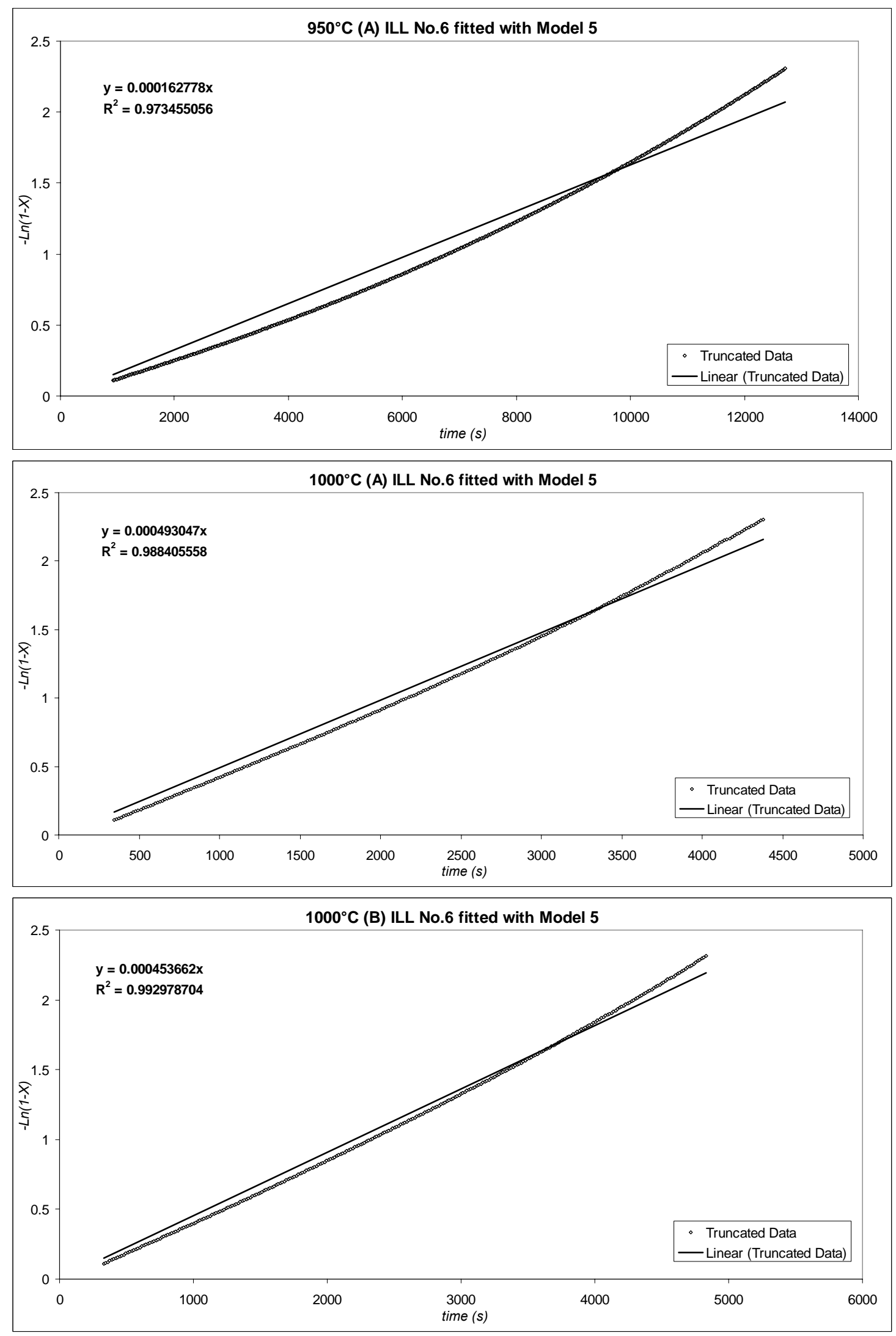

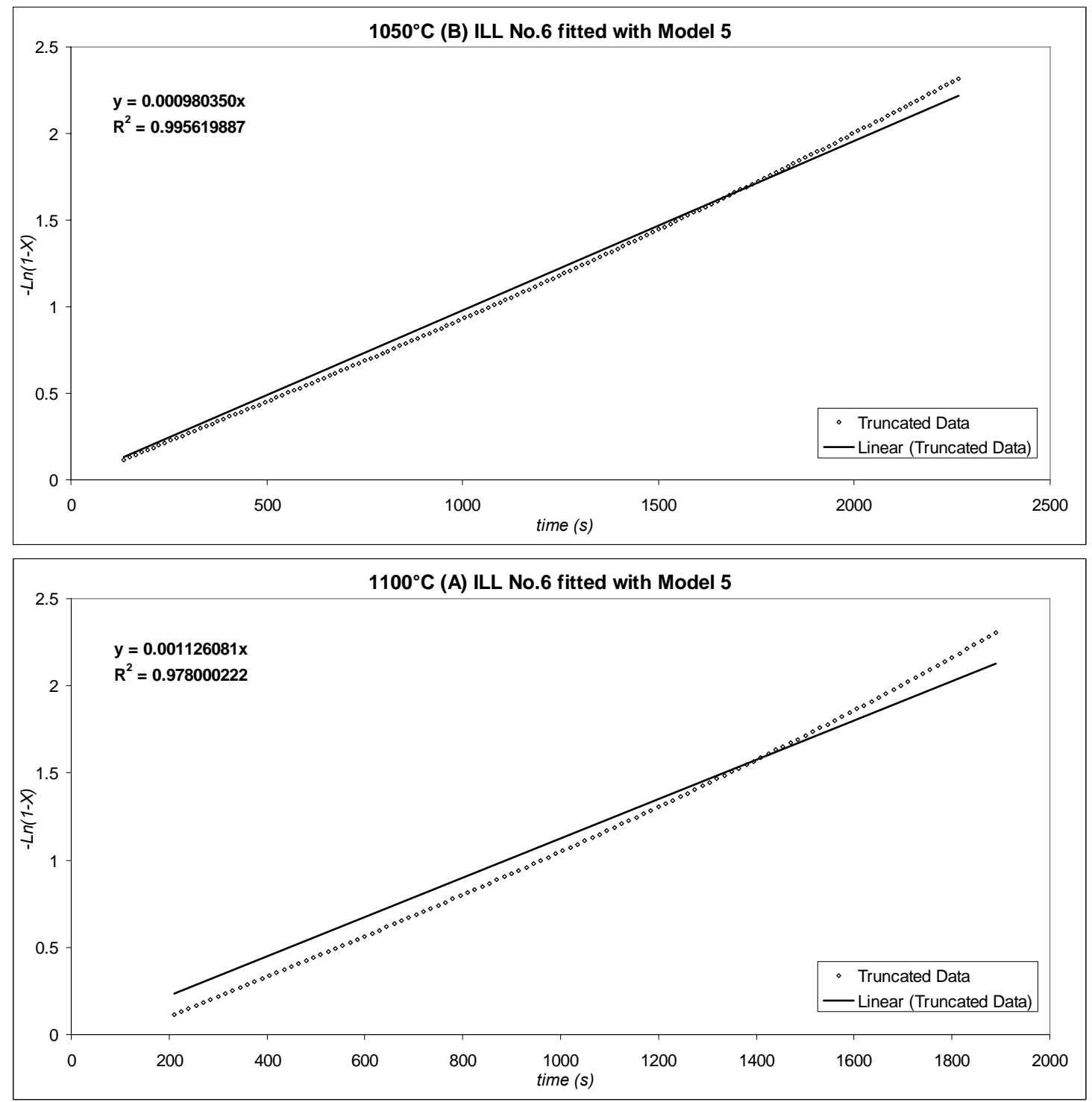

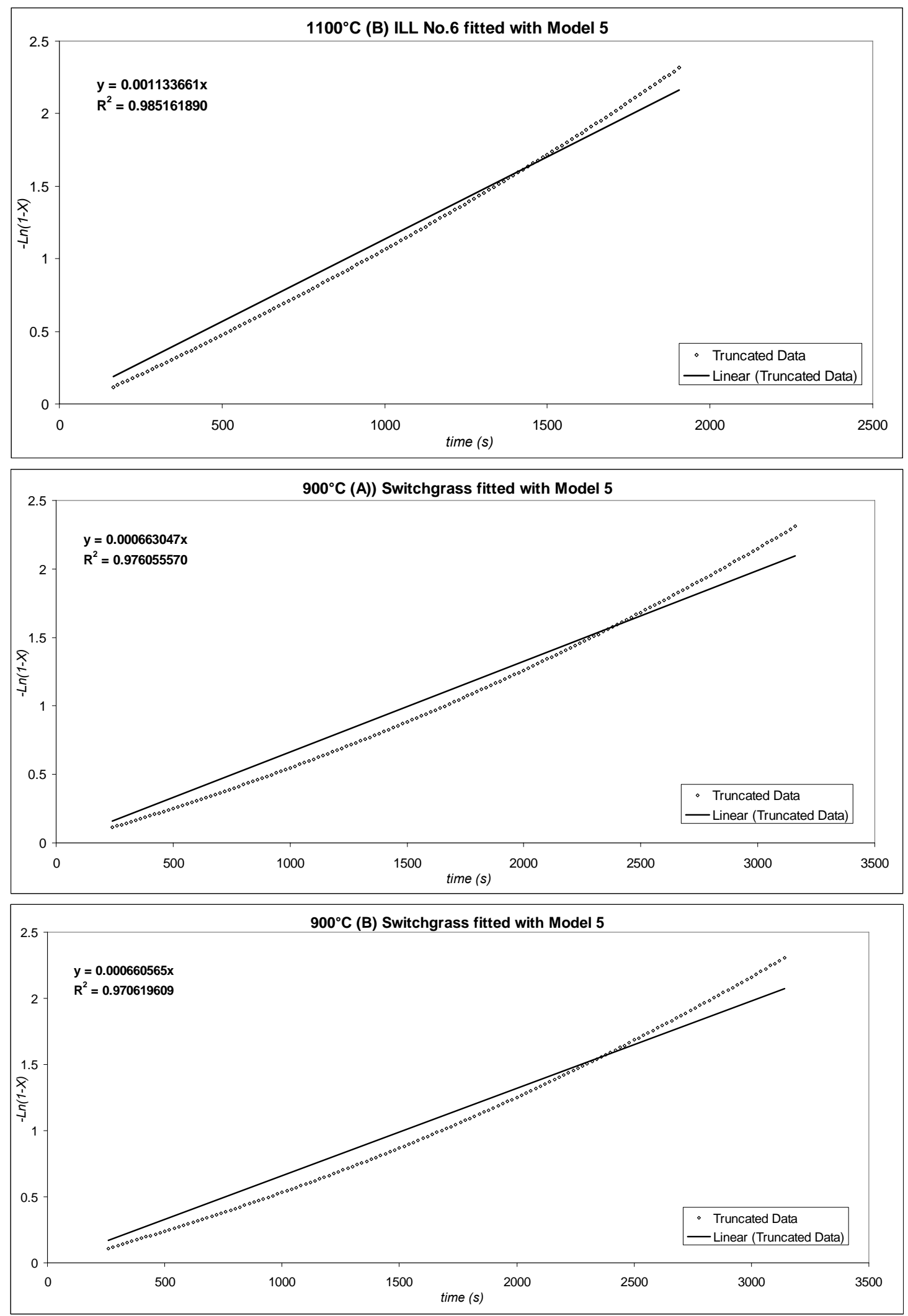

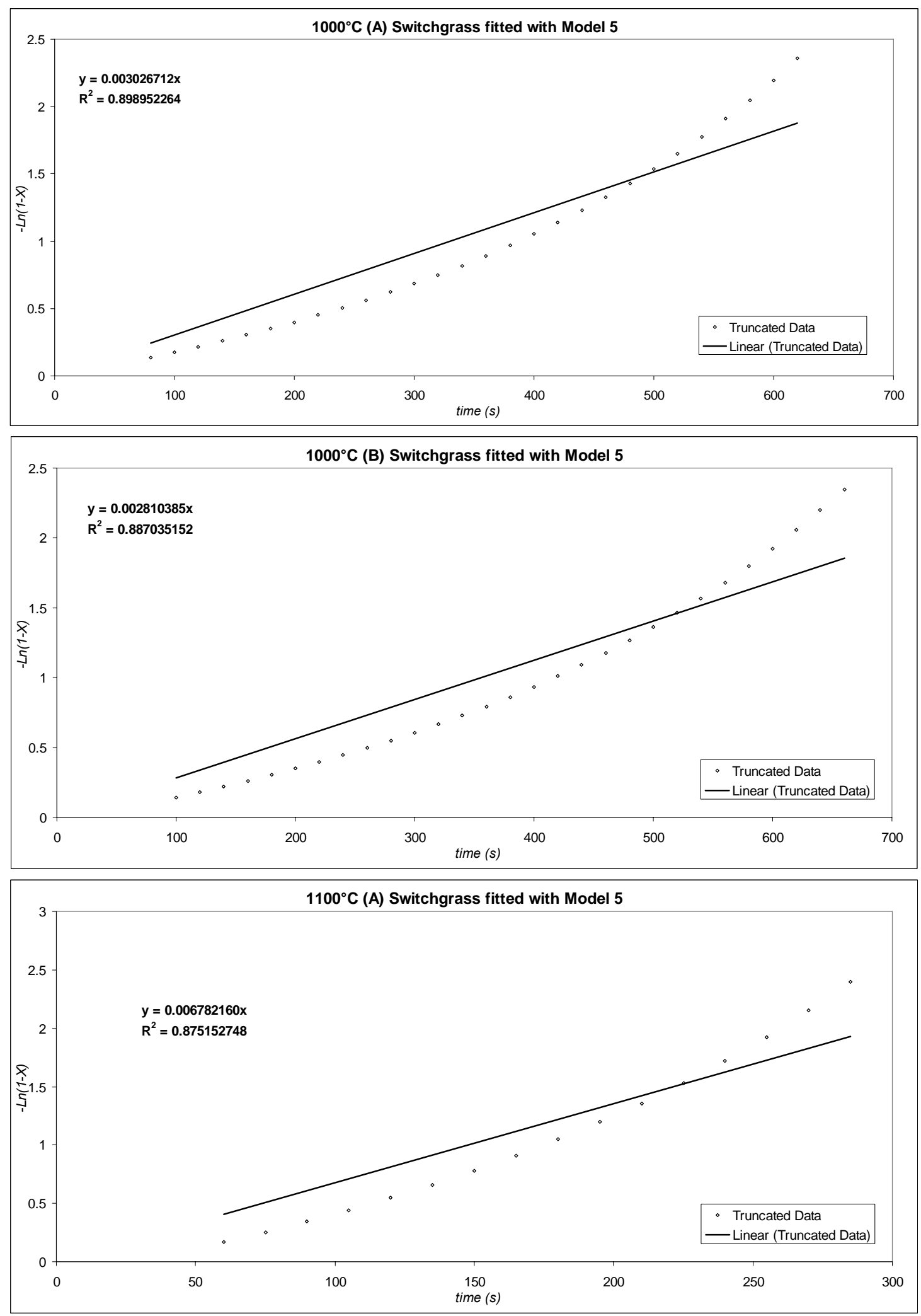

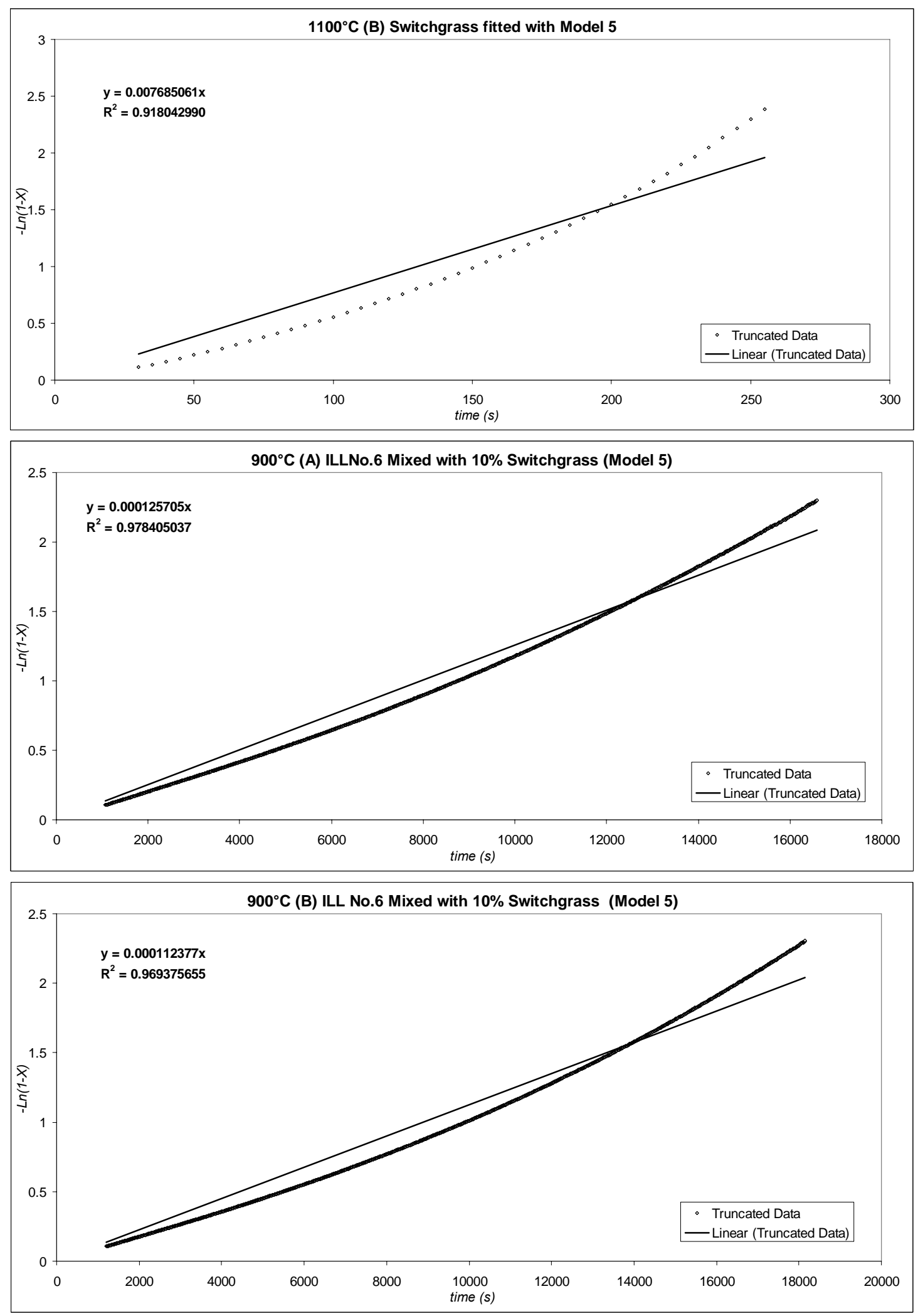

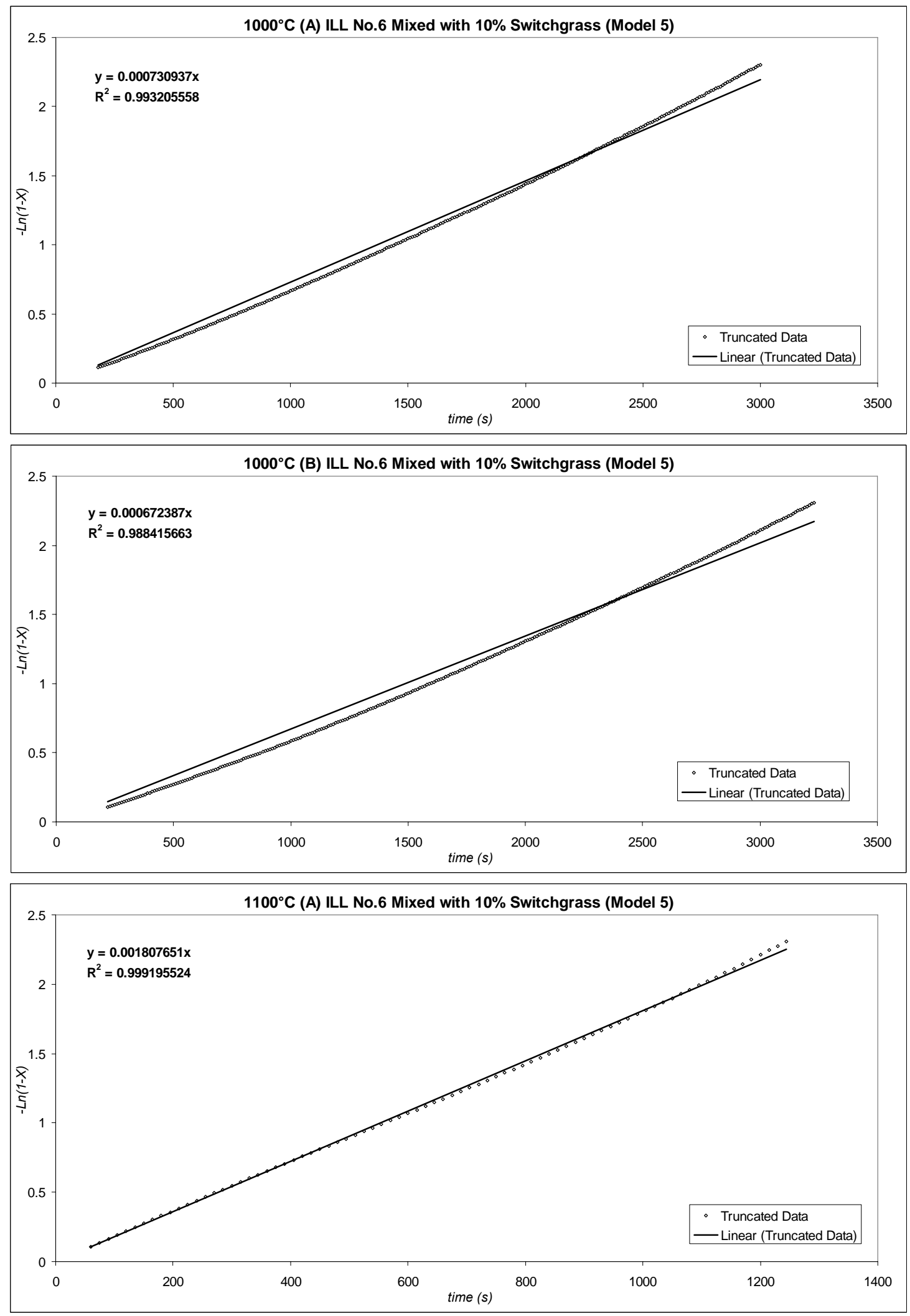

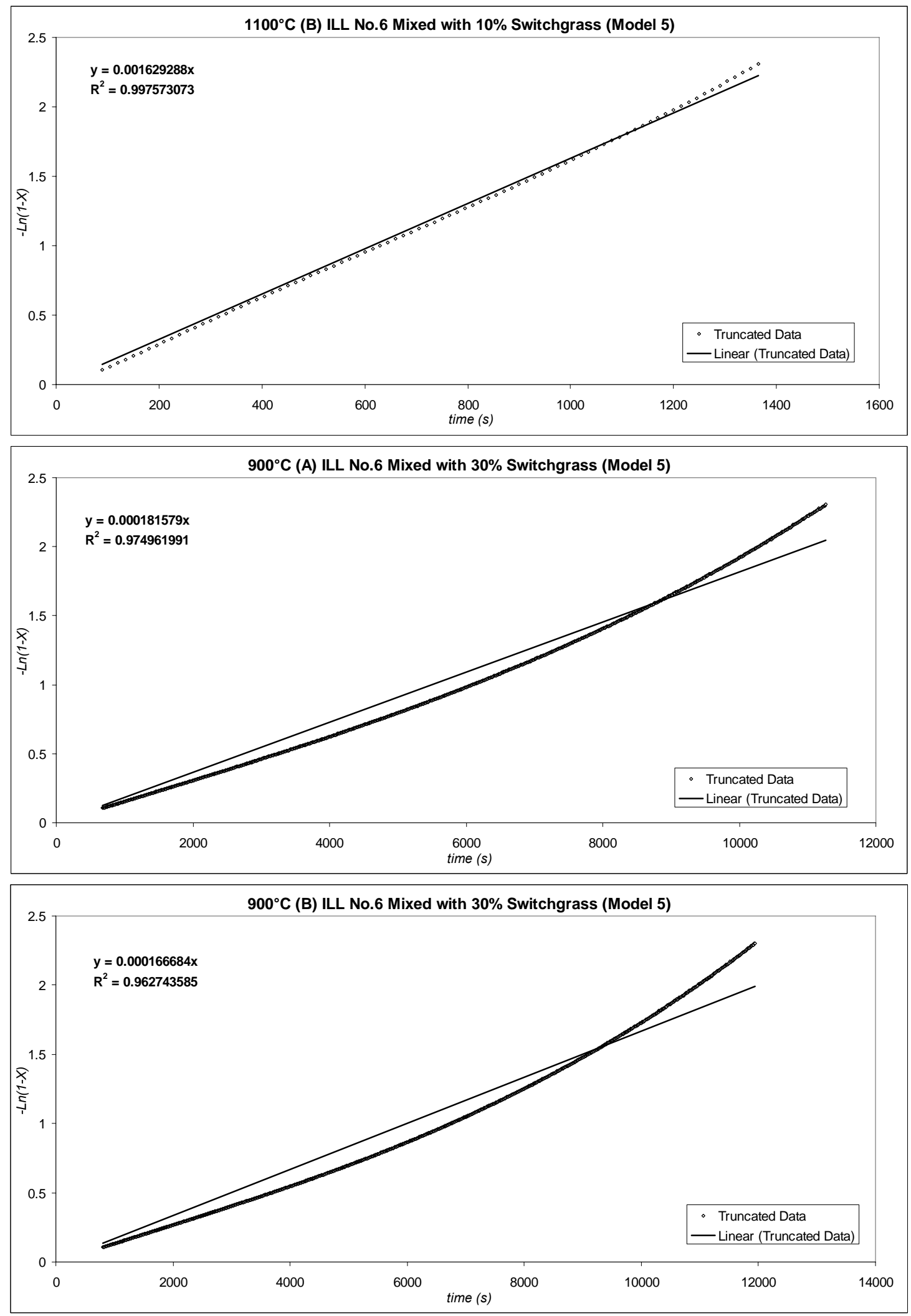

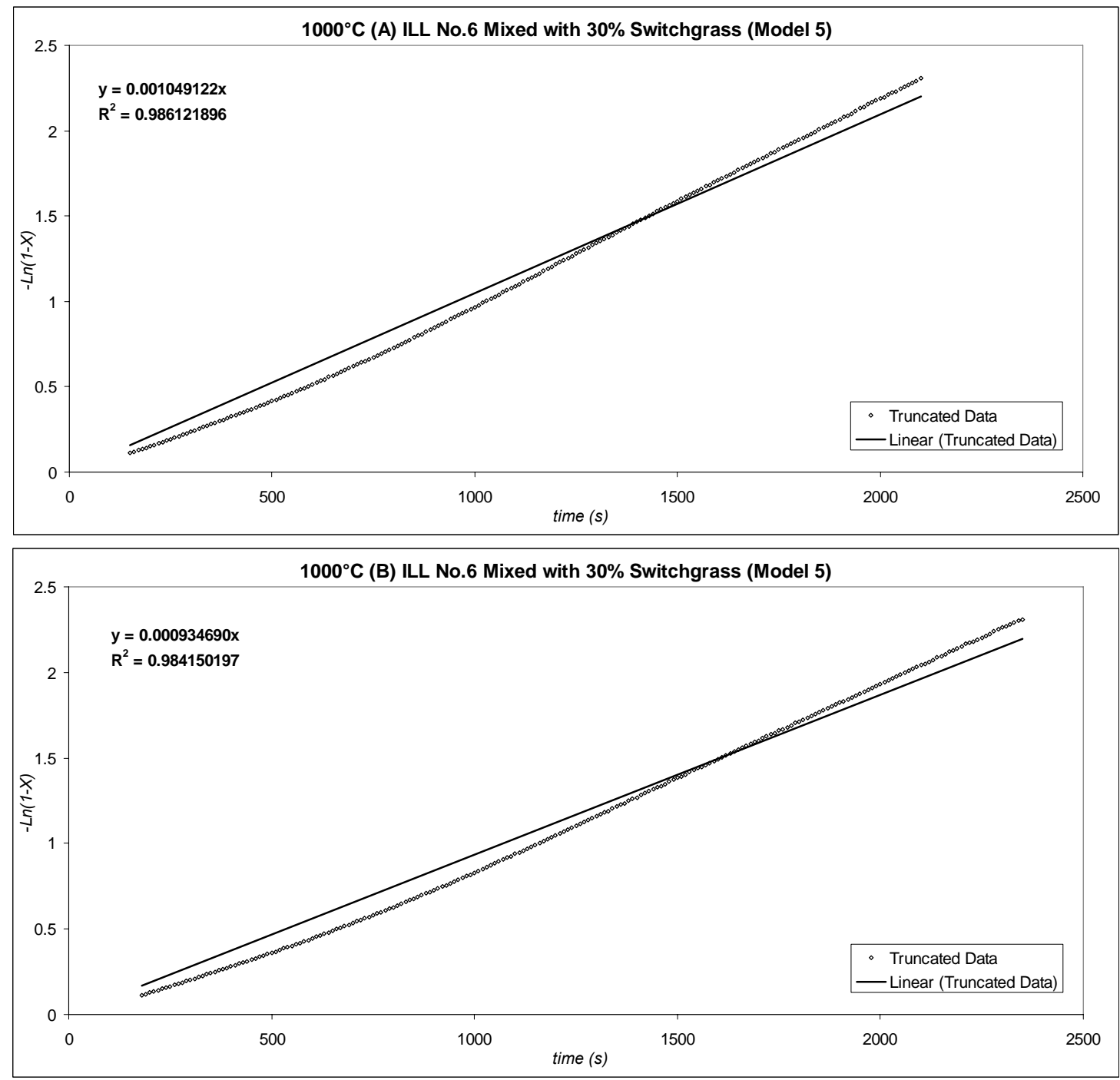

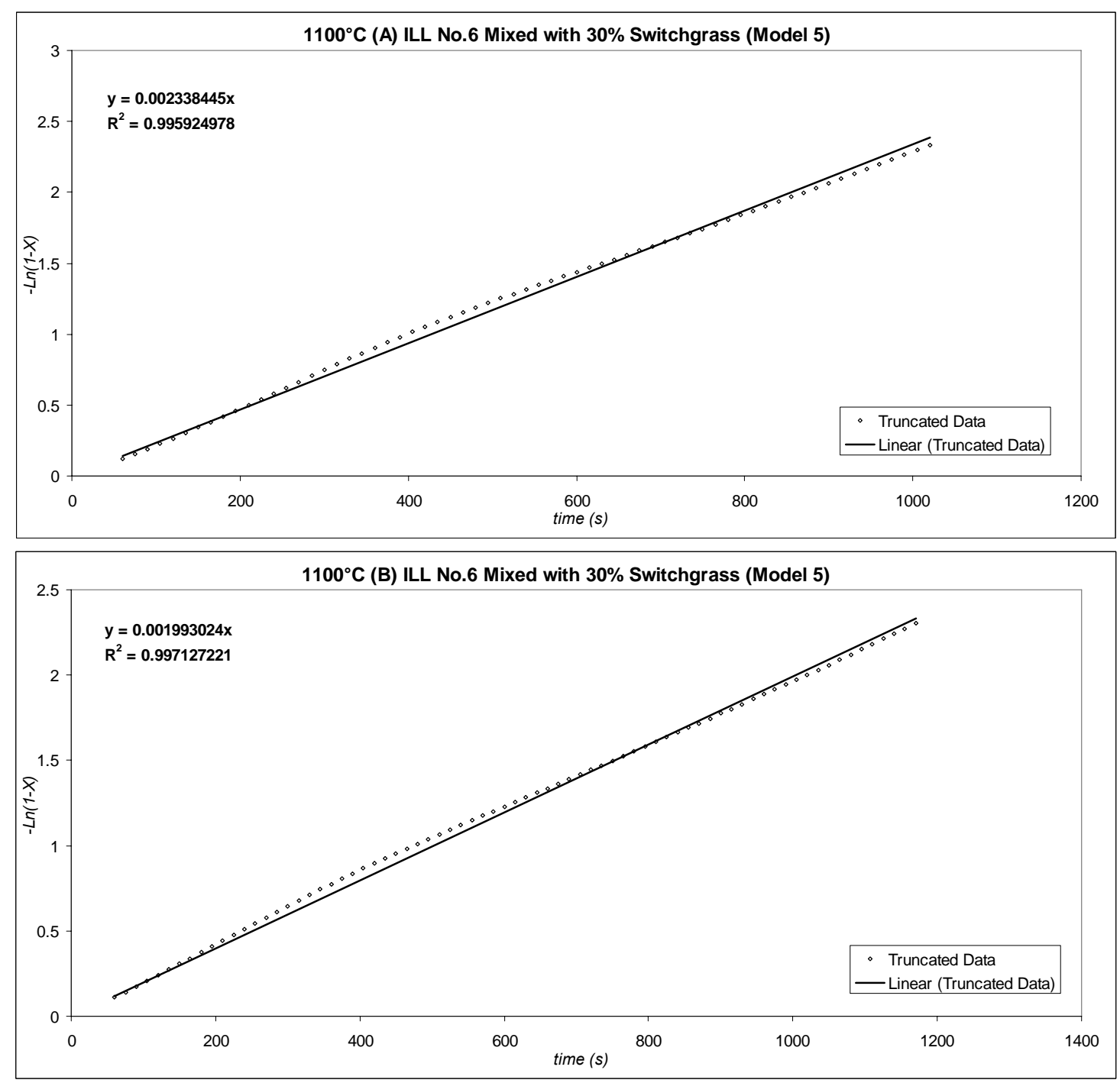
Group 3. PRB \& Corn Stover chars (24 plots)
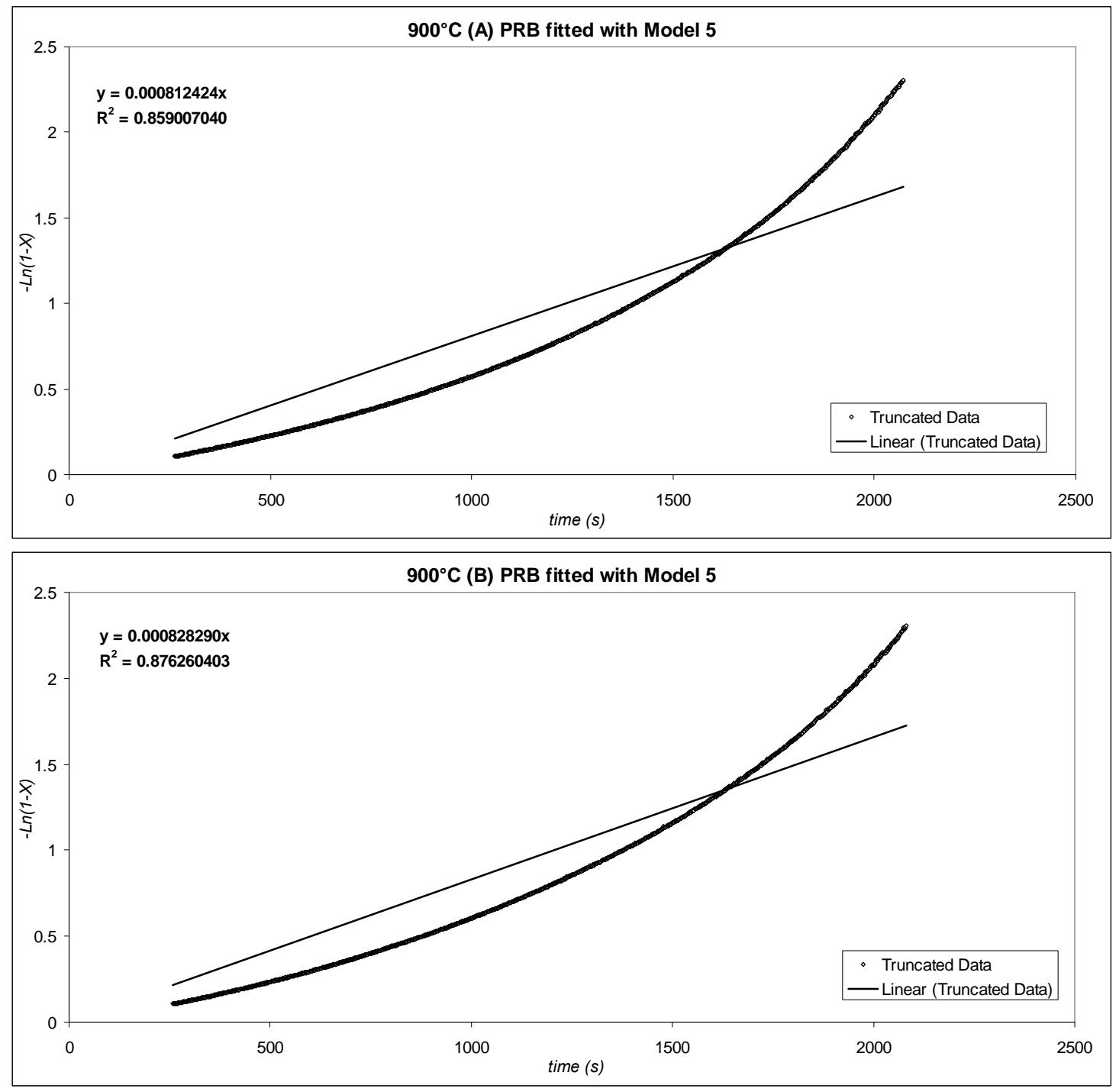

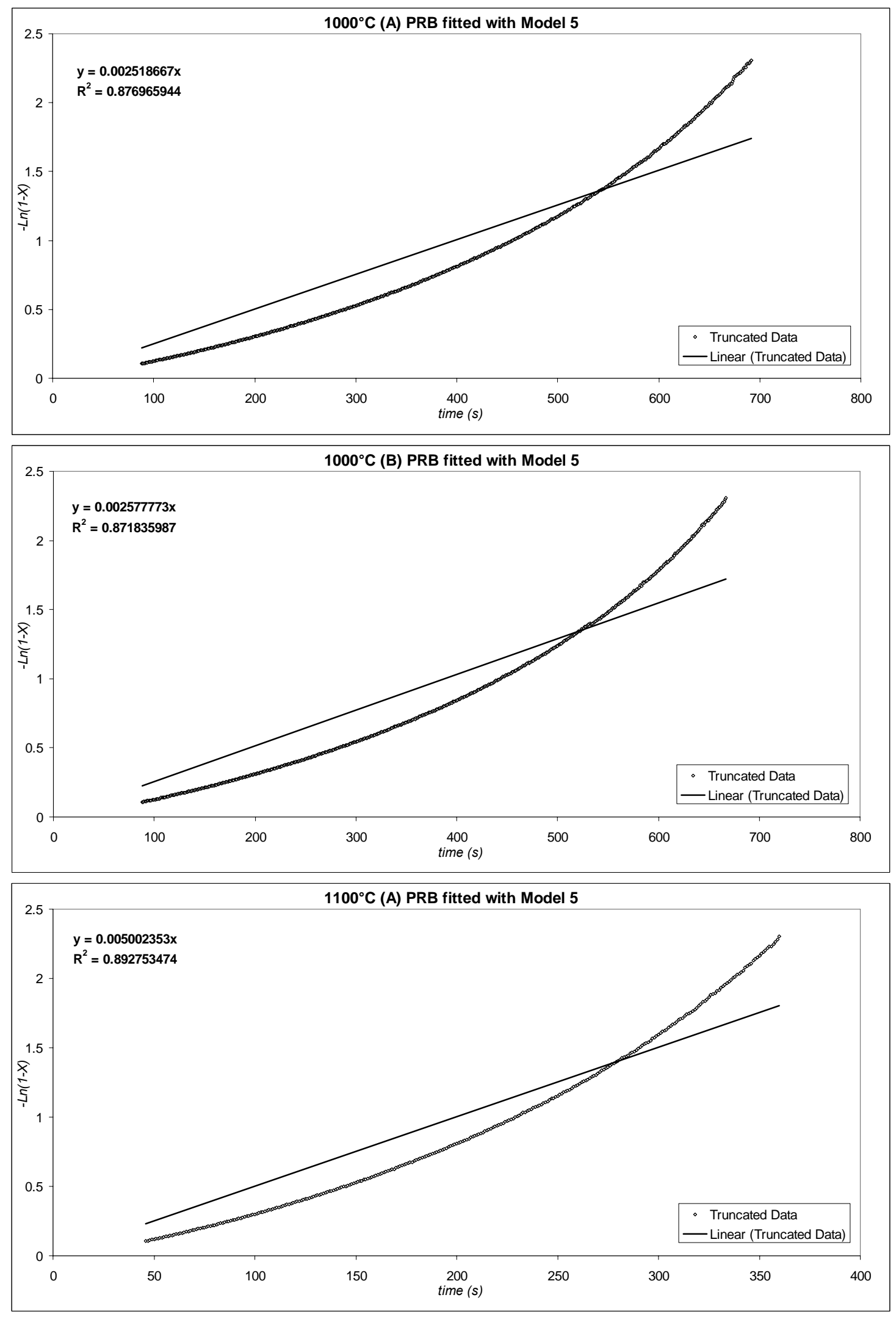

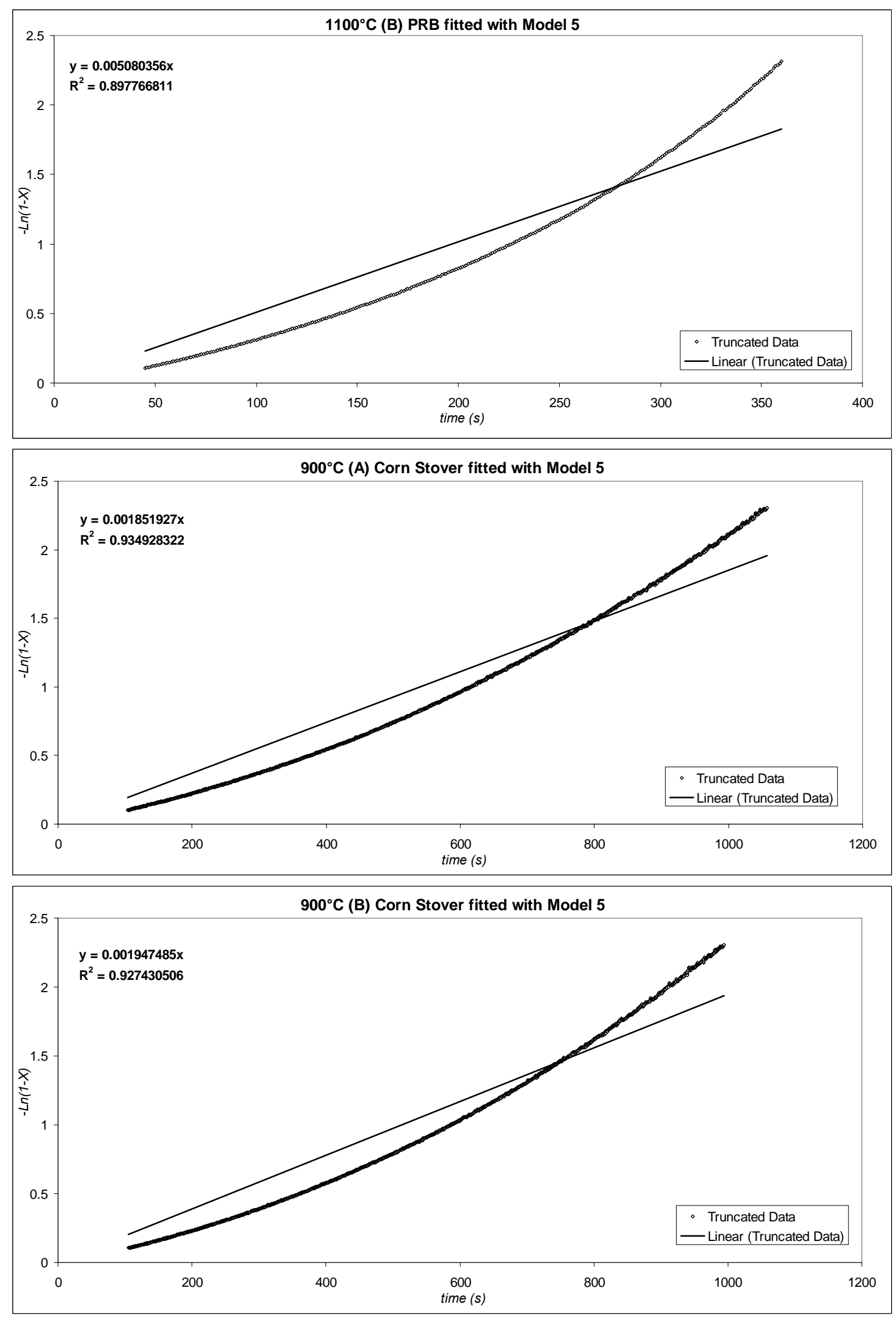

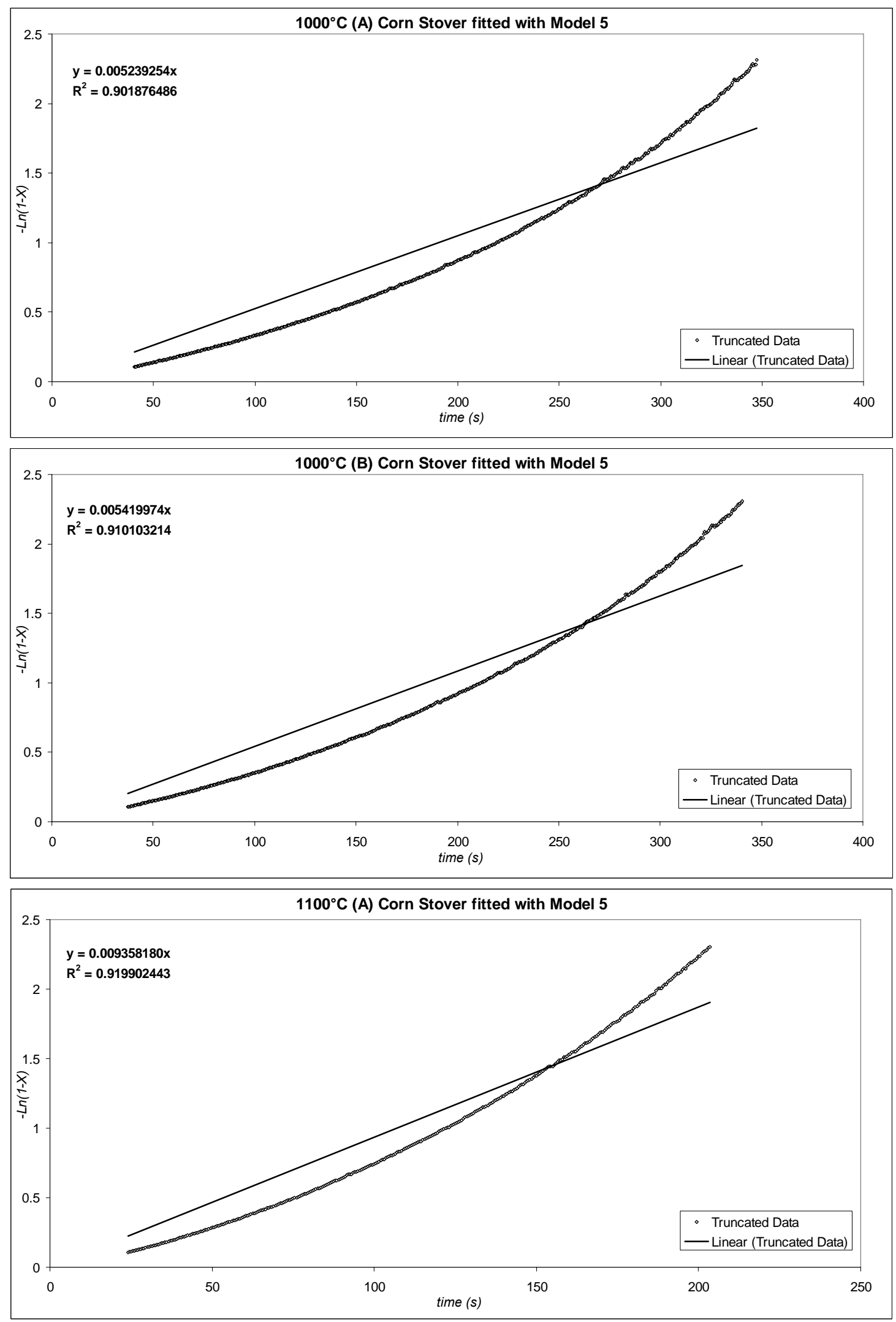

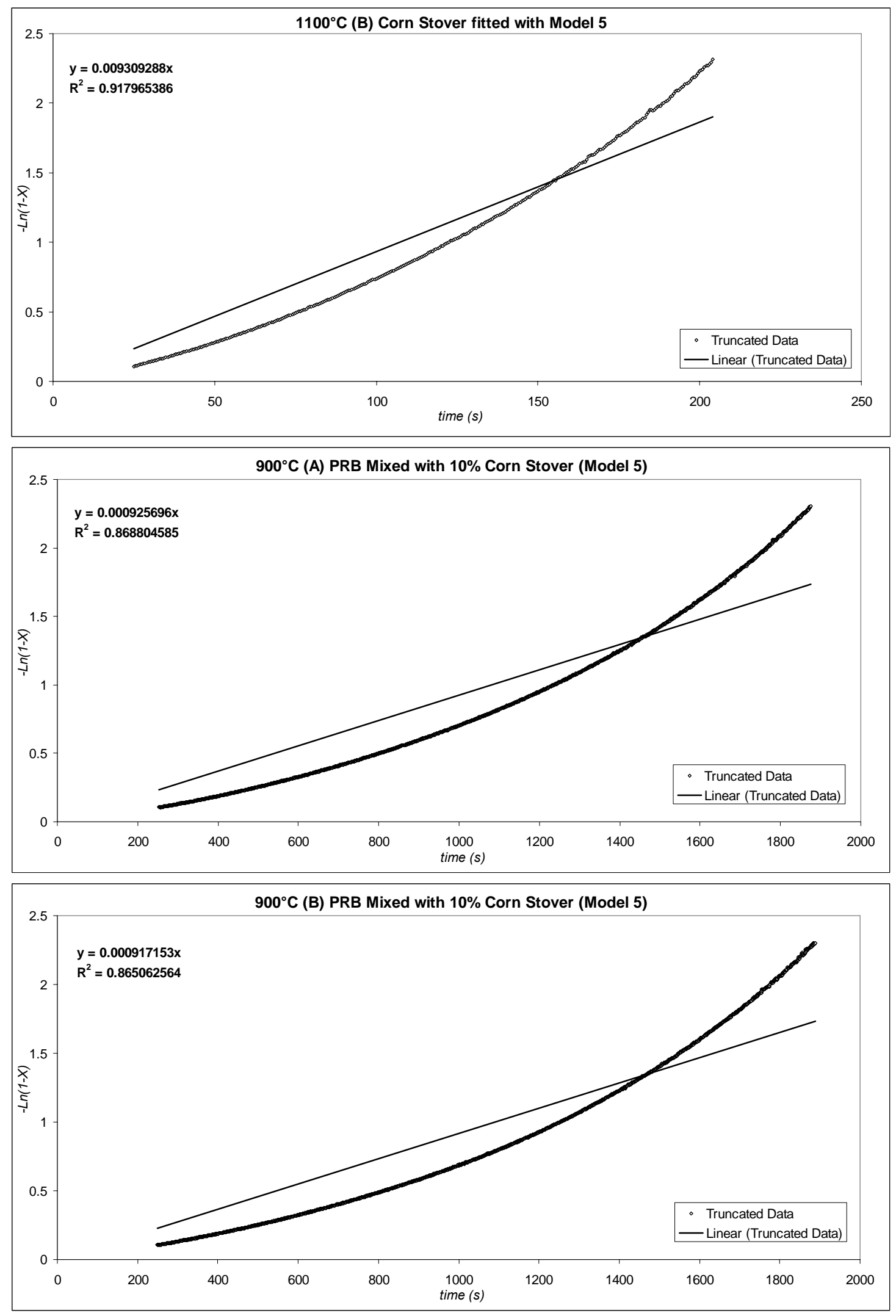

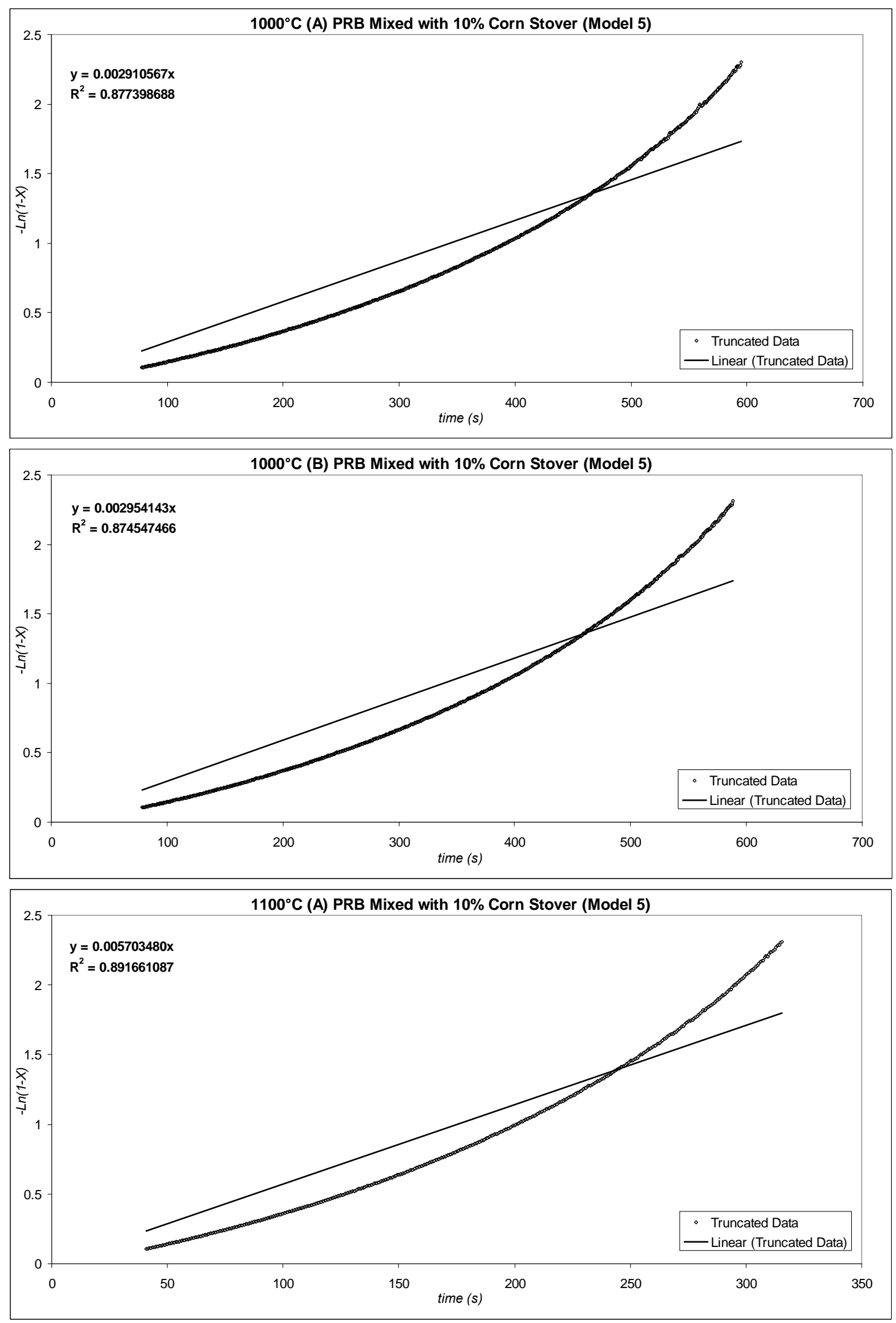

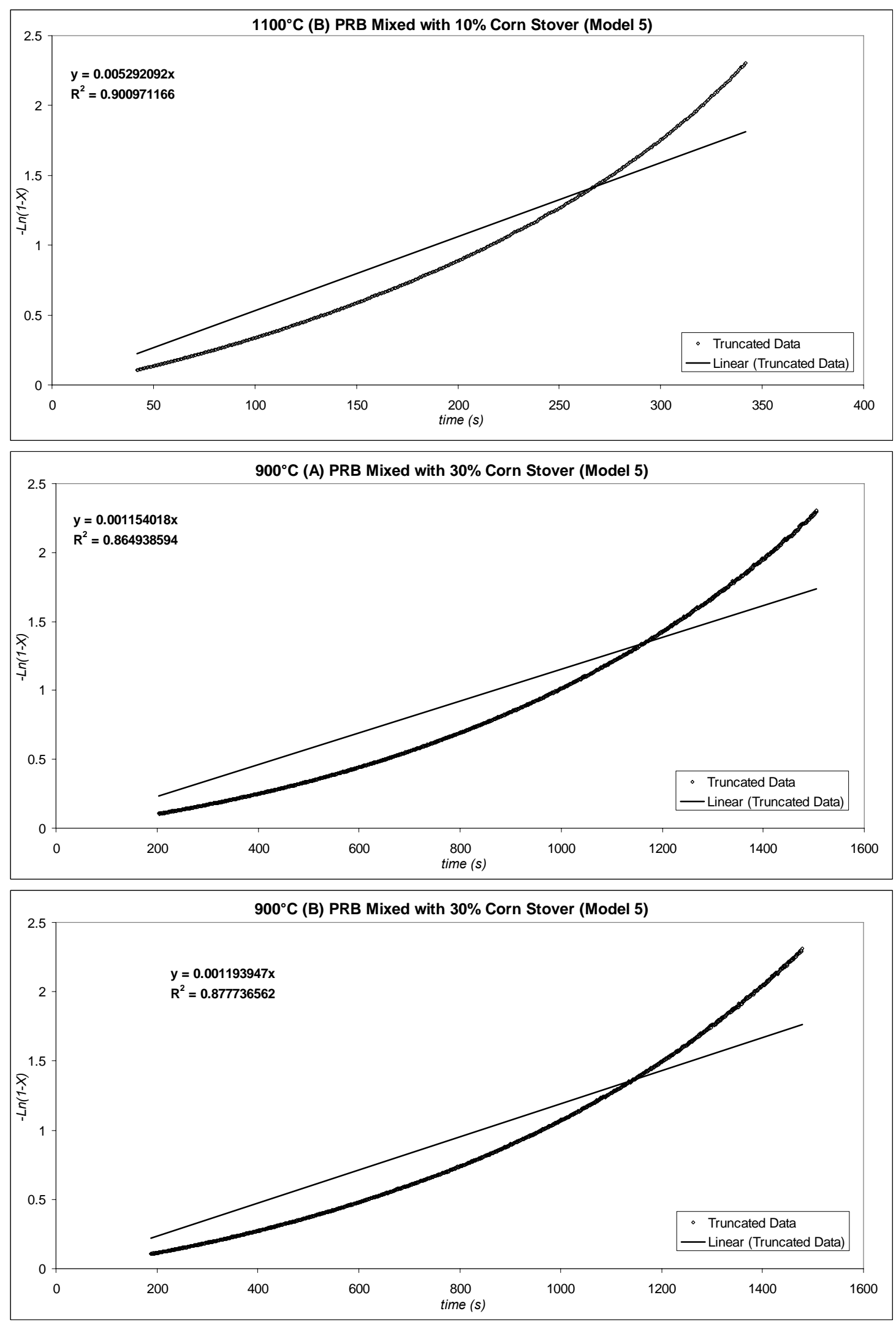

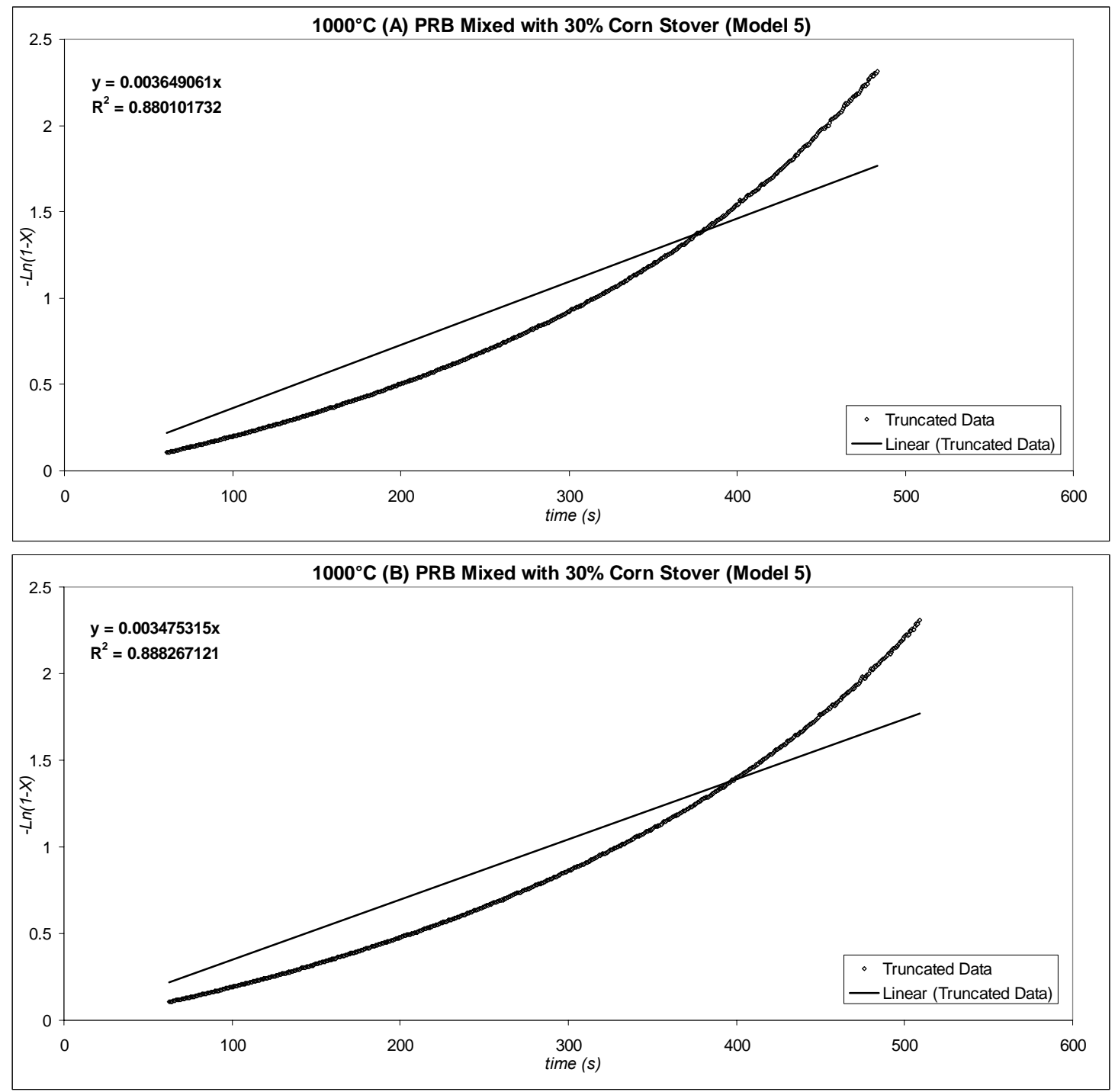

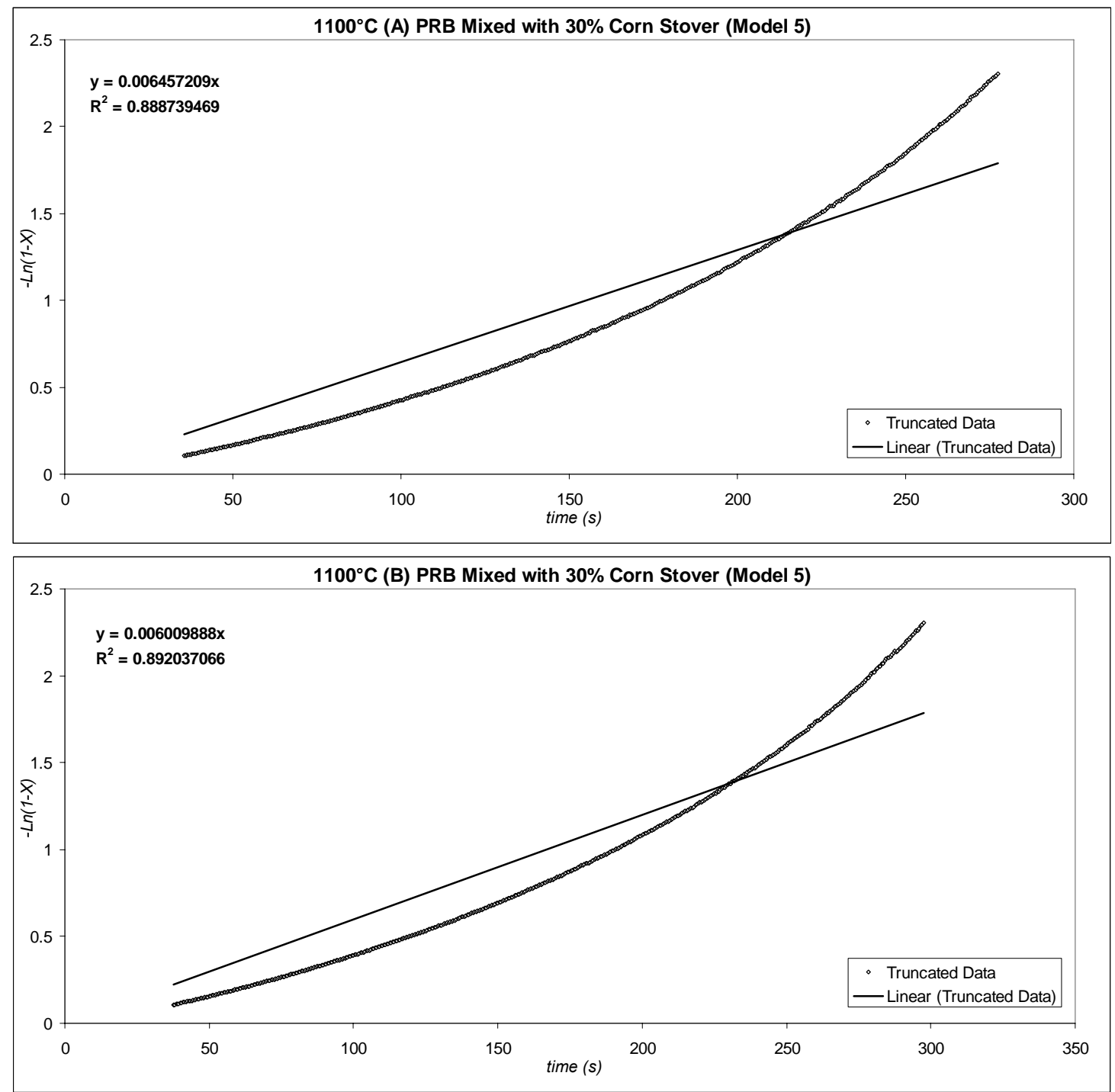

Note:

Total 74 plots fitted with Model 5. 
Appendix B. Plots of $E_{a p p}$ regression based on Model 5

Group 1. ND lignite \& Hardwood chars (4 plots)
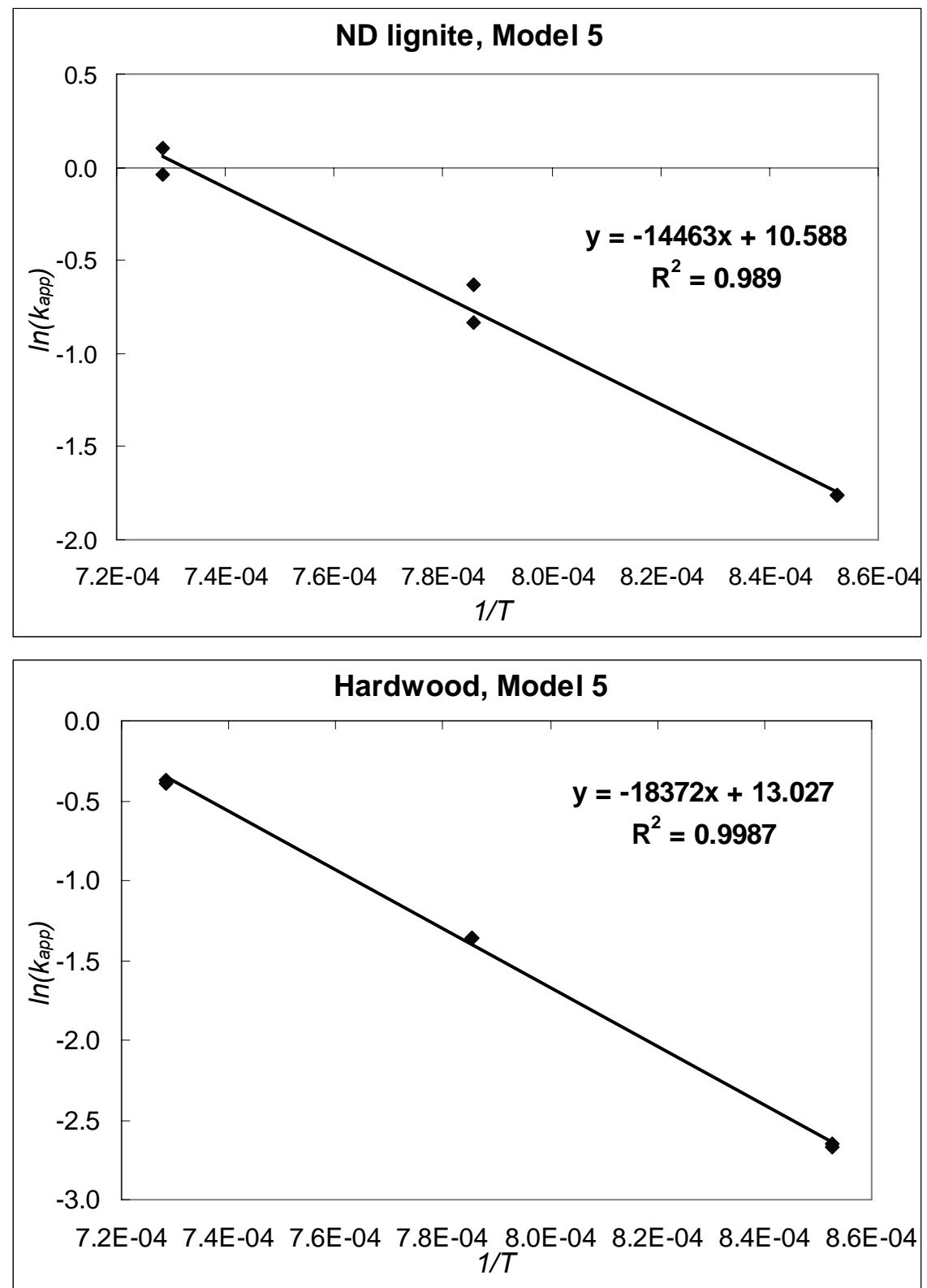

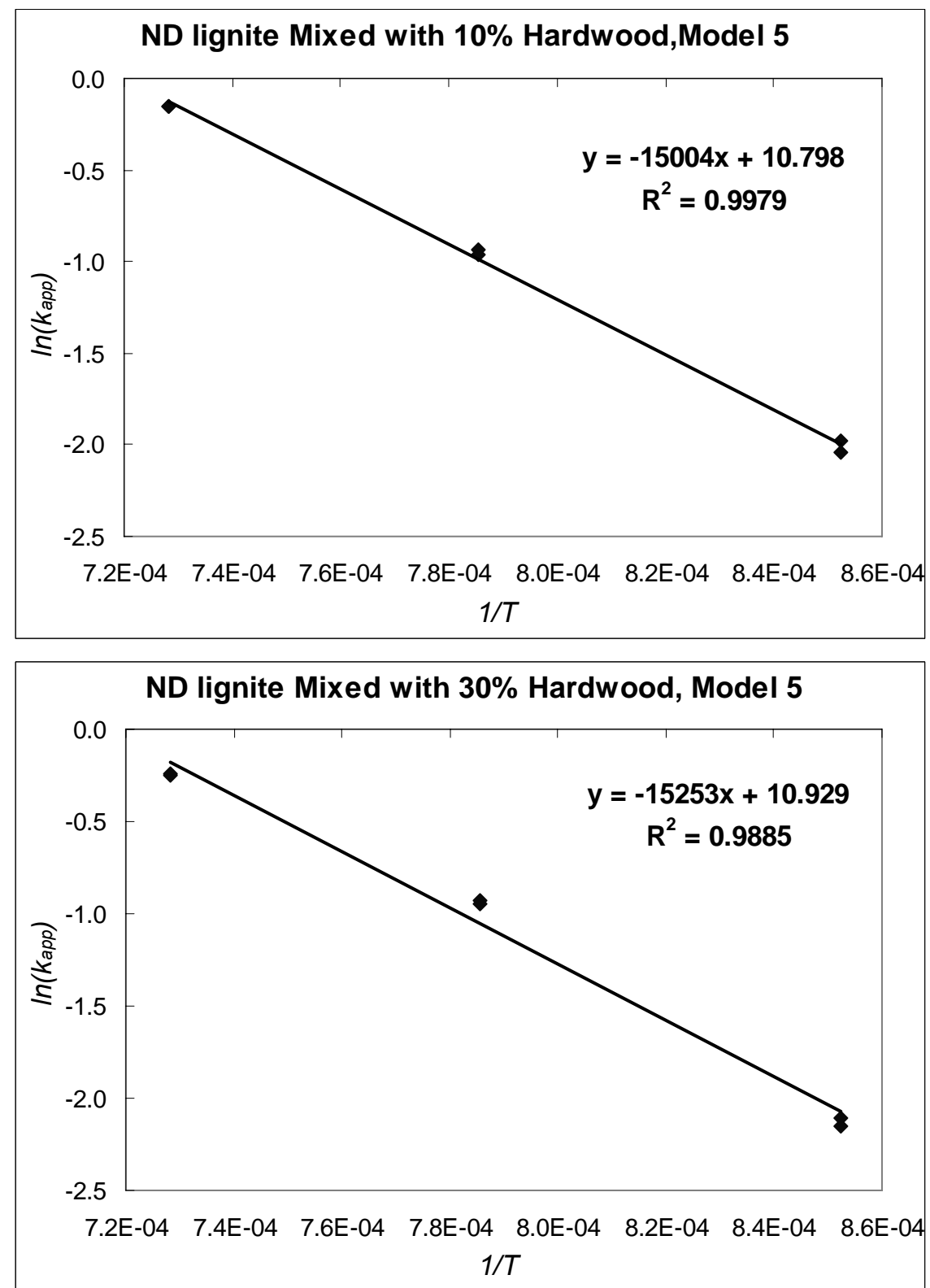
Group 2. ILL No.6 \& Switchgrass char (4 plots)
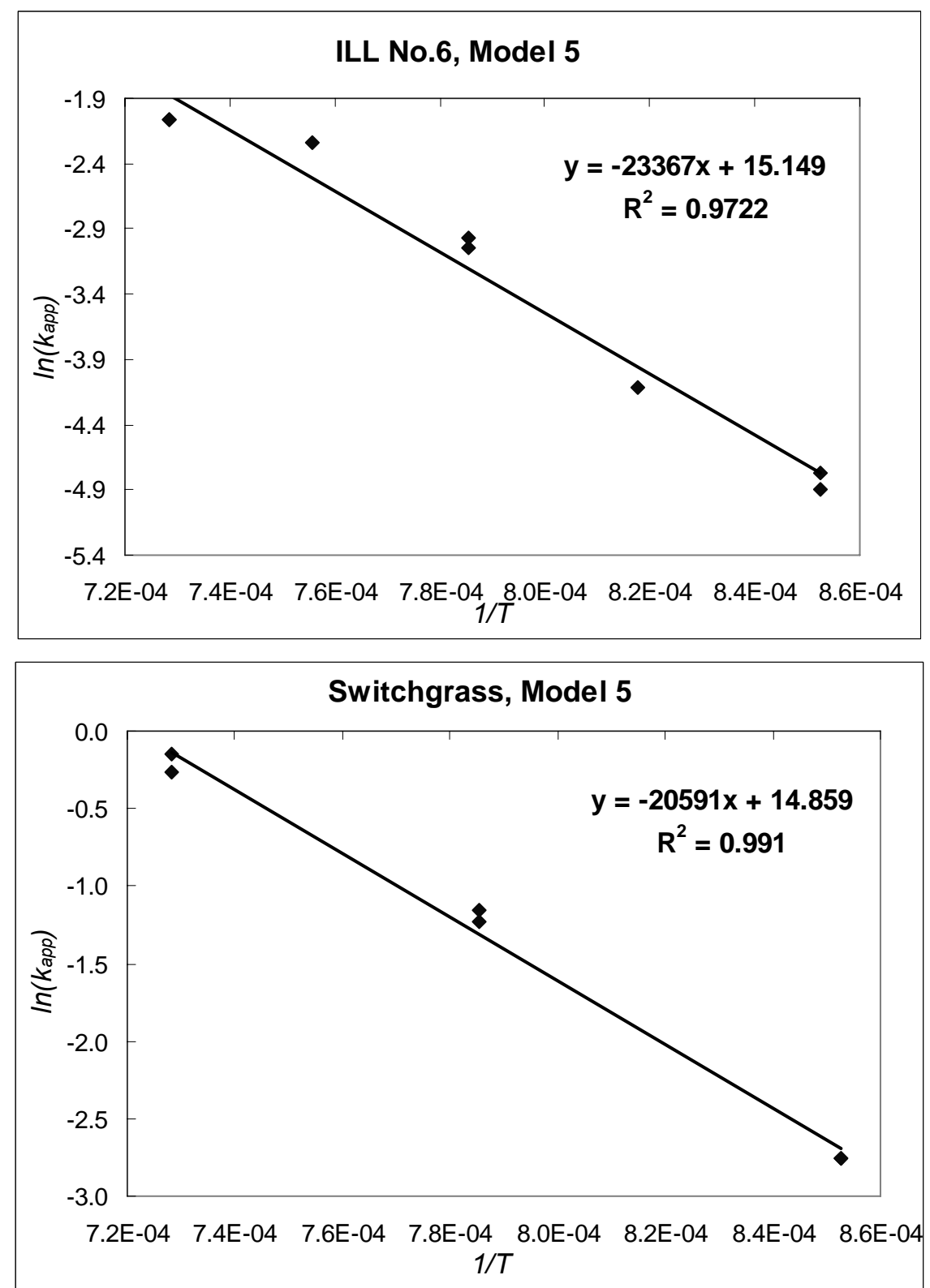

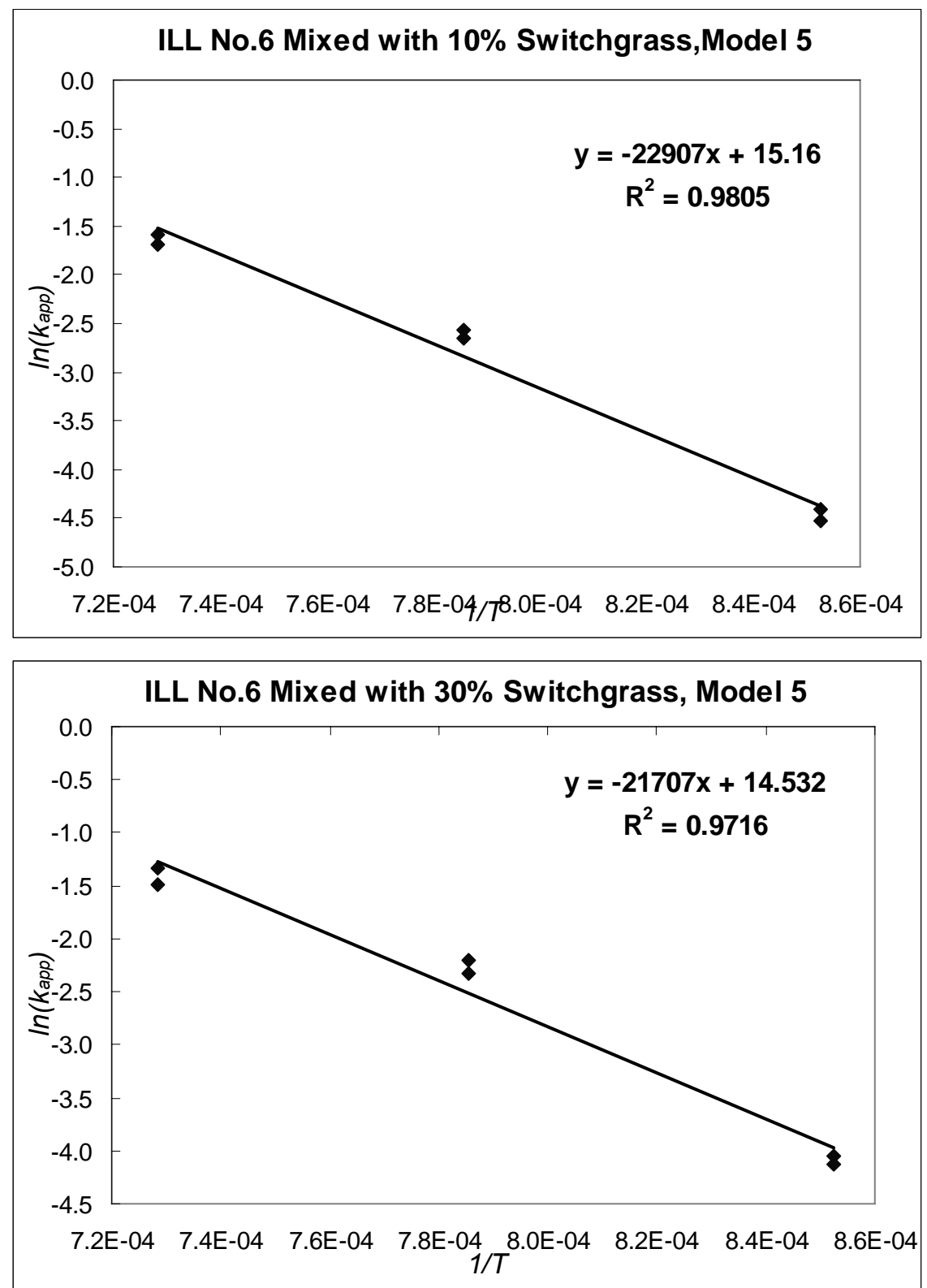
Group 3. PRB \& Corn Stover chars (4 plots)
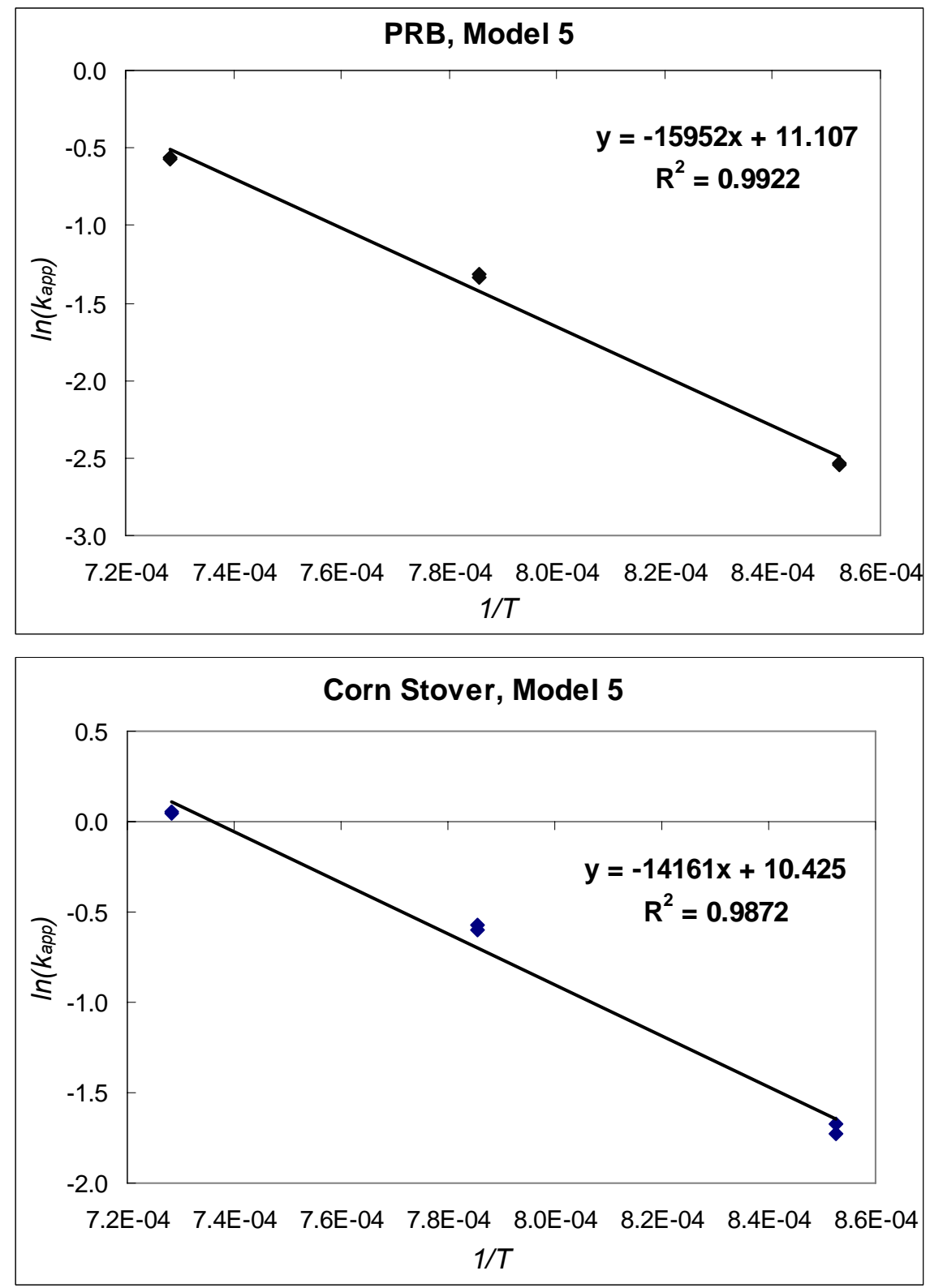

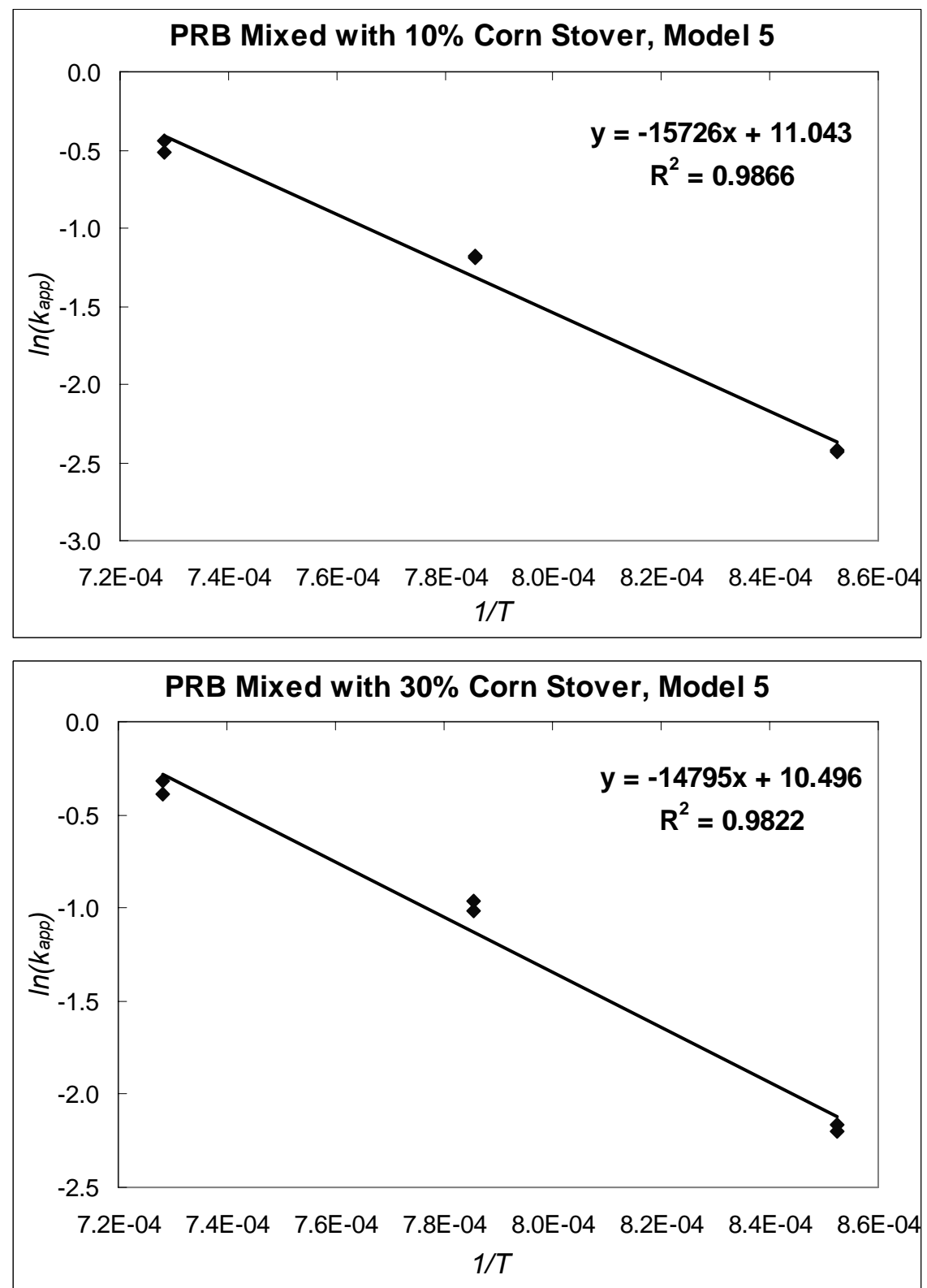

Note:

Total 12 plots are about $E_{a p p}$ regression based on Model 5 . 
Appendix C. Plots of apparent rate constant $\boldsymbol{k}_{a p p}$ fitted with Model 10

Group 1. ND lignite \& Hardwood chars (24 plots)
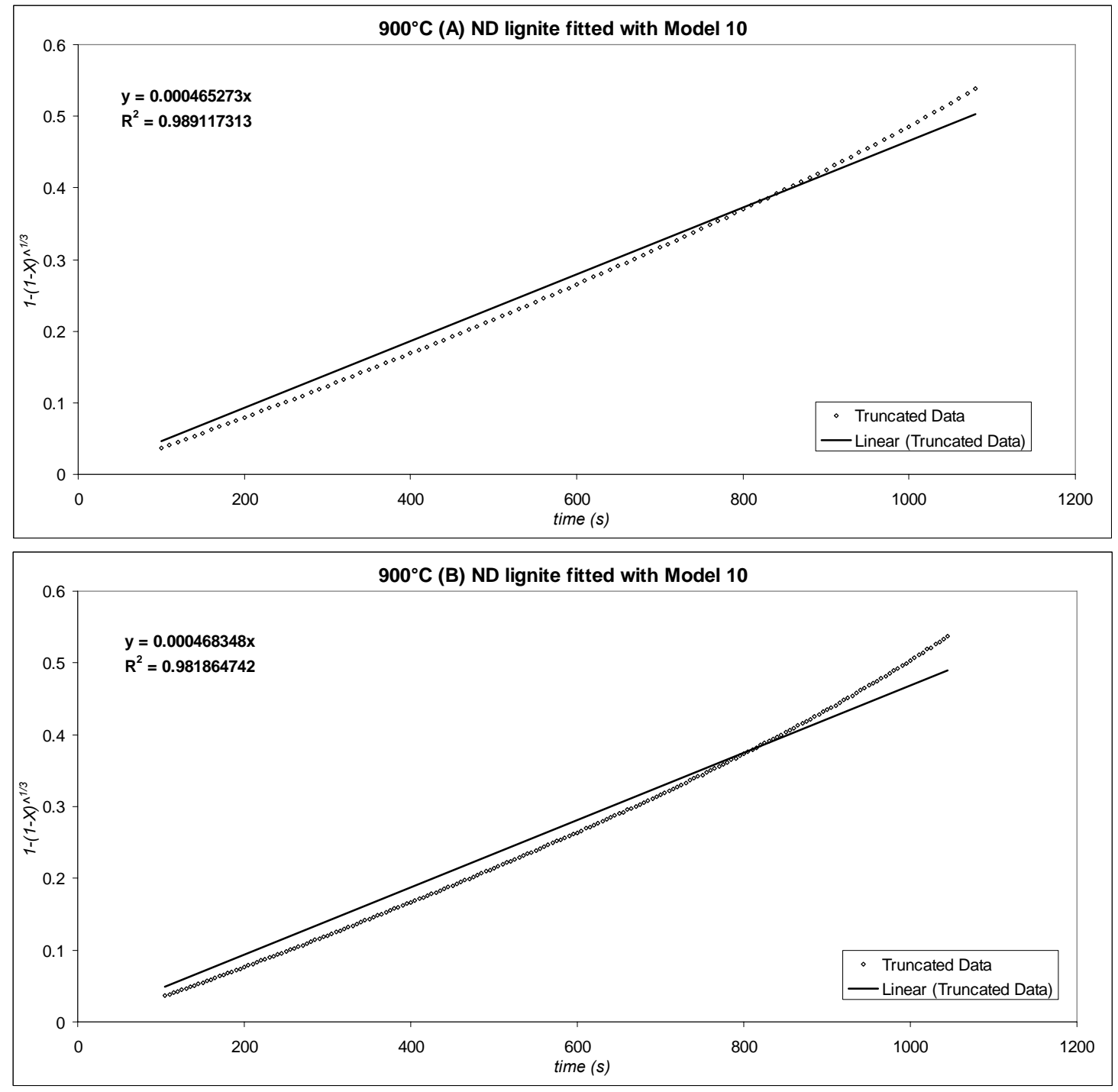

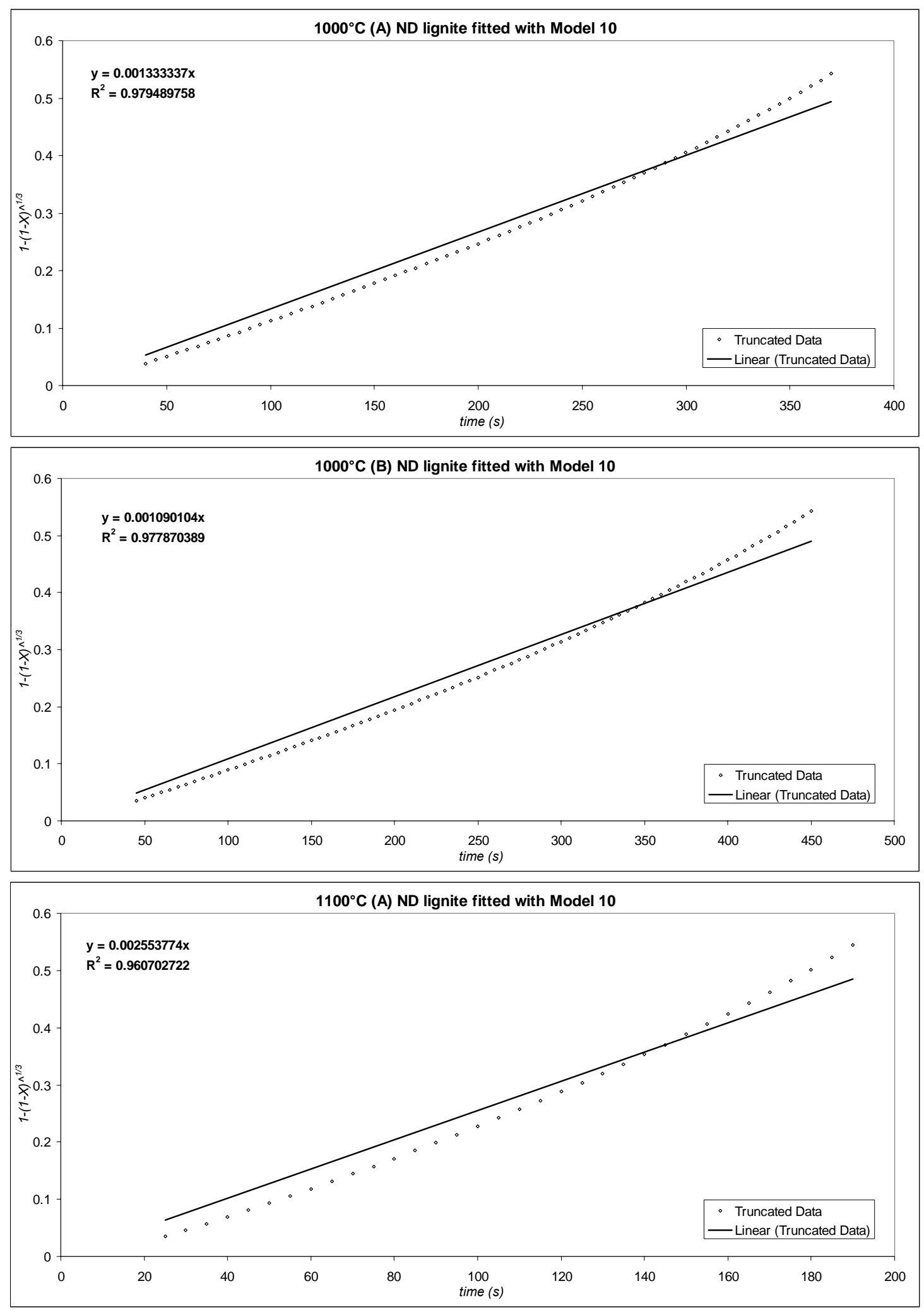

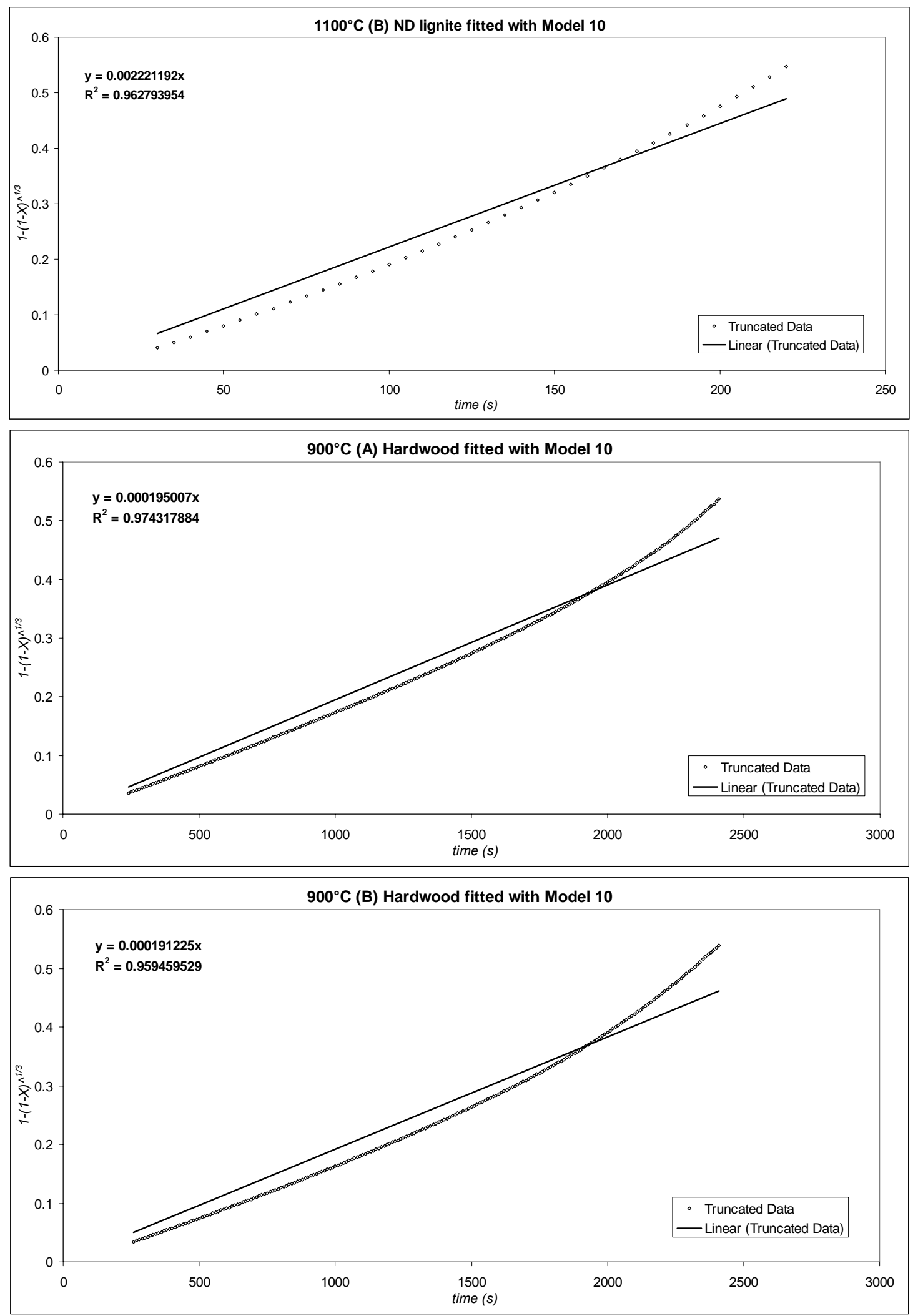

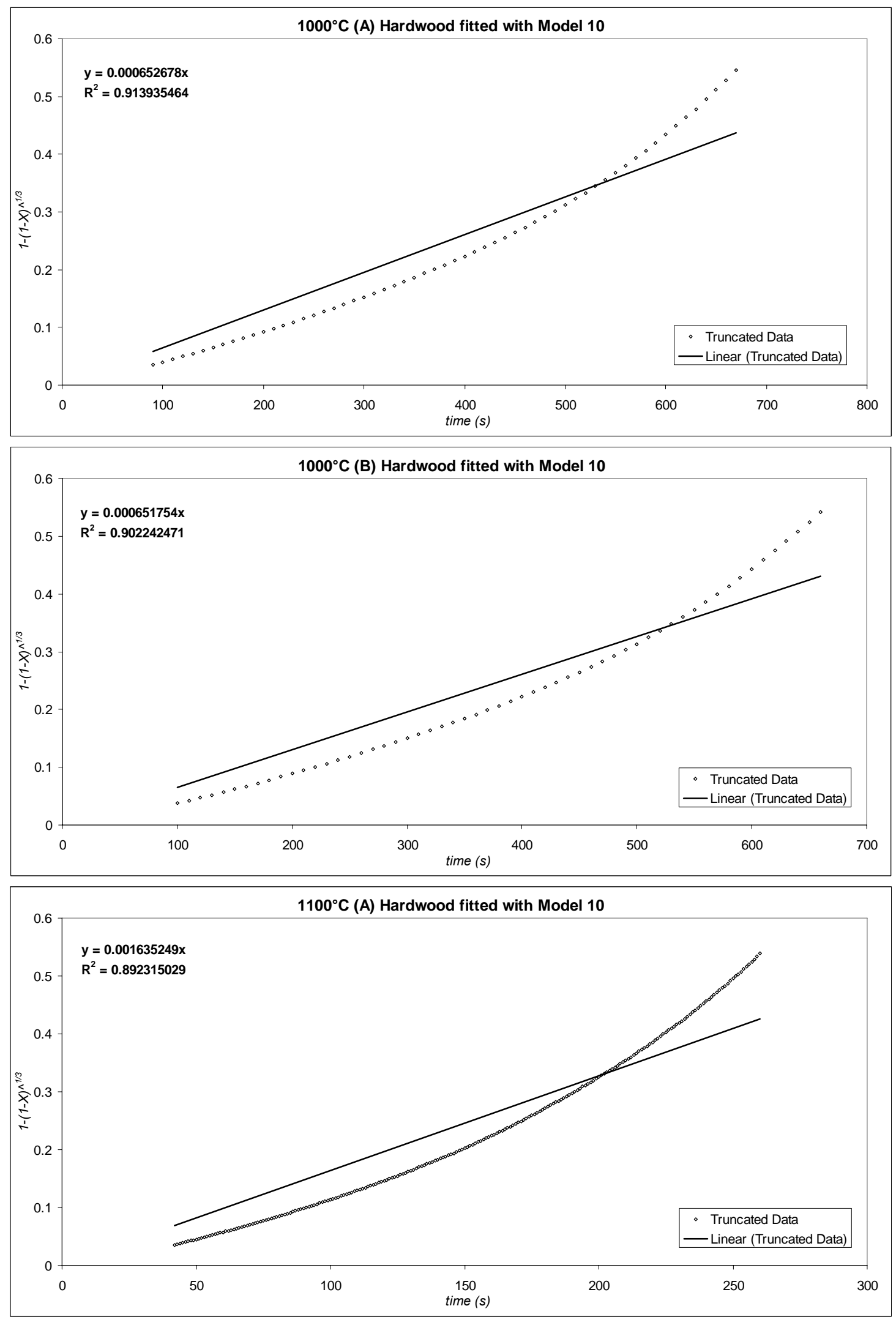

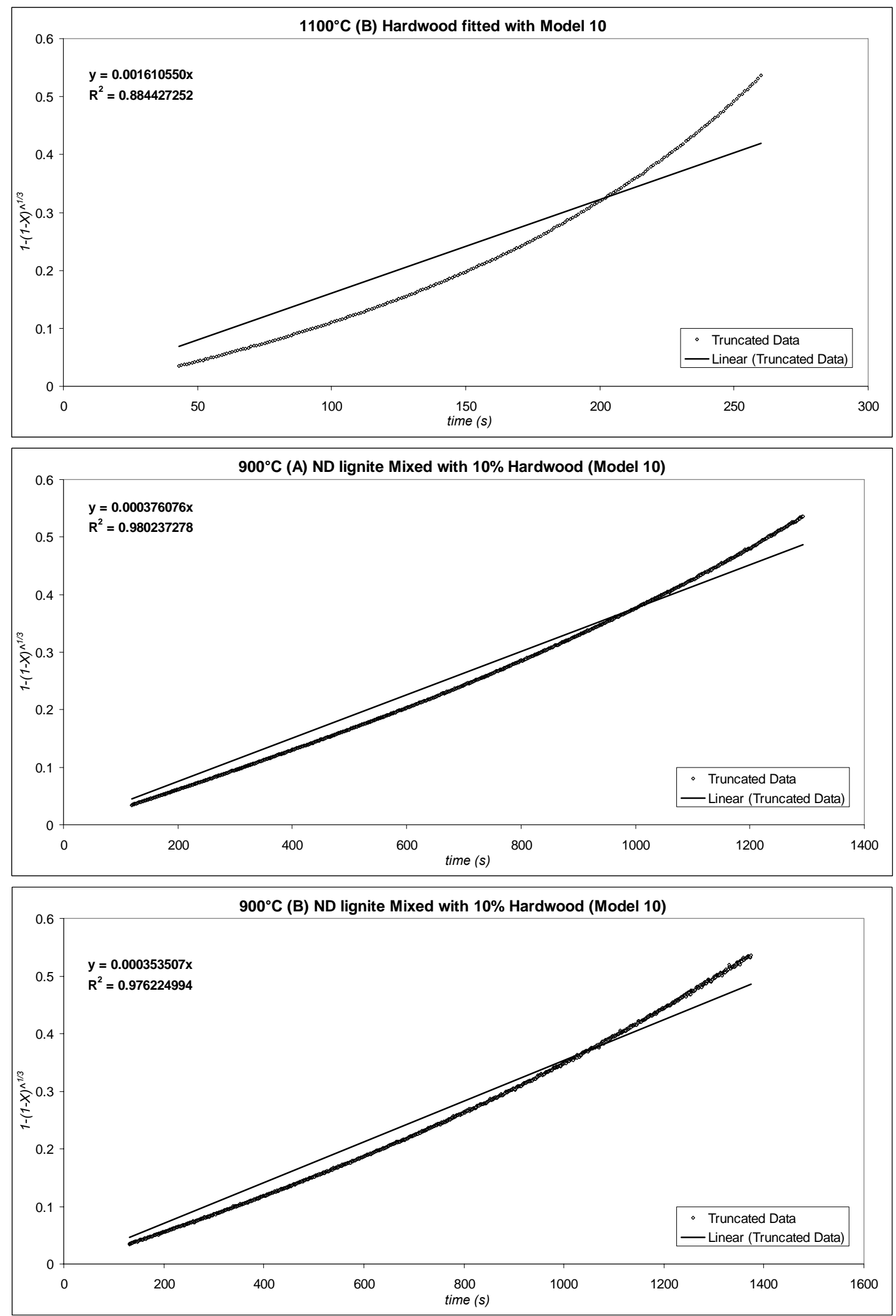

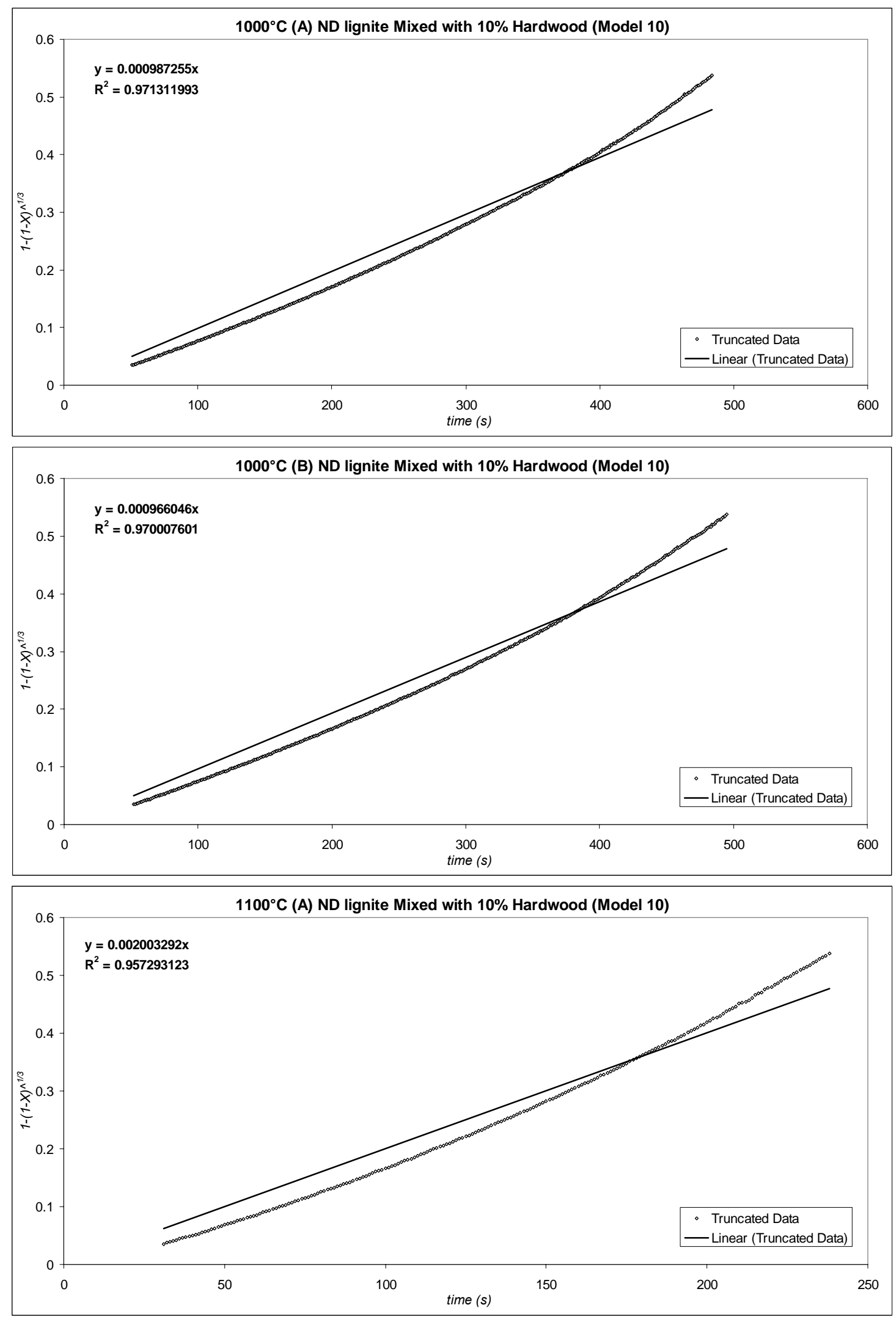

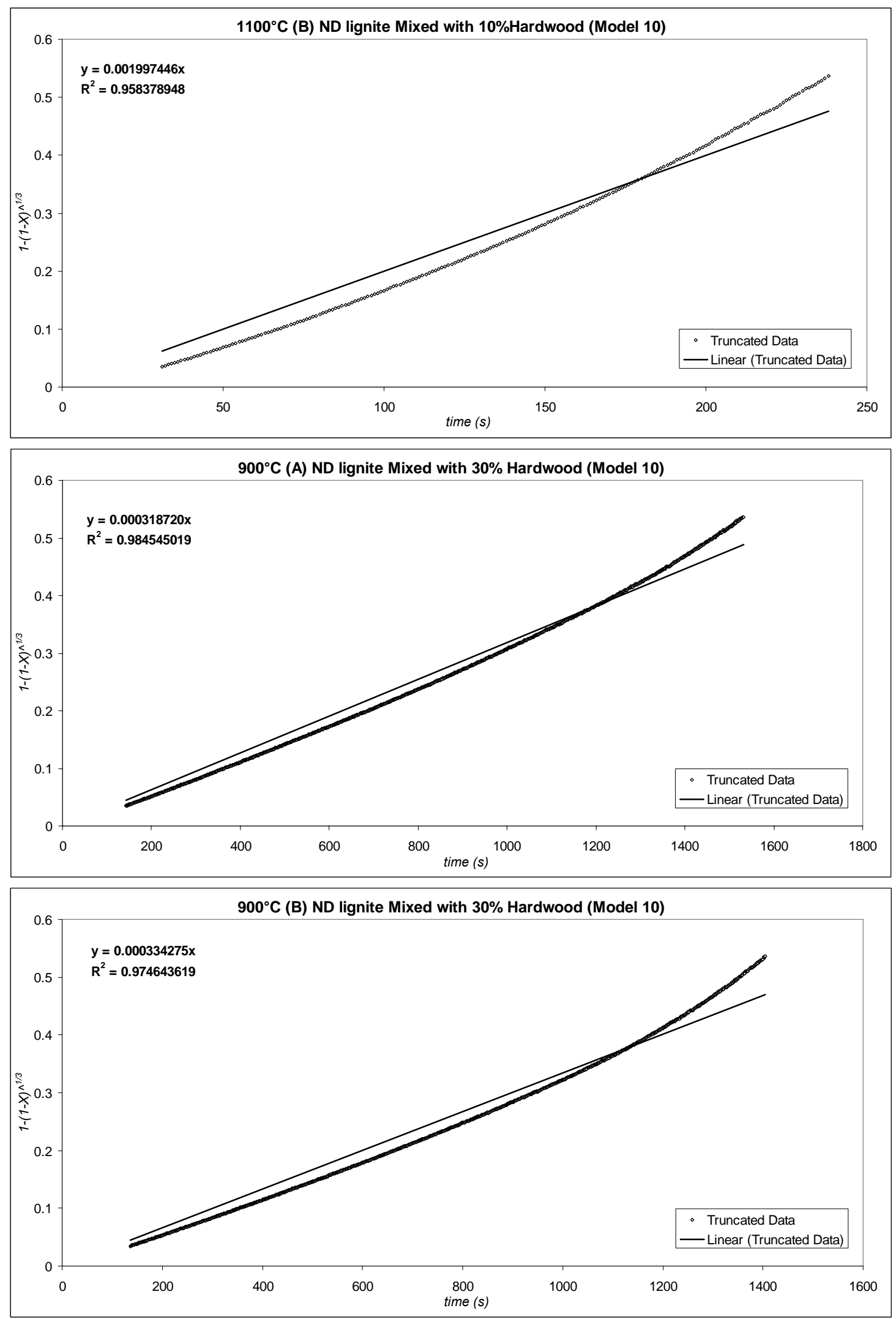

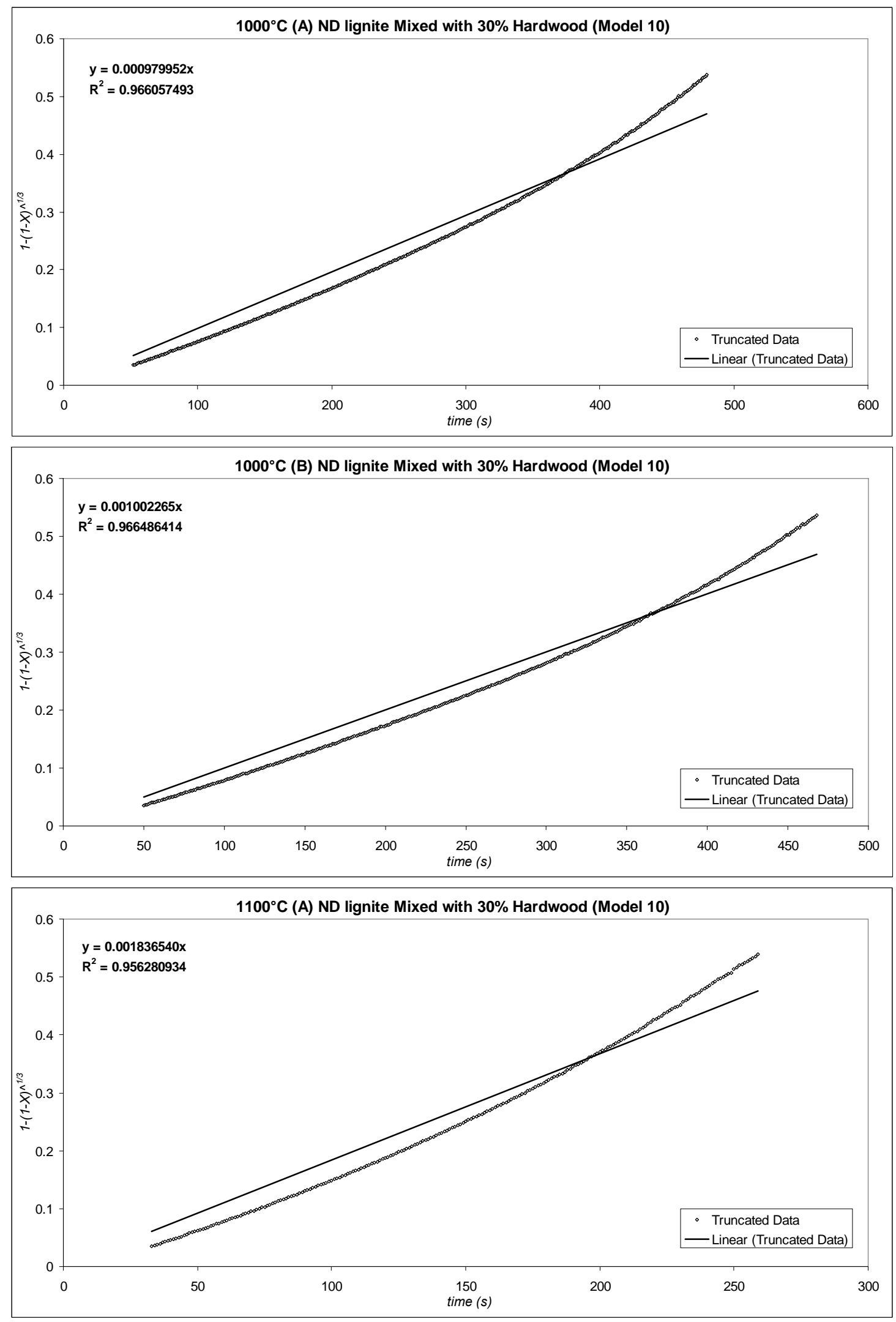


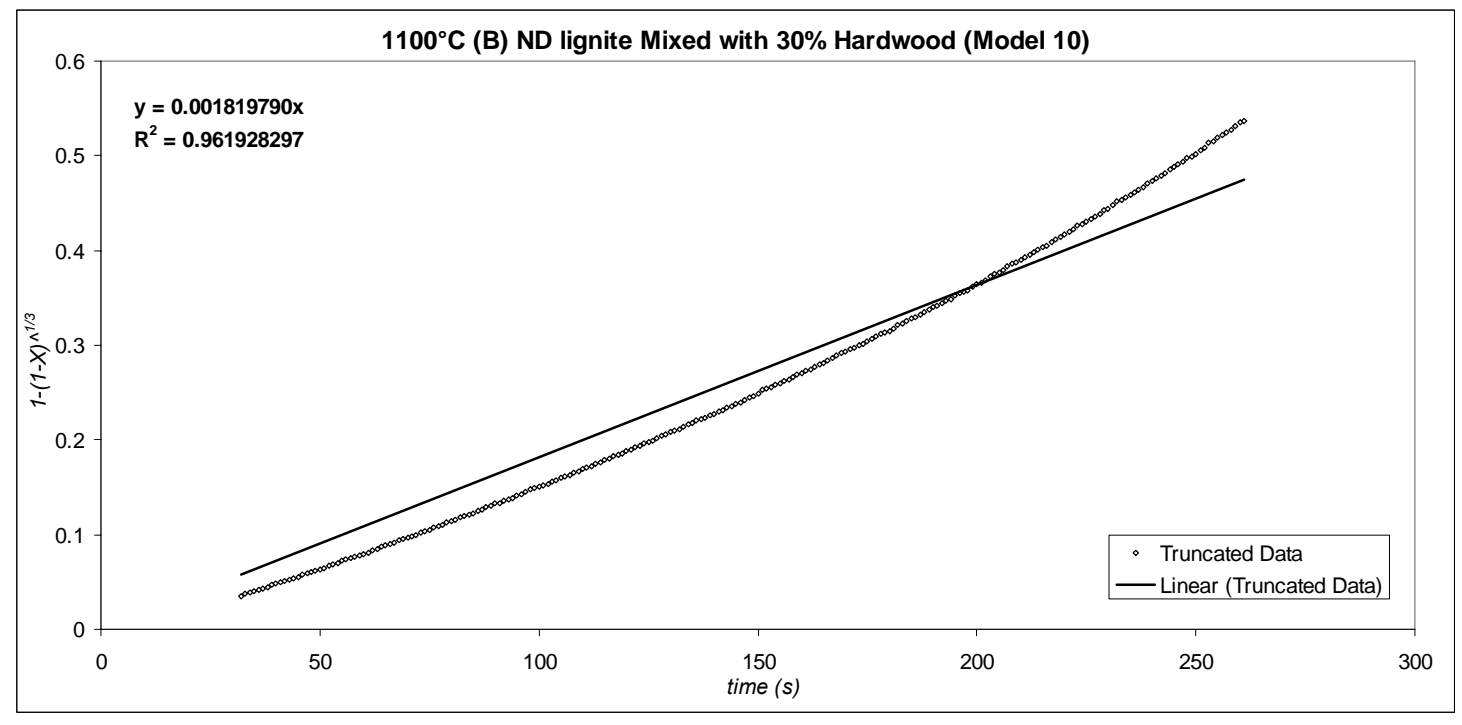


Group 2. ILL No.6 \& Switchgrass chars (26 plots)
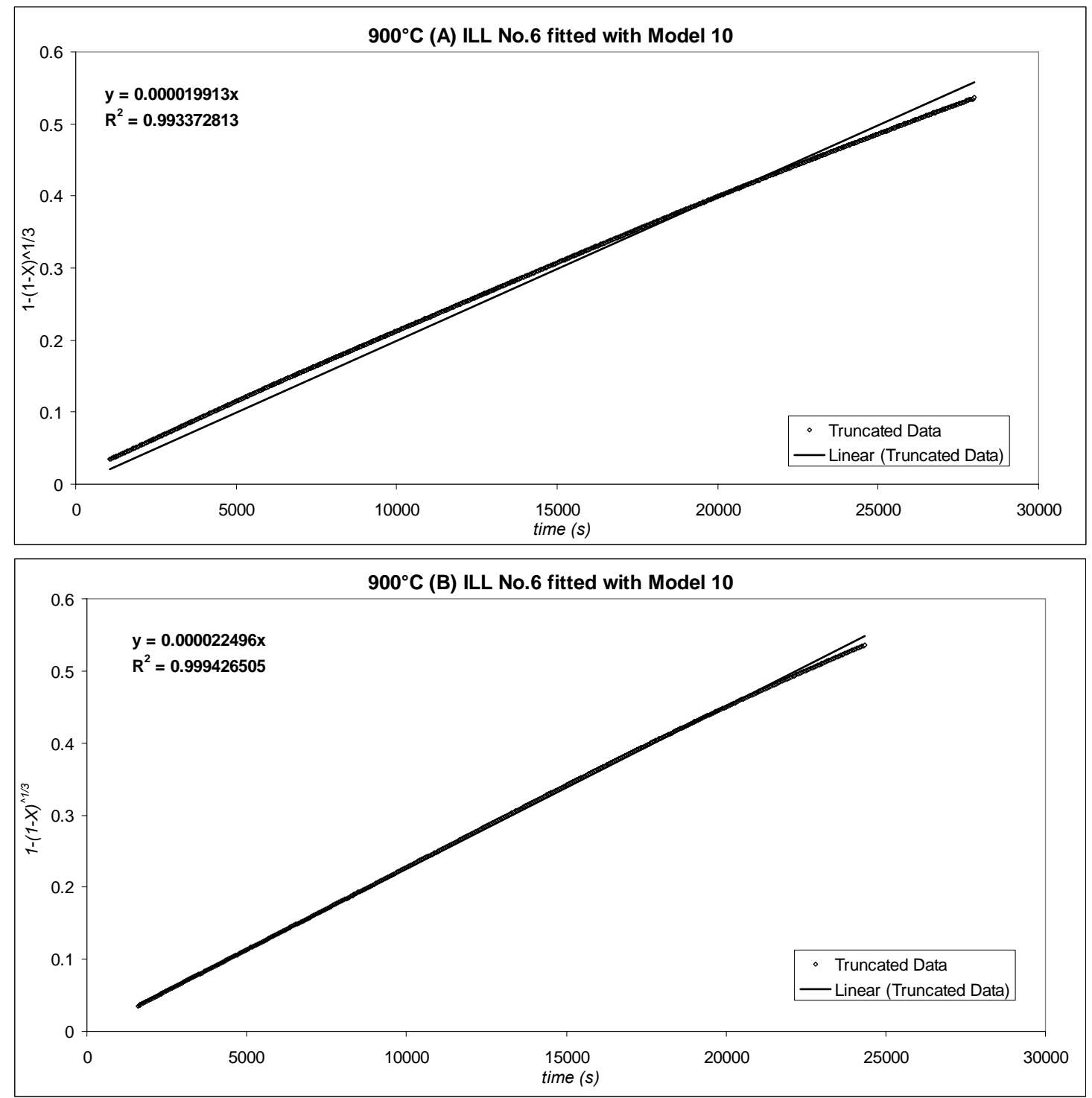

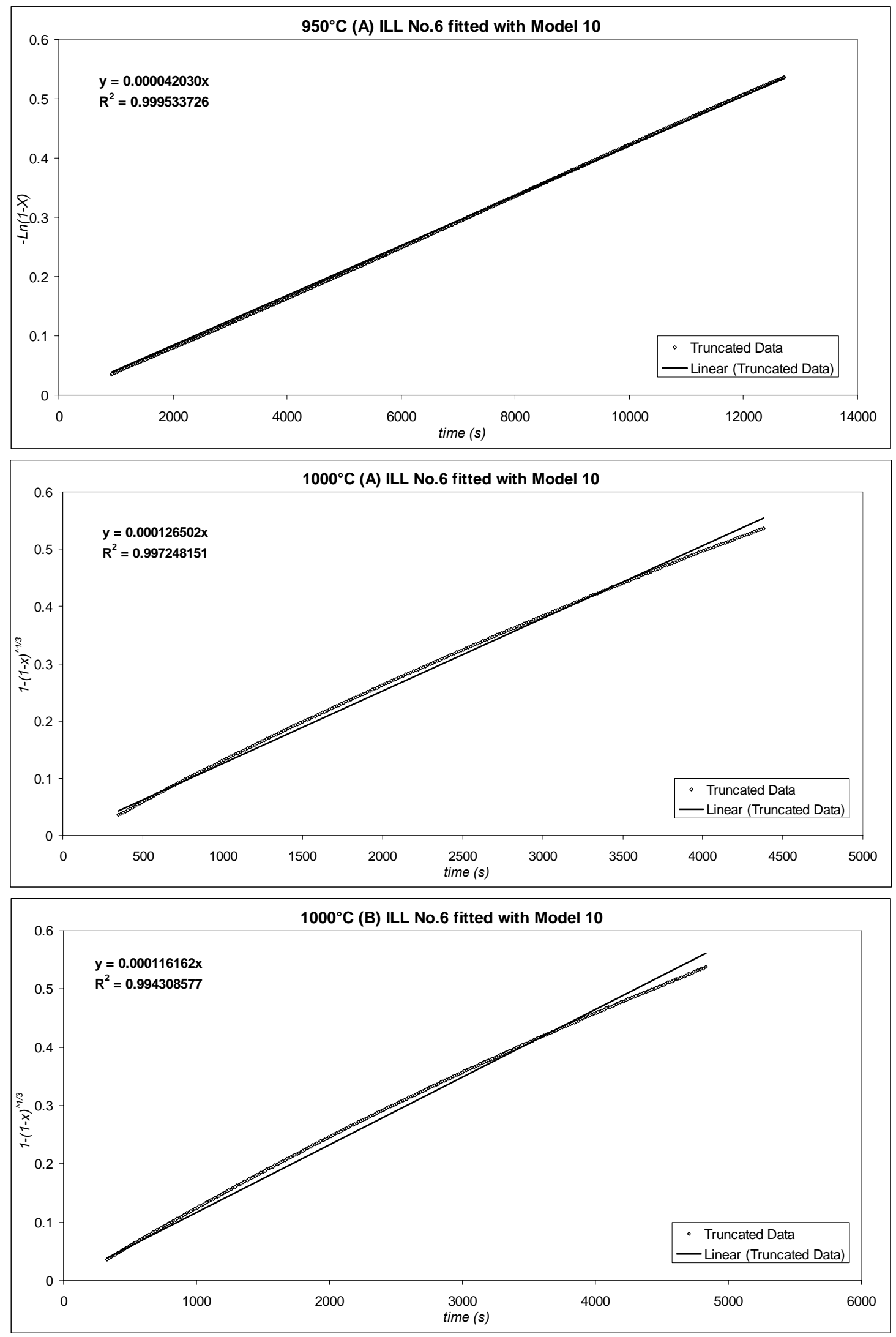

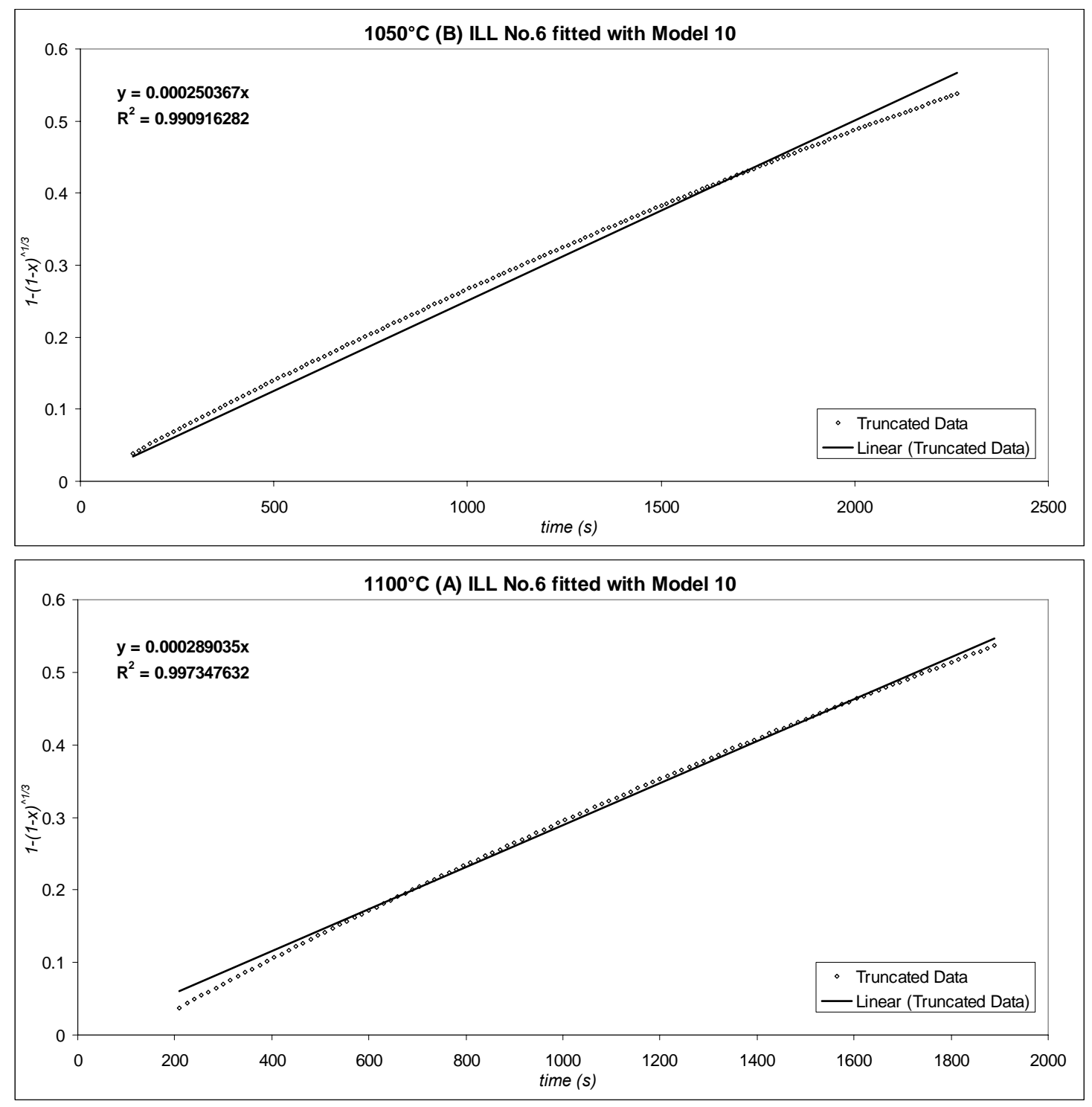

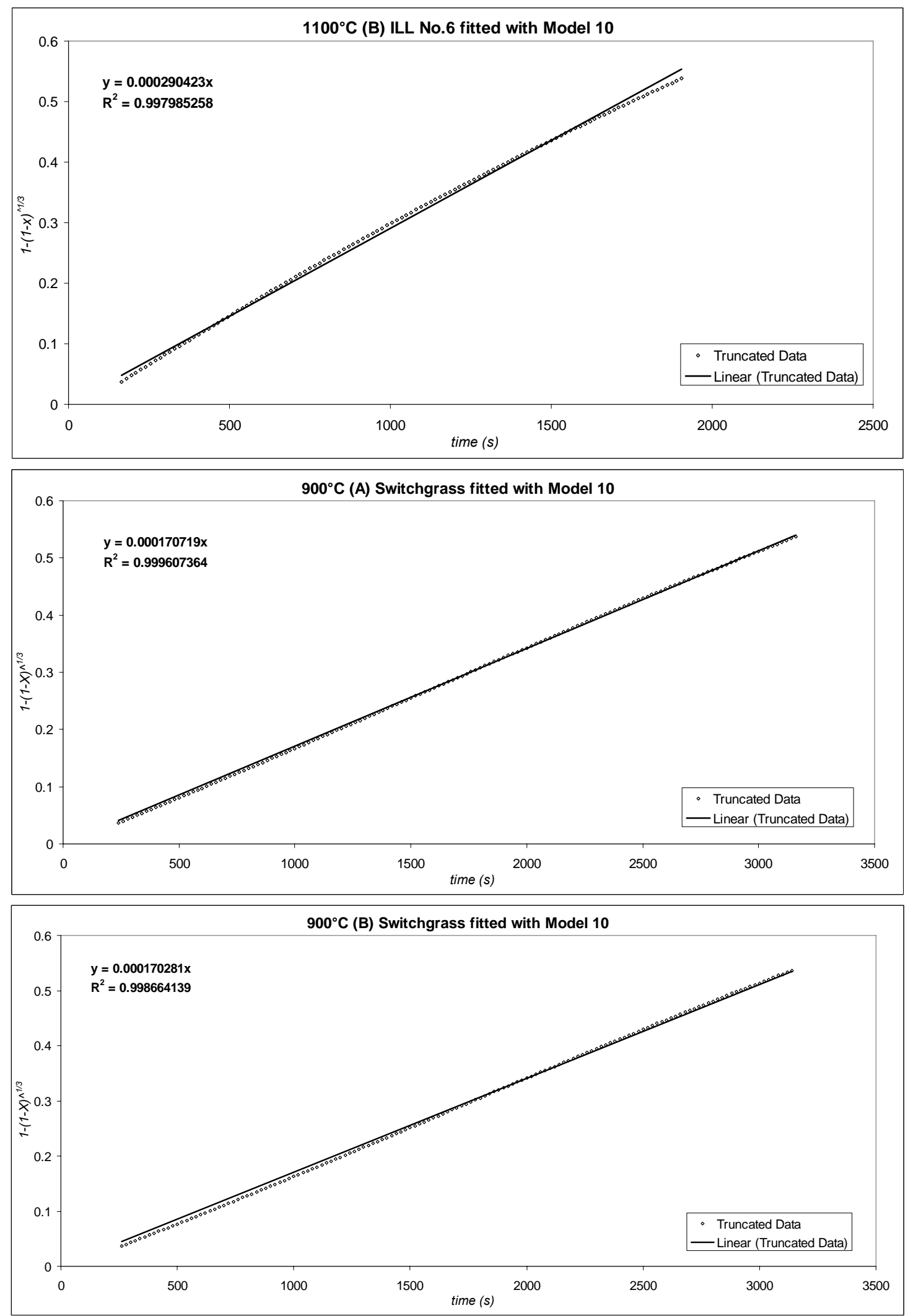

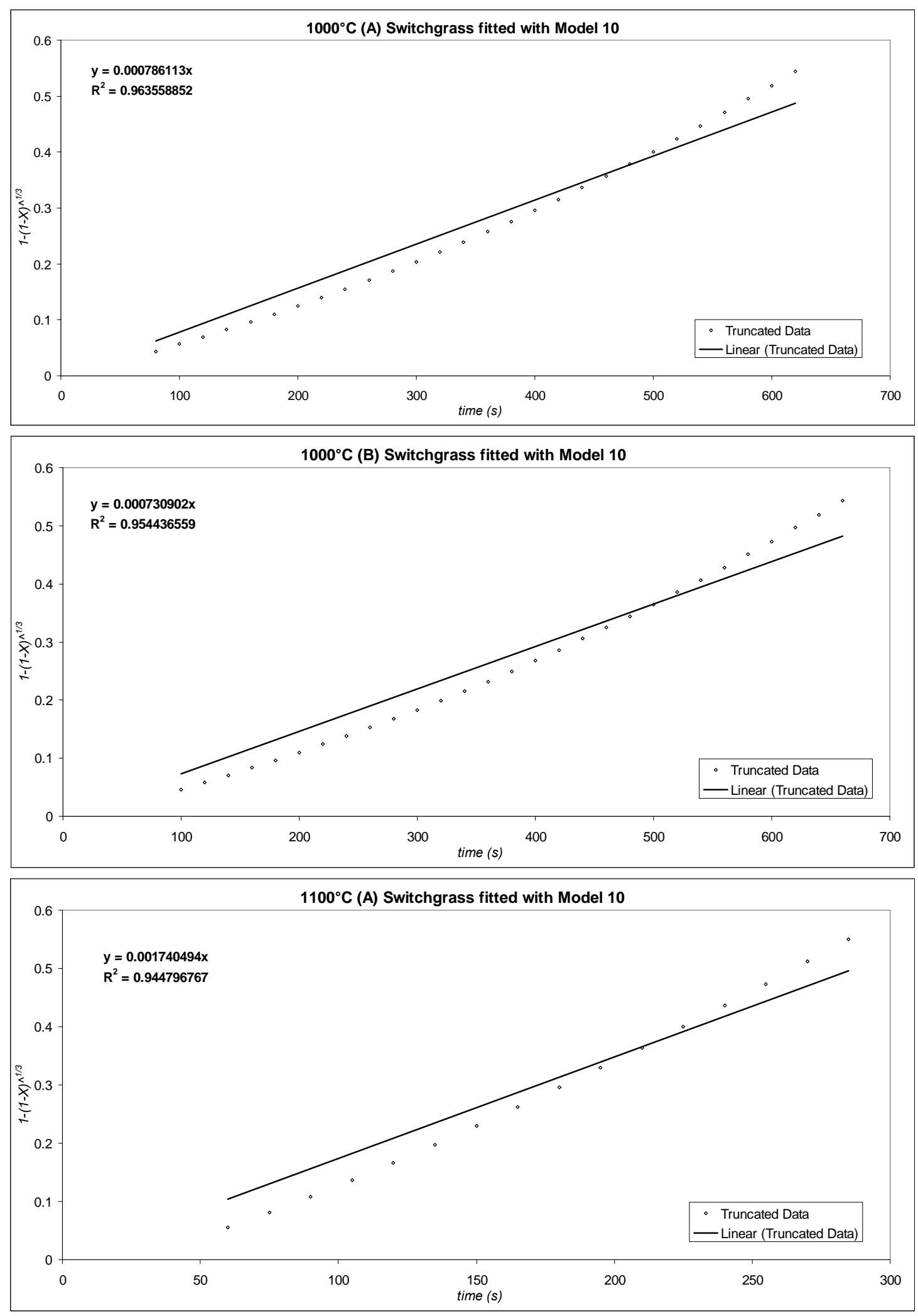

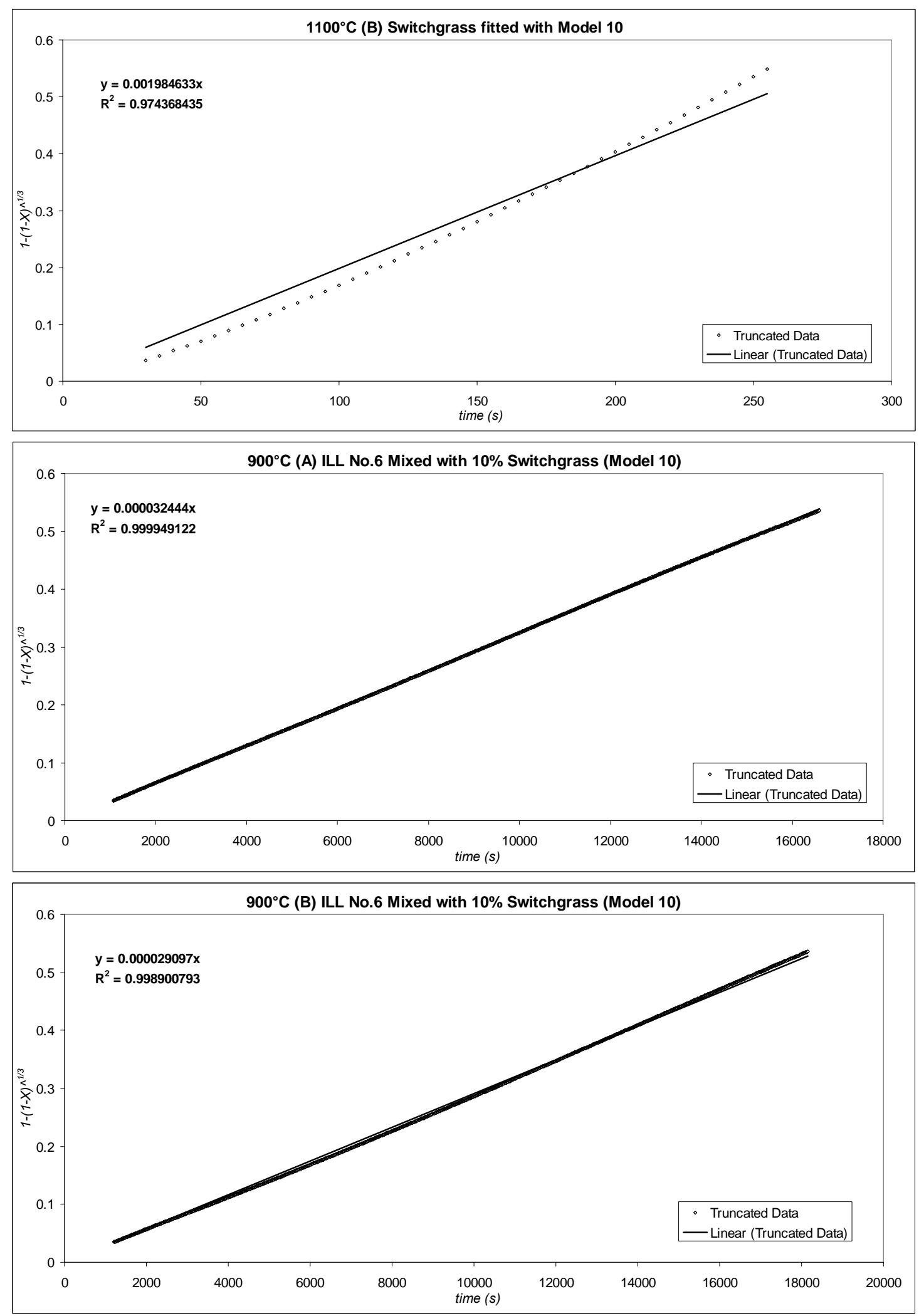

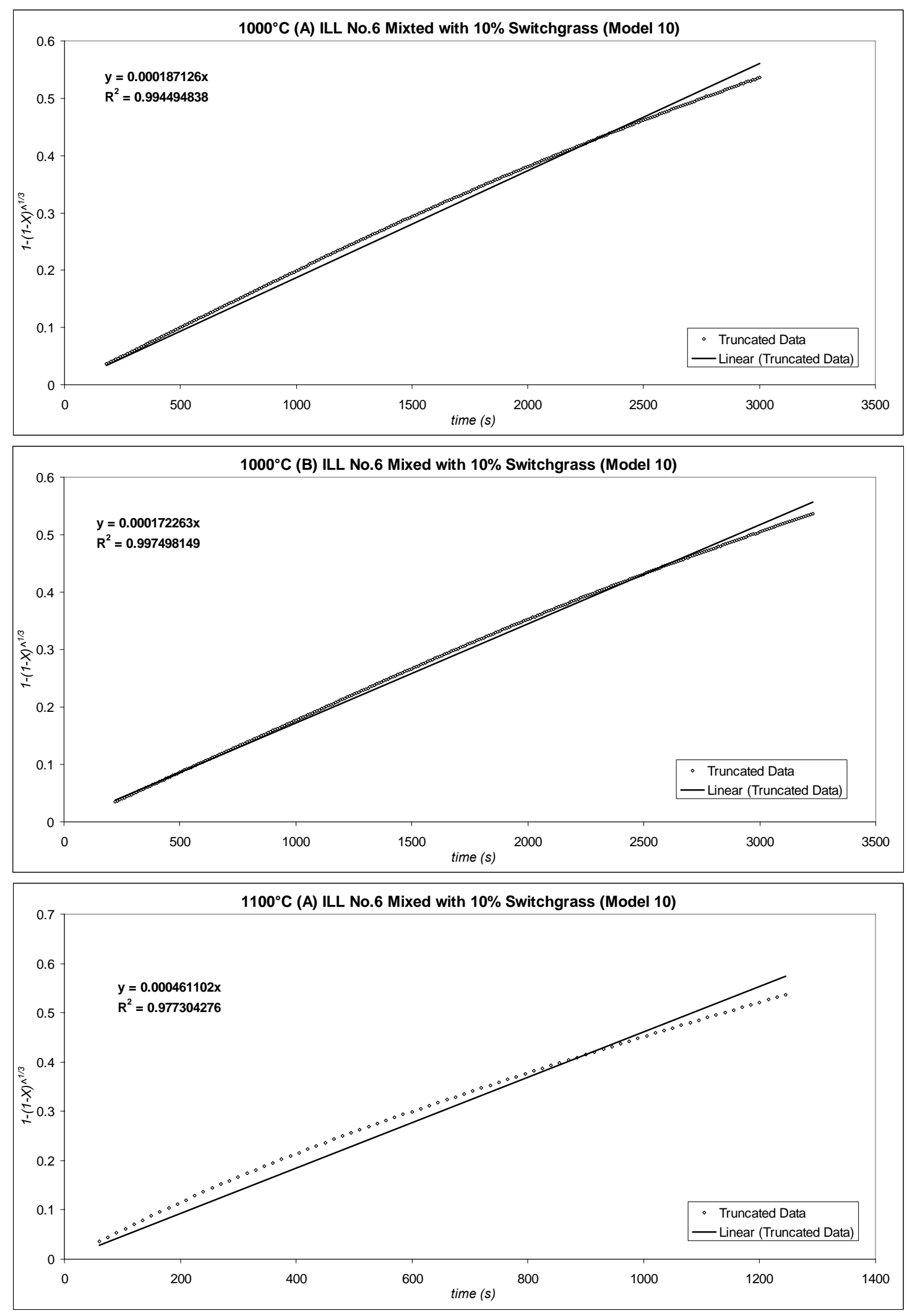

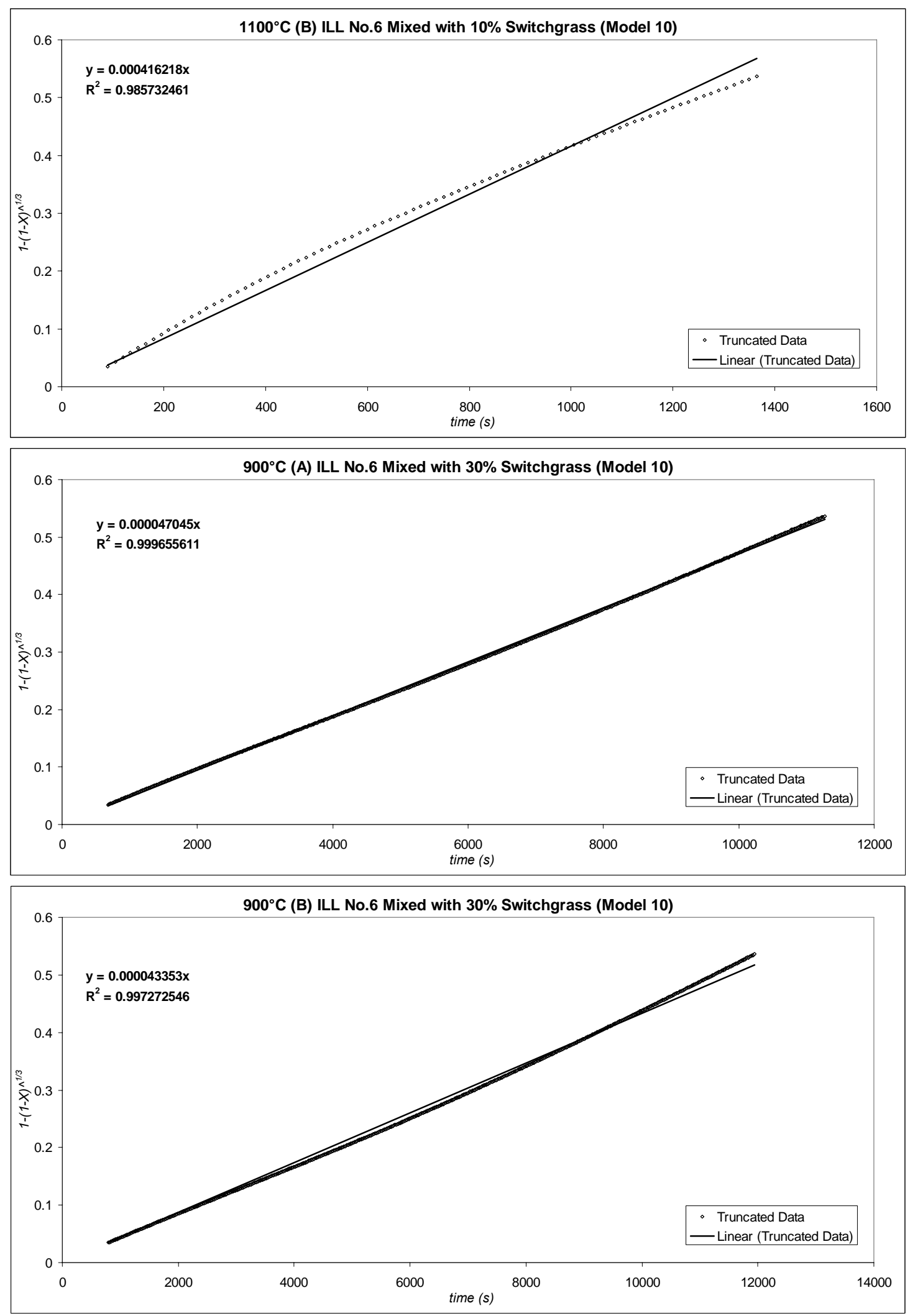

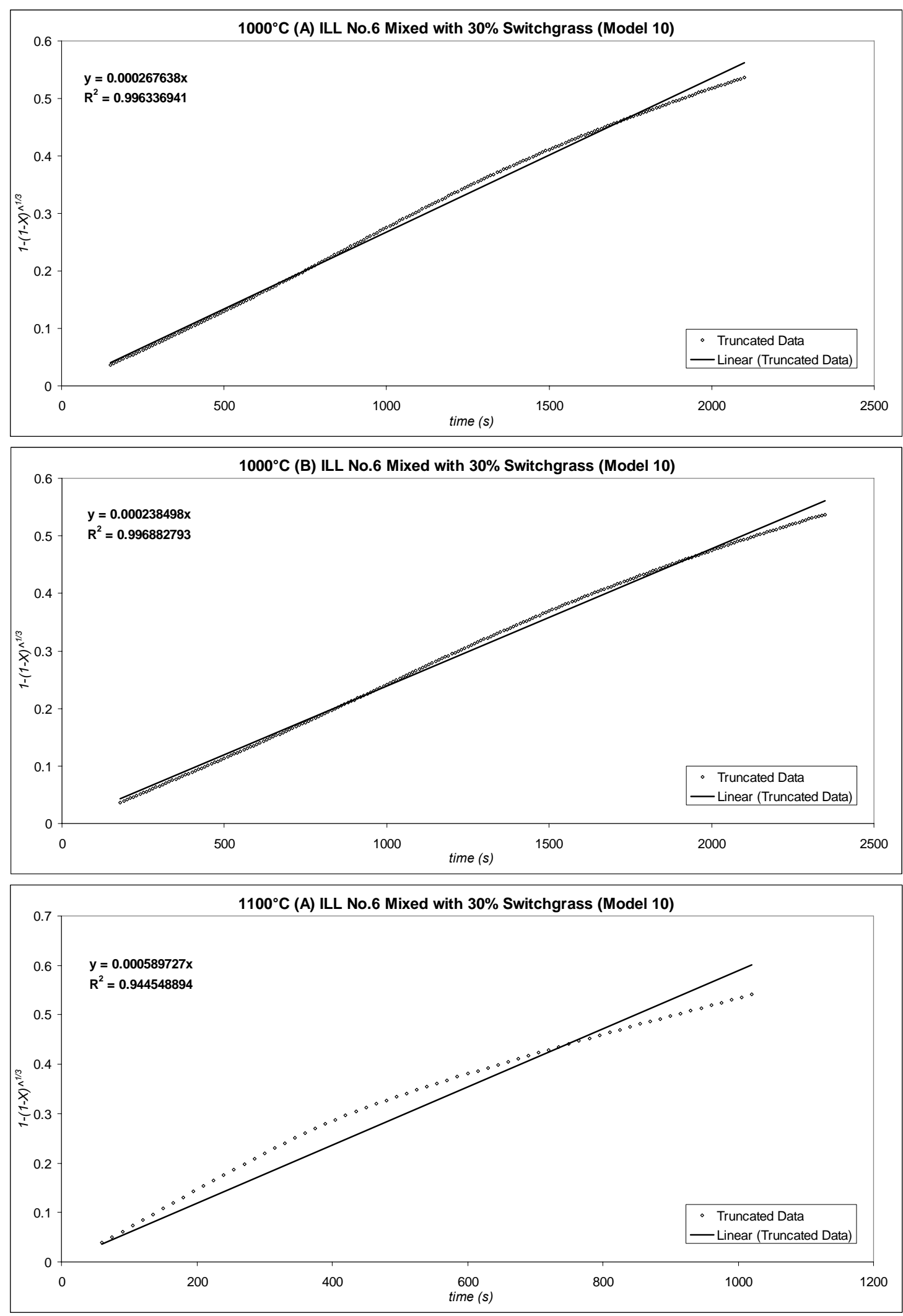


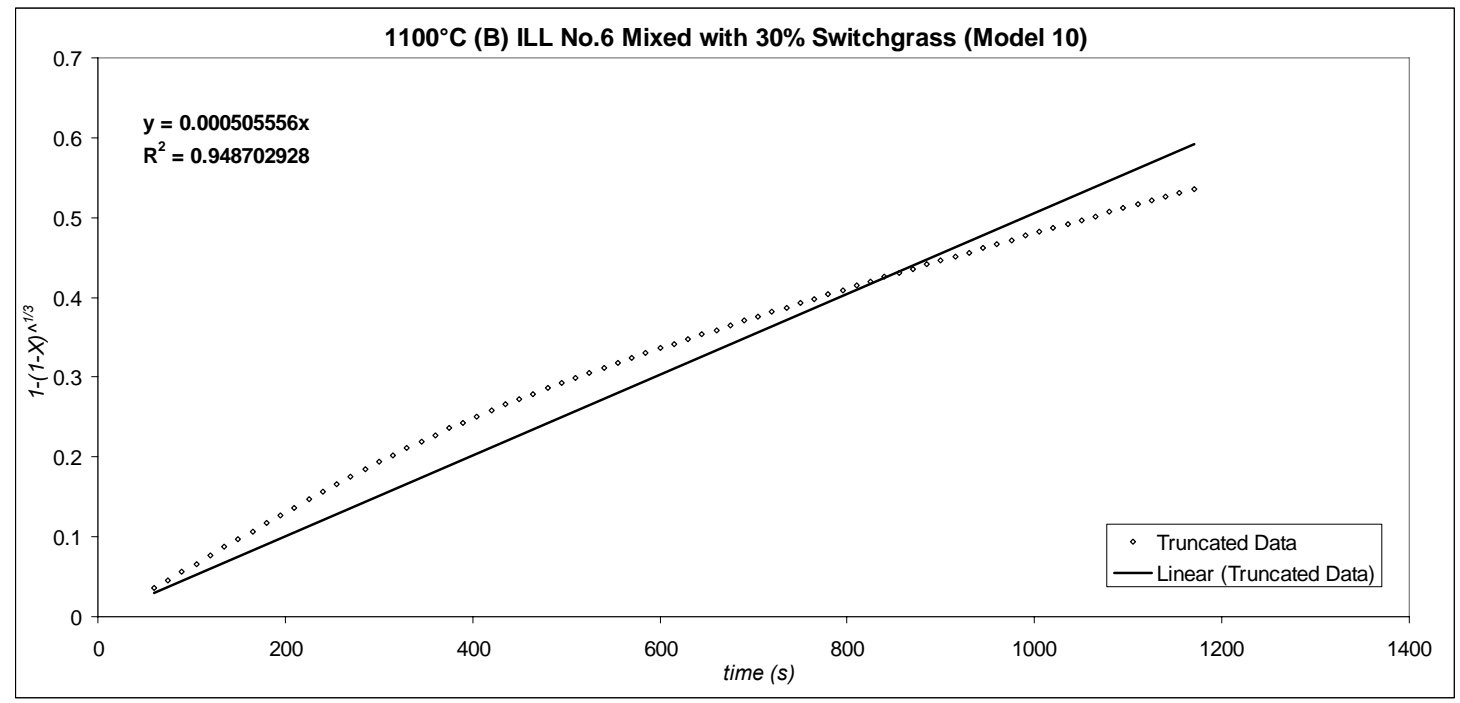


Group 3. PRB \& Corn Stover chars (24 plots)
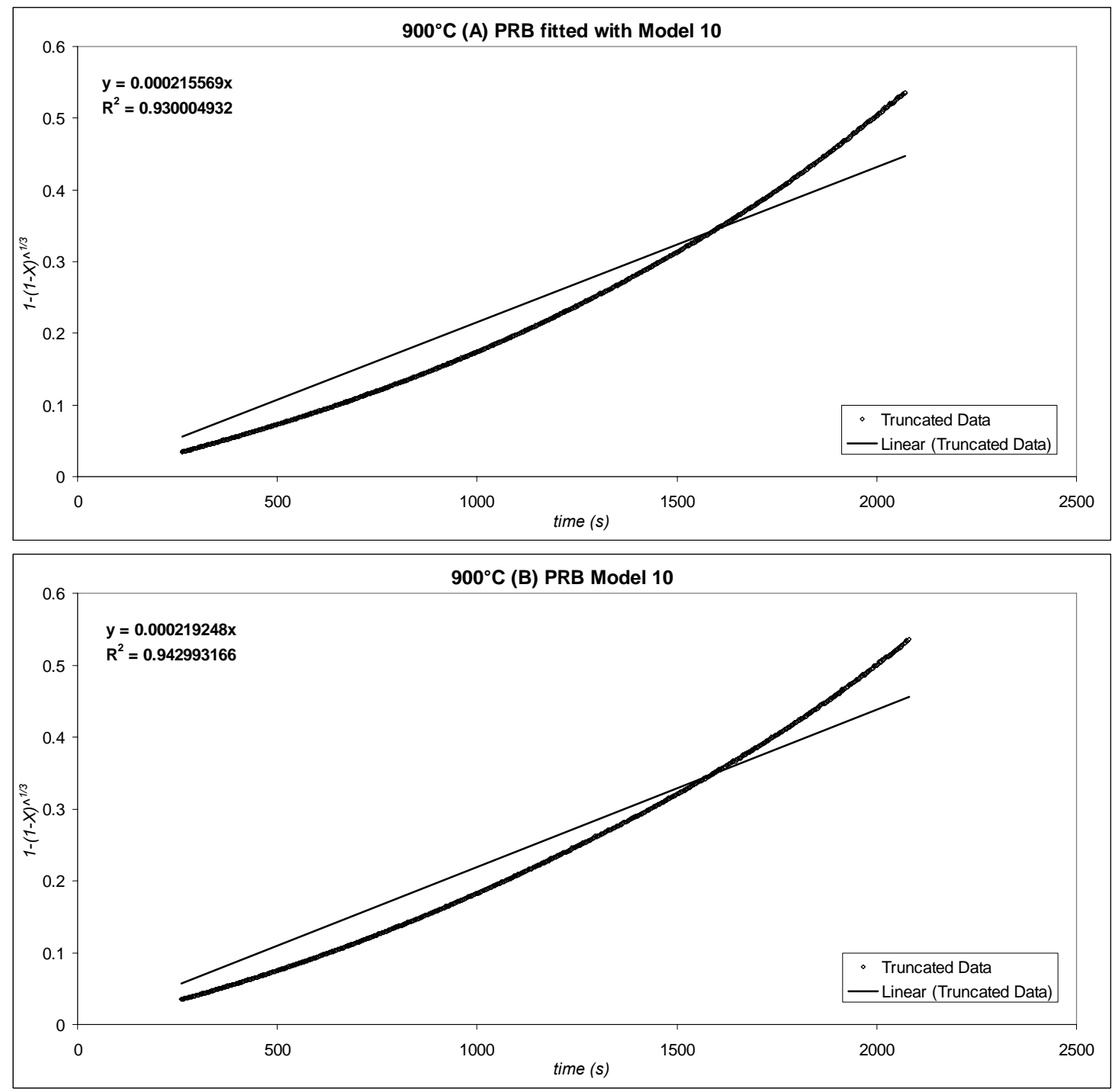

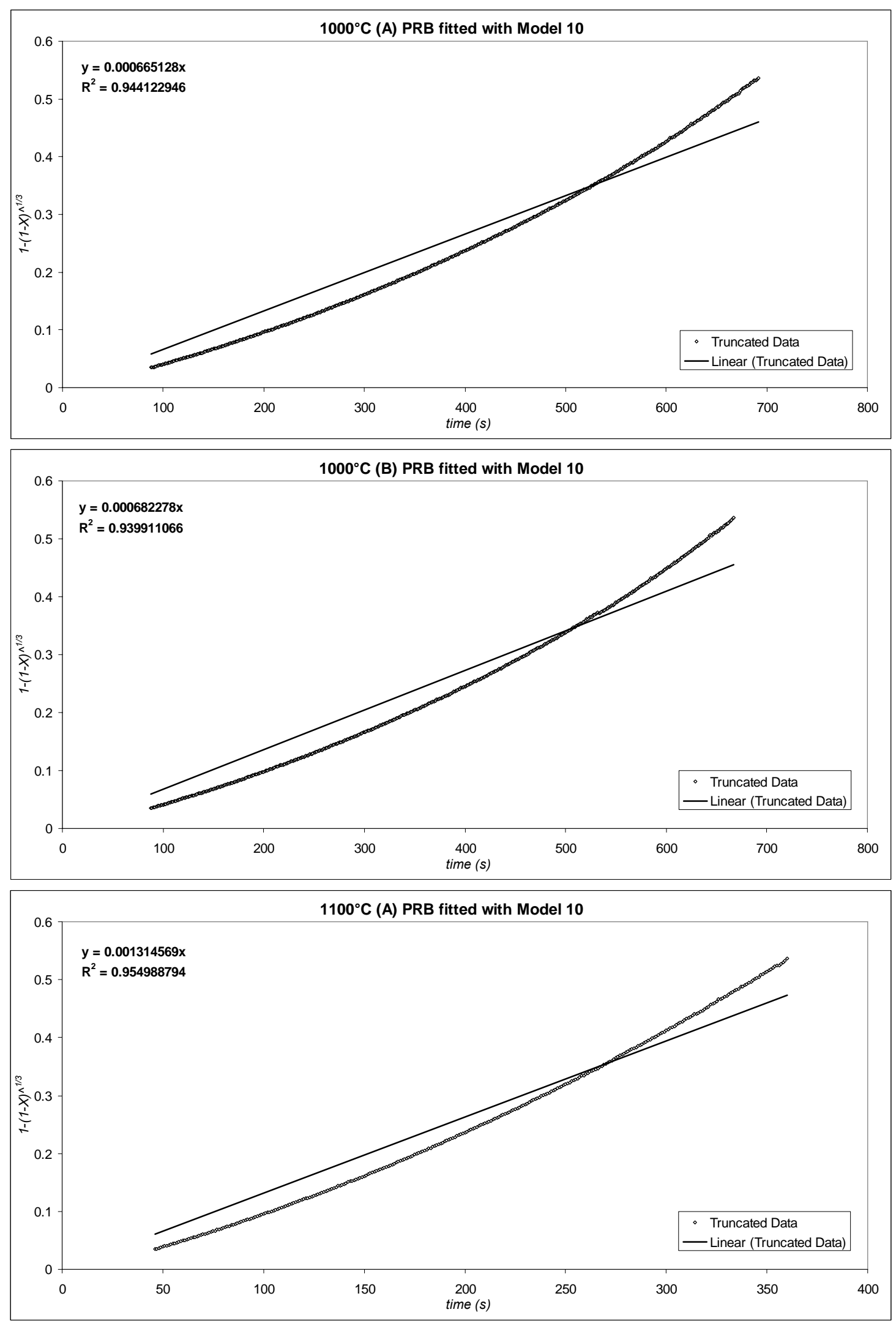

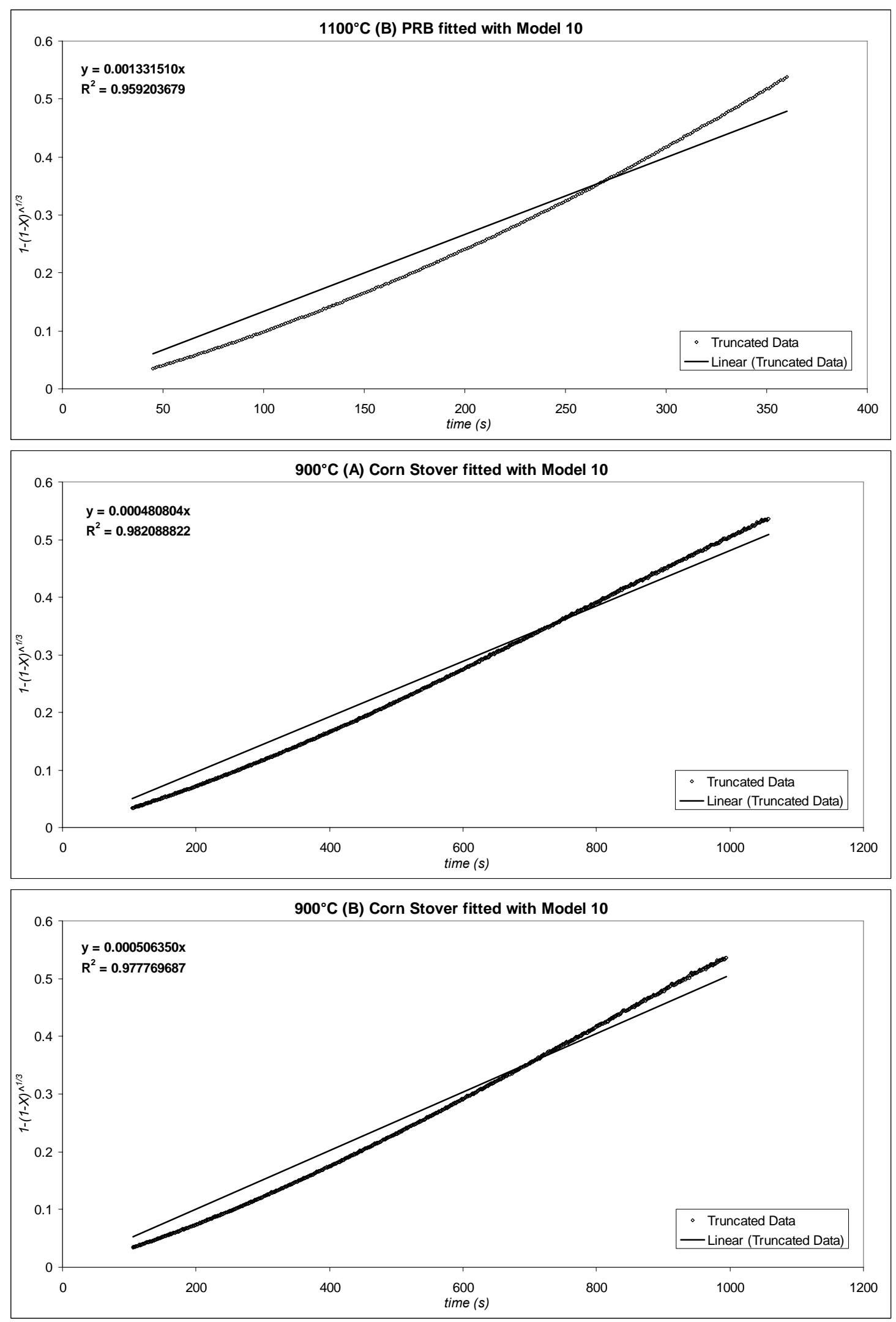

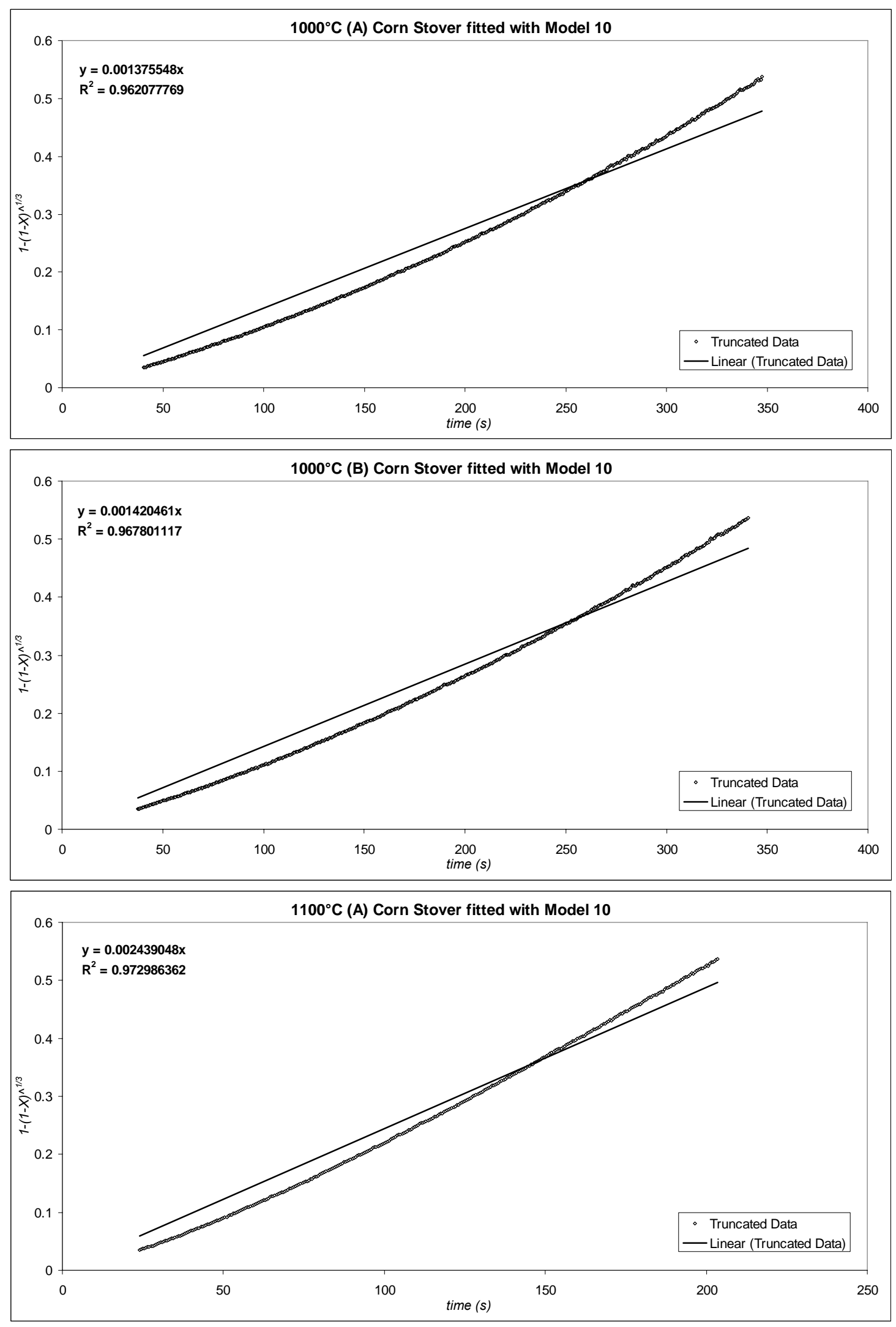

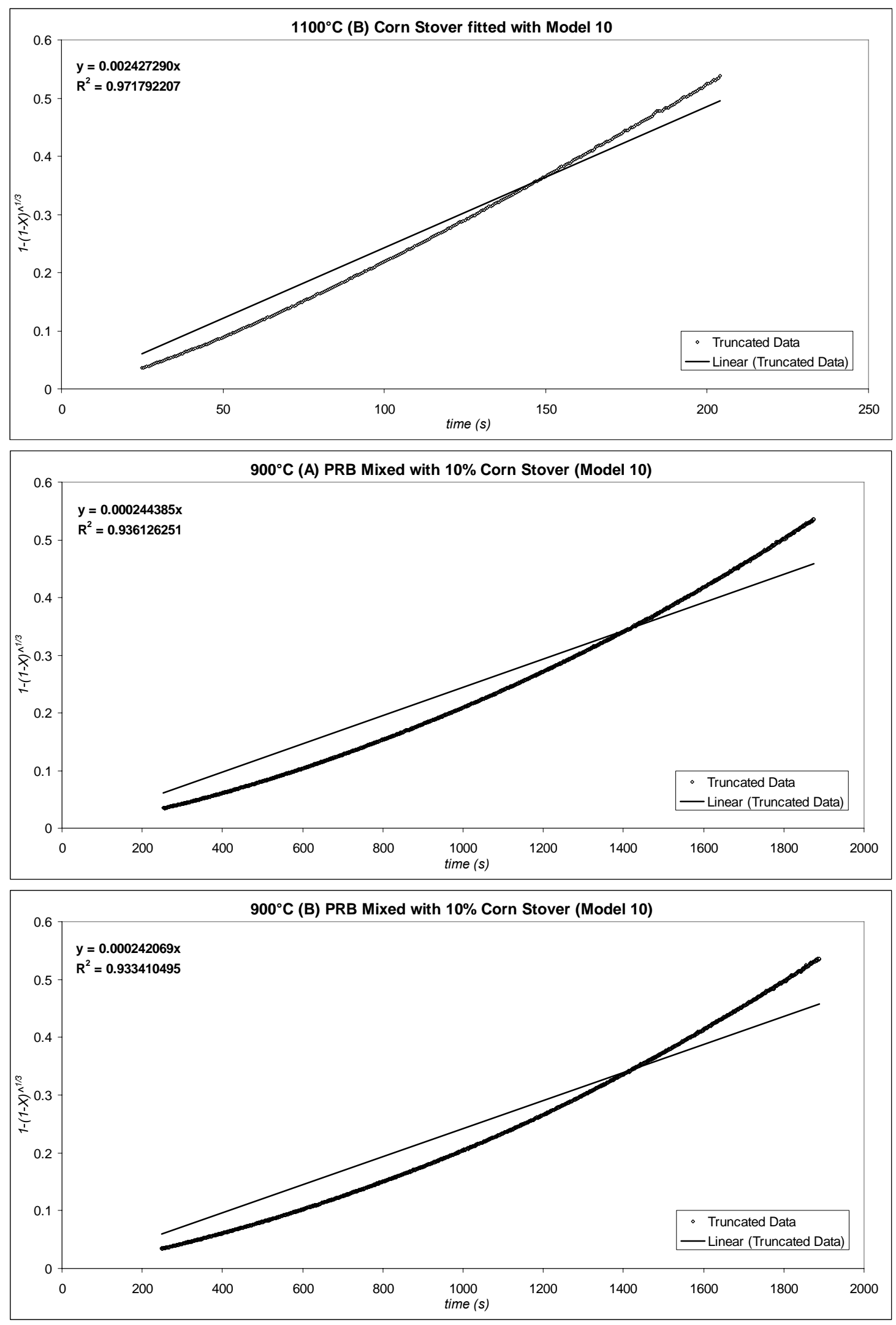

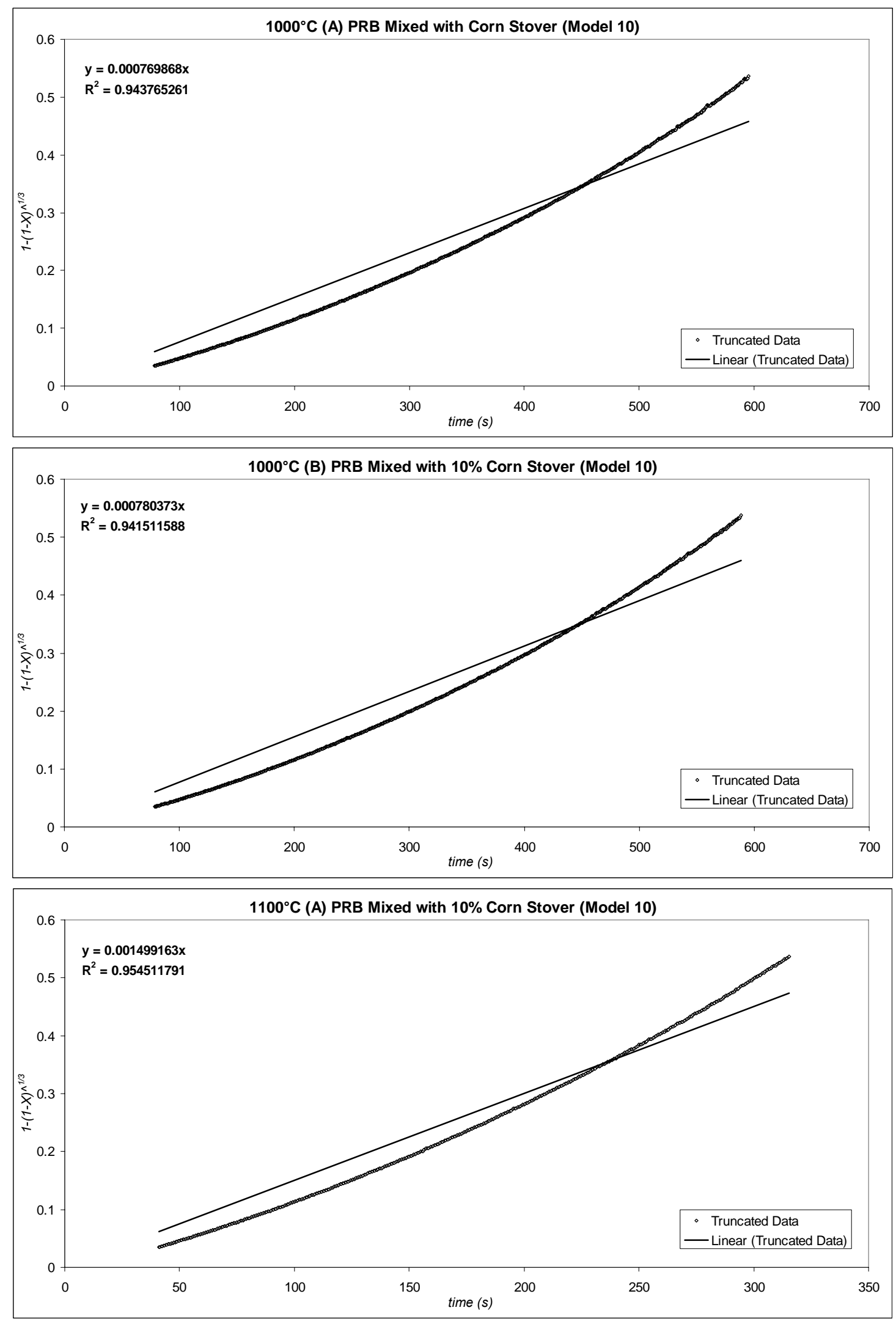

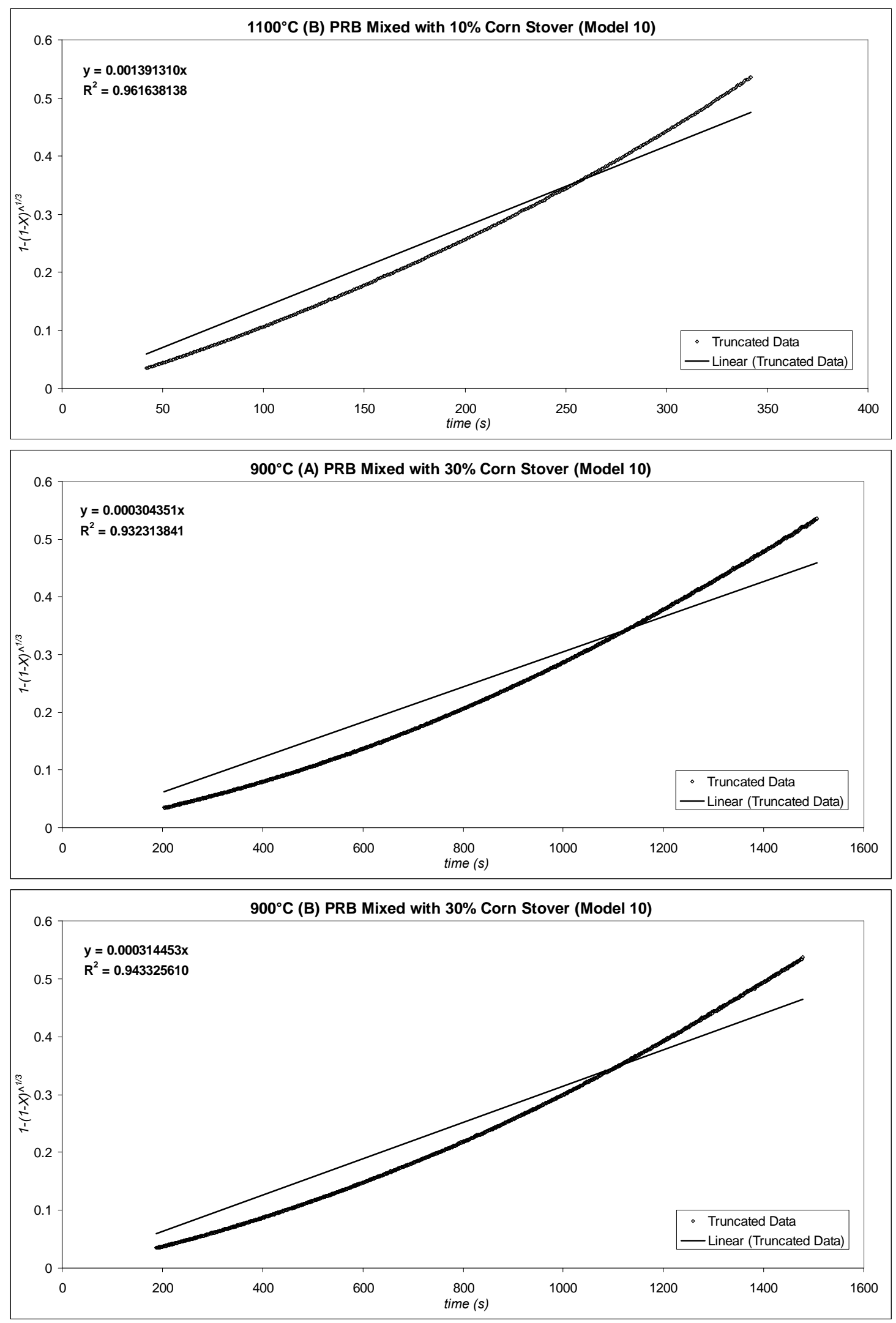

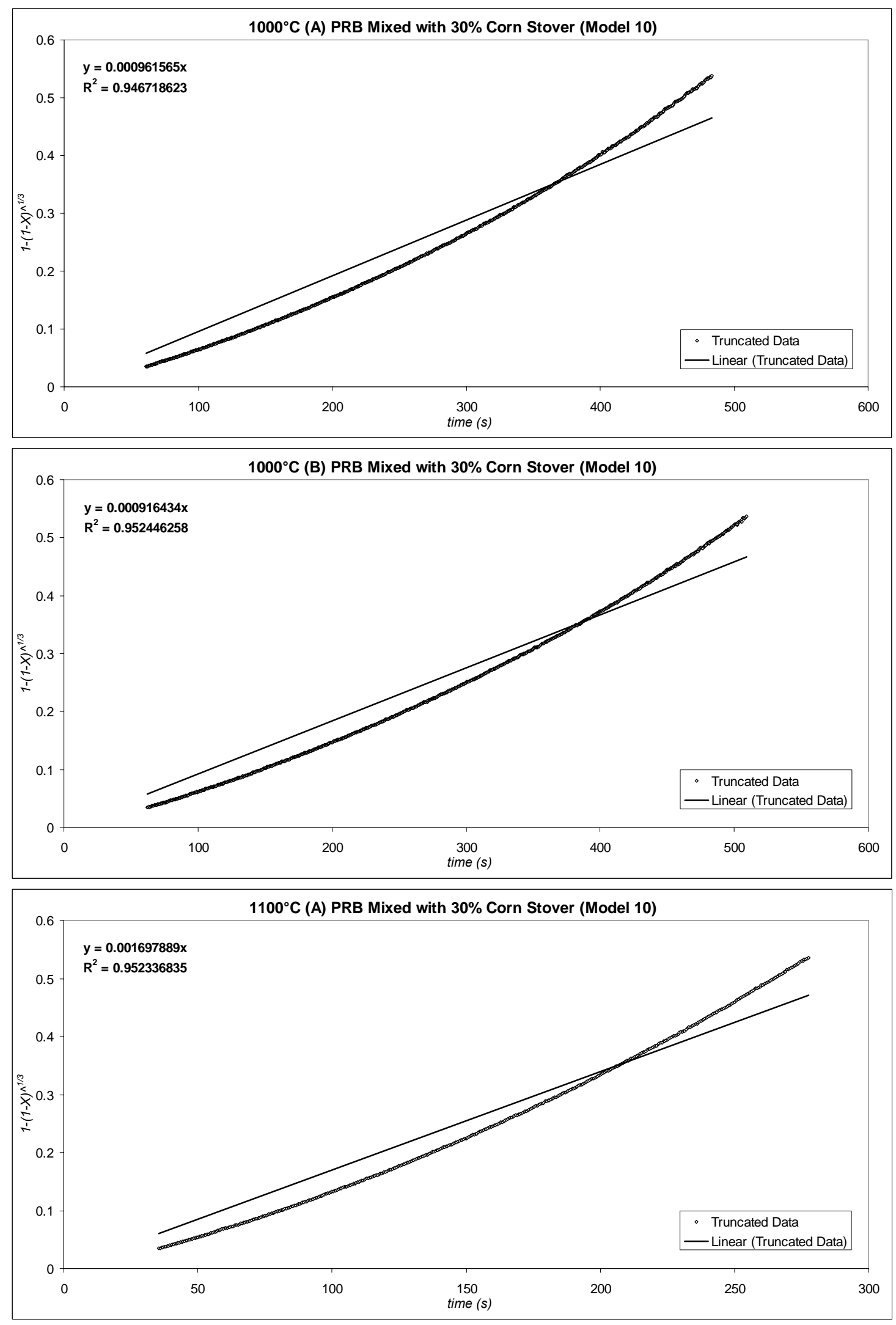


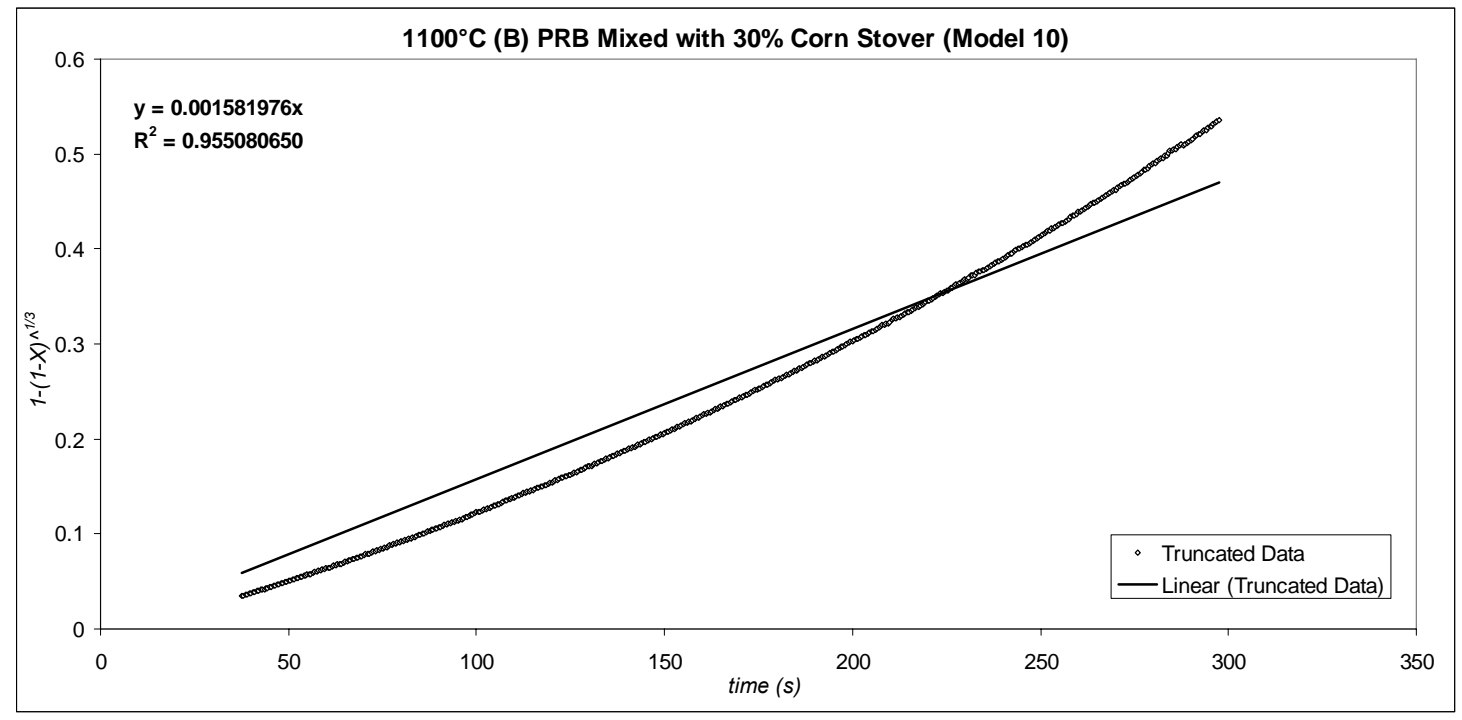

Note:

Total 74 plots fitted with Model 10 . 
Appendix D. Plots of $E_{a p p}$ regression based on Model 10

Group 1. ND lignite \& Hardwood chars (4 plots)
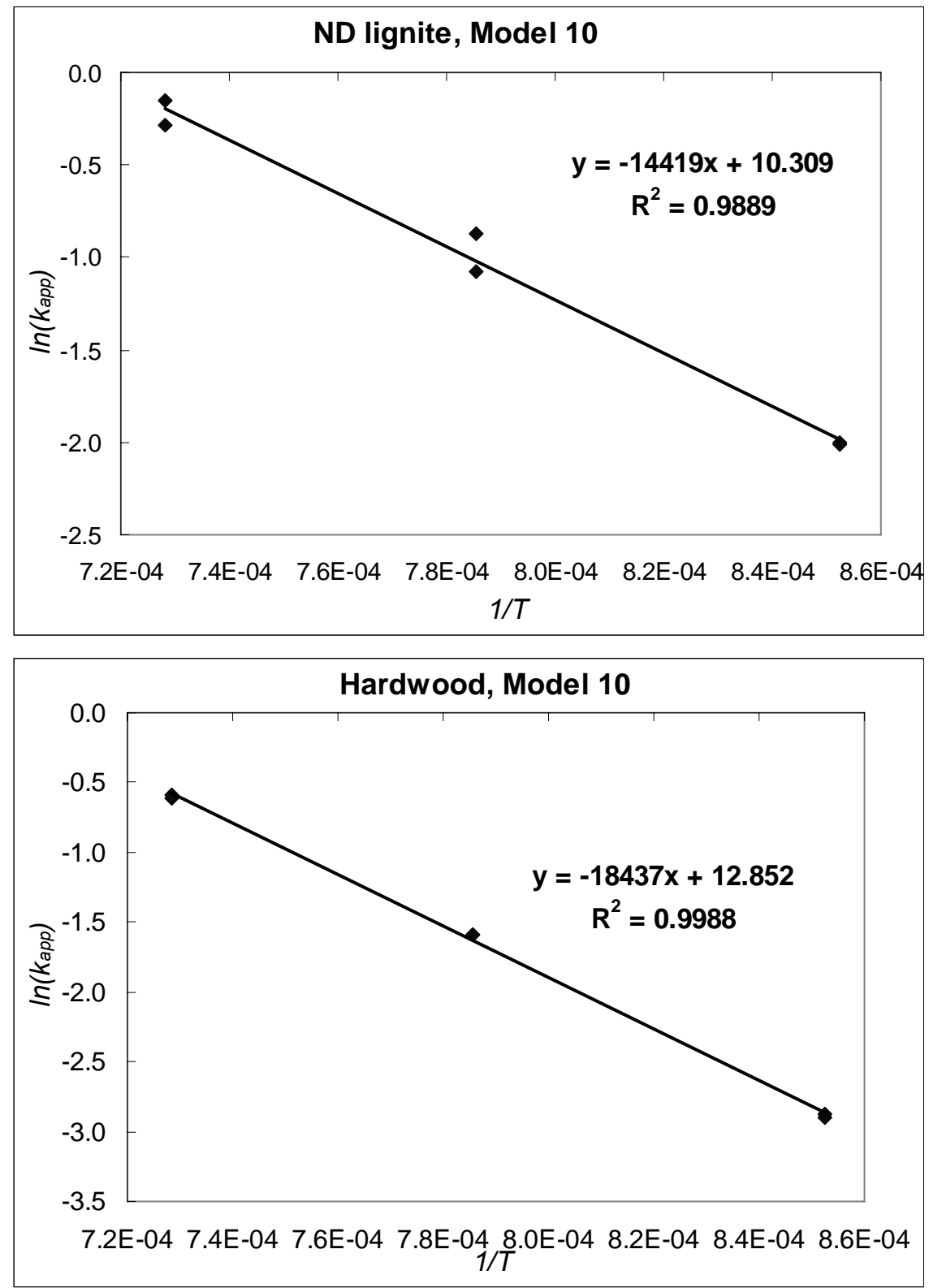

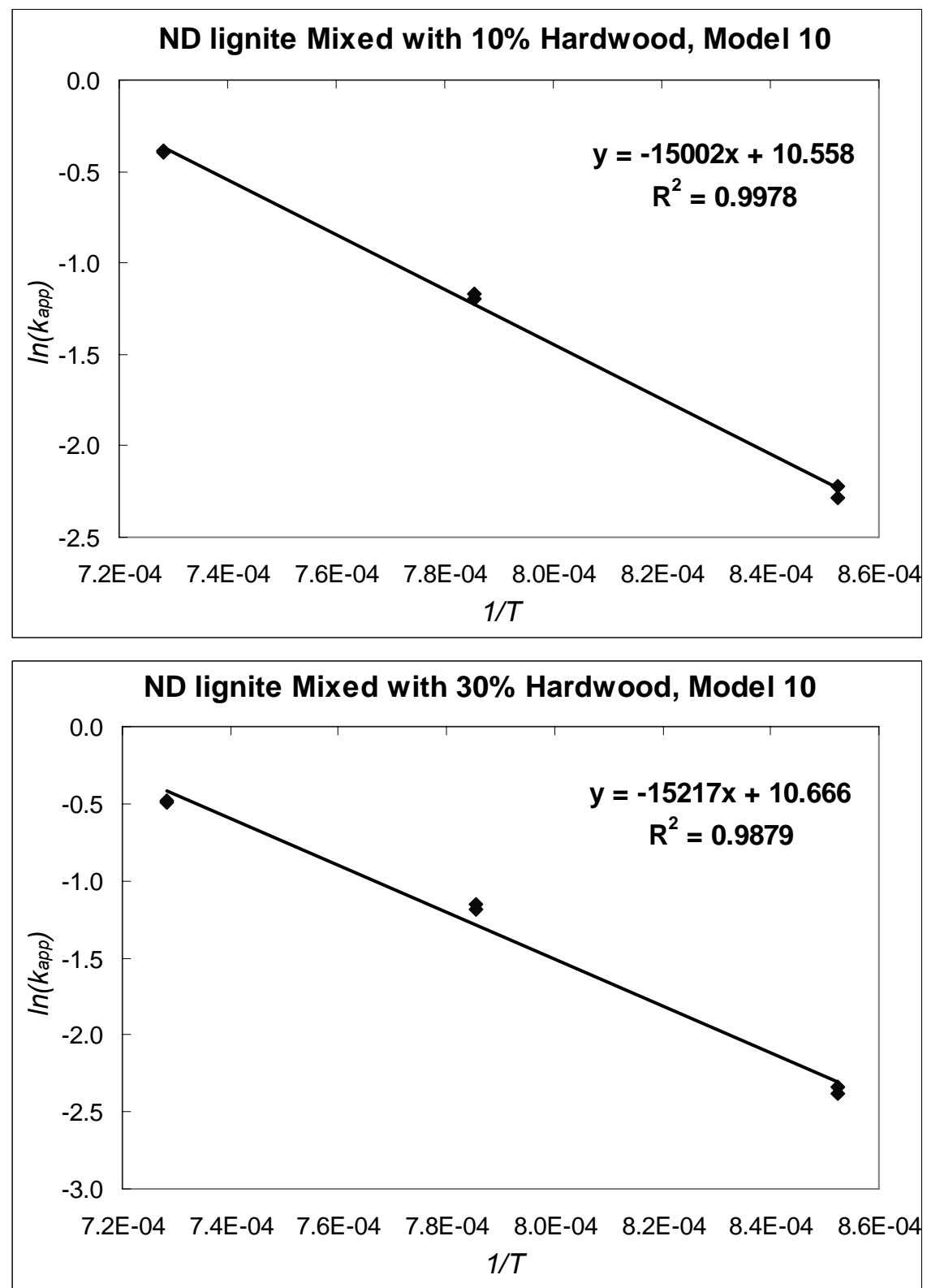
Group 2. ILL No.6 \& Switchgrass char (4 plots)
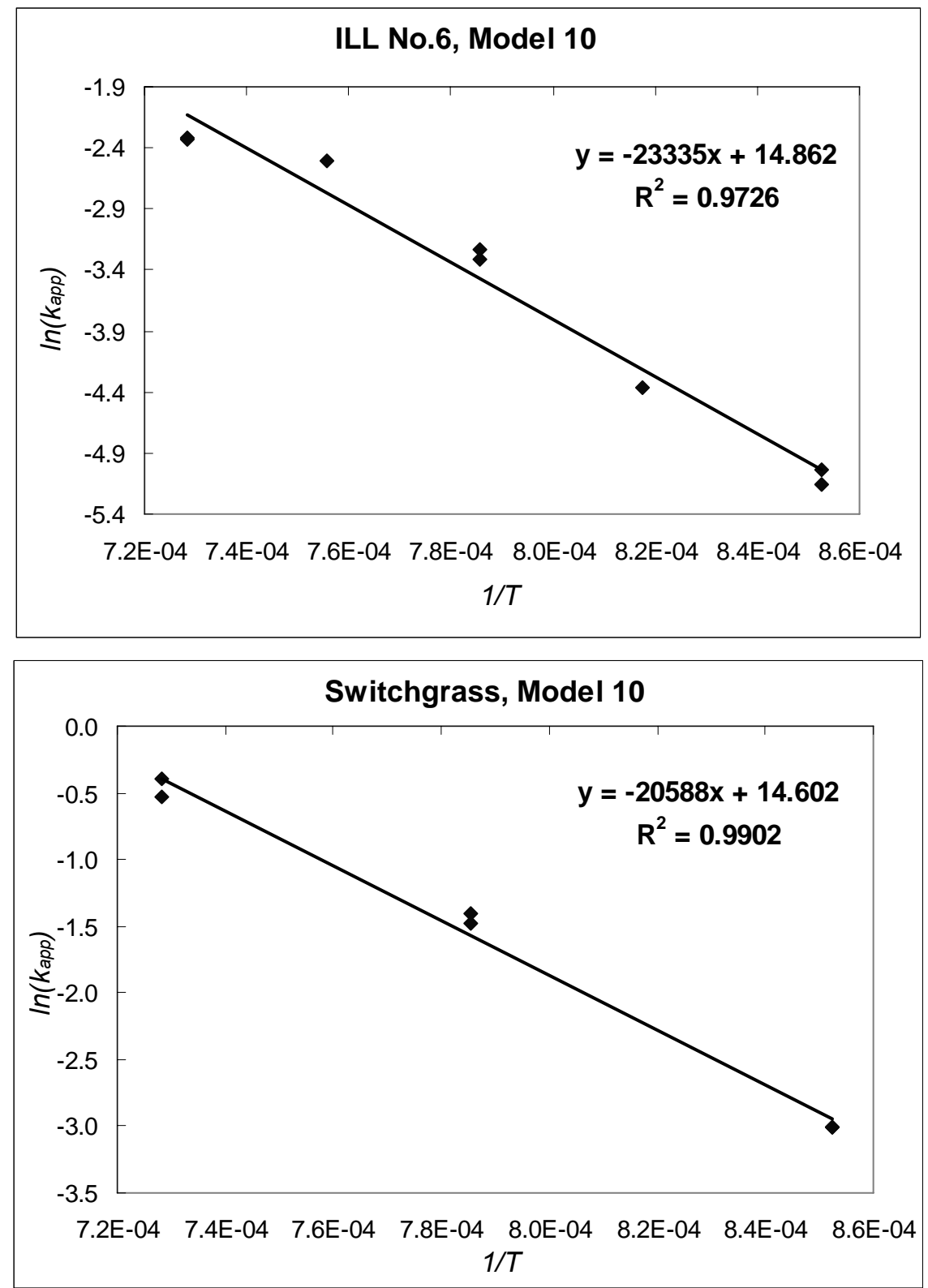

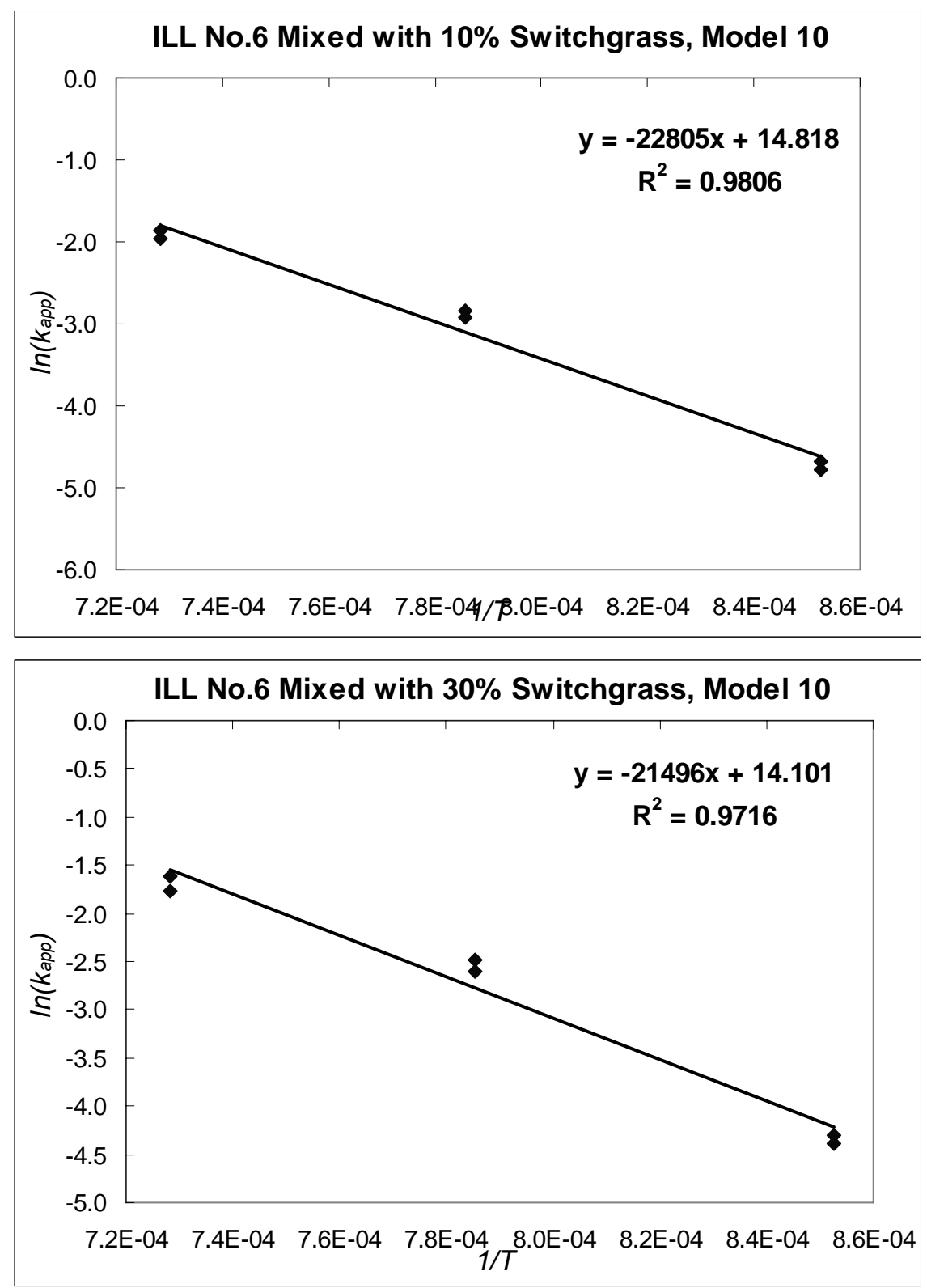
Group 3. PRB \& Corn Stover chars (4 plots)
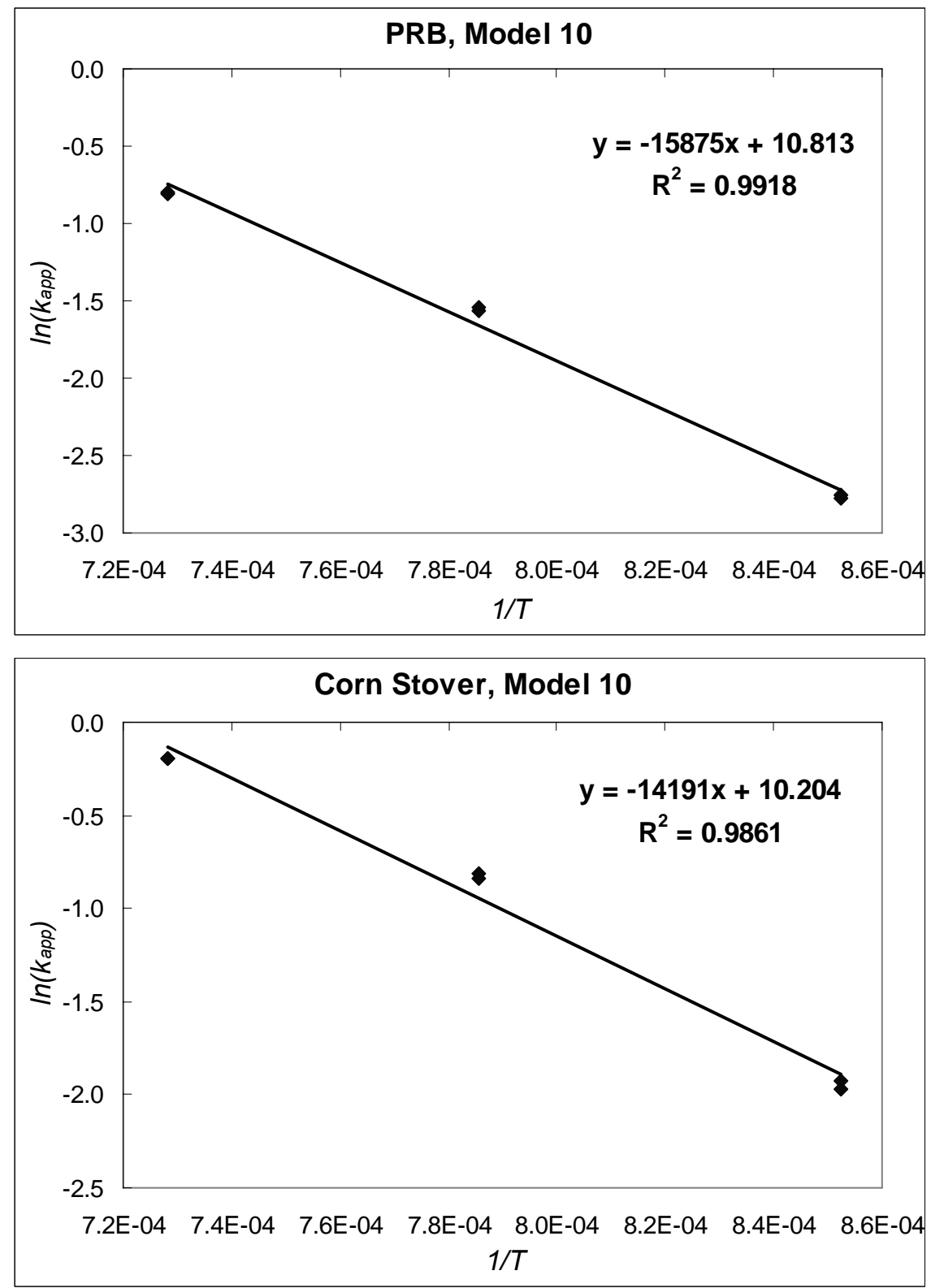

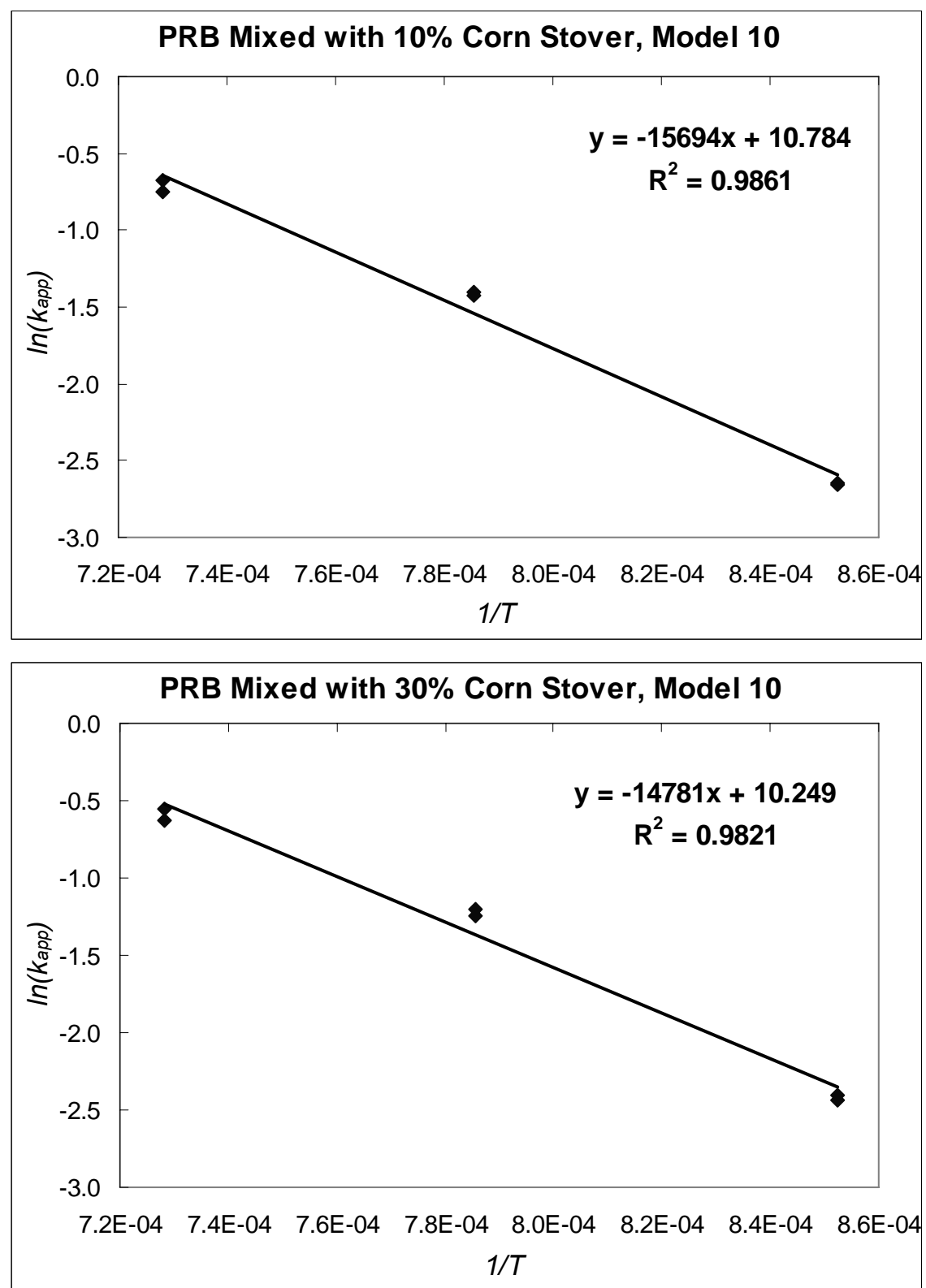

Note:

Total 12 plots are about $E_{\text {app }}$ regression based on Model 10 . 
Appendix E. Plots of $E_{a p p}$ regression based on Initial Rate Model

Group 1. ND lignite \& Hardwood chars (4 plots)
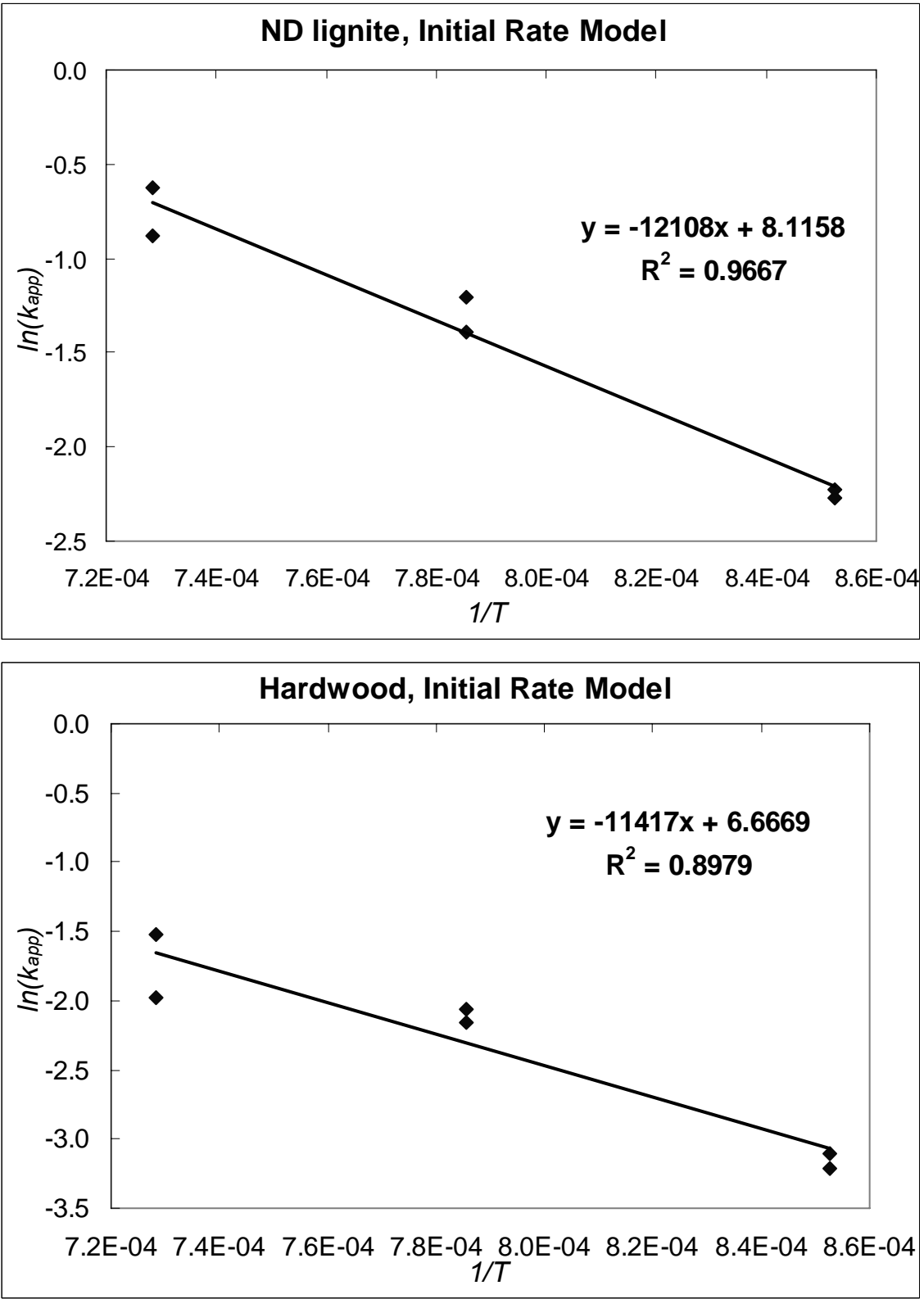

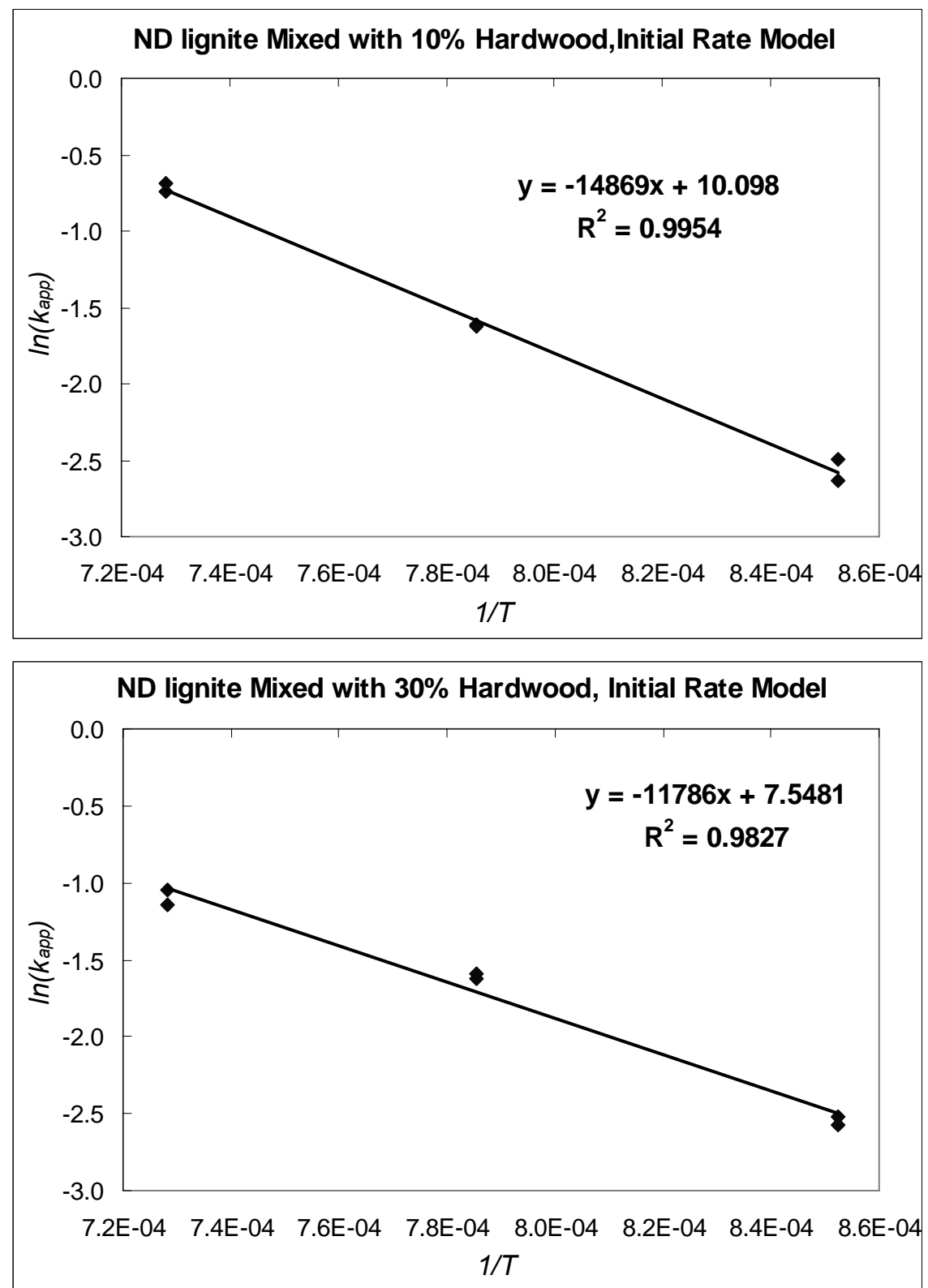
Group 2. ILL No.6 \& Switchgrass char (4 plots)
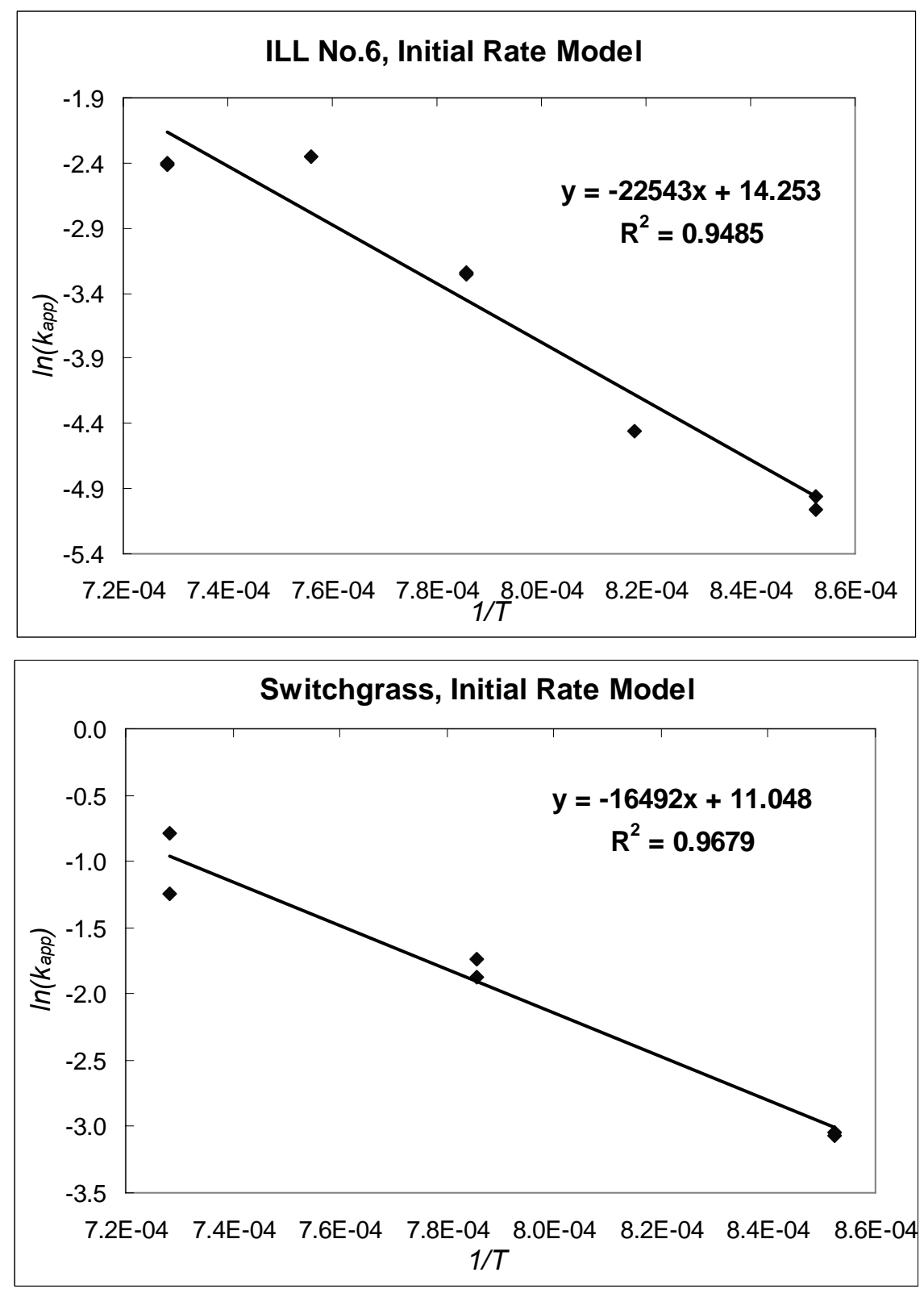

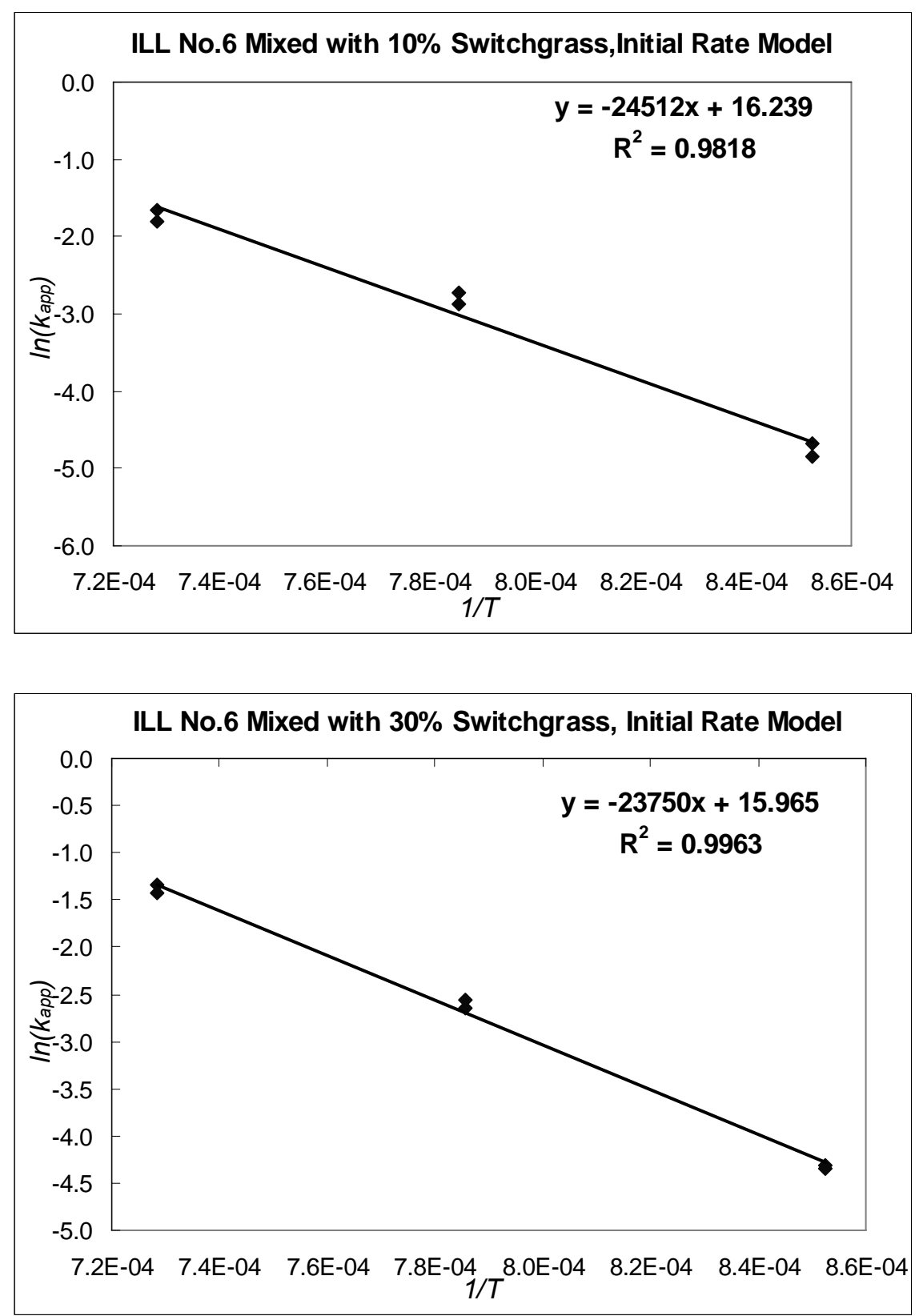
Group 3. PRB \& Corn Stover chars (4 plots)
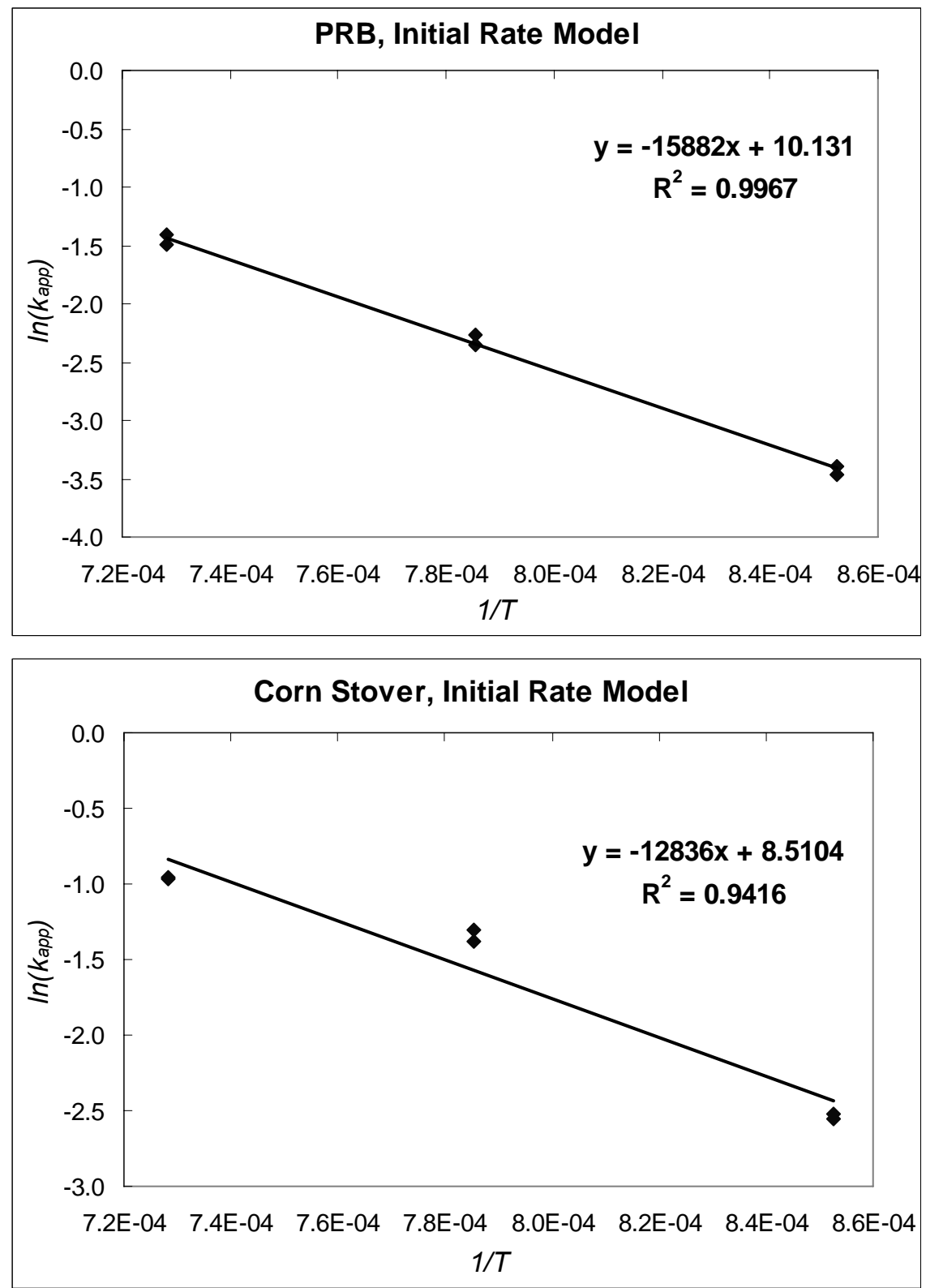

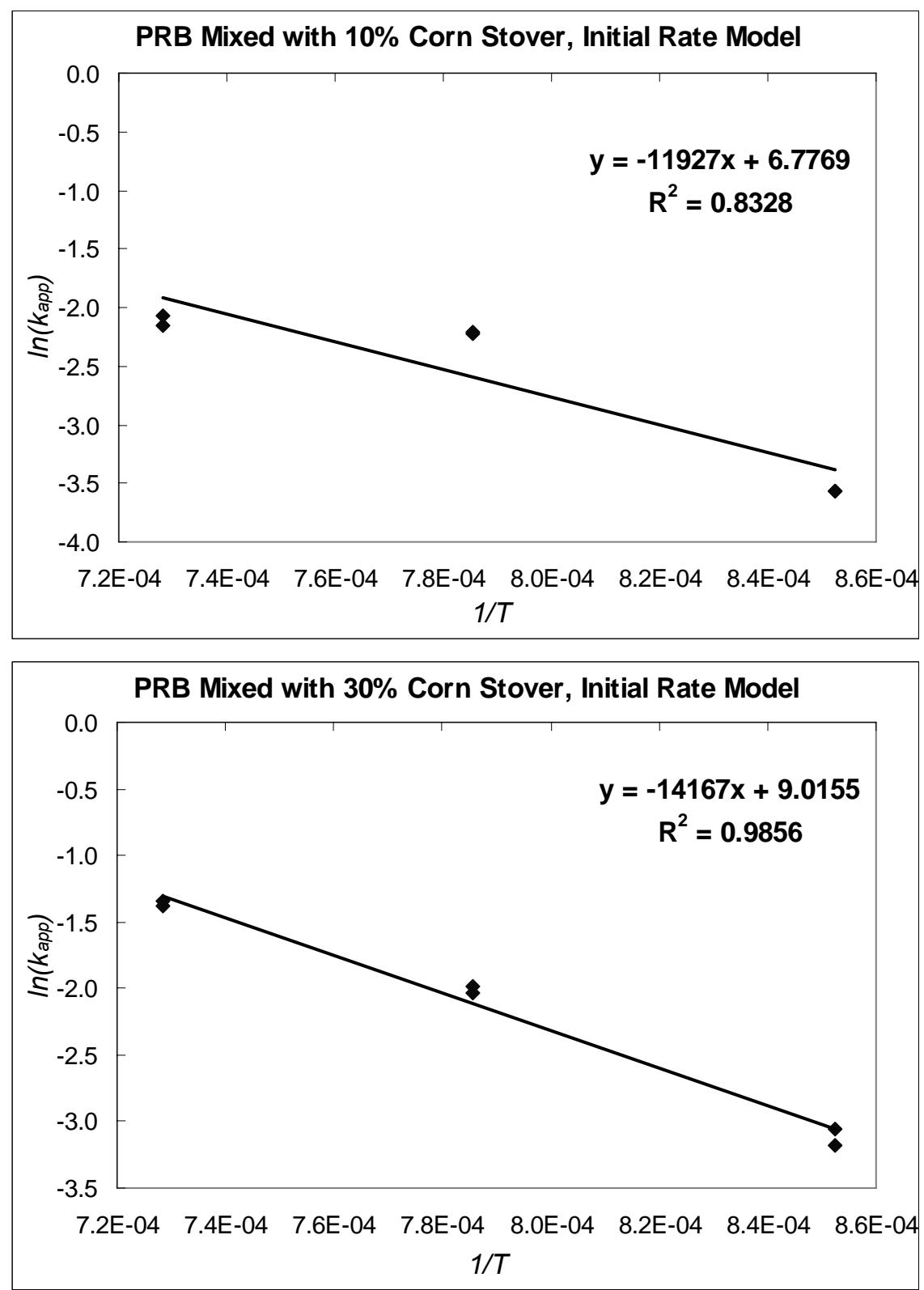

Note:

Total 12 plots are about $E_{a p p}$ regression based on Initial Rate Model. 
Appendix F. Experimental value of $(1-X)_{\text {average }}$ with different mixture ratio at $900^{\circ} \mathrm{C}$, $1000^{\circ} \mathrm{C}$, and $1100^{\circ} \mathrm{C}$

Group 1. ND lignite \& Hardwood chars (3 plots)
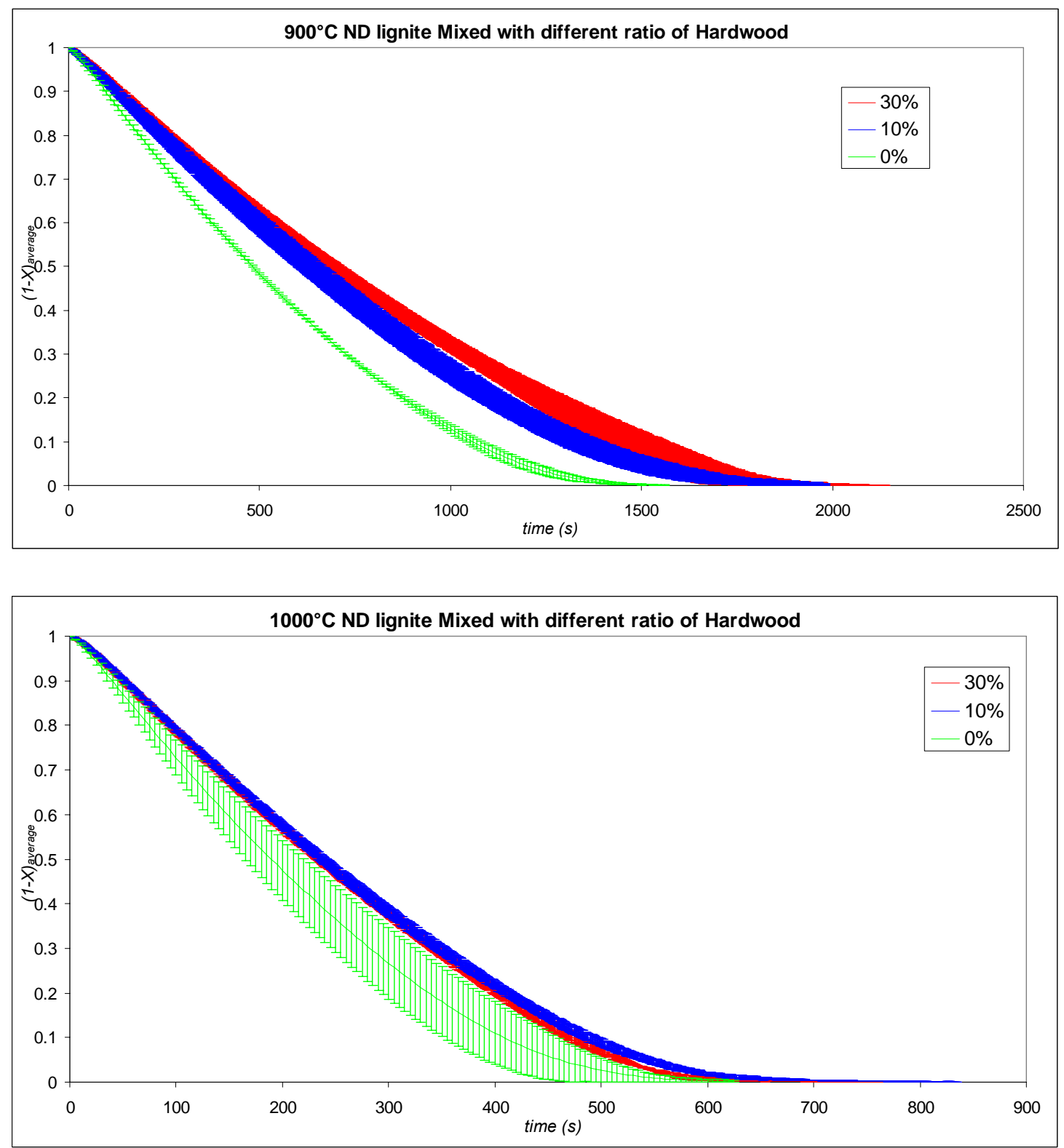


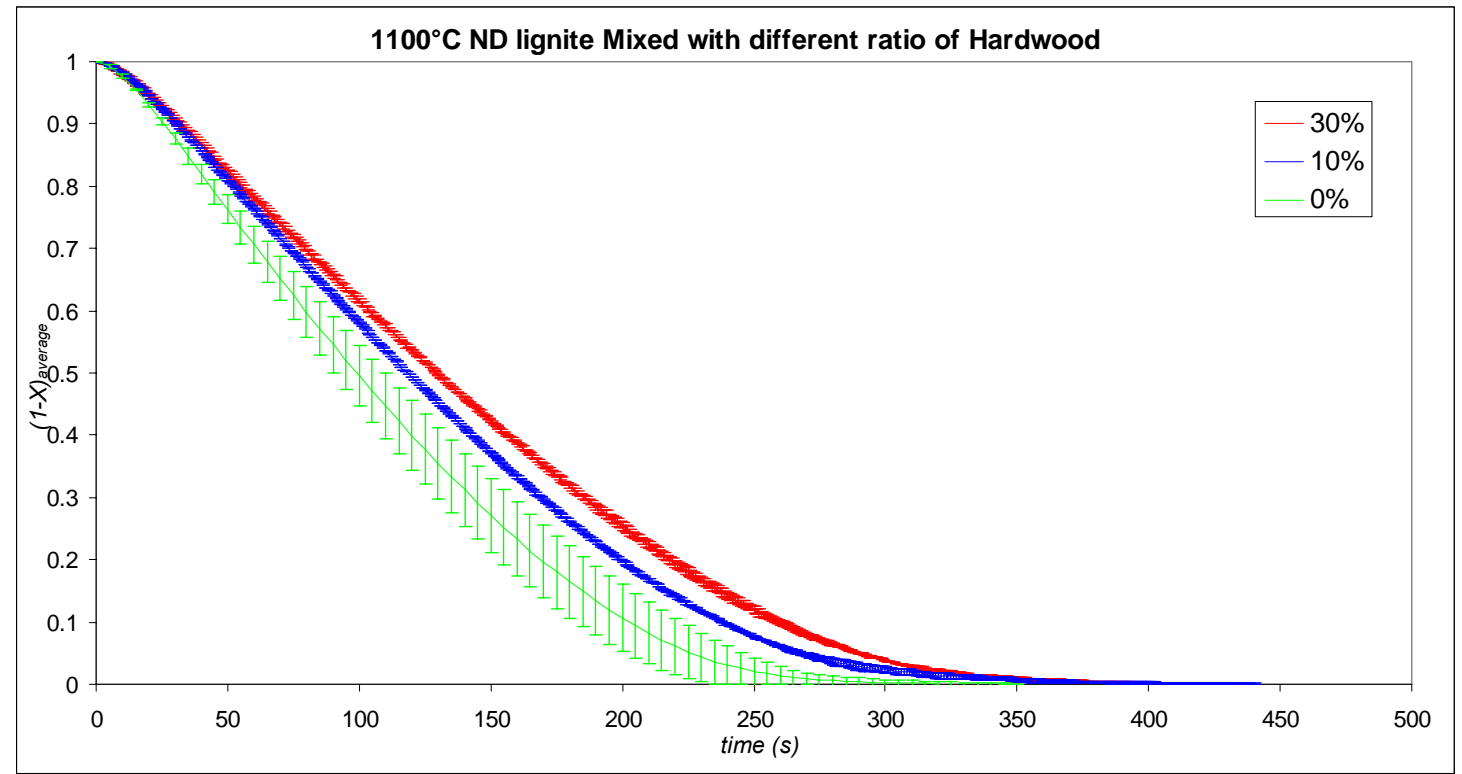


Group 2. ILL No.6 \& Switchgrass char (3 plots)
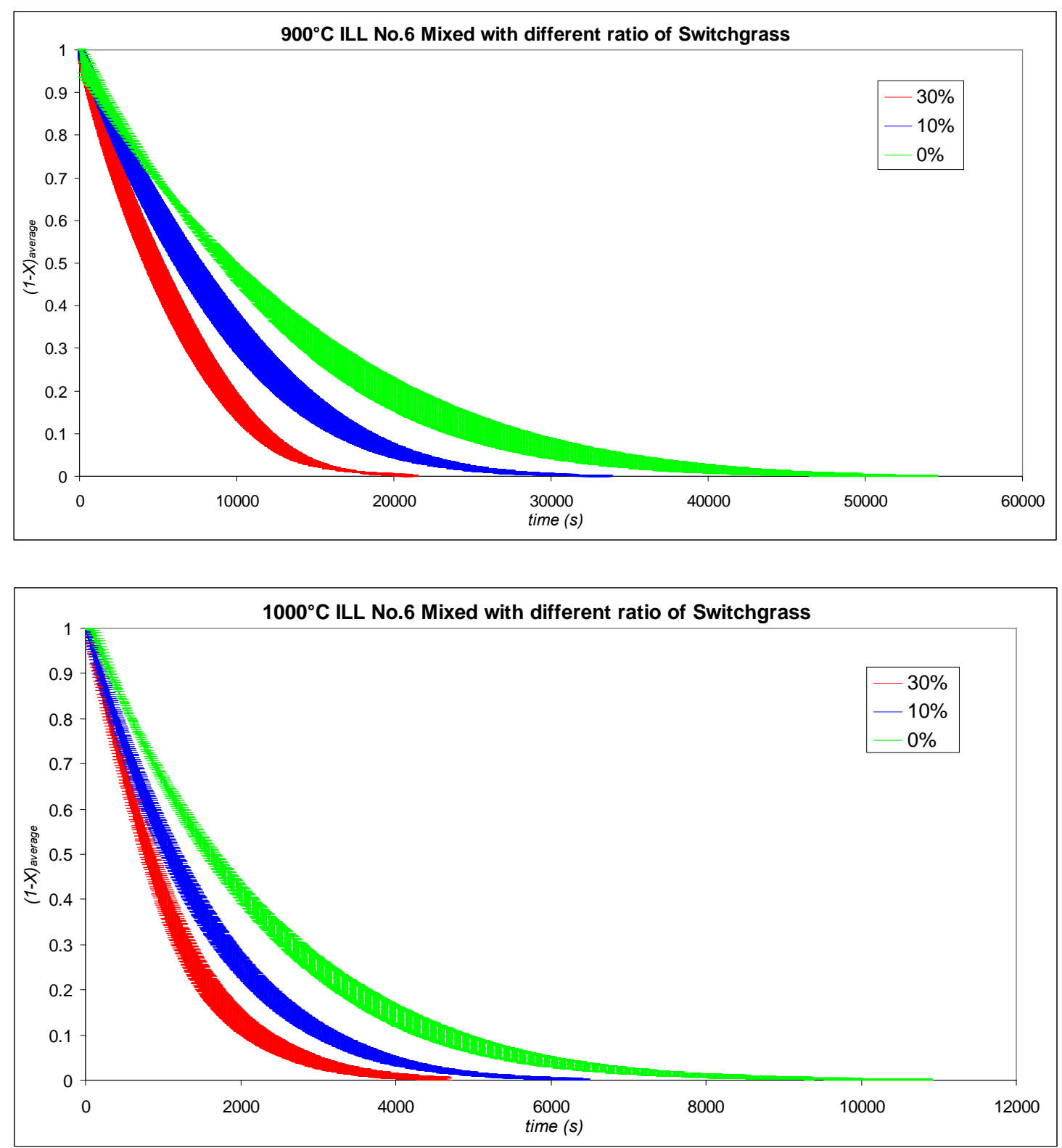


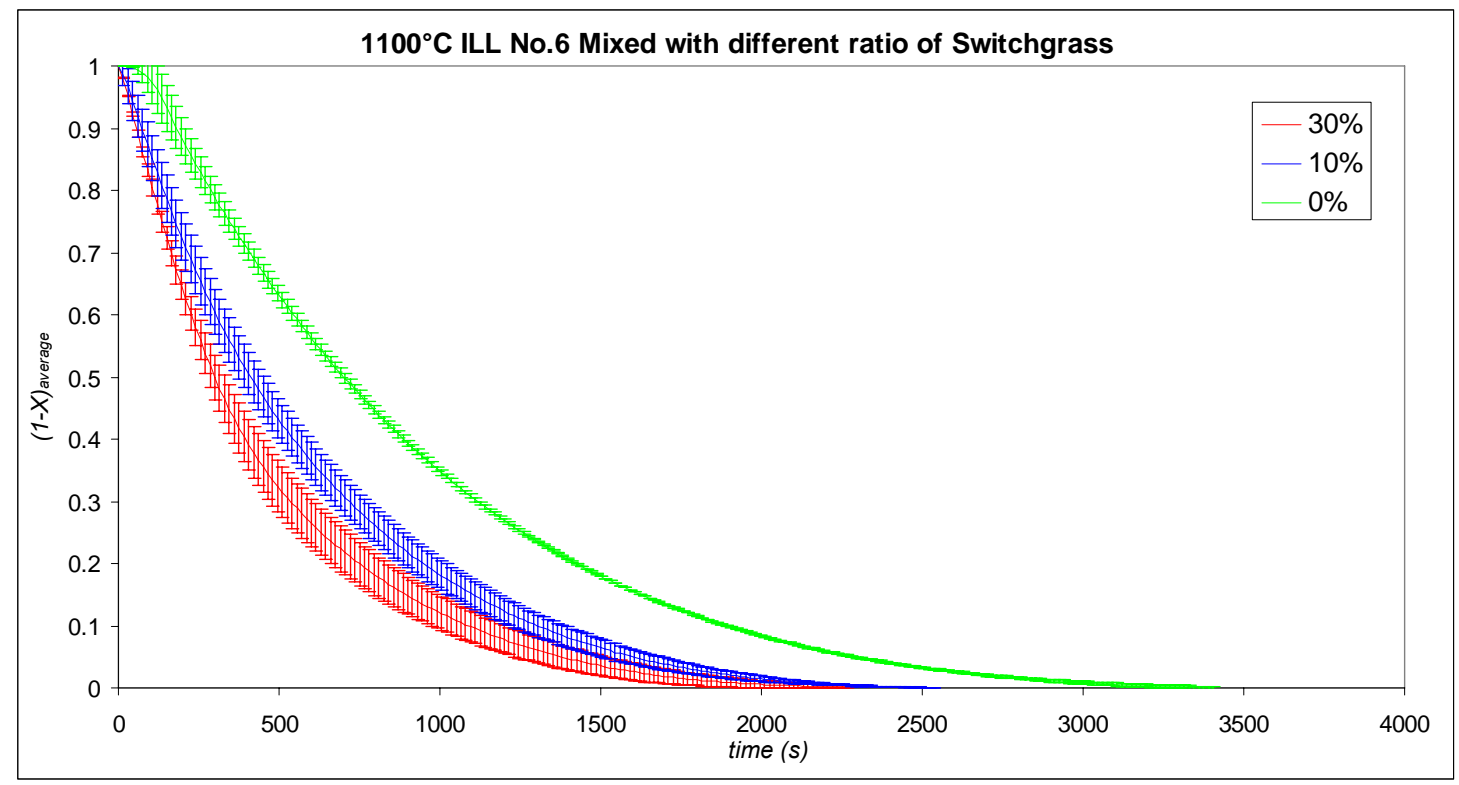


Group 3. PRB \& Corn Stover chars (3 plots)
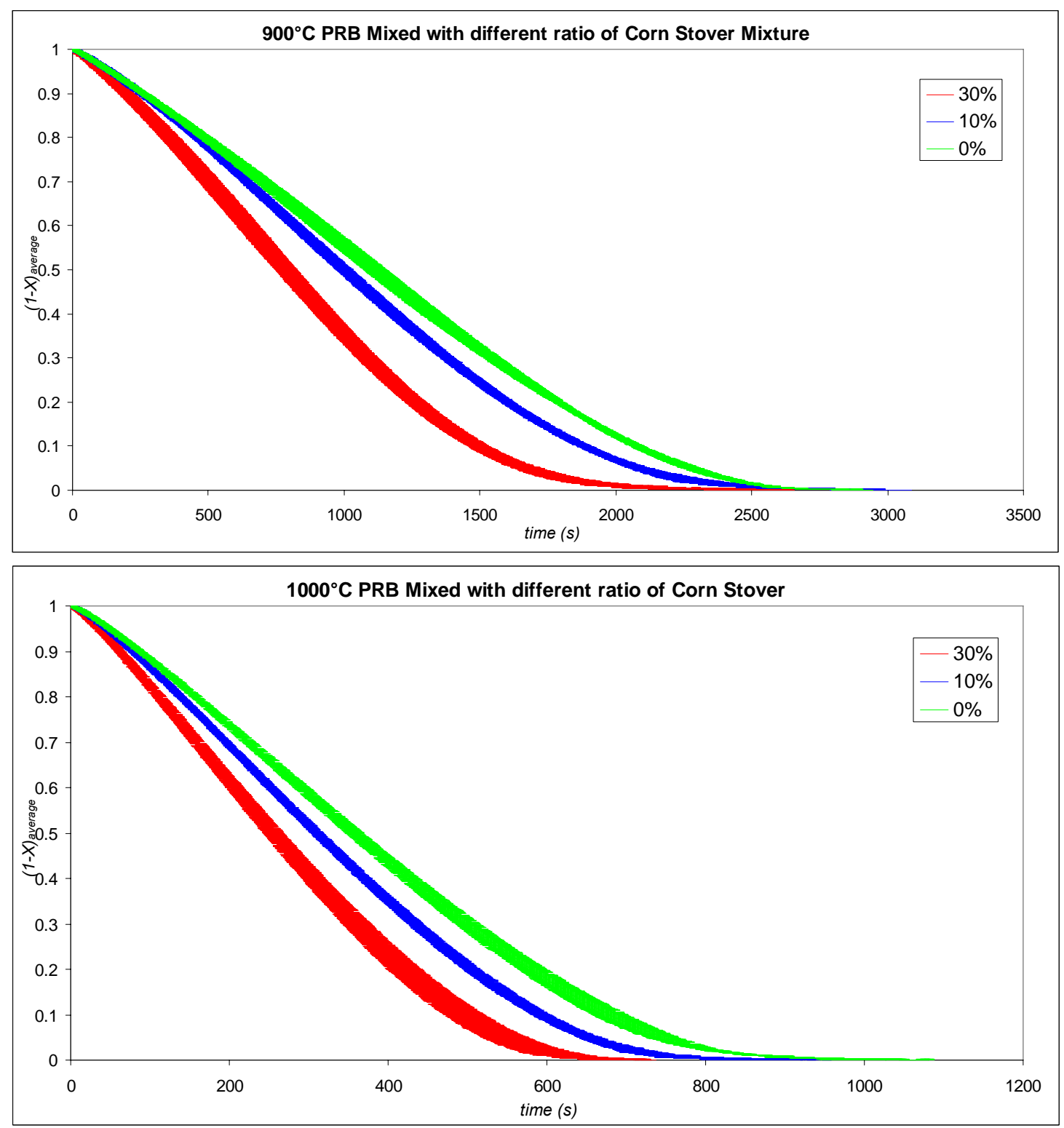


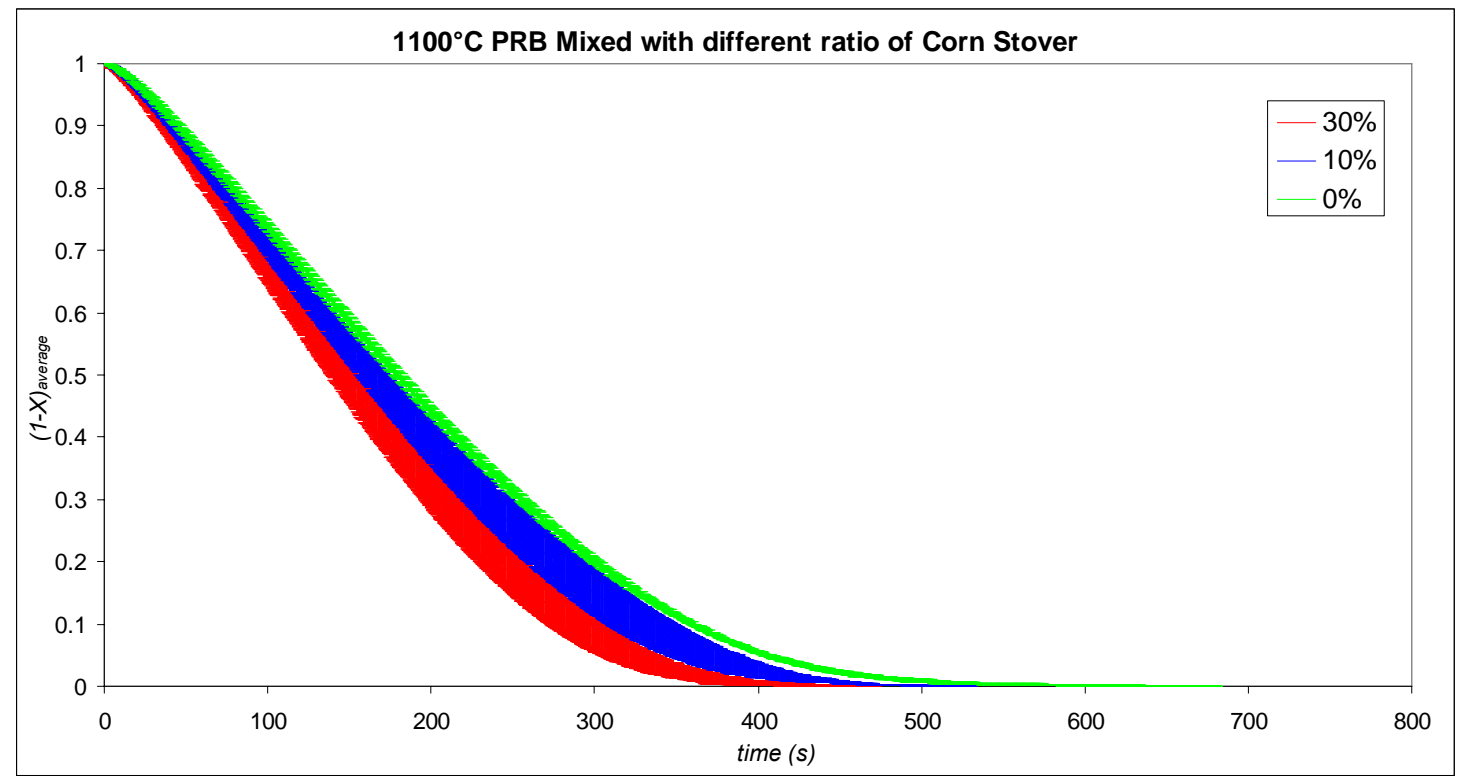

Note:

1. Total 9 plots about experimental value of $(1-X)_{\text {average }}$ for 3 groups char pairs mixed with different ratio reacted at different temperature;

2. The value of $(1-X)_{\text {average }}$ are the average data of two repeat experiment for each pair at each temperature level;

3. The color bands are the error bars, which are presented by $\mathrm{a} \pm$ Standard Deviation (STDEV). 


\section{Appendix G. Synergistic effect inspection plots for}

Group 1 ND lignite \& Hardwood chars

$10 \%$ mixed ratio at different reaction temperature (6 plots)
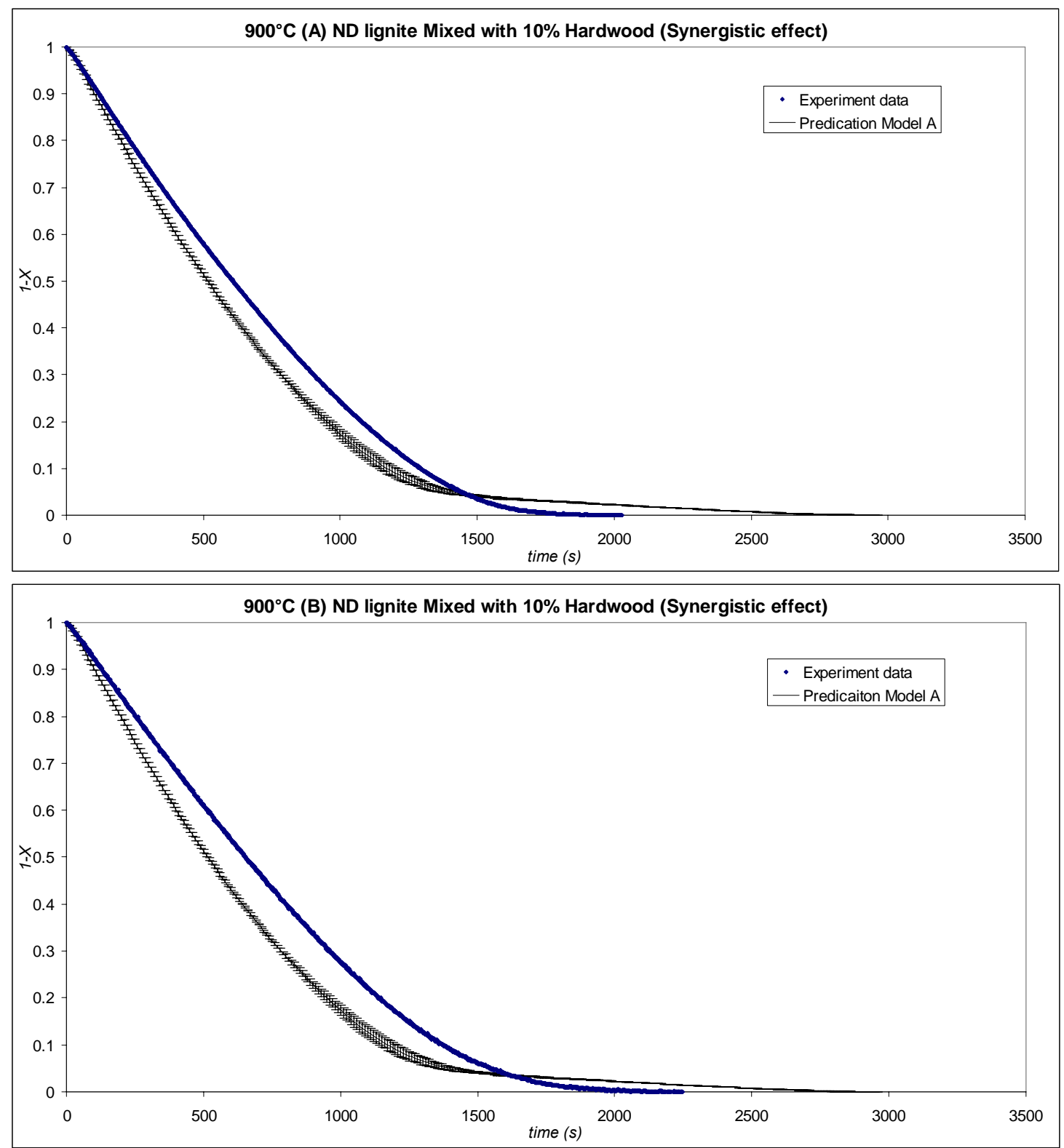

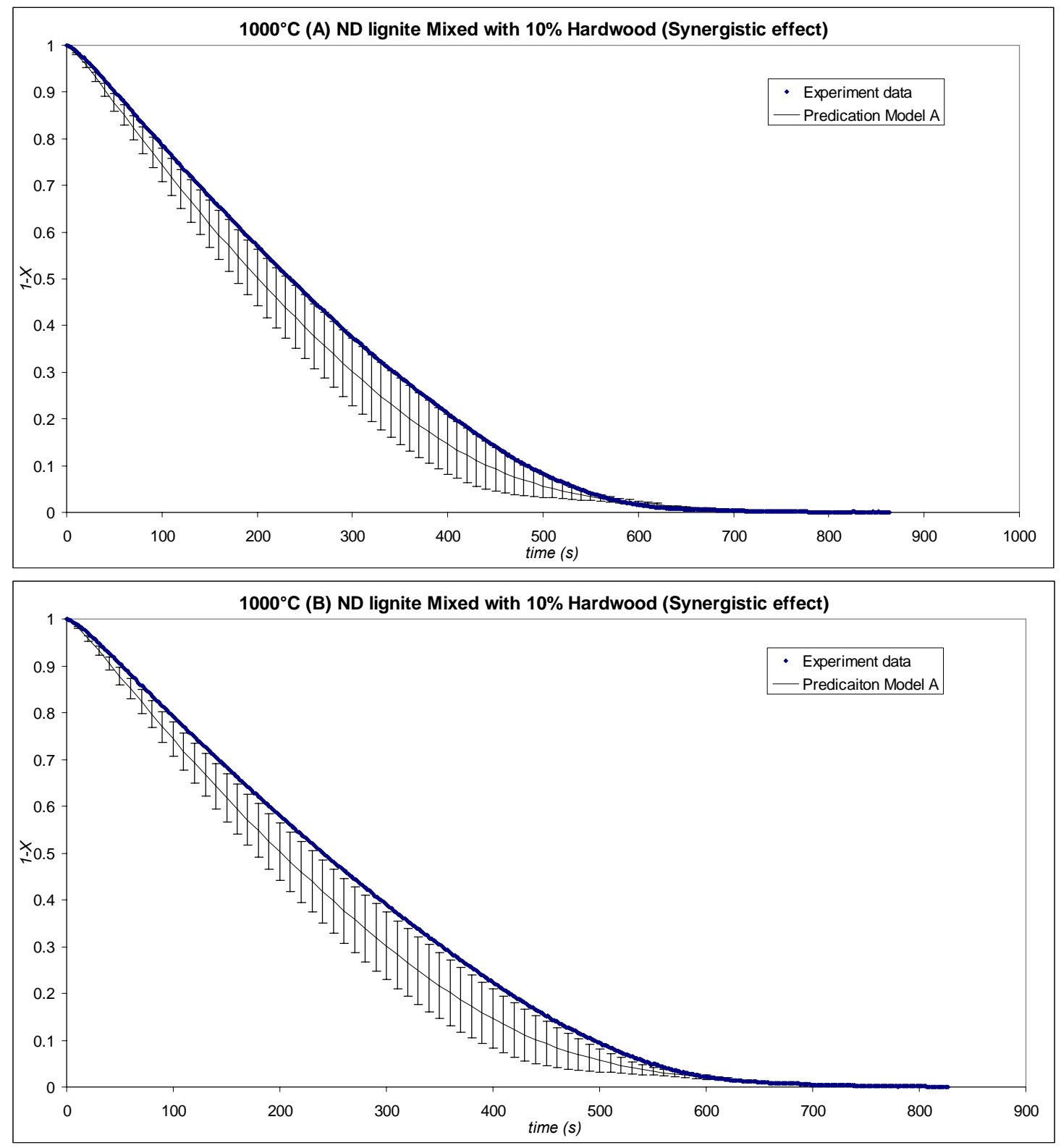

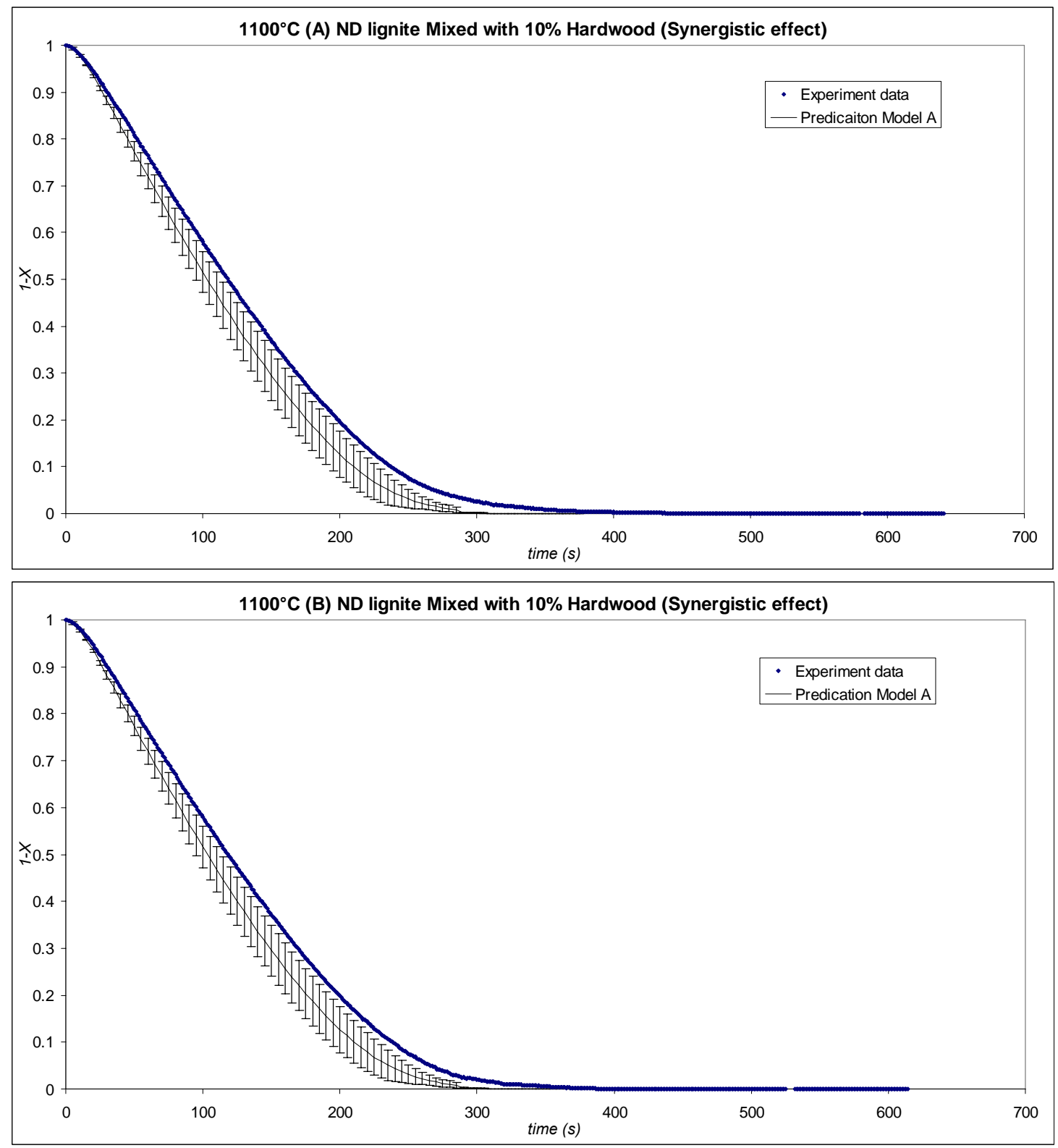
$30 \%$ mixed ratio at different reaction temperature ( 6 plots)

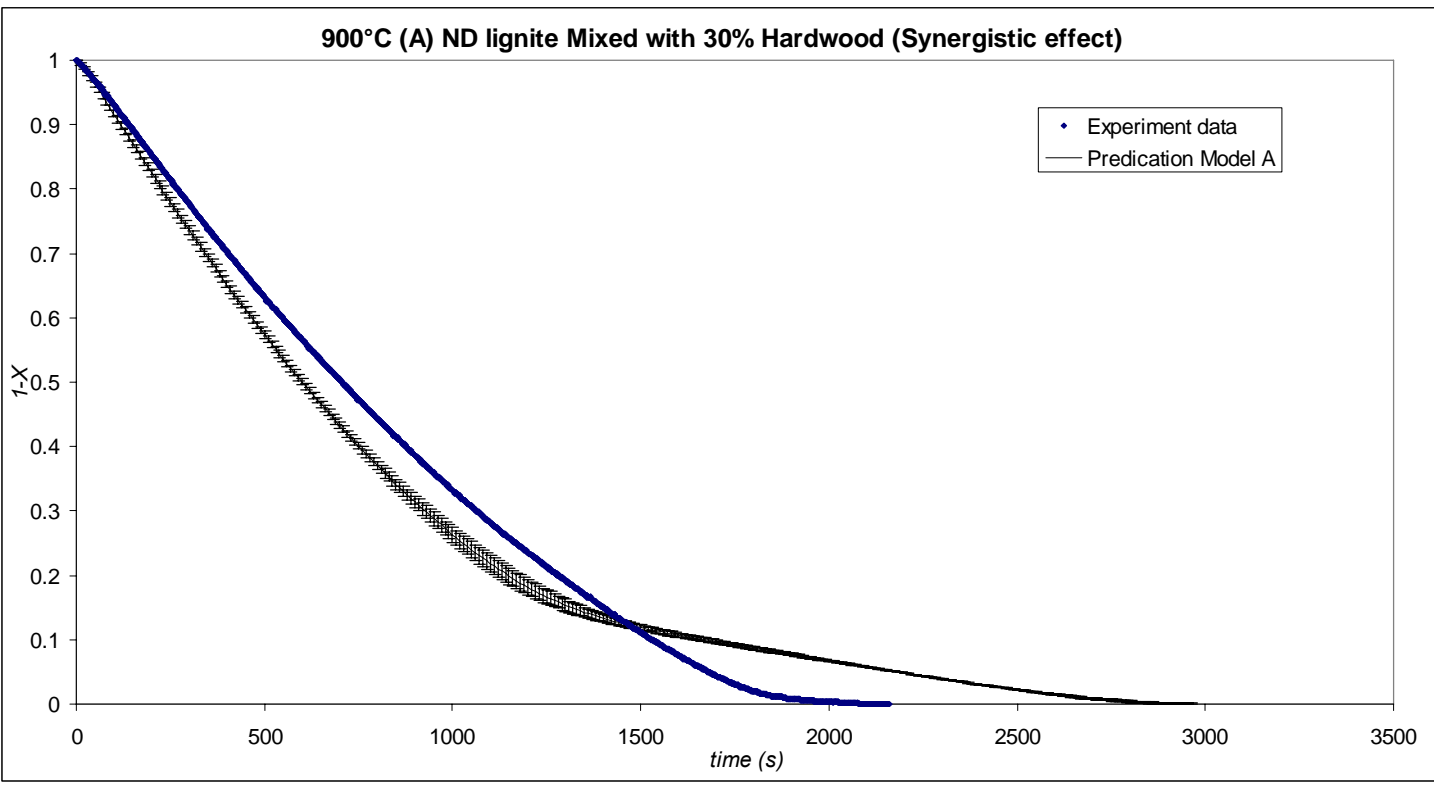

$900^{\circ} \mathrm{C}$ (B) ND lignite Mixed with $30 \%$ Hardwood (Synergistic effect)

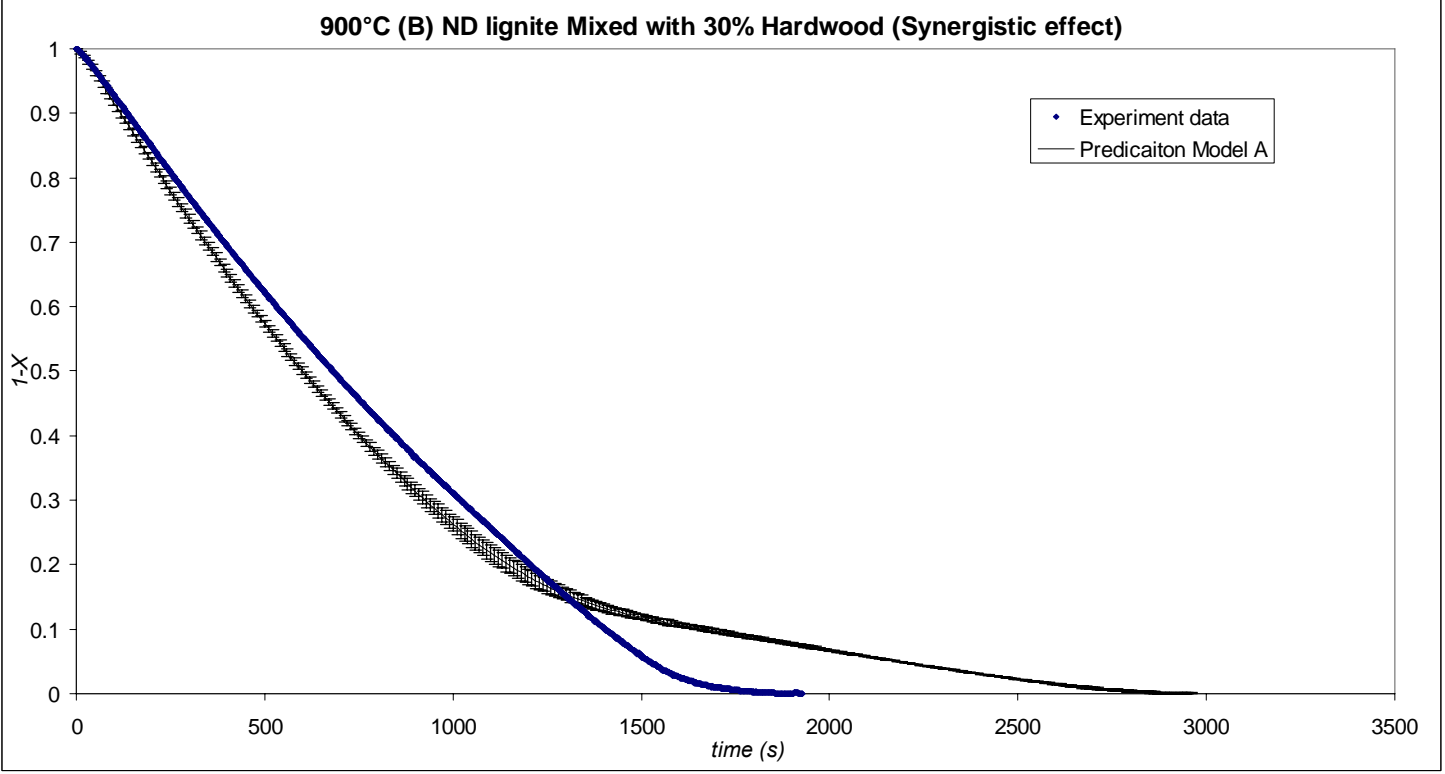



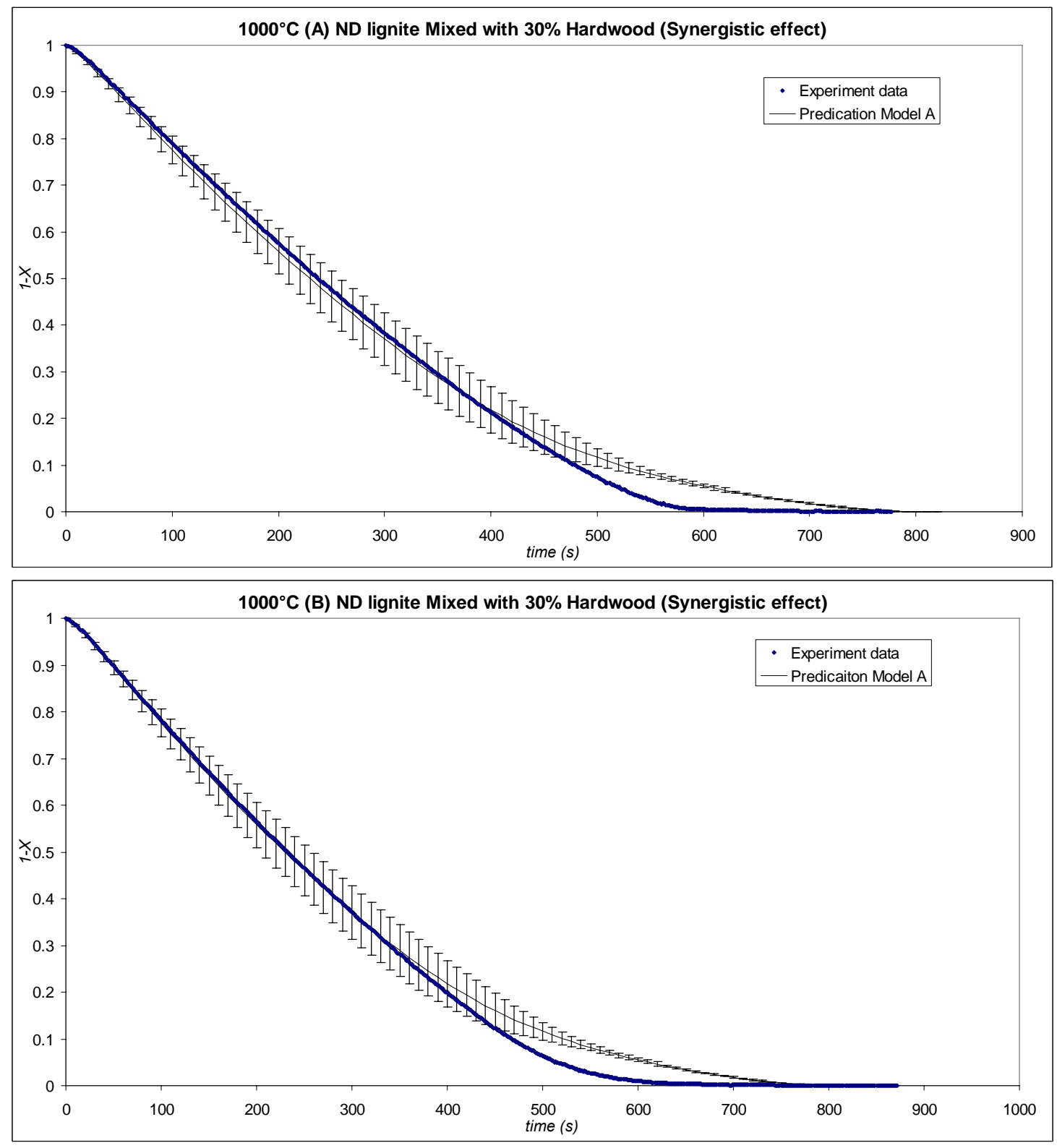

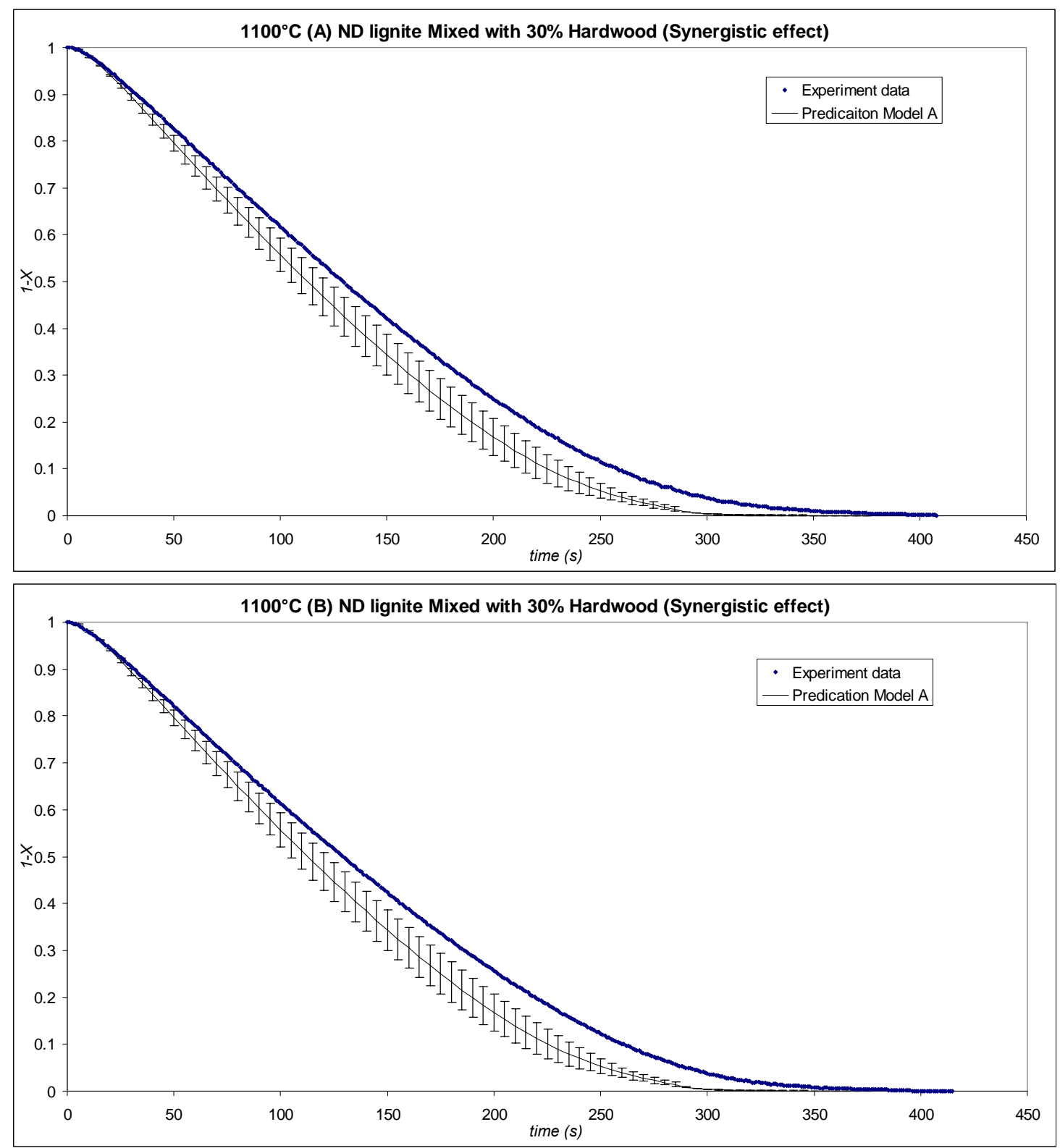

Note:

1. Total 12 plots for the synergistic effect inspection of Group 1 char pair;

2. The value of $(1-X)$ for Prediction Model $\mathrm{A}$ is the average data of two repeat experiments that include the pure coal and pure biomass char gasification;

3. The error bars of Prediction Model A are presented by a \pm Standard Deviation (STDEV), which are calculated based on the pure chars experiments result. 


\section{Appendix H. Synergistic effect inspection plots for}

\section{Group 2 ILL No.6 \& Switchgrass chars}

$10 \%$ mixed ratio at different reaction temperature (6 plots)
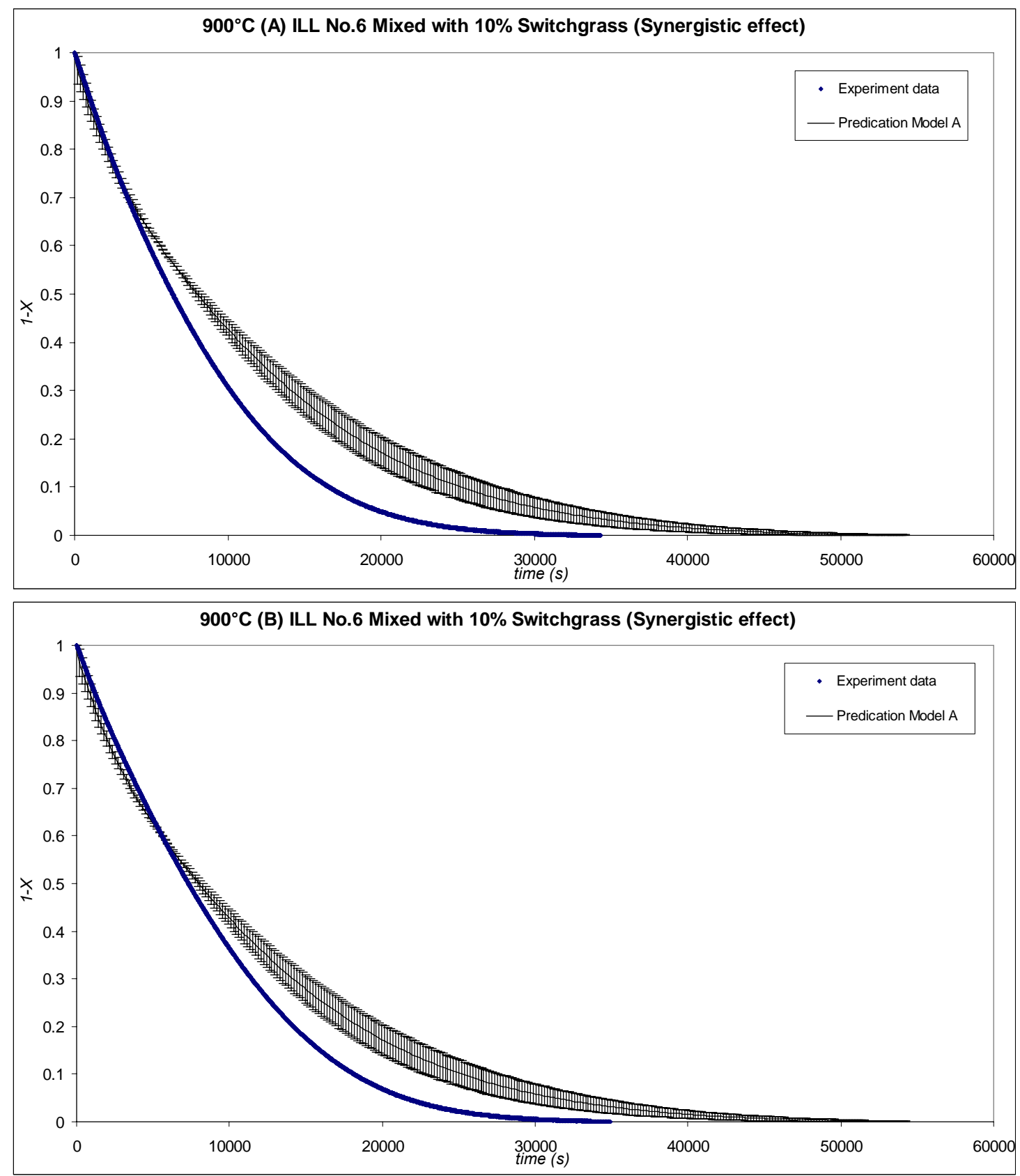

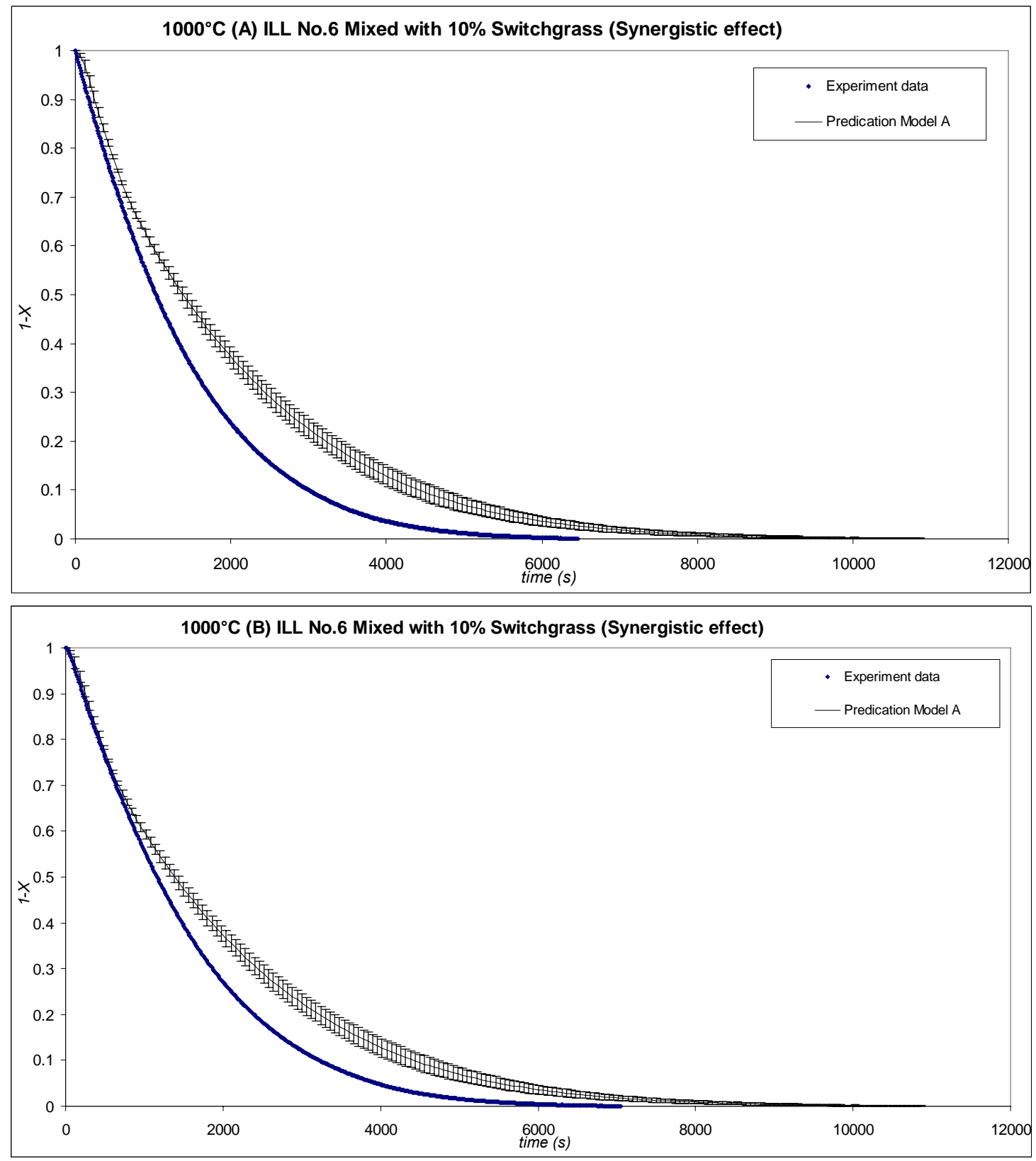

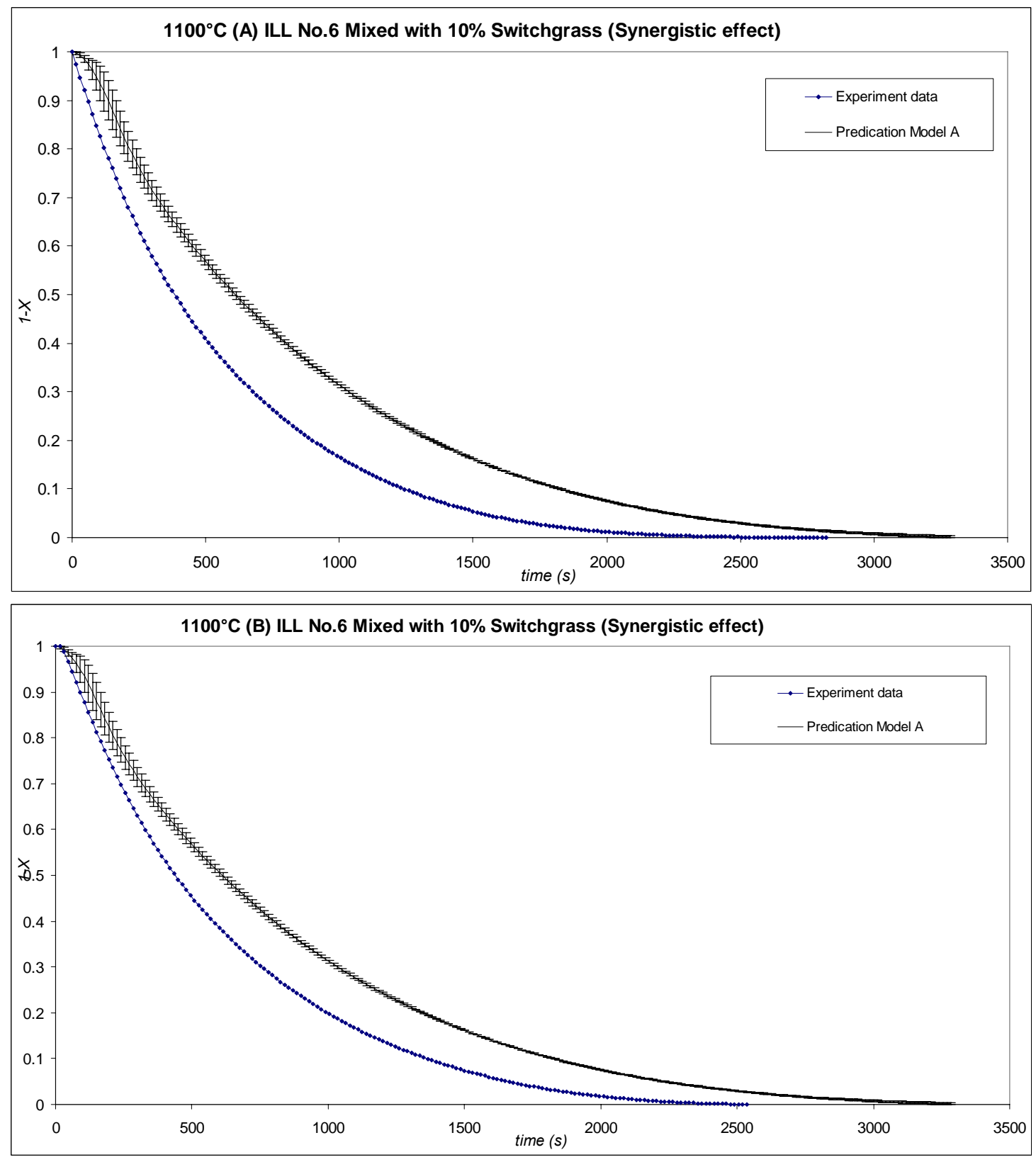
$30 \%$ mixed ratio at different reaction temperature ( 6 plots)
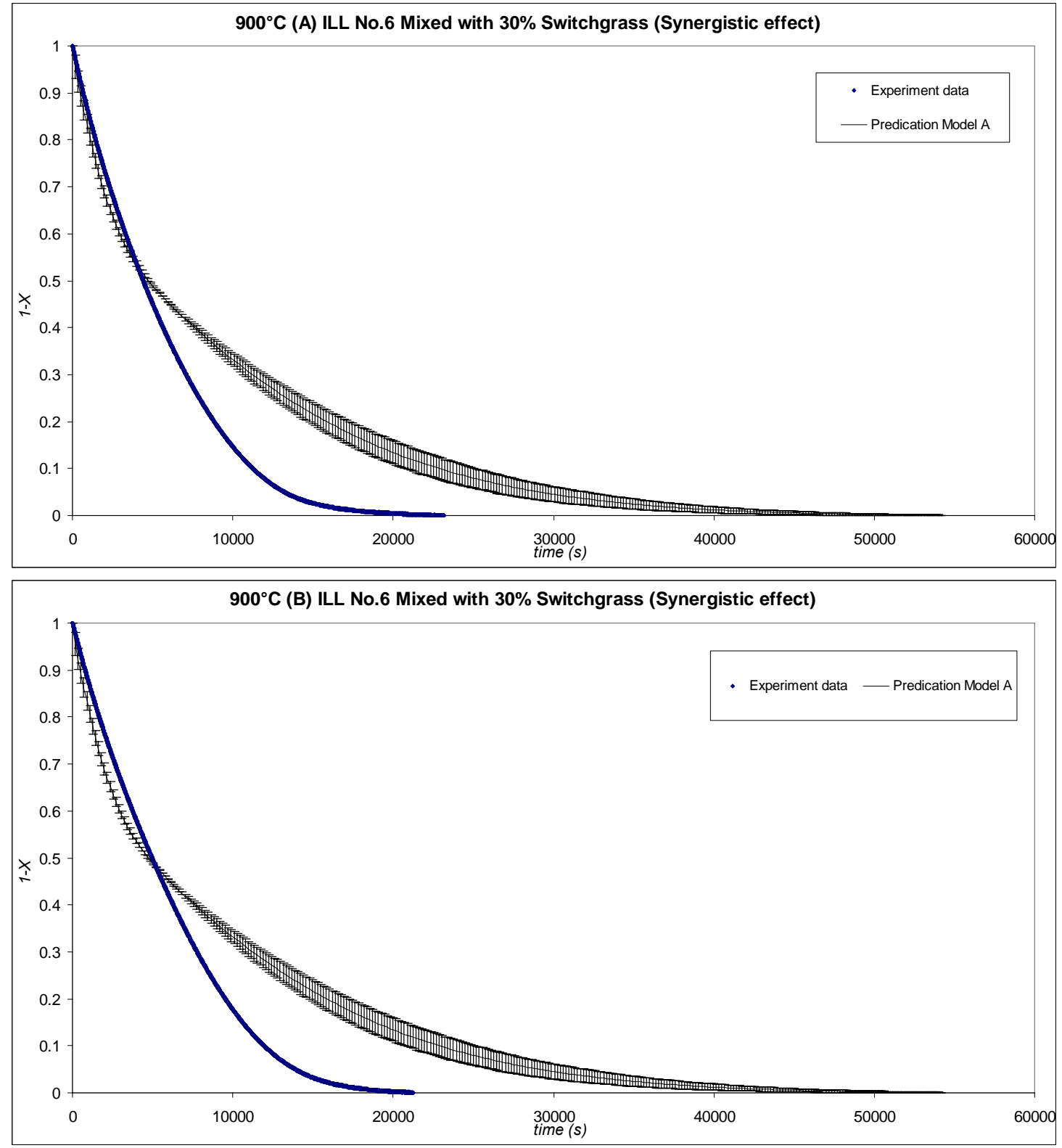

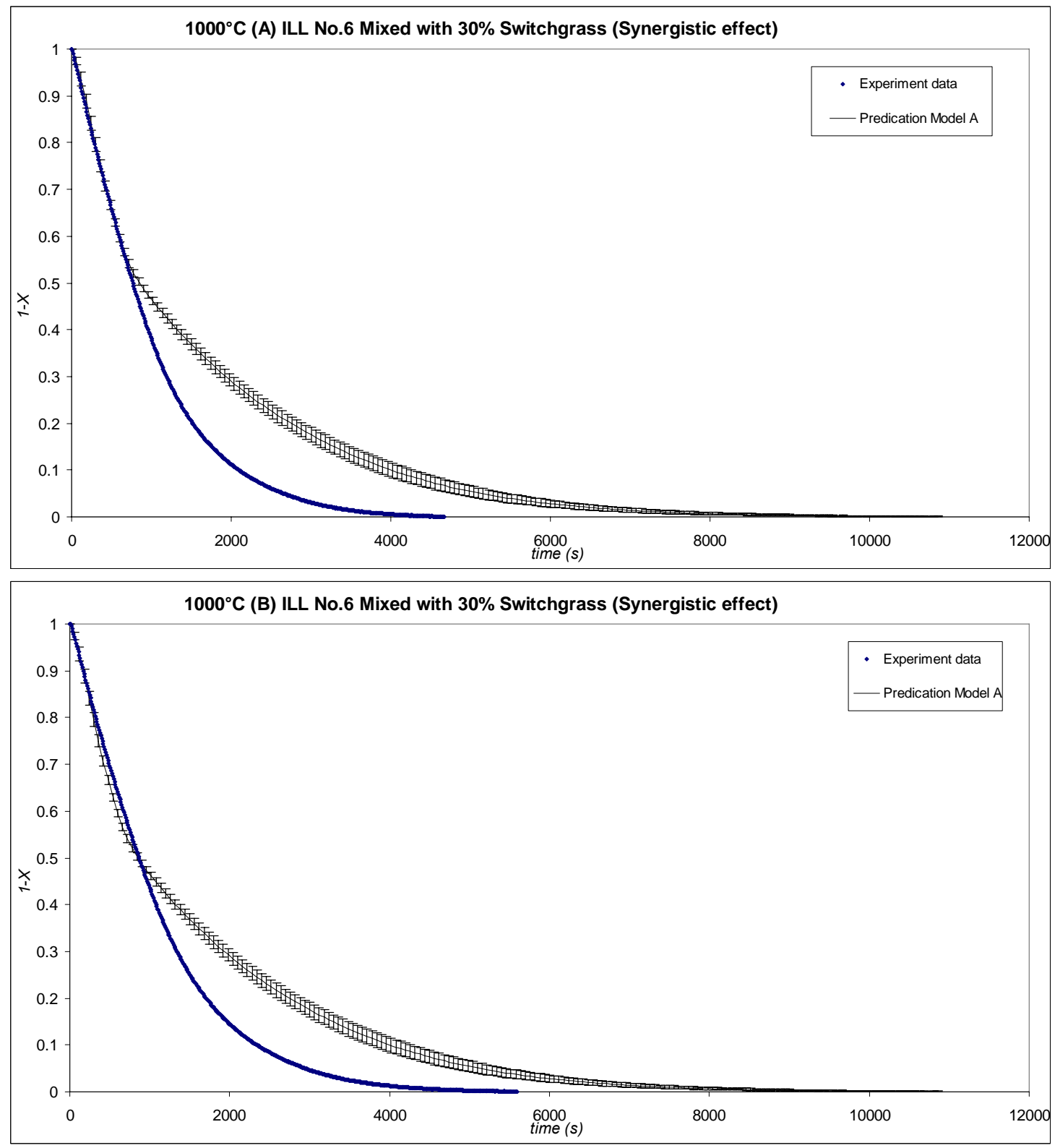

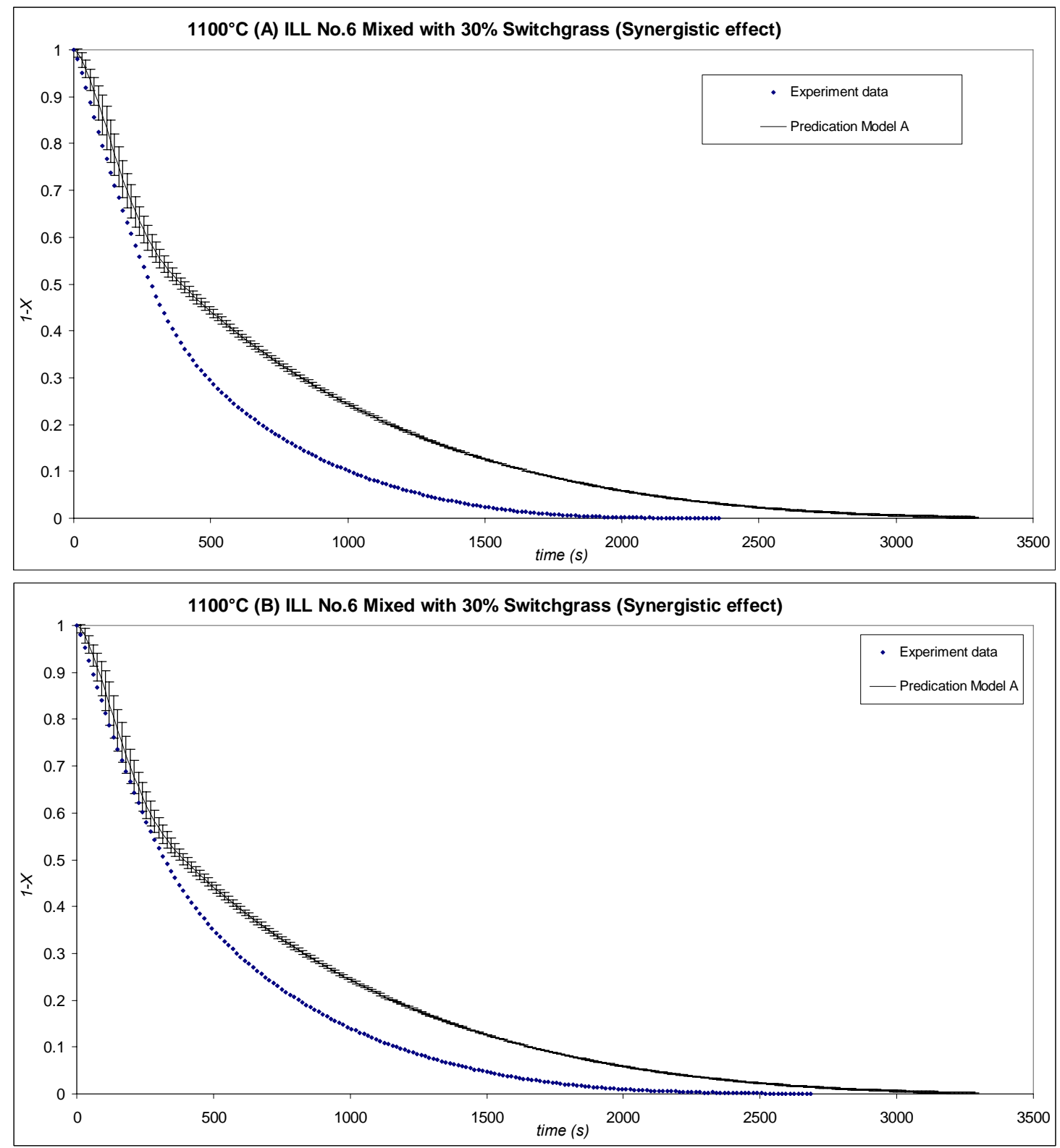

Note:

4. Total 12 plots for the synergistic effect inspection of Group 2 char pair;

5. The value of $(1-X)$ for Prediction Model $\mathrm{A}$ is the average data of two repeat experiments that include the pure coal and pure biomass char gasification;

6. The error bars of Prediction Model A are presented by a \pm Standard Deviation (STDEV), which are calculated based on the pure chars experiments result. 


\section{Appendix I. Synergistic effect inspection plots for}

Group 3 PRB \& Corn Stover chars

$10 \%$ mixed ratio at different reaction temperature (6 plots)
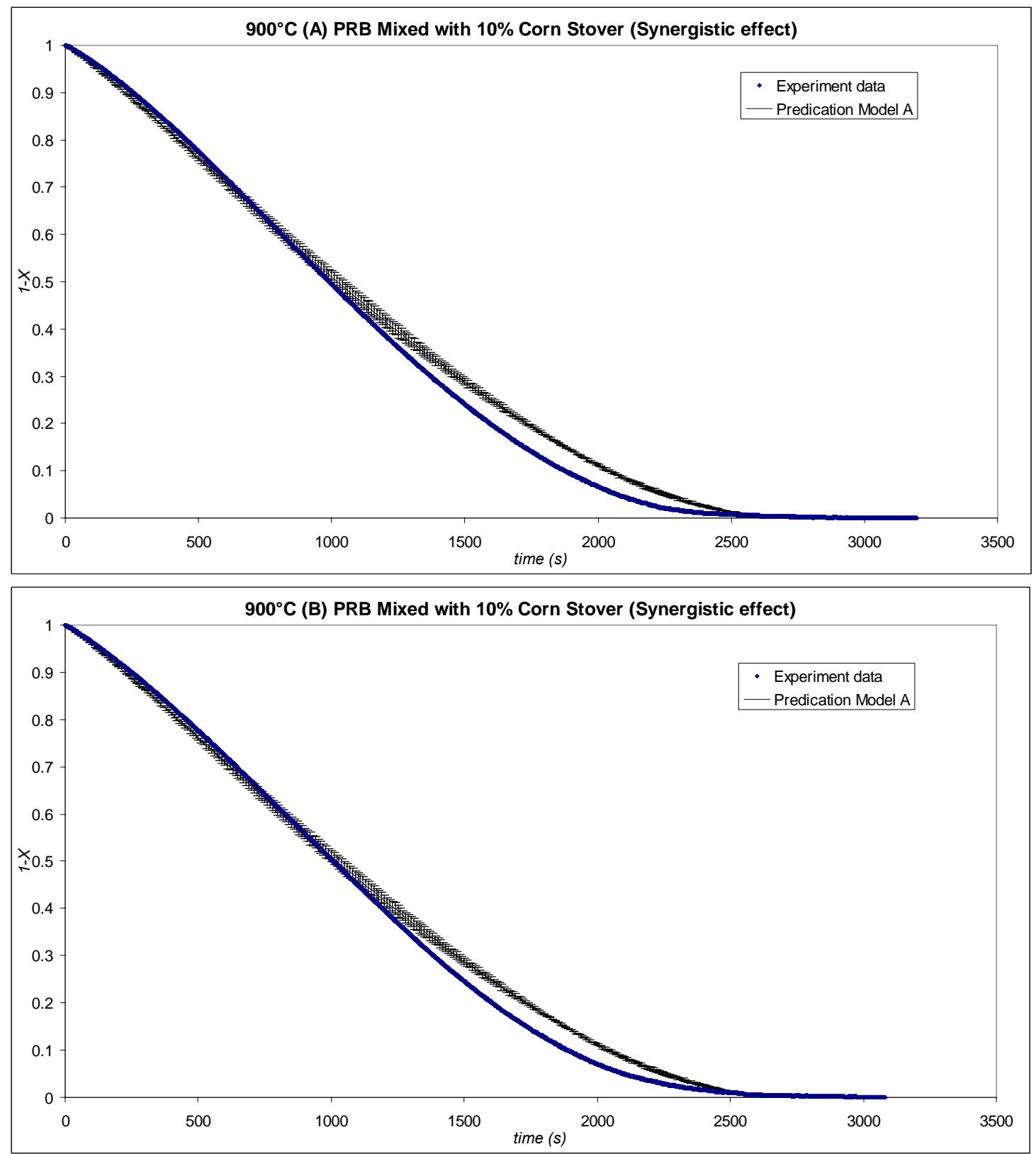

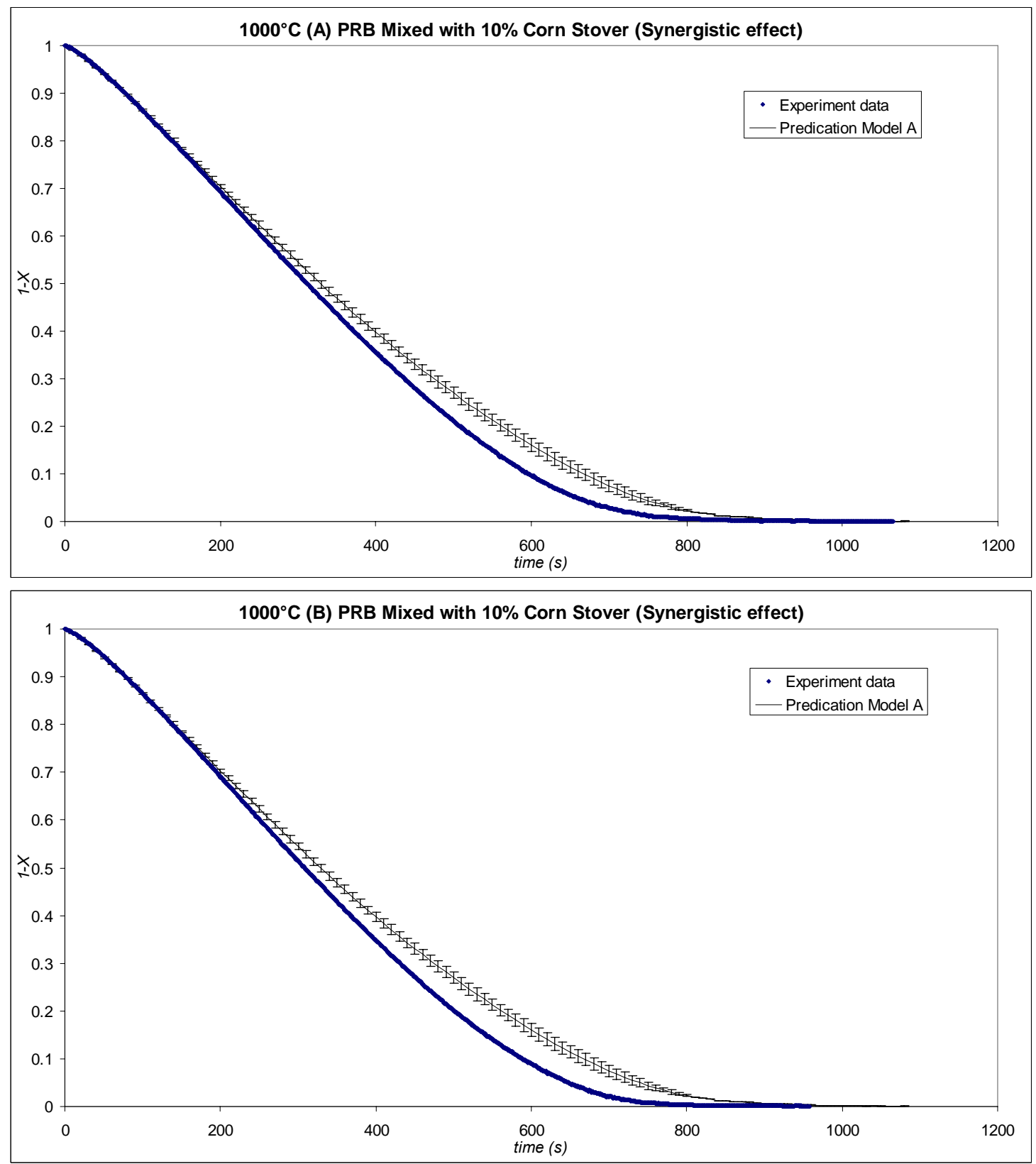

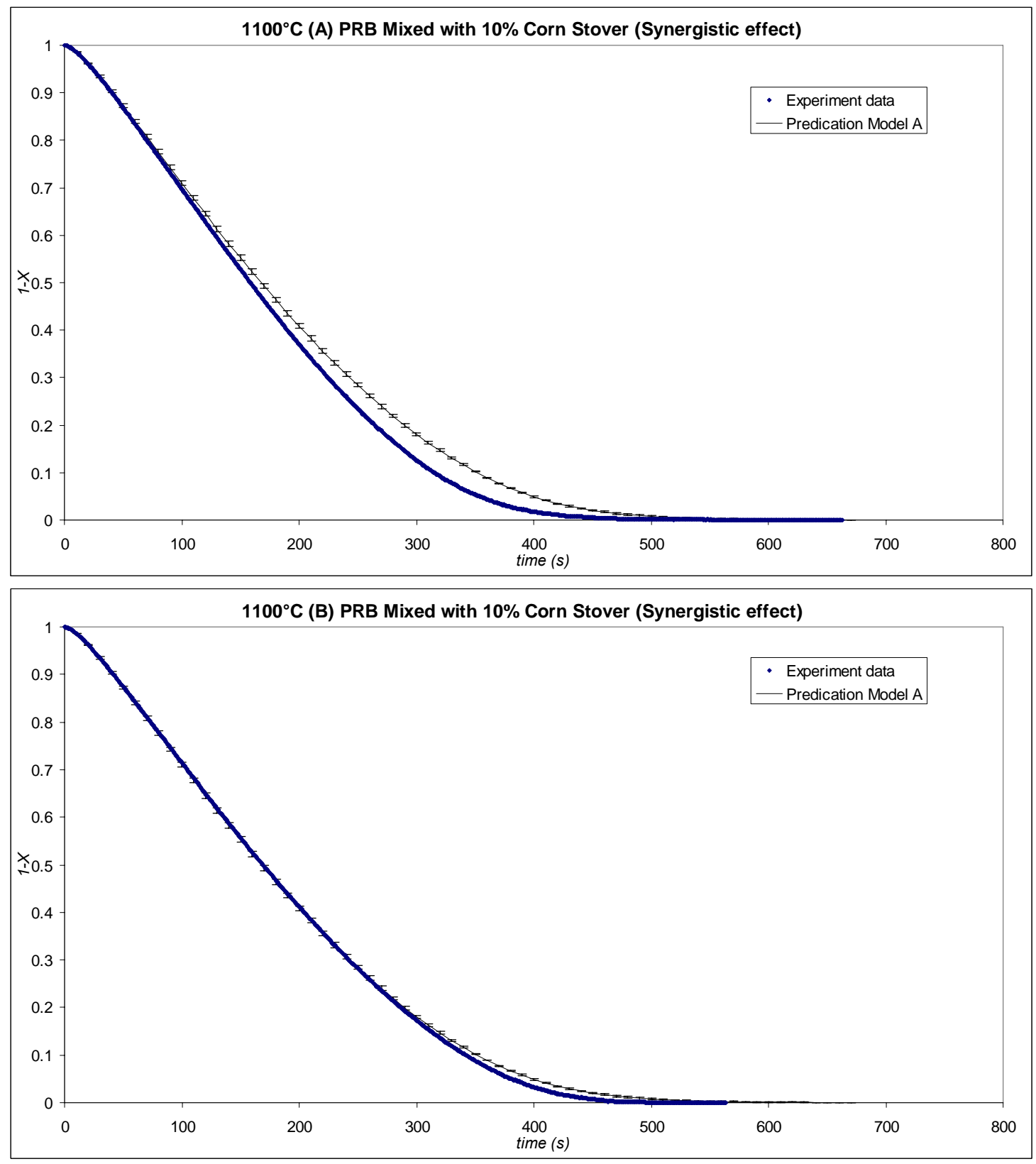
$30 \%$ mixed ratio at different reaction temperature ( 6 plots)
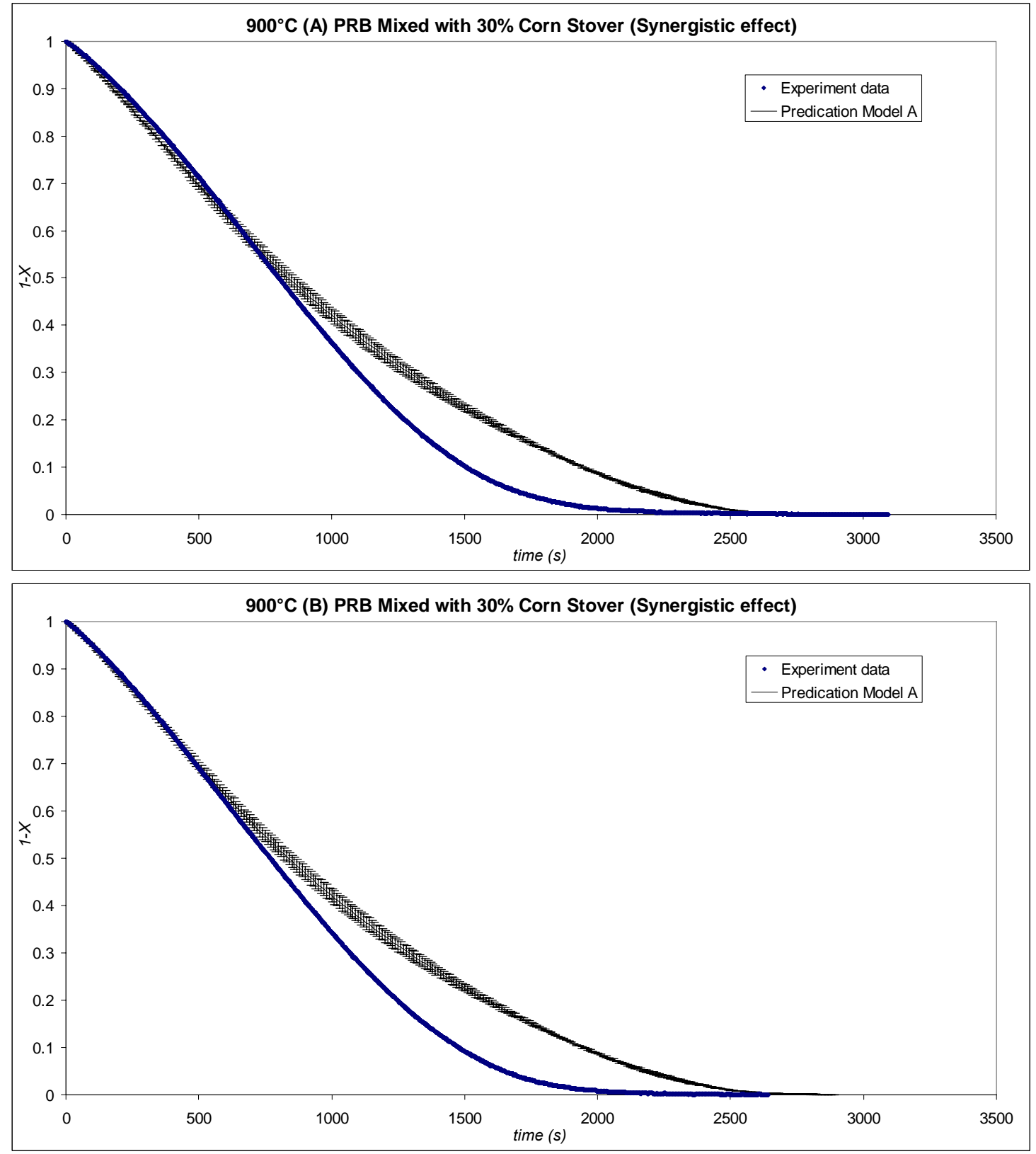

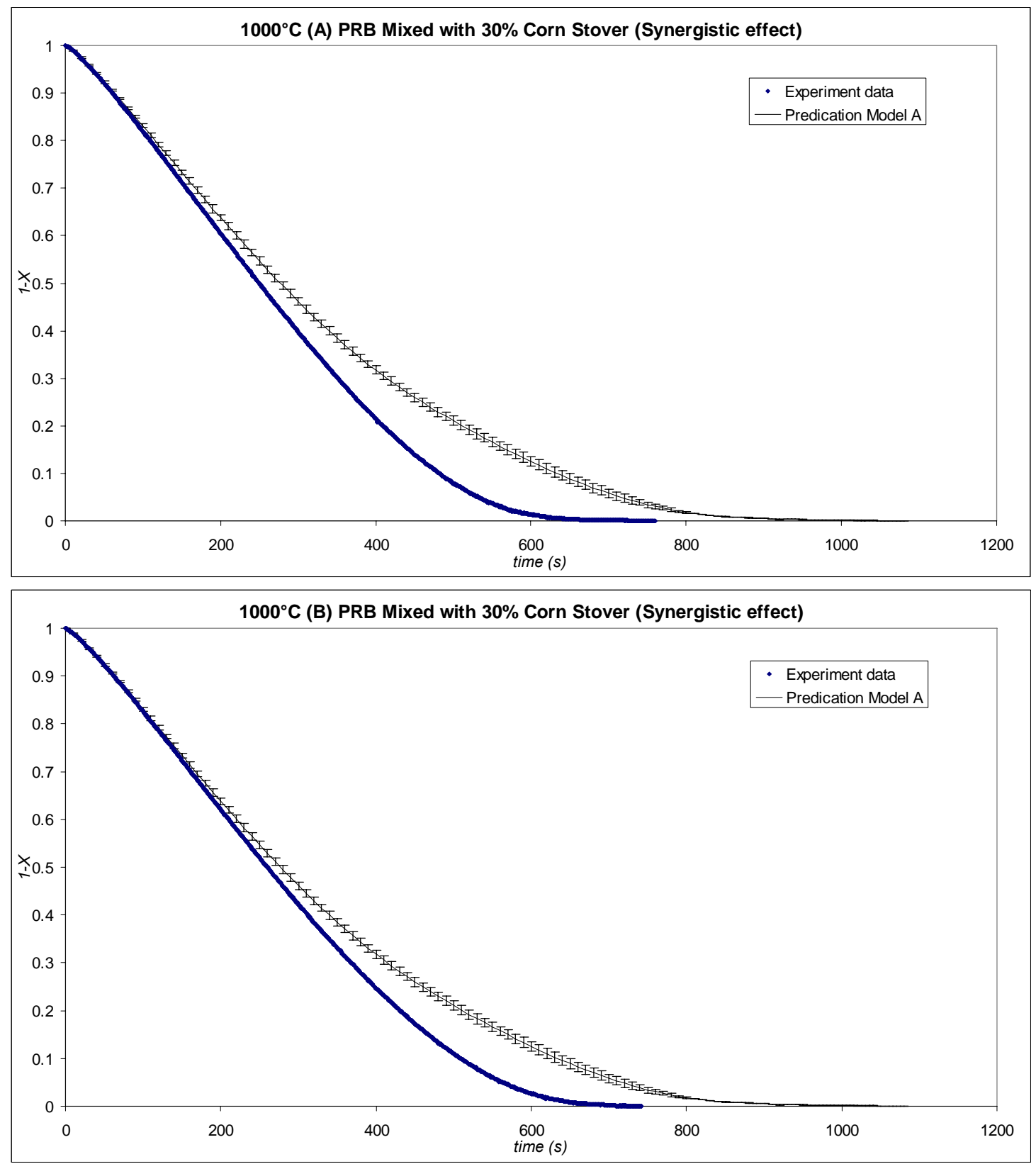

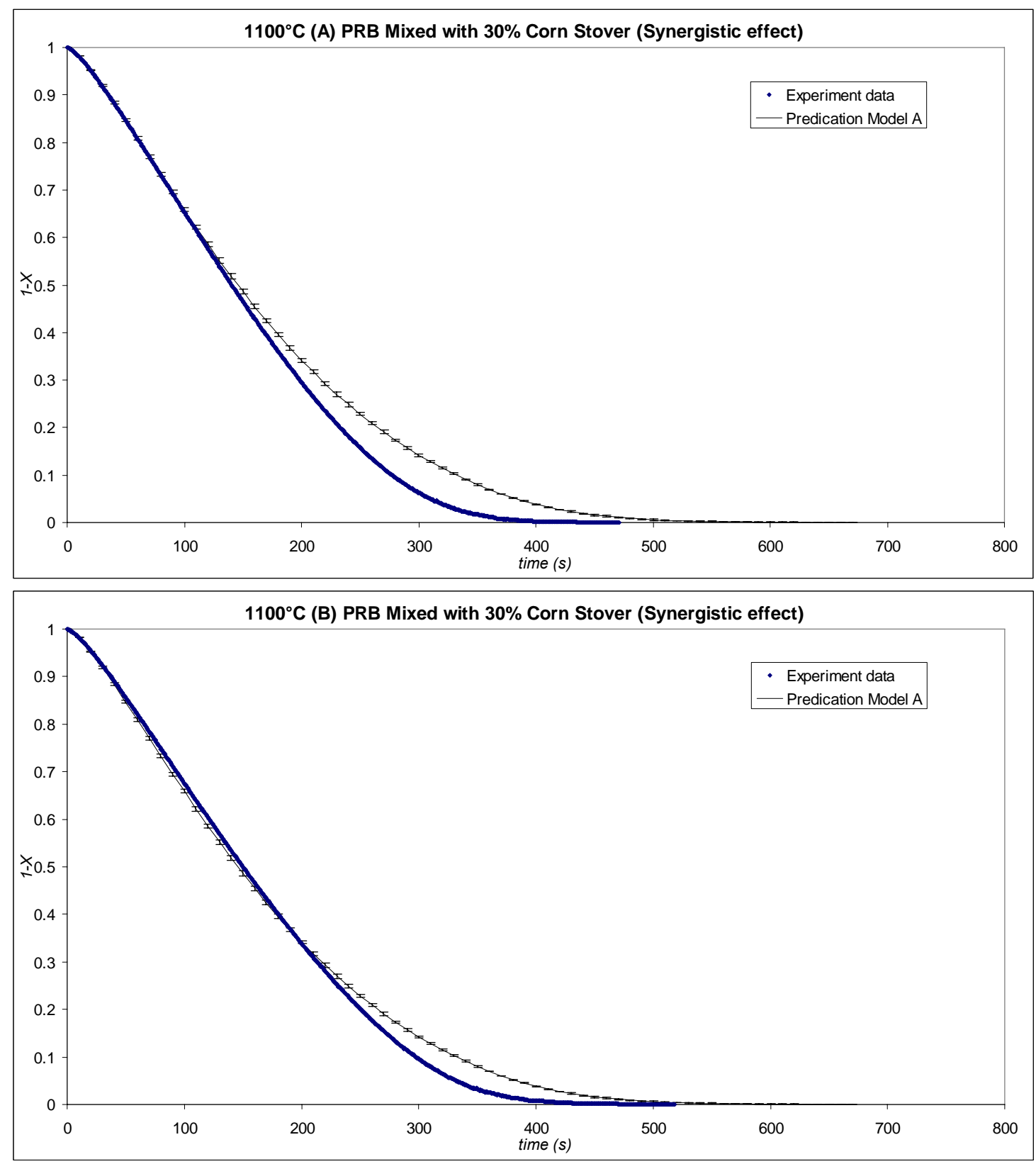

Note:

7. Total 12 plots for the synergistic effect inspection of Group 3 char pair;

8. The value of $(1-X)$ for Prediction Model $\mathrm{A}$ is the average data of two repeat experiments that include the pure coal and pure biomass char gasification;

9. The error bars of Prediction Model A are presented by $\mathrm{a} \pm$ Standard Deviation (STDEV), which are calculated based on the pure chars experiments result. 


\section{Appendix J. Safety information}

1. Safety cautions for the operation of compressed gas cylinders:

The following safety cautions are adapted from the "Safety Manual Start-up and Safety Procedures", West Virginia University Department of Chemical Engineering, 2005.

- Always secure gas cylinders with bench clamps or chains;

- Use the correct regulator for a particular gas, never attempt to use improvised adaptors;

- Transport cylinders on a cylinder cart with a safety chain;

- Protect cylinders from all sources of heat and direct sunlight in order to prevent an accidental increase in pressure;

- Don't remove protective cylinder caps until the cylinder is securely fastened;

- Check cylinders and all other connections under pressure for leaks before using. Use a soap solution and check for bubbles;

- Turn off both the main valve and regulator when not using the cylinder, and bleed off pressure in the regulator after use.

2. Safety cautions for the operation of TherMax 500 TGA system

The following safety cautions are obtained from the "Operation Manual", they include several parts of information, such as gas, electrical connection, furnace, and glassware operation and maintenance.

\section{Gas Safety:}

- Consider hazardous the properties of all gases used over the entire temperature range of the experiment;

- Be aware of the reaction products that give off over the entire temperature range of the experiment; 
- All gas line connections, gaskets, O-rings, fittings and tubing must be tight and without leaks;

- The area must be well-ventilated.

\section{Electrical Connections:}

- Be sure that power to the TG instrument is OFF before removing TG covers;

- Be sure that the TG instrument, computer, plotter and printer are turned off and unplugged before establishing electrical connections.

Furnace Temperature:

- Do not touch the furnace or reactor tube during a run. Both can be very hot and produce sever burns if touched;

- Use caution when turning the upper and lower collar which can be very hot and produce severe burns if touched.

\section{Glassware and O-rings:}

- Check glassware regularly for nicks, scratches an cracks. Damaged glassware can break, explode or implode during an experiment, releasing gases into the air;

- Check the O-rings regularly for signs of wear and replace when necessary. 